
$\sum_{\text {CONDC }} \frac{5}{2}$

$\sum_{i=1}$ (a)
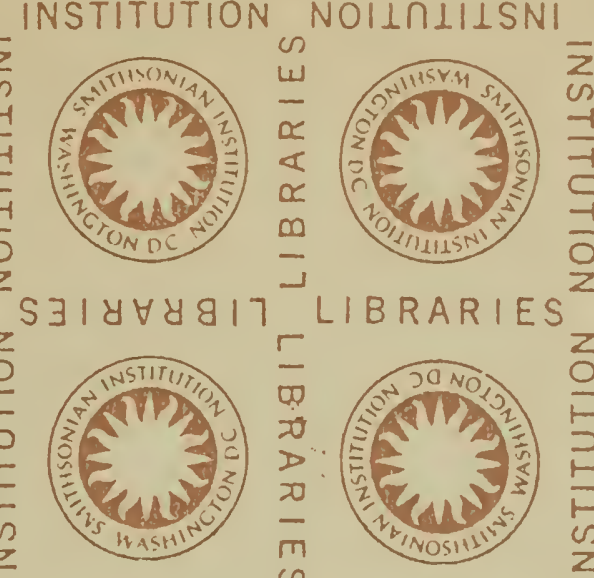

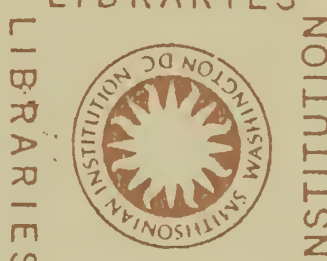

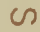

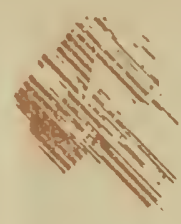

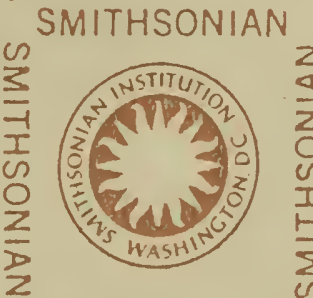
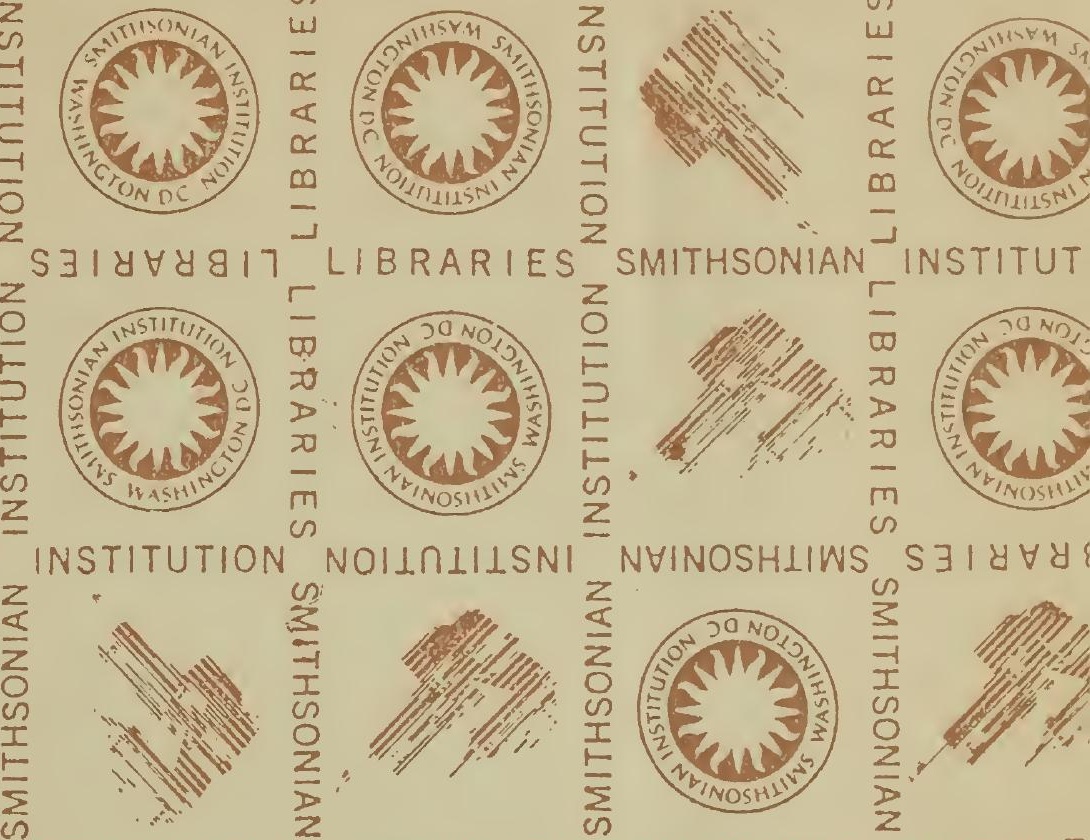

INSTITUT
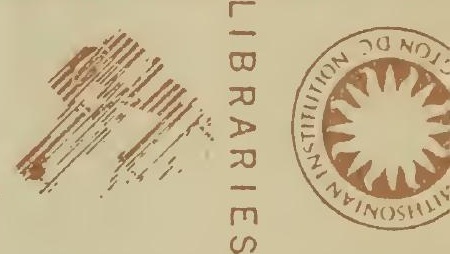

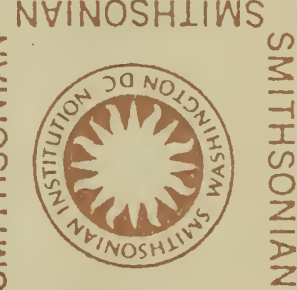

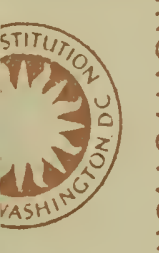
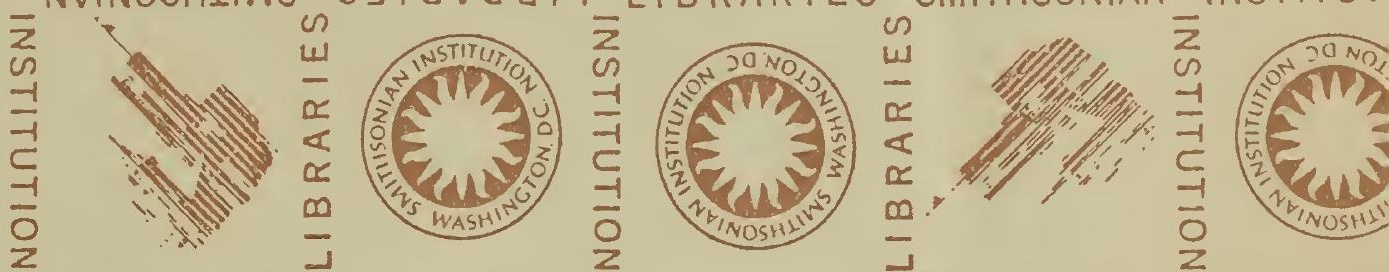

NYINOSHLIWS
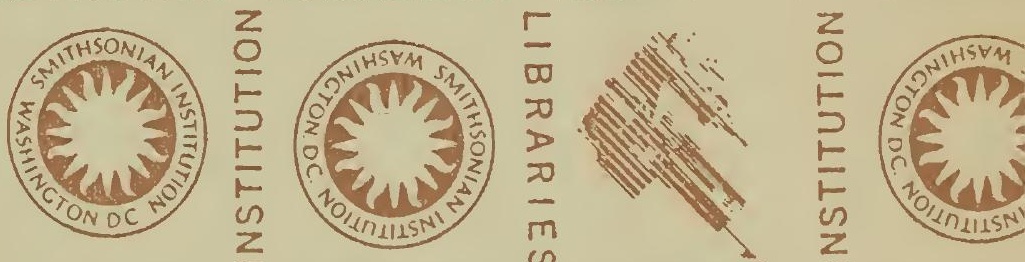

OIILSNI NYINOSHLIWS
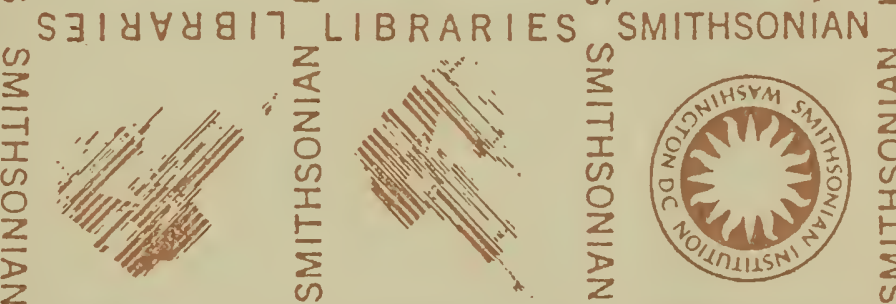

INSTITUT
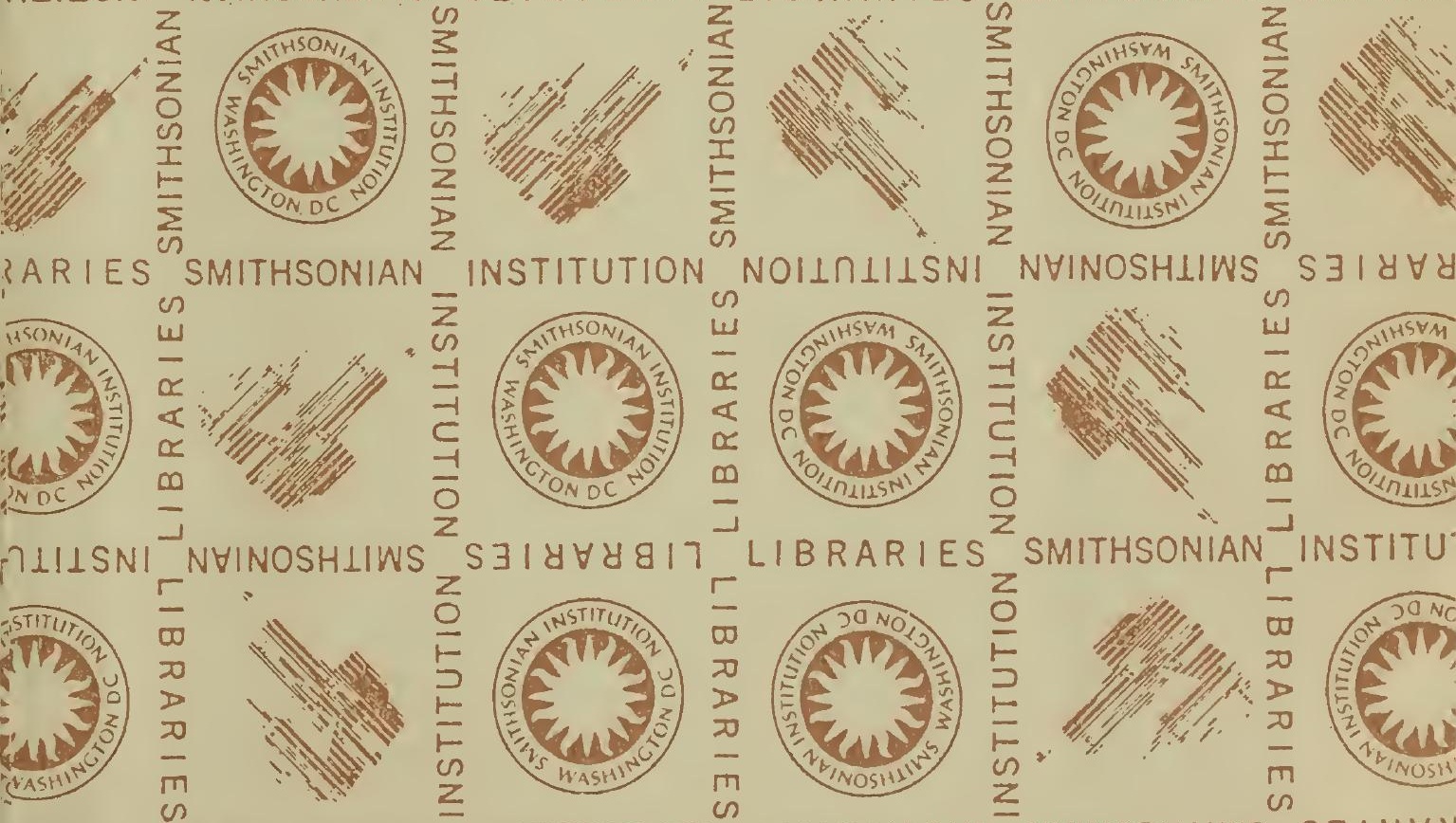

INSTITU

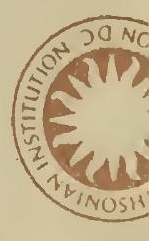

NHINOSHLIWS S $\exists I Y \forall \forall$ 

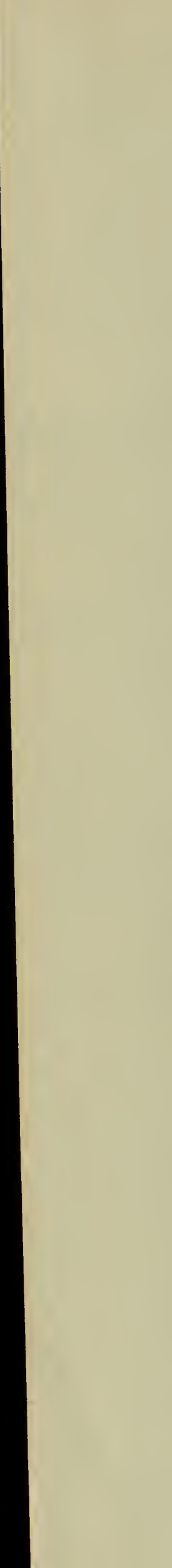




\section{THE}

\section{R A Y S O C I E T Y.}

\section{INSTITUTED MDCCCXLIV.}

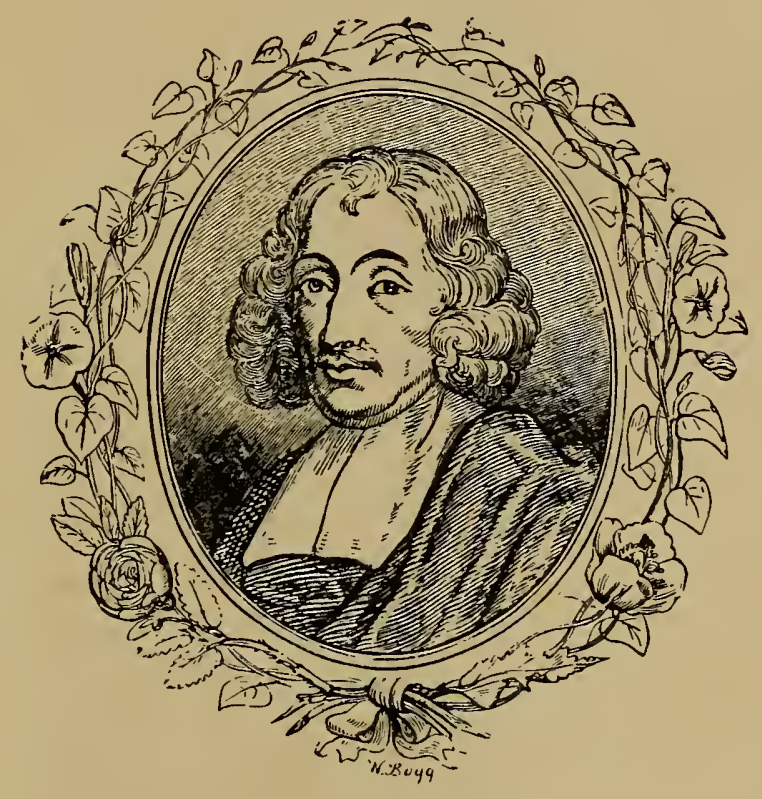

This volume is issued to the Subscribers to the RAY Socrety for the Year 1896.

L O N D O N :

MnCCoXCVII. 


\title{
Pt.l THE
}

\section{TAILLESS BATRACHIANS \\ OF}

\section{EUROPE.}

\section{PART I.}

L O N D O N :

PRINTED FOR THE RAY SOCIETY.

\author{
BY \\ G. A. BOULENGER, F.R.S.
}


TrIITTED BY ADJARD AND SON,
BaRTHOLOMEIV CL.OSE, B.C., AND 20 HANOVER SQUARE, W. 


\section{PREFACE.}

Notwithstanding the great progress attained in our knowledge of European Batrachians within the last twenty years with regard to the distinction of species and varieties, the study of their anatomy, life-histories, and distribution, there exists at the present day no work dealing with them as a whole from these different aspects.

For twenty-five years a close student and collector of these animals, which have always exercised an extraordinary fascination on my mind, I have often wished for an opportunity of supplying such a desideratum, by utilising the enormous material which had gradually accumulated in the literature, my own notes, and the unrivalled collection in the British Museum.

Thanks to the Council of the Ray Society, who, on the special recommendation of Sir W. H. Flower, acceded to my request, I have at last the satisfaction of seeing my hopes realised, and, owing to the talent of my artistic collaborators, Messrs. P. J. Smit and J. Green, in a manner which fully satisfies my aspirations. May those, few as they still are, who share my fondness for this group of animals endorse my opinion of the beautiful and accurate illustrations which are one of the principal features of this work, 
and derive from the perusal of these pages one-tenth of the pleasure it has given me to write them; I shall feel amply rewarded for the trouble I have taken.

I would also express a hope that a little book of this kind, embodying in a concise form the result of much study, at present scattered in a multitude of publications in some ten different languages, may have the effect of stimulating interest to a subject that has been too much neglected, and in the cultivation of which new workers will find much to repay their efforts, especially if applied in other regions of the globe, which, though much richer in Batrachians, have as yet yielded little or nothing to our knowledge of the life-histories.

This work has been planned with the view of assisting the beginner as well as of affording new information to the advanced student, and the synoptic treatment has therefore been frequently resorted to in the Introduction; whilst all descriptions in the systematic part are strictly comparative. Technical terms have not been avoided, but the numerous figures in the text should render them easily intelligible to the beginner.

At the desire of the Council of the Ray Society this volume is issued in two parts. The second part, continuously paged and with bibliographical and alphabetical indexes, is to follow in a few months.

The plates, twenty-four in number, have been executed by Mr. P. J. Smit and printed by Messrs. Mintern Brothers. With two exceptions, all the coloured figures have been taken from living specimens. Five of the plates (I, II, III, XVI, XVII) have already appeared in the 'Proceedings of the 
Zoological Society' (1884, 1885, 1891), to illustrate papers of mine, and have been copied with the sanction of the Committee of Publication of that Society.

The figures in the text have been drawn by $\mathrm{Mr}$. J. Green, and reproduced by the Typographic-Etching Company. Most of them are original ; if copied from other works, the source has in every case been referred to. A few cuts illustrating a paper by me on Tadpoles in the 'Proceedings of the Zoological Society' for 1891, and another by Dr. Ridewood on the development of the hyoid, published in 1897, have been reproduced by permission, for which I beg to tender my acknowledgments to the Committee of Publication of the Zoological Society.

I also wish to publicly express my thanks to Sir W. H. Flower, K.C.B., and to the Rev. Professor Wiltshire for the interest they have shown in the publication of this work; and to the various friends and correspondents who have assisted me with notes or material, especially Dr. W. G. Ridewood, to whom I am indebted for many hints and preparations; M. F. Lataste, who bas placed his private collection at my disposal; Dr. J. de Bedriaga, Count M. Peracca, Mr. F. A. Moller, Dr. F. Werner, and Herr W. Wolterstorff, who have supplied me with an abundance of living specimens from France, Italy, Portugal, Austria, and Germany ; and Messrs. Chevreux and Doumergue, through whose kindness I have been able to make observations on a large number of living specimens of Discoglossus from Algeria.

$$
\text { G. A. B. }
$$

British Museum (Natural History);

October $28 t h, 1897$. 

THE

\section{TAILLESS BATRACHIANS}

OF

\section{EUROPE.}

\section{IN'TRODUCTION.}

II. External Characters . . . . . . . . . 9

III. Integument . . . . . . . . . . . . 21

IV. Dermal Secretion . . . . . . . . 30

V. Skeleton . . . . . . . . . . 33

VI. VISCERA $. \quad . \quad$.

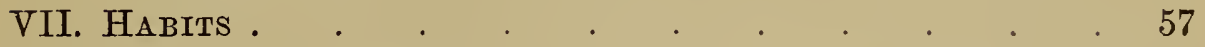

VIII. VOICE . . . . . . . . . . . . 61

IX. Pairing and Otiposition . . . . . . . 64

X. SpermatozoA . . . . . . . . . . . 75

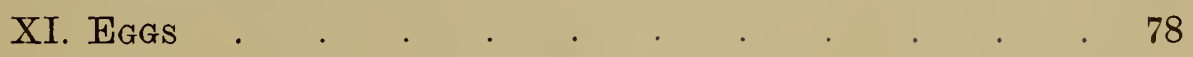

XII. Development and Metamorphosis . . . . 85

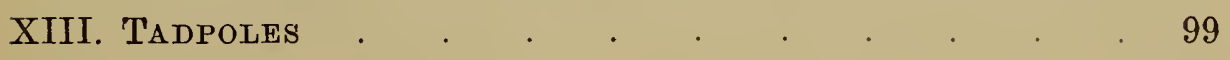

XIV. HyBRIDS . . . . . . . . . . . . 112

XV. Geographical Distribution . . . . . 115 


\section{Classification.}

For many years the Tailless Batrachians (Ecaudata s. ANurA) were classified in a very unsatisfactory manner. The genera Bufo and Hyla were, it is true, always regarded as the types of distinct groups; but Pelodytes, Pelobates, Discoglossus, Bombinator, and Alytes were placed with Rana, or in separate families in most unnatural associations.

DuMÉril and Bibror, in the eighth volume of their standard work, 'Erpétologie générale,' published 1841, after dividing the order into two sub-orders, Phanéroglosses and Phrynaglosses (= Aglossa, the two exotic genera Pipa and Xenopus), a primary division first introduced by Wagler in 1830 and which has stood the test of time, combined the Phaneroglossal genera into three families-Raniformes, Hylaformes, Bufoniformes; the two latter containing each a single European genus, whilst under the former all others were arranged in a series without further subdivision.

So unnatural an arrangement evoked criticism from all who were acquainted with the life-histories of the European forms ; and an excellent French observer of these animals, A. Thouras, in a paper published in the 'Annales des Sciences naturelles,' 1854, dwelt upon the correlation which exists between the shape of the pupil and the mode of amplexation during parturition, and proposed to group together on the one hand those genera that have a horizontal pupil and an axillary embrace, on the other those that combine a vertical or triangular pupil with a lumbar embrace. These divisions were later provided with names by $\mathrm{BRJCH}$ in 1863 (Plagioglena, Orthoglena), and by DE L'IsLe in 1877 (Alamplexes, Inguinamplexes).

How exaggerated the importance attached to this correlation, which, besides, holds good only for the European forms, is now apparent to all. Yet the arrangement proposed by Thomas was a decided advance 
on that of the 'Erpétologie générale,' and on the views of J. MÜLLER (1832), who overrated the taxonomic importance of the structure of the ear, and inspired the classification followed by STANNius in the ' $\mathrm{Zoo}$ tomie der Amphibien,' published in 1854.

The faults of the latter classification were further developed by Günther in 1858 ('Cat. Batr. Sal.'), whose avowedly artificial scheme has been followed by Fatio in 1872 and by De Betta in 1874.

Cope's epoch-making classification in 1865 ('Nat. Hist. Review'), based on a correct appreciation of the osteological characters, placed the matter on a sound footing, and his groupings, slightly modified in 1867, received confirmation, so far as European genera are concerned, from LATASTE's study of the larval characters in 1878 and 1879. In revising the classification in 1882 ('Cat. Batr. Ecaud.') I could introduce but slight improvements to Cope's scheme, as may be seen from the arrangement followed in this work, in which the various groups are placed in ascending order.

\section{Principal Schemes of Classification.}

1. Duméril and Bibron, 1841.

Tongue absent: Phrynaglosses.

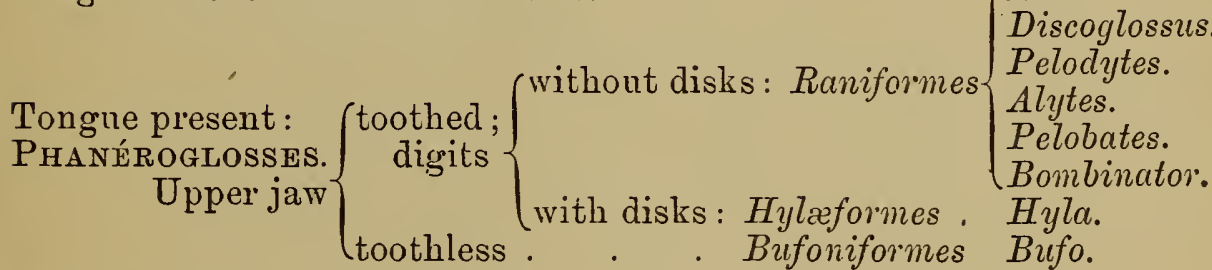

2. Stannids, 1854.

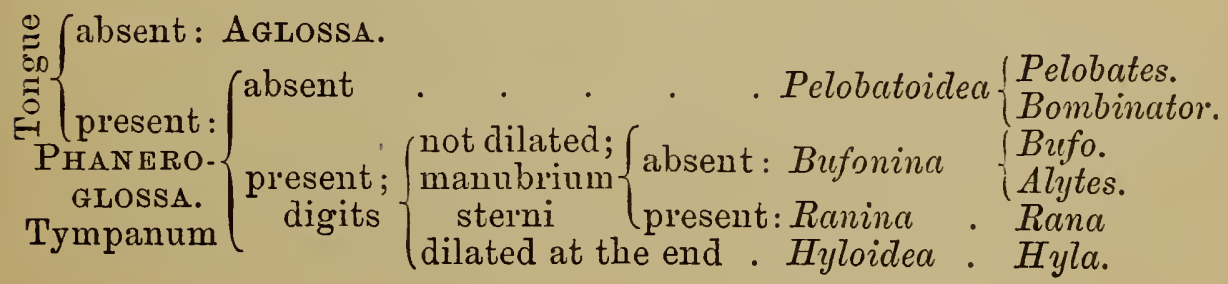


3. GÜNTHFR, 1858.

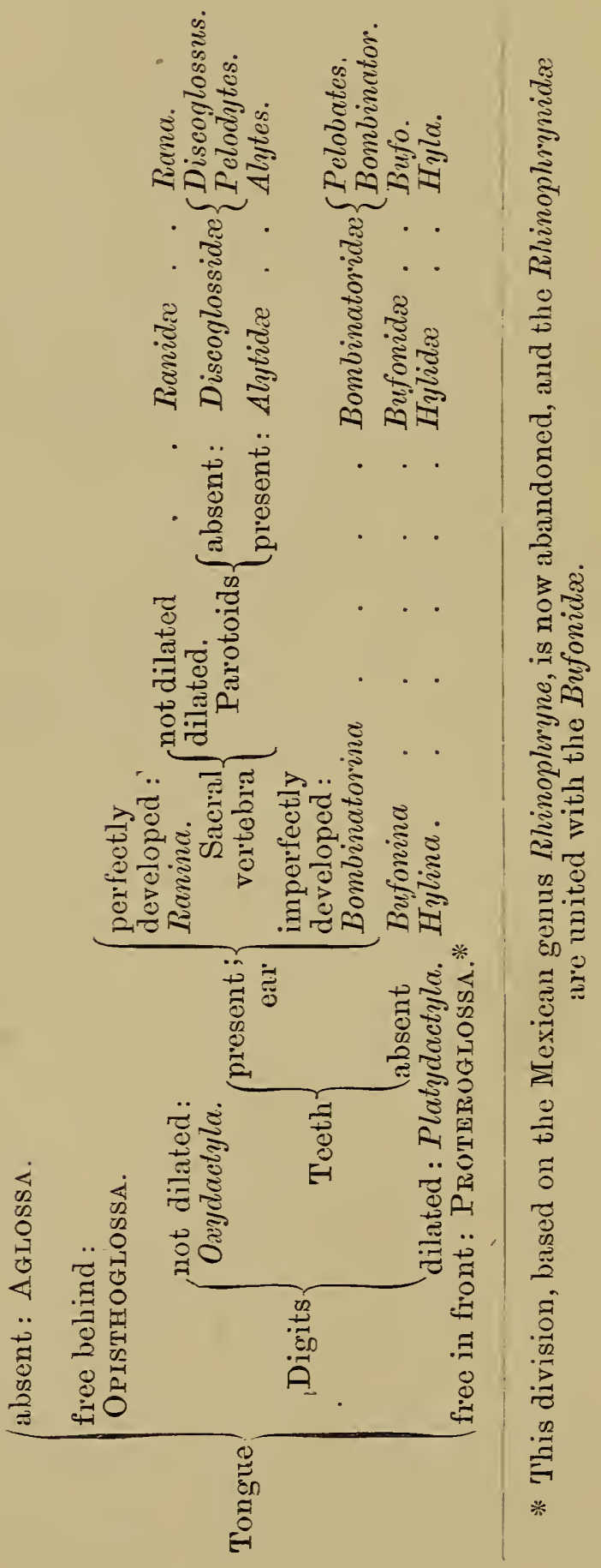


4. BruCH, 1863.

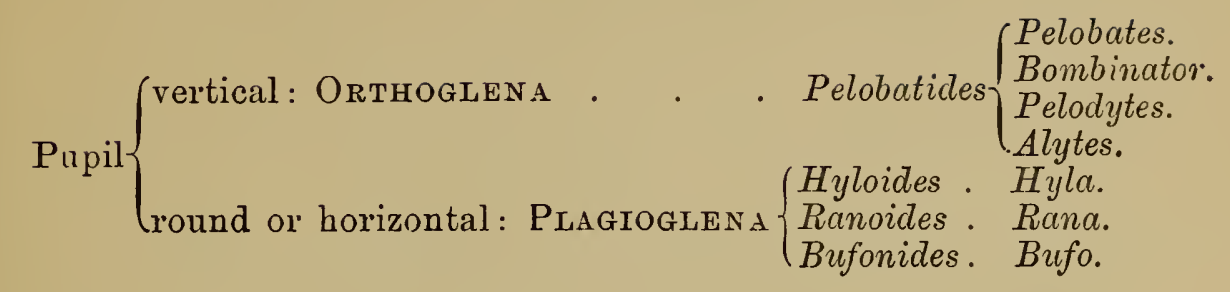

This arrangement is merely the application of the views expressed by Thomas in 1854 .

ว. Cope, 1865.

AgLossa.

Bufoniformia . . . . . Bufonidæe. Bufo.

ARCIFERA . . . .
RANIFORMIA . . . . . . Ranidæ.

The Bufoniformia correspond to the Bufoniformes of Duméril and Bibron; the Arcifera are separated from the Raniformia, which agree in the presence of teeth, by the structure of the pectoral arch; and the Discoglossidæ are defined for the first time by the opisthocœlous vertebræ provided with autogenous ribs. Some further improvements were introduced in 1867, when the Bufoniformia were split into two groups, based on the structure of the pectoral arch, that group corresponding to the Raniformia among the toothed forms, being named Firmisternia, a term the signification of which I have extended to embrace all non-arciferous forms, whether toothed or not-an improvement since accepted by Cope himself.

6. Mivart, 1869, in one of his classical papers published by the Zoological Society of London, endeavoured to combine Günther's and Cope's classifications, but his arrangement does not differ materially from 
the former author's so far as the grouping of the European genera is concerned.

7. Lathas'te, 1879.

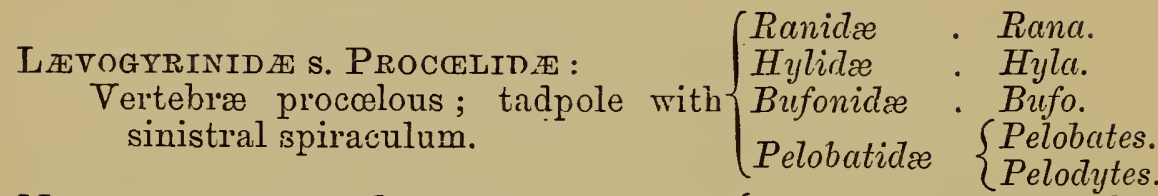

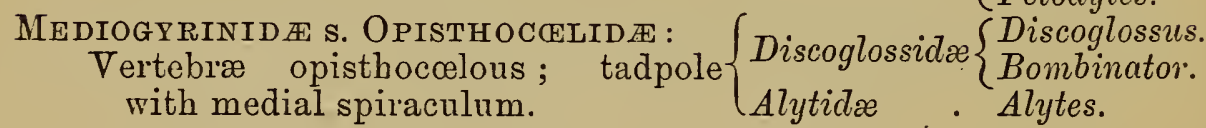

The Alytidx are separated from the Discoglossidx on account of the shape of the pupil and the aberrant mode of parturition and development.

The classification adopted in this work is shown in the following synopsis, which also includes a list of all the species represented in Europe.

\section{Order ECAUDATA.}

Sub-order Phaneroglossa.

Eustachian tubes separated; tongue present.

\section{Series A.-Arcifera.}

Coracoids and præcoracoids connected by an arched cartilage (the epicoracoid), that of the one side overlapping that of the other.

\section{Family 1.-Discogrosside.}

Vertebræ opisthocœlous; short autogenous ribs attached to the anterior diapophyses; diapophyses of sacral vertebra dilated; upper jaw toothed. 
1. Discoglossus, Otth, 1837.

1. pictus, Otth, 1837.

2. Bombinator, Merr., 1820.

2. ignens, Laur., 1768.

3. pachypus, Fitz., 1838.

3. Alytes, Wagl., 1830.

4. obstetricans, Laur., 1768.

5. cisternasii, Boscá, 1879.

\section{F'amily 2.-PeLobatider.}

Vertebræ procœlous; * no ribs; diapophyses of sacral vertebra strongly dilated; upper jaw toothed.

4. Pelodytes, Fitz., 1838.

6. punctatus, Daud., 1802.

5. Pelobates, Wagl., 1830.

7. fuscus, Laur., 1768.

8. cultripes, Cuv., 1829.

\section{Family 3.-BUFONID叛.}

Vertebræ procœlous; no ribs; diapophyses of sacral vertebra dilated; jaws toothless.

6. Bufo, Laur., 1768.

9. vulgaris, Laur., 1768.

10. viridis, Laur., 1768.

11. calamita, Laur., 1768.

\section{Family 4.-Hүцірж.}

Vertebræ procolous; no ribs; diapophyses of sacral vertebra dilated; upper jaw toothed; terminal phalanges claw-shaped.

7. Hyla, Laur., 1768.

12. arborea, L., 1766.

* In the European geneira. 
Series B.-Firmist'ernia.

Coracoids firmly united by a simple epicoracoid cartilage; pracoracoids resting with their distal extremity upon the coracoids, or connected with the latter by the epicoracoid cartilage.

\section{Family 5.-Ranide.}

Vertebræ procœlous; no ribs; diapophyses of sacral vertebra cylindrical; upper jaw toothed.

8. Rana, L., 1766.

13. esculenta, L., 1766.

14. arvalis, Nilss., 1842.

15. camerani, Blgr., 1886.

16. temporaria, L., 1766.

17. græca, Blgr., 1891.

18. iberica, Blgr., 1879.

19. latastii, Blgr., 1879.

20. agilis, Thom., 1855.

We are thus now acquainted with twenty wellestablished species, as against twelve and eighteen enumerated in the two preceding general works on the Batrachians of Europe, viz. SchreIber's 'Herpetologia Europæa,' 1875, and de Bedriaga's 'Froschlurche Europas,' 1889.

Most of the additions made during the last twenty years fall to the genus Rana, and are in fact dismemberments of the Linnean species $R$. temporaria. That the forms here admitted as species are fully entitled to that rank, no one acquainted with their histories will contest for a moment. Nor, among recent accessions to our knowledge, is the distinction of the two species of Bombinator or the two of Alytes likely to meet with any opposition. But the rank to be assigned to the principal forms of Hyla arborea and Rana esculenta, regarded by me as only varieties, perhaps remains an open question in these days of extreme multiplication of species. 


\section{External Characters.}

As these Batrachians have no neck, the head passes directly into the body, and, except in Pelobates, where the skin is closely adherent to the rugose skull, the demarcation is consequently aifficult to trace. By drawing a line connecting the articular extremities of the mandible we obtain approximately the exact length of the bead, the greatest width being at the commissures of the jarvs. The head is more or less flattened, with prominent eyeballs covered above by the upper eyelid, which is continuous with the rest of the cephalic integument. The upper surface of the head may be limited on each side by an angular line extending from the tip of the snout to the upper

Fig. 1.

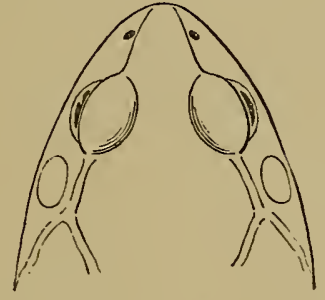

A

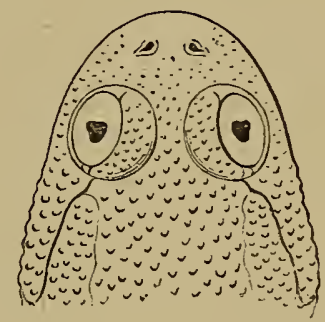

B

Upper views of heads of (A) Ranu temporaria and

(B) Bombinator igneus.

eyelid, the canthus rostralis, continued behind as a ridge or fold, the supra-temporal ridge (Fig. 1, 4 ). In some forms, such as Bombinator igneus (Fig. 1, B), the snout is simply arched from one lip to the other, and there is no trace of a canthus rostralis. The side of the snout below the canthus rostralis is called the loreal region. The length of the snout is taken by applying the points of the compasses to the anterior border of the (bony) orbit and the very tip of the snout, on the median line.

The nostrils are small valvular openings, situated between the end of the snout and the eyes, alter- 
nately opening and closing as the throat is drawn in and swollen out during respiration.

The eye is large, lateral (Fig. 1, A), or directed upwards and outwards (Fig. 1, B), and protected by three lids: the upper thick and coloured, the lower rudimentary and immoveable, and the nictitating membrane, transparent or partially pigmented, which ascends over the eyeball to meet the upper lid. The eye can be covered without the vision being much impaired by elevation of the nictitating lid, as when the frog is under water, or completely closed when the eyeball is drawn in and the upper eyelid descends to meet the lower. The iris is brilliantly coloured with metallic pigment, golden, silvery, or bronzy, with or without an admixture of red or black. The pupil when fully distended is round and large, but when contracted affects various shapes, which afford important characters for the distinction of the genera. Thus the contracted pupil of Rana, Hyla, and Bufo is horizontal, oval with an angle in the lower border

FIG. 2.
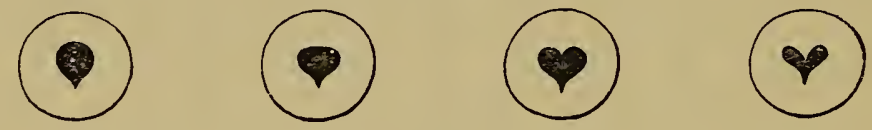

A
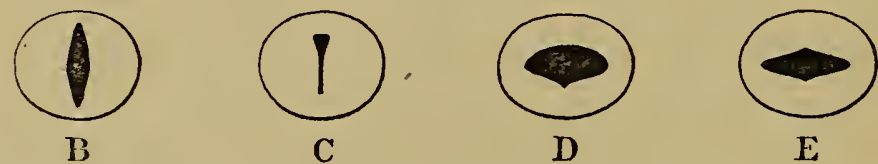

Different forms of pupils. A. Bombinator pachypus. B. Alytes obstetricans. c. Pelobates fuscus. 1). Rana arvalis. E. Bufo vulgaris.

in Rana (Fig. 2, D), and Bufo viridis and calamita, with an upper and lower angle in Hyla and Bufo vulgaris (Fig. 2, E). That of Discoglossus and Bombinator may be described as roundish or subtriangular according to specimens, the lower angle being always distinct, but the upper border sometimes convex, when the 
pupil appears nearly round, or straight when the subtriangular form obtains (Fig. 2, A). In some specimens of Bombinator the upper border is even emarginate, so as to produce the shape of a heart; and when extremely contracted the pupil divides into three branches, affecting the shape of a $Y$ (Fig. 2, A) This type of pupil approaches the vertical, and in some specimens of Discoglossus the much-contracted pupil is in fact a little deeper than broad. In Alytes, Pelodytes, and Pelobates (Fig. 2, B, c) we find a regular cat's pupil, vertically elliptical or club-shaped, linear when fully contracted.

The tympanum, or drum of the ear, is absent in Bombinator and Pelobates. When present it may be concealed under the skin, as in some specimens of Discoglossus, Pelodytes, and Bufo vulgaris, or appear on the temple behind the eye as a round or oval disk covered with thin skin (Fig. 1, s, p. 9).

The mouth is large, and cleft to beyond the eyes. The jars are edentulous in Bufo; the upper is armed with numerous closely-set teeth in the other generaten to fifteen in each præmaxillary, forty to fifty in each maxillary. The teeth have sharply-pointed, slightly-hooked crowns with long shafts applied to the inner side of the præmaxillary and maxillary bones. The palate (Fig. 3, p. 12) is pierced by two pairs of orifices, the choanx, or inner openings of the nostrils anteriorly, and the openings of the Eustachian or auditory tubes, situated near the commissures of the jaws; the Eustachian tubes are extremely fine, or sometimes even indistinct, in Bombinator. In all the genera except Bufo there are two groups or series of teeth, each implanted on an eminence of the vomerine bones; these vomerine teeth are situated between or behind the choanæ, as shown on p. 12 , Fig. 3, A, c, D.

The tongue, thick and papillose, flat, is attached in front and in the middle, and the posterior portion, by being bent over and rapidly thrust out of the mouth, 
acts as an organ of prehension in most tailless Batrachians; in the Discoglossidæ, however, as in the newts and salamanders, the tongue is entirely or nearly entirely adherent to the floor of the mouth, and the prey is seized by the jaws. The tongue serves also as an organ of taste, for although frogs seize almost any moving object, they will reject before deglutition anything that is noxious to them, as may be witnessed on offering a frog a brandling or manure-worm (Allolobophora foetida), a ladybird beetle, or a young Bombinator. Before being swallowed, the food, if it be a smail mollusc, crustacean, or hard beetle, is crushed between the tongue, the depressed eyeballs, and the vomerine teeth; if the latter be absent, as in Bufo, the sharp, sometimes

Fig. 3.

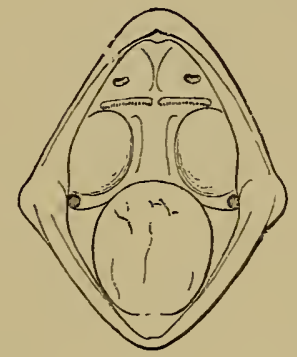

A

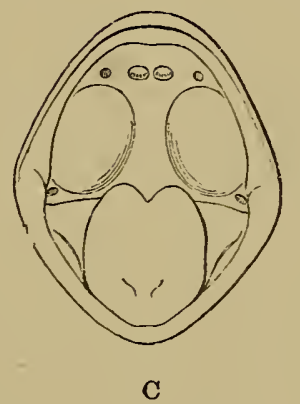

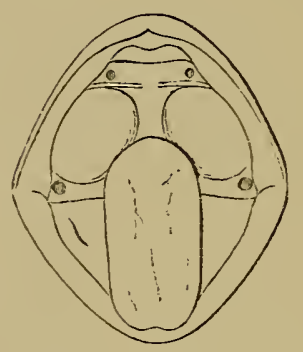

B

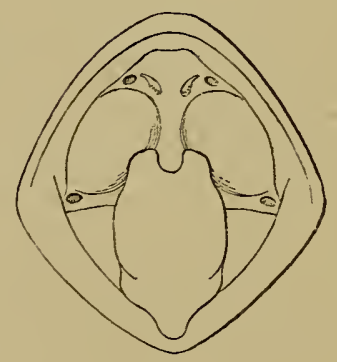

$\mathrm{D}$

Open mouths of-A. Discoglossus pictus. B. Bufo calamita. c. Hyla arborea. D. Rana temporaria. Showing the shape of the tongue and the disposition of the choanæ, Eustachian tubes, and vomerine teeth.

serrated edge of the palatine bones supplies their function. The tongue is circular and entire in the 
Discoglossidx (Fig. 3, $\Lambda$ ); circular and entire or feebly nicked behind in the Pelobatidx and Hyla (Fig. 3, c), resembling a mushroom when thrust out; elliptical or pyriform and entire in Bufo (Fig. 3, в); oval and forked behind in Rana (Fig. 3, D). In the two latter genera the extensibility of the tongue is so great that a large specimen is able to seize a prey two inches distant from it.

Owing to the nature of the skin and the absence of true ribs, the shape of the body varies enormously according to the degree of moisture of the subcutaneous sacs, the inflation of the lungs, or the condition of the ovaries, and all measurements that are not based on the bony framework are useless for systematic purposes. The frogs of the genus Rana appear hump-backed in a squatting posture, an angle being produced at the articulation of the cylindrical sacral diapophyses with the ilia; the other genera, with flattened and dilated sacral diapophyses, have a rounded back when at rest, as may be seen on comparing a true frog with a toad or tree-frog. The vent, or cloacal opening, is a small rounded orifice at the very posterior extremity of the body, above and between the thighs.

The fore limb is divided into a brachium or arm, an antebrachinm or forearm, and a manus or hand with four functional fingers, of which the third is the longest. The length of the first finger as compared to the second is often used as a specific character. In order to preclude misunderstandings, it is well to remark that when the first finger is stated to extend as far as or beyond the second, the two are taken to meet halfway. A rudimentary pollex is often indicated externally by a tubercle at the base of the inner finger (Fig. $4, \mathrm{~A}$ ).

The hind limb is longer, usually very much longer, than the fore limb, and divided into four distinct segments - the femur or thigh, the crus or tibia, or leg, the tarsus, and the pes or foot. Anatomically, 
the tarsus is, of course, part of the foot proper; but as it here forms a distinct segment, the term foot is used in a restricted sense. The foot is measured from the base of the metatarsal tubercle; it has five elongate toes, gradually increasing in length to the fourth, the fifth being again shorter. There is in addition a rudimentary sixth toe, the so-called præhallux, conspicuous externally in the form of a. tubercle or spur at the base of the inner toe. In Pelobates (Fig. 4, B) this præhallux or inner metatarsal tubercle acquires a very great development, is covered by a horny sheath with sharp cutting edge, and serves as a shovel for digging in the soil. 'There is often another tubercle on the sole, at the base of the fourth toe; this so-called outer metatarsal tubercle (Fig. 4, c) is merely a thickening of the integument.

FIG. 4.

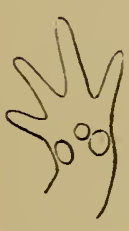

A

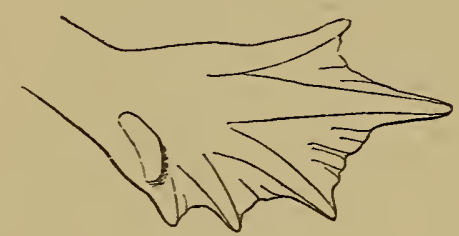

B

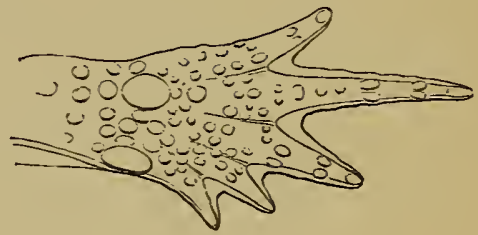

C

A. Hand of Alytes obsteliricans. B. Foot of Pelobates fuscus. c. Foot of Bufo calamita (lower views).

Other dermal tubercles are usually present, more or less developed, single (Fig. 6, A, p. 16) or paired (Fig. 4, c), under the digits at the articulations between the phalanges; they are called subarticular tubercles. The fingers are free except in Hyla arborea, in which they are provided with a rudimentary web. The toes are more or less webbed or bordered by membranes in all our Batrachians, but the extent of the web varies greatly according to the species, and is usually more developed in males than in females, especially during. the breeding season. The web is usually smooth and transparent; it is thicker, and often warty, especially towards the margin, in Bufo. 
In our single representative of the arboreal type, the tree-frog-Hyla arborea - the extremities of the fingers and toes are expanded into adhesive disks (Fig. 6, в), which assist the animal in climbing on vertical smooth surfaces. These disks do not act as suckers, as was once believed, but adhere by rapid and intense pressure of the distal phalanx and special muscles upon the lower surface, which is at the same time provided with numerous glands producing a viscous secretion. The upward rotation of the terminal phalanx, the swollen base of which is hinged upon an interarticular cartilage situated under the extremity of the penultimate phalanx, and can be raised or lowered like the claw of a cat, is easily to be observed on a living specimen. When the disk does not adhere (Fig. 5), its upper surface shows a short ridge produced by the clawlike terminal phalanx, and the lower surface is convex with some longitudinal grooves. During adhesion, on the other hand, the claw-like phalanx is no longer visible on the upper surface, but is indicated by a groove, whilst the lower surface is flat and expanded.

FIG. 5.

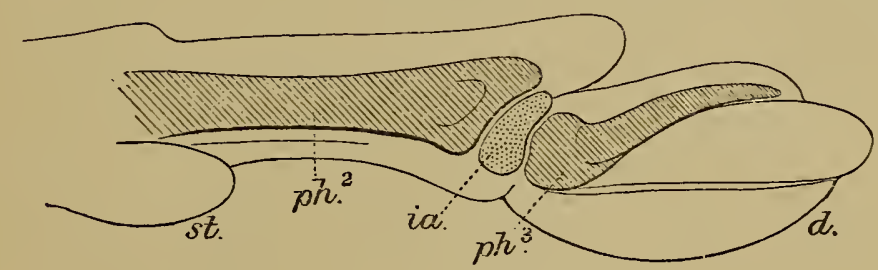

Section through the extremity of the third toe of Hyla arborea, the bones being indicated by oblique bars. $p h^{2}, p h^{3}$. Second and third phalanges. ia. Interarticular cartilage. $d$. Adhesive disk. st. Subarticular tubercle.

The adhesion of tree-frogs to smooth vertical surfaces is, however, not effected entirely through the above-mentioned organs, their function being supplemented by the suctorial action of the belly, such as is developed, though to a lesser degree, in the young of most Batrachians which, devoid of digital expan- 
sions, are nevertheless able to slowly ascend a pane of glass.

In most of our genera the fourth and fifth toes are cleft almost to the base, and the metatarsal portions of them are separated by the web. In two genera, Bufo and Hyla, this is not the case; the metatarsals of the two outer toes are bound together by the common integument, the angular divergence of the fifth toe proceeding only from the basal phalanx, as may be seen from the following figures (Fig. 6) representing the foot of the common frog and that of the treefrog.

Fig. 6.

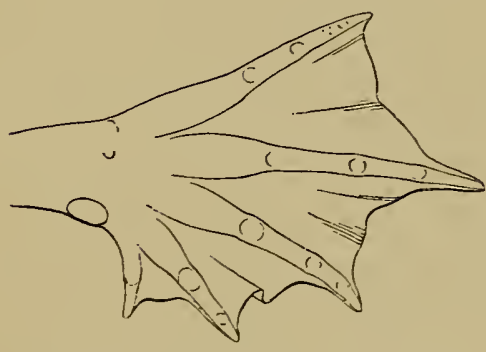

A

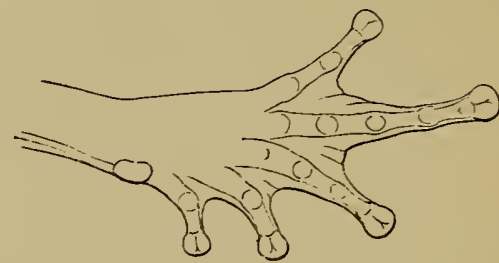

B

Lower surface of foot of Rana temporaria (A) and Hyla arborea (B).

The tree-frog differs from other Batrachians in having the articulations of the limbs, especially the wrist, marked above by a strong fold, reminding one of the arms and legs of a jointed papier-maché doll.

The proportions of the hind limbs to the body are best appreciated by bending the limb forwards against the side, and ascertaining the position of the tibiotarsal or tarso-metatarsal articulation; a certain allowance must, however, be made in cases when the abdomen of a female is much distended with ripe ova. A convenient method of appreciating the length of the tibia as compared to the femur is to fold the limb so as to place the former at a right angle to the axis of the body, as shown in the accompanying figure (Fig. 7); in which position the heels (tibio-tarsal articulation) meet. when the tibia is nearly equal to the thigh, fail to meet when shorter, or overlap when longer. 
FIG. 7.
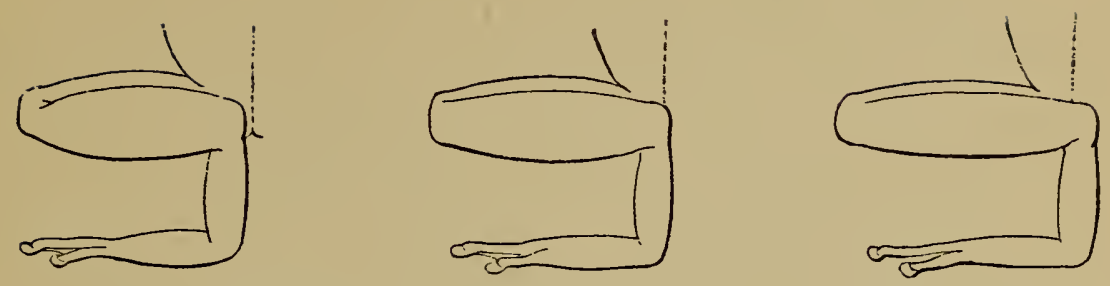

Limbs of Hyla arborea, showing variations in the proportion of the tibia. The dotted line indicates the middle line of the body.

The great development of the hind limbs enables these Batrachians to proceed by leaps ; there is, however, one exception among the European forms, viz. Bufo calamitu, in which the limbs are so short as to render hopping impossible, and this toad progresses at a running pace when pursued. The other extreme is furnished by Rana agilis, which orwing to its extremely long hind limbs is able to cover a distance of six feet at one leap. The aquatic habits of a Batrachian can, as a rule, be gauged by the extent of the web between the toes: thus Bufo calamita and Alytes, which have only rudimentary webs, are very bad swimmers, and do not venture far from the shore; whilst Rana esculenta and Bombinator, with their broadly-webbed toes, spend nearly the whole of the active period in the water. But there are exceptions: Pelobates, the toes of which are completely webbed, sojourns but a very short time in the water; it is true that in this case the web is probably of use for pushing aside the soil in the process of digging.

The following synopsis of the species is based entirely on external characters, and applies to both sexes.

I. Tongue circular, entire, adherent, or slightly free behind; vomerine teeth behind the level of the choanæ; first finger shorter than second (DisCOglosside). 
A. Pupil round, subtriangular, or cordiform.

1. Vomerine teeth in long transverse series; tympanum distinct or concealed under the skin . . . 1. Discoglossus pictus.

2. Vomerine teeth in two groups; no tympanum.

Tibia shorter than the foot

2. Bombinator igneus.

Tibia as long as or a little longer than the foot . . . 3. Bombinator pachypus. B. Pupil vertical; romerine teeth in short transverse or slightly oblique series; tympanum distinct.

Three palmar tubercles; fourth finger as long as or slightly shorter than second

4. Alytes obstetricans.

Two palmar tubercles; fourth finger much shorter than second 5. Alytes cisternasii.

II. 'Tongue circular, entire or slightly notched, and free behind; vomerine teeth between the choanæ; pupil vertical (PELOBATIDE).

A. Tympanum distinct or concealed under the skin; toes webbed at the base and bordered; inner metatarsal tubercle small, soft

6. Pelodytes punctatus.

в. No tympanum; toes nearly entirely webbed; inner metatarsal tubercle large, hard, compressed, sharp-edged.

Interorbital space and occiput convex; metatarsal tubercle yellowish or pale brown

7. Pelobates fuscus.

Interorbital space and occiput flat; metatarsal tubercle black . 8. Pelobates cultripes.

III. Tongue elliptical or pyriform, entire, free behind ; no teeth ; pupil horizontal (BUFONIDE).

Toes at least nearly half webbed, with paired subarticular tubercles; no tarsal fold; inter- 
orbital space at least as broad as the upper eyelid . . . . 9. Bufo vulgaris.

Toes at least nearly half webbed, with single subarticular tubercles; a tarsal fold; fingers very obtuse; interorbital space narrower than the upper eyelid . 10. Bufo viridis.

Toes webbed at the base, with paired subarticular tubercles ; a tarsal fold usually present; interorbital space narrower than the upper eyelid; hind limb not, or but slightly, longer than head and body... . 11. Bufo calamita.

IV. Tongue cordiform, free behind; fingers and toes dilated at the end into distinct disks; fingers webbed at the base; vomerine teeth between the choanæ; pupil horizontal (HyLide).

12. Hyla arborea.

V. Tongue forked and free behind; pupil horizontal (RANIDE).

A. Vomerine teeth between or extending slightly behind the level of the choanæ; interorbital space not more than half as broad as the upper eyelid . 13. Rana esculenta.

B. Vomerine teeth extending behind the level of the choanæ; interorbital space at least onehalf the width of the upper eyelid.

1. Tibio-tarsal articulation rarely reaching the tip of the snout, and never beyond; distance between the dorso-lateral folds five to seven times in the length from snout to vent.

Inner metatarsal tubercle large, hard, compressed, measuring: one-half to two-thirds its distance from the tip of the inner toe; first finger extending beyond second; tibia shorter than the fore limb. . . 14. Rana arvalis.

Inner metatarsal tubercle small, soft, oval; first and second fingers equal, or first extending 
slightly beyond second; tibia as long as or slightly shorter than the fore limb

15. Rana camerani.

Inner metatarsal tubercle small, soft, oval; first finger extending beyond second; tibia considerably shorter than the fore limb

16. Rana temporaria.

2. Tibio-tarsal articulation reaching the tip of the snout or beyond; tibia nearly as long as the fore limb; distance between the dorso-lateral folds contained four to five and a half times in the length from snout to vent.

a. Tympanum not more than two-thirds the diameter of the eye, distant from it.

Distance between the nostrils greater than the interorbital width; first and second fingers equal, or first extending slightly beyond second; inner metatarsal tubercle nearly half the length of the inner toe, as long as the diameter of the tympanum . . . 17. Rana græca.

Distance between the nostrils greater than the interorbital width; first and second fingers equal, or first extending slightly beyond second; inner metatarsal tubercle one-third the length of the inner toe, shorter than the diameter of the tympanum . . 18. Rana iberica.

Distance between the nostrils not greater than the interorbital width; first finger extending beyond second; inner metatarsal tubercle onethird the length of the inner toe, shorter than the diameter of the tympanum

19. Rana latastii.

$b$. Tympanum two-thirds to five-sixths the diameter of the eye, and close to it; first finger extending beyond second; inner metatarsal tubercle very prominent, but moderately large.

20. Rana agilis. 


\section{IN'TEGUMEN'I.}

The integument of the Ecaudata differs from that of other Batrachians in the slight attachment to the

FIG. 8.
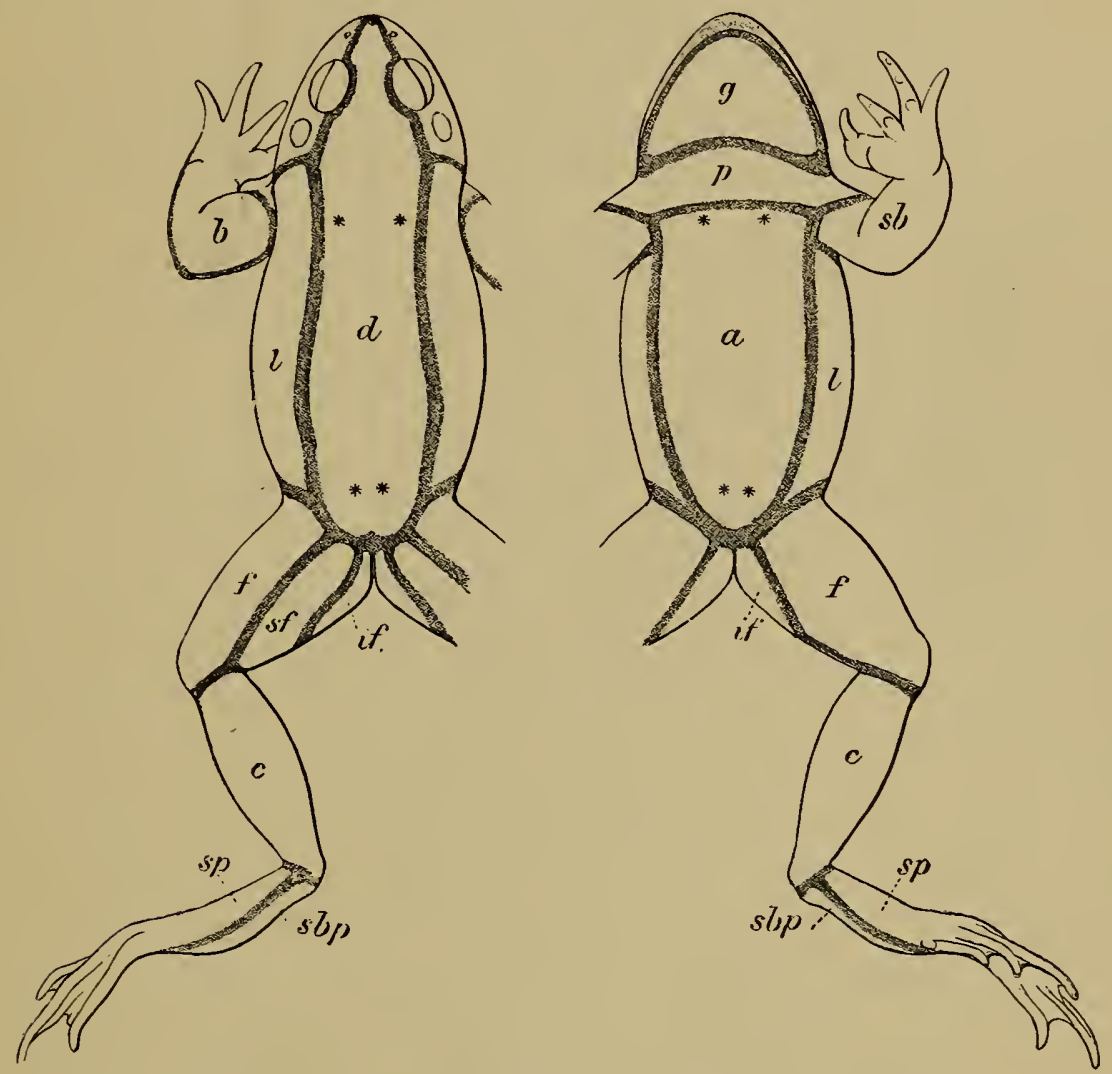

Rana temporaria, showing the dermal attachments and the disposition of the lymph.sacs, upper and lower views. The position of the lymph-hearts is indicated by asterisks.
a. Abdominal sac. | g. Gular
sac. I $s b$. Subbrachial sac.
b. Brachial
,$\quad$ if. Interfemoral :,
c. Crural
d. Dorsal
f. Femoral
",
, $\quad$ l. Lateral
p. Pectoral
,",
sbp. Subplantar
sf. Supra-femoral ",
sp. Supra-plantar ,"

muscles, thus rendering the skinning of a frog a most easy operation. But the body is not enclosed in a loose sac, as is often stated in popular descriptions; there are definite lines of attachment (Fig. 8) by means of connective tissue, which form the demarca- 
tions between the lymph-sacs that exist on both the dorsal and ventral surfaces immediately beneath the integument.

The lymph, fed by the moisture absorbed through the skin, is pumped into the veins by two pairs of lymph-hearts, contractile muscular sacs, the anterior of which are situated in the muscular tissue close to the transverse processes of the third vertebra, the posterior on the sides of the urostyle near its extremity; their pulsations may be observed on the back of the living frog.

The number and extent of the lymph-sacs varies in the different genera. In Rana and Pelodytes there are 22, 4 unpaired and 9 pairs. The dorsal sac extends from the tip of the snout to above the vent, and is limited by the line of attachment which corresponds to the canthus rostralis, the supra-orbital border, the supra-temporal fold, and the glandular dorso-lateral fold. The lateral sac is limited below by a band on each side of the belly, which may be marked externally by a slight groove; the abdominal surface of the head and body is divided into three sacs, gular, pectoral, and abdominal, with partitions across the præcoracoid and coracoid regions. The further sacs (brachial, subbrachial, femoral, supra-femoral, interfemoral, crural, supra- and sub-plantar) belong to the limbs. In Hyla there is besides a close areolar attachment of the abdominal integument. The Discoglossidæ differ in the absence of coracoid attachment, or if such exists, as in Discoglossus, it is widely interrupted on the middle line; there is, therefore, no distinct pectoral lymph-sac. In Pelobates the skin of the belly is attached in its posterior half. In $B u f o$ the ventral integument is more or less broadly attached, together with the whole of the dorsal integument.

One of the most remarkable peculiarities connected with the integument of Batrachians is the cutaneous respiration, or the power which the surface of the 
skin possesses of effecting those changes in the blood which are usually performed by the lungs or gills, and by which frogs may remain active for long periods under water. Results of various experiments have proved that pulmonary respiration alone is not sufficient to support life withont the aid of that of the cutaneous surface; whilst some of the tailed. Batrachians have lately been shown to be deprived of both lungs and gills, so that the contrary does not hold good for them. But in order to carry out this important function it is of course necessary that the surface be kept in a moist state, and this is effected by a secretion of fluid from the skin itself.

An immense number of close-set glandular cæca open upon the surface of the skin, the slime-cells, in addition to which a greater or lesser number of larger poison-secreting glands are scattered or disposed in very conspicuous prominent aggregations, such as the dorso-lateral fold of Rana, the large dorsal warts of Bufo and Bombinator, and especially the so-called parotoids, situated above the ear in $\dot{B} u f_{0}$ and Alytes, and a similar gland on the calf of Bufo calamita (Fig. 9, p. 24). These glands are pierced with large pores, visible to the naked eye or with the aid of a low magnifier. A round gland, the frontal or pineal gland, the homologue of the so-called parietal eye of reptiles, is nore or less discernible under the skin of the forehead in front of and between the eyes; this gland, in the early stages, was connected with the brain. The presence of lime concretions in the skin of old specimens of Bufo vulgaris has been first pointed out by Leydig. 'The same have been found in $B$. calamita by $\mathrm{O}$. Seeck.

A character which does not appear to have been noticed before is the presence of a filiform line or raphe, on which the skin is much thinner, extending along the middle line of the back from the snout to the extremity of the coccygeal region in all specimens of Bufo. 'This raphe, which may best be observed on 
a stripped skin held against the light, gives rise to the yellow vertebral line which is normal in Bufo calamita, and only exceptional in $B$. viridis and vulgaris, independently of another light vertebral streak which is sometimes also present. The independence of the two is most conspicuous in cases of deviation of the former, as often bappens in Bufo calamita, which appears to be caused by the presence of large glands in the course of the raphe necessitating a winding (Fig. 9).

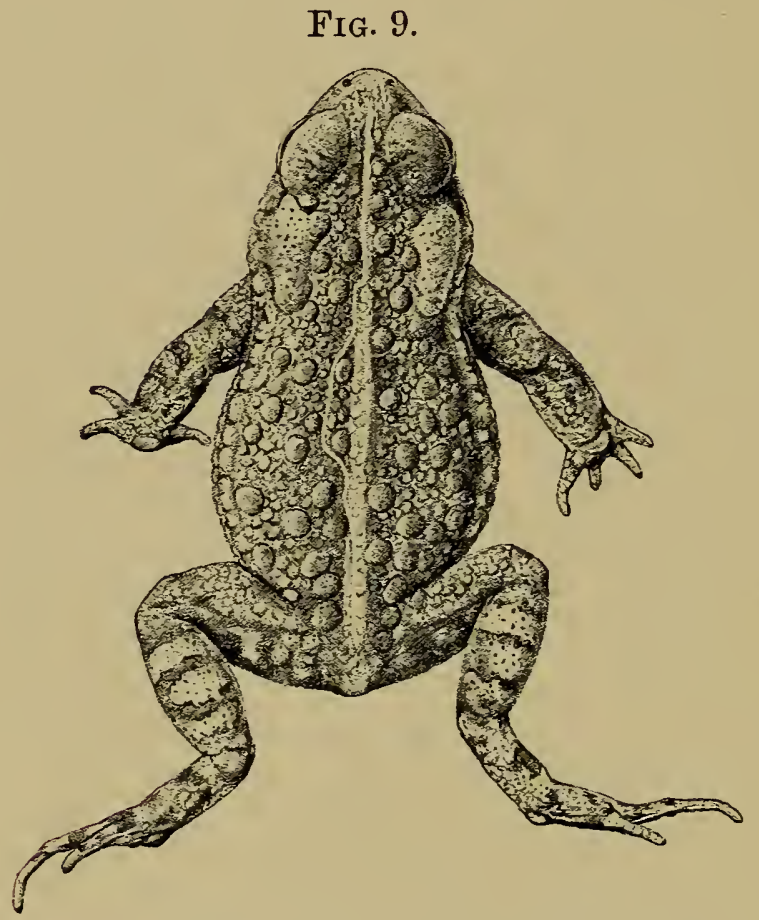

Bufo calamita, showing yellow raphe, independent of light vertebral streak, and its deviation from the median line in the middle of the back.

The epidermis is remarkable for the formation of horny cells, as the spines on the warts of some toads and Bombinator (Fig. 10, p. 29), or the sheaths on the tips of the digits in Bufo and Pelobates, or on the metatarsal tubercles when these are much developed. There are also, in some Batrachians, special small, pearl-like warts, mostly pigmentless, the "tact-spots" 
of Merkel, formed by the grouping together of terminal ganglion-cells. These sense-organs are found principally on the limbs and flanks of Rana esculenta, more developed in males than in females; the small warts on the fore limbs of Pelobates, which have by some been compared with the nuptial horny excrescences, seem to be of the same nature. Very similar productions appear during the breeding season in the females of Rana temporaria and $R$. arvalis, but are of a merely temporary character, and will be noticed in the chapter on Pairing and Oviposition, together with the horny excrescences which arm the digits or other parts in the males at the same period, and assist them in maintaining their hold whilst pairing.

Pigment, usually confined to the cutis, sometimes occurs in small quantity in the epidermis. As Leydig has shown, five kinds of special cells may be present in the cutis-black, yellow, red, white, and metallic or iridescent, the last being the so-called guanin-cells or iridocytes. The yellow and black pigments combine to produce the bright green colour, as in normal specimens of Rana esculenta typica and Hyla arborea: if the yellow pigment be absent, as in the German specimens of Rana esculenta, var. ridibunda, the black and gold produce the dull green or olive hue; if both yellow and gold pigments are absent, the black below the cloudy medium of connective tissue and epidermis produces blue, as in the sky-blue specimens of Rana esculenta and Hyla arborea. In the play of the special pigment-cells or chromatophores, which contract or expand and radiate, we find the explanation of the changes of colour which some specimens undergo with so great rapidity. A tree-frog will turn from yellow to green and black in less than an hour, yellow when the black pigment contracts, black in the opposite process.

That these rapid changes of colour harmonise, within certain limits, with the surroundings is well known. The researches of Dutartre on Rana escu. 
lenta have shown that the changes are controlled by the animal, the contraction or expansion of the chromatophores not being due entirely to the direct action of light and moisture upon the skin, but also to a reflex action of the sympathetic nervous system brought about by the visual impression. Comparative experiments conducted on frogs possessed or deprived of the sense of sight, and placed in different conditions of light, show the blind individuals to change colour much less rapidly.

The changes which we observe in Hyla, Rana, and $B u f o$ are not limited to the ground colour, but also extend to the markings. The tree-frog, normally uniform, may become covered with lighter or darker dots or spots, sometimes disposed with great regularity and even assuming the form of cross-bars on the limbs. An edible frog, of a fine grass-green with few black spots above and with a pure white belly when captured, way shortly after, when transferred to an aquarium, appear largely marbled with black both above and beneath.

F. Werner has proposed to group the European Batrachians, with respect to this peculiarity, into such as actually change colour (Alytes, Hyla, Bufo, Rana), and such as only lighten or darken their shade (Discoglossus, Pelodytes, Pelobates). He considers Bombinator as representing a third category, no changes of any kind taking place; but I cannot agree with him in this, as I have seen B. pachypus pass from yellowish to a very dark brown, and also vary in the presence, absence, or distinctness of the light and dark markings.

In a recent work on East African Reptiles and Batrachians G. Tornier endeavours to show that the yellow and red pigments do not exist as chemical entities, but are only degenerations of the brown pigment or "melanin." And as a first " simple and sure" proof of his contention he adduces the example of Pelobates fuscus larvæ, which according to him are 
"quite black," and during metamorphosis assume the light yellowish-grey ground colour through the greater part of the pigment-cells turning pale. A more glaring misrepresentation could not be imagined. Far from being black, the tadpole of Pelobates fuscus is normally pale brown, with darker spots and marblings, as may be seen from the figure in this work. And the tadpole of Pelobates cultripes, a species which has the same dark spots as P. fuscus after transformation, is usually very pale reddish yellow. A proof that the yellow and red pigments are chemically distinct from the brown or black is to be found in the different action of alcohol on them. Thus yellow pigment is rapidly destroyed; therefore green frogs turn olive or blue in spirit. Certain crimson pigments, not unfrequent in frogs, resist the action of alcohol and light better than the brown, which by discoloration may turn to reddish brown or rufous, these two reds strongly contrasting in specimens that have long been in spirit. Tornier goes even so far as to doubt the presence of any but the brown pigment in reptiles; surely the green of certain tree-snakes of the genera Dryophis and Lachesis, which colour the spirit in which they are preserved to the extent of resembling green Chartreuse, is due to the presence of a chemically distinct colouring matter, and has no relation whatever to the green of frogs, which, produced, as we have seen, by a combination of black and yellow, disappears in spirit when the latter pigment is destroyed.

Another instance of the same author's carelessness in the selection of examples is to be found a little further in the same work (p. 130), where he declares that Batrachian larvæ which develop in the light are, with few exceptions, uniformly dark, or more usually deep black, and retain that coloration until close to the metamorphosis. I believe the exception is just the other way. The embryos of Bombinator and Alytes are yellowish or pale brown striped with blackish, those of Hyla uniform yellowish, those of Rana 
esculenta feebly pigmented; and of black tadpoles, or of a dark brown approaching black, I only know Bufo and Rana temporaria; all the other European species are only exceptionally, not normally very dark. That the light cannot have a great effect in producing the pigment in Batrachian larvæ is shown by Alytes and Bombinator, both of which develop the same amount of pigmentation, the one under paternal care never being exposed to daylight, the other reared in pools or puddles exposed to the full action of the sun's rays.

Cases of melanism, or better, absence of iridocytes and all pigment but the brown or black, which may be very abundantly and exclusively present, have been observed by Héron-Royer in Alytes obstetricans, by Alfred Dugès, and more recently by Héron-Royer and by Vaillant, in Rana esculenta. I found a similar young specimen of the latter species in a marsh near the Belgian coast in 1884; the back was brown, nearly black, the hinder side of the thighs and the ventral surface pigmentless, transparent flesh-colour, the iris black without any gold. A male specimen of Rana græxca from Italy, showing the same abnormality in the absence of all but the brown colour, was sent to me last spring by Count Peracca, and is figured on Plate XXII of this work.

Albinism, or absence of the brown pigment, on the other hand, has been observed in a young Bombinator pachypus by Fatio, in larvæ of Alytes obstetricans by Lataste and Héron-Royer, who succeeded in rearing them through the metamorphosis, in a larva of Discoglossus pictus by myself, in Rana esculenta by Pavesi, in larvæ and young of Bufo viridis by Born, Camerano, and myself, in larvæ of Rana temporaria by Lessona, Fischer-Sigwart, and Camerano; an adult female of the latter species found in England was exhibited alive by Mr. Rowland Ward at the Linnean Society in 1891, and another, from Wiltshire, presented by Mr. IV. Hannaford, is now preserved in the British 
Museum. These albinos are of a uniform yellowish flesh-colour, with silvery or golden iris and cherry-red pupil; the yellow ventral blotches are preserved in Bombinator. A figure of a young Alytes albino reared by Lataste is given on Plate VII. Albino specimens of Alytes obstetricans obtained from tadpoles by HéronRoyer paired in confinement, and produced offspring that were likewise affected with complete albinism. But for the difficulty in getting these Batrachians to breed in captivity, a race of albinos could no doubt be fixed by artificial selection, as in the case of the axolotl, the numerous "white" examples of which are said to be all descended from an albino male which paired with normal females in the Jardin des Plantes at Paris some thirty years ago.

Batrachians often "change skin,"-about once a month during the spring and summer. The thin, transparent outer layer of the epidermis becomes detached about the mouth, and, lubricated by an abundant secretion of the slime glands, is pulled off by movements of both fore and hind limbs, often in a single piece turned inside out, especially when the operation is performed in the water, and finally swallowed by its owner. The casting of the epidermis on land is a slower process, accompanied by ludicrous contortions; in the common toad it may last nearly an hour.

Frg. 10.

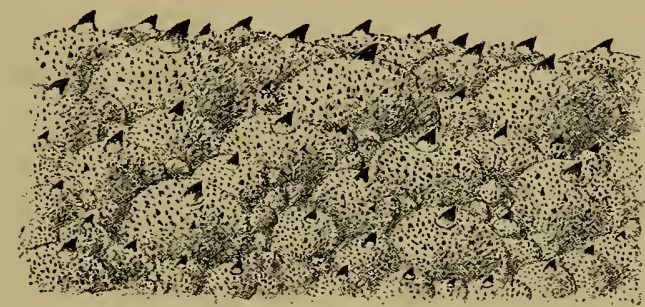

Piece of dorsal integument of male Bombinator pachypus $(\times 8)$, showing warts and epidermal horny asperities. 


\section{Dermal Segretion.}

The skin of the dorsal surface of all Batrachians is, as we have seen, studded with glands and follicles. In various species, of which our Bufones are good examples, some of the larger glands appear as very prominent warts pierced with wide pores, especially a large mass situated on each side of the back of the head behind the eyes, which has received the misnomer of parotid, a name now generally changed to parotoid gland. These glands secrete, more or less abundantly according to the species, a viscid or milky more or less and variously odorous fluid, which is exuded, when the animal is disturbed, by means of the contraction of small muscles disposed in the skin around the glands. If the larger glands be pressed or subjected to an electric current the secretion is squirted out with great force, and sometimes to a considerable distance. Kobert recommends, as the best means of obtaining an abundant supply of toadpoison, the subcutaneous injection of a small dose of chloride of barium ; after a fer minutes the animal is so covered with its secretion as to appear as if coated with whitewash. The object of the secretion is to guard Batrachians from the attacks of various enemies. A dog will not often repeat the experiment of seizing a toad; the signs of pain which it evinces after the poisonous fluid has come into contact with its mouth is familiar to most of those who have kept young dogs in the country. That excellent Hungarian naturalist, Prof. v. Méhely, relates the serious effects of the poison of Bufo viridis on a small terrier which accompanied him on a collecting excursion. A large toad, found under a stone, was at once attacked by the dog, but no sooner seized was let go again with signs of great repulsion; the toad had instantly become covered with a thick white secretion. The dog approached it once more and then withdrew, sneezing and 
howling and rubbing its foaming mouth on the grass. After a few minutes the dog was seized with convulsions, and had to be carried home exhausted. On the next day it had a swollen mouth and burning nose. It did not completely recover until the following day.

That the toad's poison does not protect it against snakes is well known,-our common Tropidonotus, for instance, not feeling any more repulsion for it than for a frog, although it will not eat Bombinator. It is the experience of those who have handled freshly caught specimens of the latter that the secretion of these Batrachians acts as a sternutatory, and causes irritation of the mucous membrane of the nose and conjunctiva, the effect being comparable to the early stages of a cold in the head. German violinists, it is said, when suffering from moist hands, are accustomed to check the perspiration by handling live toads. Many collectors of Batrachians have learned, to their discomfiture, how the introduction of examples of certain species in the bag containing the spoil of their excursion may cause the death of the other prisoners, and common tree-frogs are stated to have died from the contact, in the same small terrarium, of examples of an American species, Hyla versicolor, which, owing to its warty skin, is often designated as a "tree-toad ;" for although the poison has no effect on the skin of individuals of the species which produces it, frogs of different species, however closely allied, may poison each other by mere contact. When ingurgitated or inoculated the poison acts even on the individual by which it has been secreted, as has been proved by various experiments, but death is only produced by using a stronger dose than is required for killing individuals of another species.

The poison of Batrachians, unlike that of snakes, is not a septic, but acts upon the heart and the central nervous system. That of the common toad has been compared, as regards its effects, to Digitalis and Erythrophlæum. For a long time authorities disagreed 
as to the nature of the secretion; some regarded it as an acid, others as an alkaloid. Phisalix, in 1890 , claimed to have solved the question by reconciling both views, he having found toads to be simultaneously possessed of two different kinds of glands, different both anatomically and physiologically. 'These are mucous or slime glands spread over the greater part of the body, the exudation of which is controlled by the animal; and specific glands (the parotoids and the larger dorsal glands), the product of which can only be squirted out by foreign agency. The secretion of the former glands is an alkaloid, and acts as a narcotic; that of the latter is an acid, and acts as a convulsive. The anatomical differences of the two kinds of glands have since been worked out by Paul Schultz, who, however, regards the product of the slime glands as innocuous.

Phisalix and Bertrand's recent investigations have shown the active principle of toad-poison, the so-called phrynin, to be also present in certain quantities in the blood of these Batrachians.

Even the frogs of the genus Rana, so sensitive to the poison of other Batrachians, are not free from toxic properties. A goldfinch inoculated by Panl Bert with the dermal secretion of Rana esculenta died in one minute; a frog of the same species in one hour and a quarter.

The secretion of Alytes, Pelodytes, and Pelobates smells like garlic, so strongly in the last that I have observed the odour to remain for hours in a room after I had purposely irritated a few specimens. That of Bufo calamita smells like boiled indiarubber, like ignited gunpowder, or a Dutch clay pipe smoked for the first time, according to Rösel's cornparison; whilst that of its near ally, Bufo viridis, always reminds me of a linseed poultice.

A chemical comparative study of the dermal secretion in the various types of European tailless Batrachians is still a desideratum. 


\section{Skeleton.}

The skull is more or less strongly depressed, and remarkable for the extremely large orbits and the reduction in the number of elements. We have to distinguish between the chondrocranium, or primitive skull-consisting mainly of cartilage with a few ossified parts, with a large fontanelle or membranous space in the interorbital region, and foramina for the exit of the cranial nerves, -and the membrane bones, which may be removed by maceration.

The ossified parts of the chondrocranium, or cartilage bones (Fig. 11), are the eth moid or sphenethmoid, forming a ring round the anterior part of the brain-case, the

FIg. 11.

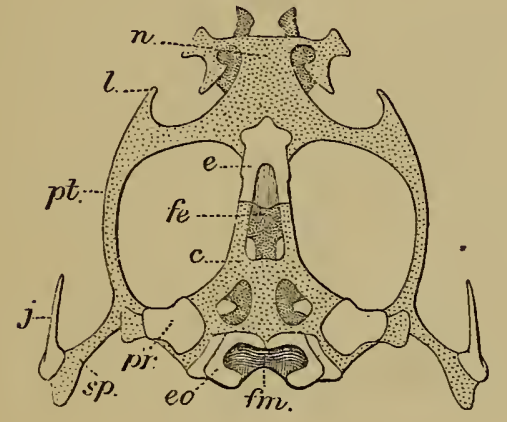

A

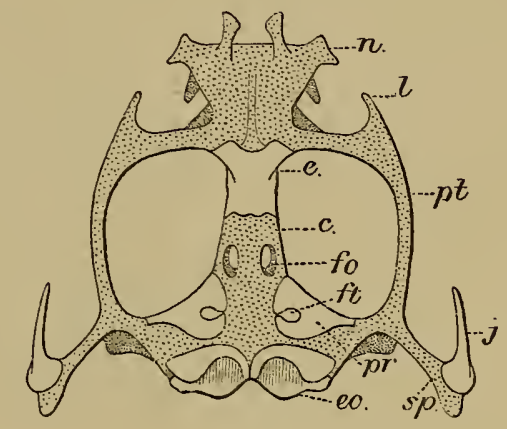

B

Chondrocranium of Rana esculenta.

A. Upper view. B. Lower view.

c. Brain-case.

e. Ethmoid.

eo. Exoccipital.

fe. Fontanelle.

fm. Foramen magnum.

fo. Optic foramen.

$f t$. Trigeminal foramen. $j$. Jugal.

l. Lachrymal process.

$n$. Nasal capsule.

pr. Prootic.

pt. Pterygoid branch.

sp. Suspensorium.

(paired) prootic behind the orbit, the (paired) exoccipital on each side of the foramen magnum, forming the (paired) occipital condyle articulating with the first vertebra, and a styliform jugal connecting the cartilaginous suspensorium of the mandible or the ossified quadrate with the maxillary. 
FIg. 12.

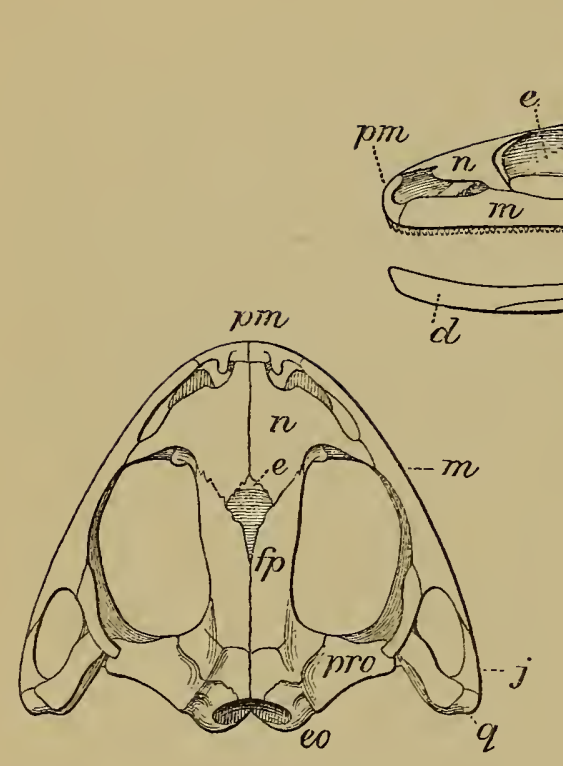

A

$\mathrm{C}$

fo eo
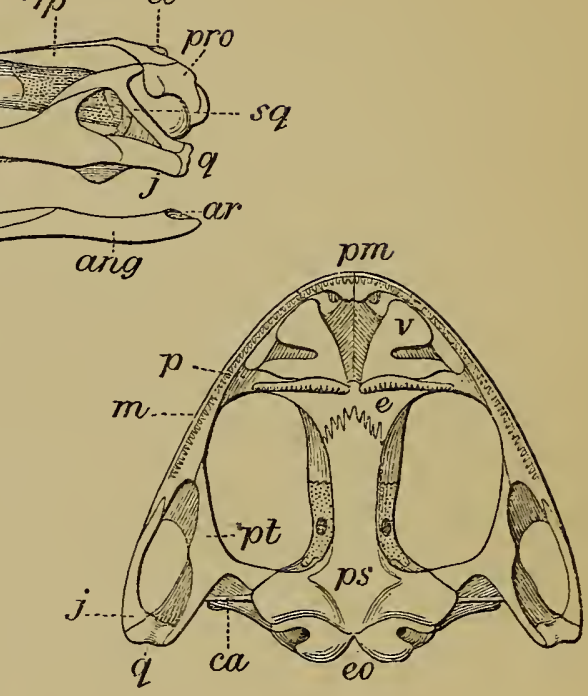

$\mathbf{B}$

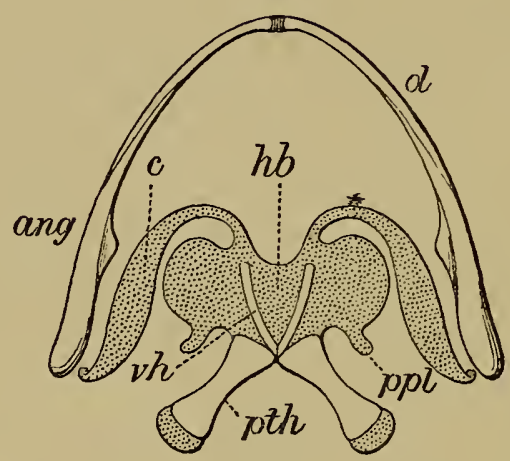

$\mathrm{D}$

Skull, mandible, and hyoid of Discoglossus pictus.

A. Upper view of skull. B. Lower view of skull. C. Side view of skull and mandible. D. Lower view of mandible and hyoid.

ang. Angular.

ar. Articular.

c. Cornu of hyoid.

ca. Columella auris.

d. Dentary.

e. Ethmoid.

eo. Exoccipital.

fp. Fronto-parietal.

$h b$. Body of hyoid.

j. Jugal.

$m$. Maxillary.

n. Nasal. $p$. Palatine.

pm. Præmaxillary.

ppl. Postero-lateral process of hyoid.

pro. Prootic.

ps. Parasphenoid.

pt. Pterygoid.

pth. Thyroid process of hyoid.

$q$. Quadrate.

sq. Squamosal.

v. Vomer.

vh. Ventral ossicle of hyoid. 
The membrane bones, all paired with the exception of the parasphenoid (and in Pelobates the frontoparietal), are the following :-Præmaxillary, maxillary, squamosal, pterygoid, palatine, vomer, parasphenoid, nasal (often called præfrontal), and fronto-parietal. A small ossification behind the narial opening is the turbinal, regarded by some as the true nasal. The cranial ossification may be feeble, and a considerable portion of the cartilaginous primordial cranium remain exposed,-as, for instance, in Bombinator, which, together with Pelodytes, is remarkable for the lack of palatine bones ; or it may be extraordinarily developed, with superaddition of dermo-ossification, as in Pelobates, one species of which ( $P$. cultripes) is distinguished by the expansion of the fronto-parietal and

FIG. 13.

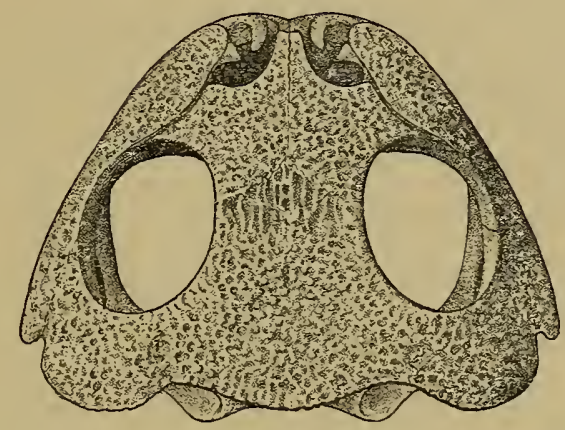

Upper view of skull of Pelobates cultripes.

squamosal, which join to form a complete roof over the prootic (Fig. 13). The genus Pelobates is further remarkable in having the fronto-parietal single, whilst in all other European genera it is paired, and in many species so separated along a portion of the median line as to leave the endocranial or fronto-parietal fontanelle exposed between the two. The nasals may join in the middle line, or be more or less widely separated from each other. The upper lamina of the ethmoid is usually exposed between the fronto-parietals and the nasals, and in Pelobates fuscus it is so prolonged forwards as to reappear between the nasals and the præmaxillaries. 
The squamosal is a hammer-shaped bone, the anterior branch of which may be much reduced, as in Bufo, long and free, as in Rana, or join the maxillary, as in Discoglossus and Pelobates.

The vomers vary much in size according to the genera; they are largest in Discoglossus, where their posterior toothed border corers over the palatines. The latter bones, if present, are narrow and transverse, and extend across the whole palate; in Bufo their lower surface forms a cutting, sometimes serrated edge, which makes up for the absence of romerine teeth. The pterygoids are trifurcate, and the anterior branch may or may not reach the palatines, or may be much produced forwards when the latter bones are absent, as in Bombinator. The parasphenoid is a large bone shaped like a $T$, or like a dagger with very short handle.

Most genera have a cartilaginous tympanic ring applied to the outer surface of the hammer-shaped squamosal, in the upper portion of which ends the slender, ossified, stapedial rod (columella auris). The tympanum is absent in Pelobates, and both the tympanum and the stapedial rod in Bombinator, which in this respect again resembles the tailed Batrachians.

In Discoglossus three bones invest the Meckelian cartilage which forms the ramus of the mandible; the dentary in front, the angular or angulo-splenial behind, and extending more to the front on the inner side, and a small bone which articulates with the quadrate, the articular. In Rana the articular remains cartilaginous, but the symphysial cartilages ossify, forming. the so-called mento-Meckelian or symphysial bones, which in adult specimens fuse on the upper side with the dentary (Fig. 14). These symphysial bones are less distinct in Hyla and Bufo, less still or even almost indistinguishable in the Pelobatidx and Discoglossidx.

The hyoid varies very considerably in the different 
genera. The body is broad with well-developed, sometimes ossified postero-lateral, but no anterior, processes in the Discoglossidx (Fig. 12, D, p. 34); with anterior processes and short postero-lateral ones in the Pelobatidae and Rana (Fig. 14); elongate

\section{FIG. 14.}

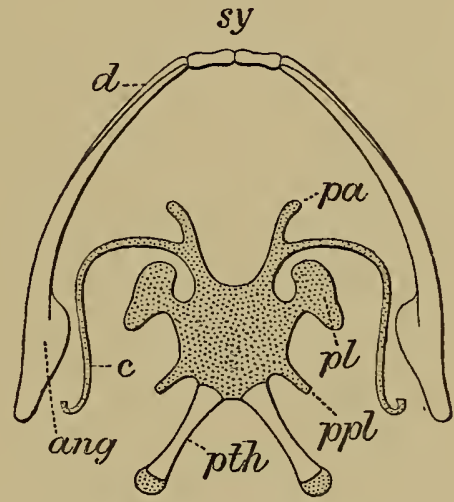

Mandible and hyoid of Rana esculenta, lower view.

ang. Angular.

c. Cornu of hyoid.

c. Dentary.

pa. Anterior process of hyoid. $p l$. Lateral process of hyoid.

ppl. Postero-lateral process of hyoid. pth. Thyroid process of hyoid.

sy. Symphysial (mento-Meckelian).

and without anterior processes in Bufo. In Pelodytes and Pelobates the anterior processes are much expanded, converge towards each other, and join the lateral processes, enclosing a fenestra on each side of the hyoid plate. The cornua are broad in the Discoglossidx, moderately broad in Bufo, slender in Rana; they are detached from the body of the hyoid in the Pelobatidx. The thyroid processes are always ossified, and form a pair of diverging styles, in front of which, on the ventral side, a slender, single or paired, $\mathrm{V}$ - or $\mathrm{H}$-shaped ossification may be present, as in Discoglossus, Alytes, and Pelodytes (Fig. 12, D, p. 34).

The vertebral column (Fig. 15) is formed normally of ten segments, viz. eight dorsal vertebræ, one sacral, and the urostyle or coccyx,-or of nine if the urostyle be fused with the ninth vertebra, as is frequent in Pelobates.

The vertebræ are much depressed, especially the 
so-called centra, the articulary balls of which are transversely elliptical, and the neural arch is either closed above (vertebræ imbricatim clausæ, according to the definition of Mertens), as in the Discoglossidæ and Pelobatidx, or notched between the zygapophyses so as to expose the spinal cord between every two vertebræ; the latter type is most marked in Rana, in which,

FIG. 15.

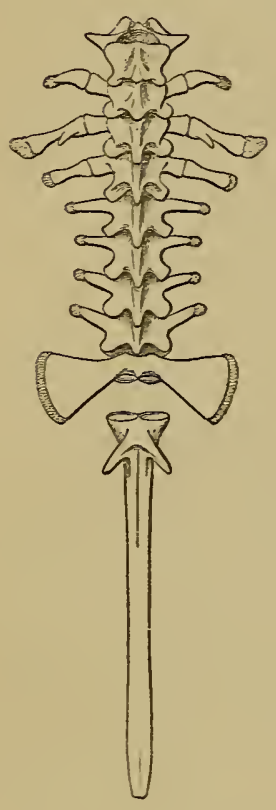

A

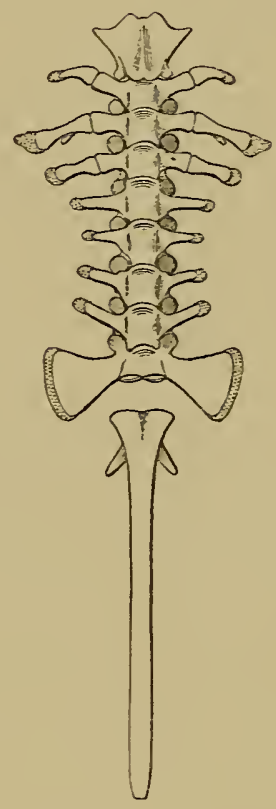

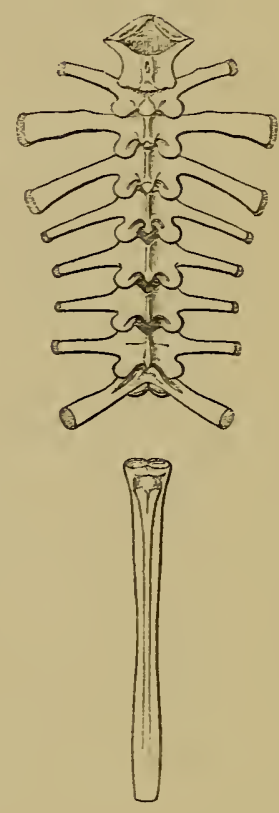

B
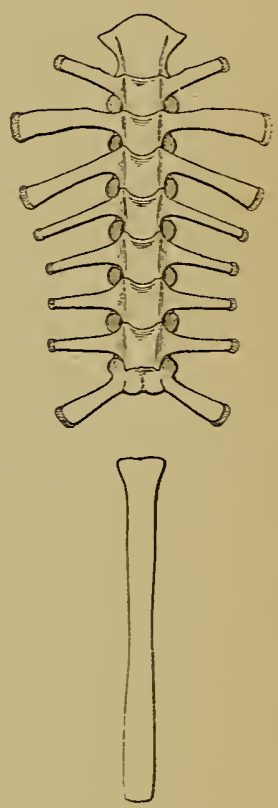

Vertebral columns of (А) Discoglossus pictus and (В) Rana esculenta, upper and lower views.

the lateral openings for the exit of the spinal nerves being also of large size, the vertebral column forms an open work above and on the sides. Neural spines are absent or represented by a low keel, which is much prolonged posteriorly in Discoglossus and Pelobates. The articulation is convexo-concave or opisthocœlous in the Discoglossidr, concavo-convex or procœlous in the other groups. In those forms in which the vertebræ are procœlous the eighth is biconcave; the ninth being invariably biconvex.

The first vertebra is devoid of transverse processes 
(diapophyses), but these are present on the succeeding eight vertebræ, and in the Discoglossidæ alone the first three are segmented off into short autogenons ribs. The transverse processes of the ninth vertebra give attachment to the ilia, and are therefore termed sacral; their form differs much according to the genera,-cylindrical in Rana, flattened and subtriangular in Discoglossus, Alytes, Bufo, and Hyla, or very strongly dilated in Bombinator, Pelodytes, and Pelobates. In the latter genus the sacral processes are often yielded by the urostyle. The diapophyses terminate in cartilaginous epiphyses.

The urostyle, or coccyx, formed by coalescence of at least two vertebræ, is a cylindrical solid rod with more or less distinct dorsal crest, and articulates with the sacral vertebra by two sockets, except in Bombinator, in which there is but one. In Pelobates the urostyle is normally fused with the ninth vertebra, and contributes to the sacrum; in the Discoglossidx a. slender transverse process is present on each side at the base of the urostyle.

Abnormalities in the vertebral column are not unfrequent, and many remarkable cases have been described by Goette, Lataste, Camerano, Bourne, Adolphi, and Howes. Thus two vertebræ may fuse, or the number of segments may be increased to eleven, as in a vertebral column of Alytes obstetricans described by Lataste; in this interésting specimen the ninth vertebra bears on the left side the dilated sacral diapophysis, whilst the diapophysis of the opposite side is slender and does not differ from that of the vertebra in front of it; the tenth vertebra, on the other hand, bears a dilated diapophysis on the right side and a cylindrical one on the left; the urostyle is quite normal, with the basal processes developed as usual. I have also examined a skeleton of Bombinator pachypus, with eleven segments, all, including the sacral vertebra and the urostyle, appearing perfectly normal in shape. 
The pectoral arch falls into two distinct types, - the arciferous (Fig. 16, A), in which the præcoracoid

FIG. 16.
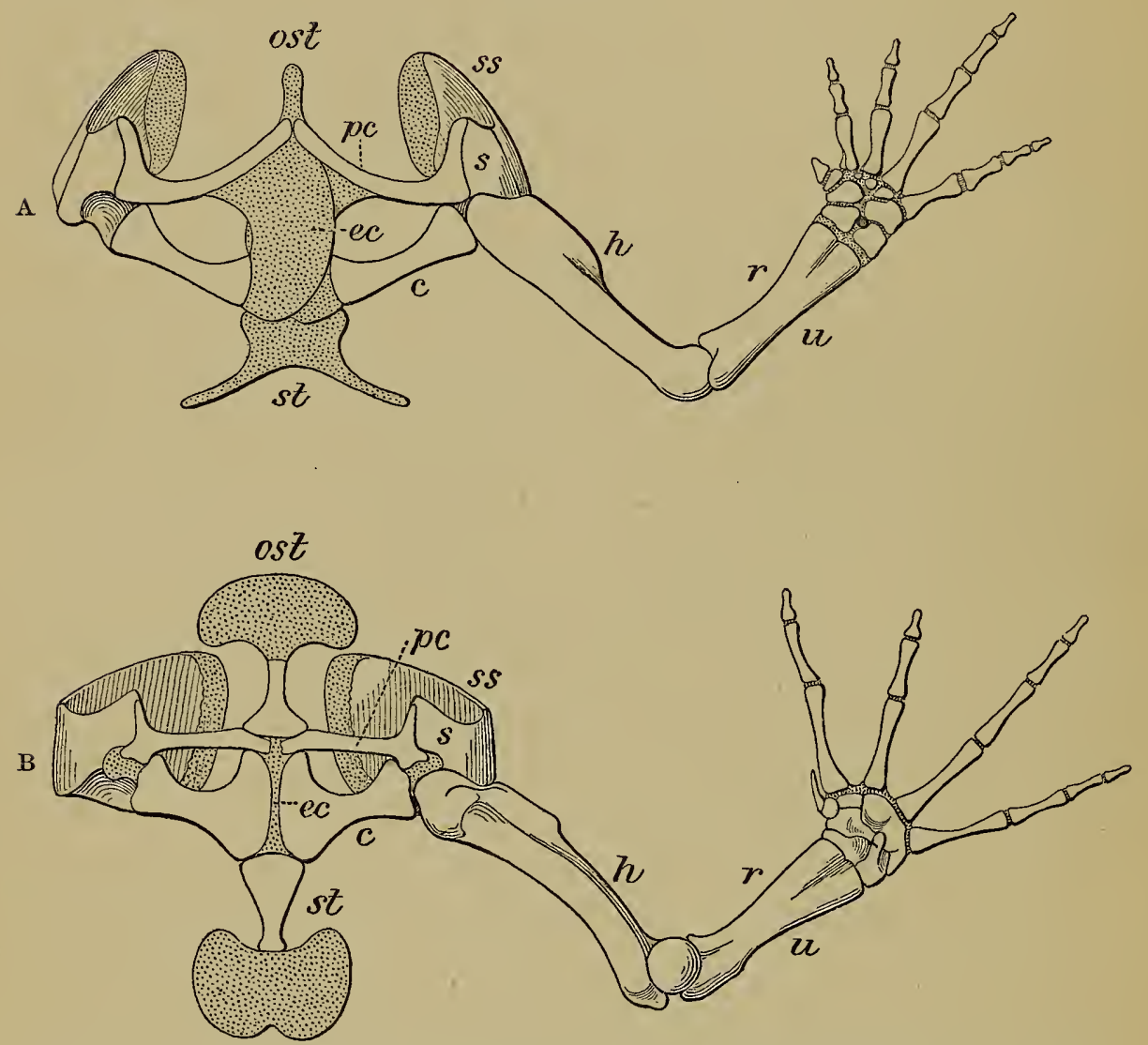

Pectoral arch and fore limb of (A) Discoglossus pictus and (B) Rana esculenta. Ventral view.
c. Coracoid.
ec. Epicoracoid.
$h$. Humerus.
ost. Omosternum.
pc. Præcoracoid.
$r$. Radius.
s. Scapula.
ss. Supra-scapula.
st. Sternum.
$u$. Ulna.

(præcoracoid + clavicle) and coracoid are widely separated from each other distally, and connected by an arched cartilage (the epicoracoid), the right usually overlapping the left; and the firmisternal (Fig. 16, B), in which both præcoracoid and coracoid nearly abut on the middle line, and are only narrowly separated by the fused epicoracoids. The latter type is exemplified by the true frogs (Ranid ) in the adult state, although 
when quite young these Batrachians present a condition similar to that which persists throughout life in the other families.

A cartilage in the median line in front, supported by a bony style in Rana, is the so-called omosternum; a larger one behind is the sternum. This is also provided with a bony style in Rana, Pelodytes, and Pelobates; or a portion of it may be calcified, as in Hyla and Bufo. In the Discoglossidx the sternum is produced into two posteriorly diverging cartilaginous or calcified styles.

The shoulder-blade is divided into two parts, the ossified scapula proper and the supra-scapula, cartilaginous or incompletely ossified, bent over at an angle to the scapula.

The præcoracoid enters the glenoid cavity in the Discoglossidr, Bufonidx, and Hylidx, but not in the three other families, where the cavity is formed by the scapula and coracoid.

The humerus is a feebly curved bone with a globular distal condyle and a strong præaxial crest, which is more developed in males than in females, and which in the former may be supplemented by a second crest lower down. The head is replaced by an epiphysis, which calcifies late, or never as in the Discoglossidæ and Pelobatidæ. The radius and ulna are fused to a single bone, which is shorter than the humerus. 'I'he ulnar part projects beyond the radius at the articulation with the humerus.

The carpal bones vary from six to eight. In the more primitive carpus, such as is represented by the Discoglossidx (Fig. 17, A), we find, following the nomenclature of Howes and Ridewood, two elements in contact with the radius-ulna, the radiale and ulnare; two, regarded as centralia, in the second row; and four, plus a vestigial ligamentous fifth, in the third row. The fourth distal carpale may fuse with the outer centrale, as in Pelodytes (в), or also with the third distal element, as in Bufo, Hyla, and Rana (c). 
In the Pelobatidx and Bufonidx the inner centrale is in contact with the radius.

FIG. 17.

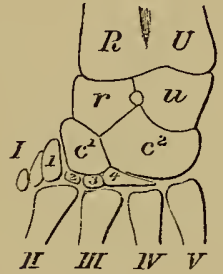

A

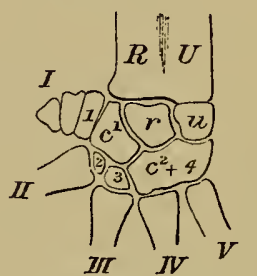

B

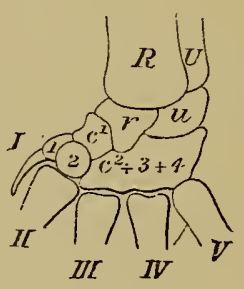

C

Carpus of-A. Bombinator pachypus. B. Pelodytes punctatus. c. Rana temporaria. (After Howes and Ridewood.)

$R$. Radius. $U$. Ulna. $r$. Radiale. $u$. Ulnare. $c$. Centrale. 1-4. Distal tarsalia. I-V. Digits.

There are four functional fingers, with elongate metacarpals, and 2, 2, 3, 3 phalanges. The distal phalanx is pointed or slightly expanded at the end, somewhat as in the human skeleton; or bears a wellmarked transverse branch, giving it a T-shaped appearance, as in $R . g^{\prime} æ c a$; or it assumes a peculiar claw-shaped conformation in the Hylidx, which is described and figured above, p. 15. In addition to these four fingers there is a rudimentary thumb or pollex, usually more developed in males than in females, and which, besides its metacarpal, may show one or two ossicles representing phalanges. The metacarpal of the pollex is very strongly developed in the male Discoglossus, which is also remarkable for the enlargement of the second metacarpal, bearing a crest along the inner side.

The pelvis (Fig. 18) is much elongate, and shaped like a pair of tongs, the free extremities of which are attached to the diapophyses of the sacral vertebra. The lateral branches are formed by the ilia, which, with the ischia behind them, bound the acetabulum; the third element, the pubis, situated ventrally between the ilium and the ischium, is often cartilaginous or calcified, and absent in Bombinator. In Pelobates 
FIG. 18.
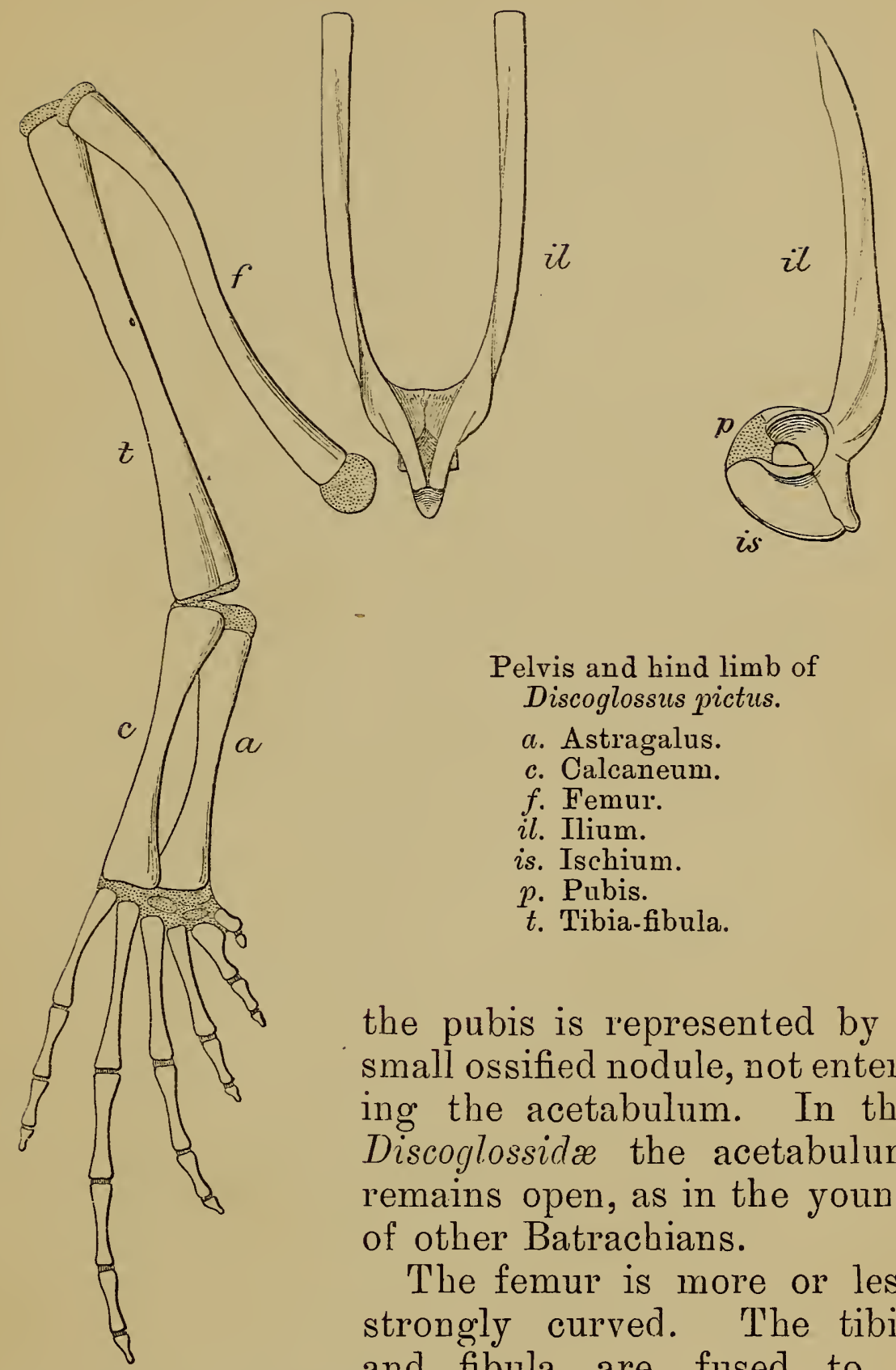

Pelvis and hind limb of Discoglossus pictus.

a. Astragalus.

c. Calcaneum.

f. Femur.

il. Ilium.

is. Ischium.

$p$. Pubis.

$t$. Tibia-fibula.

the pubis is represented by a small ossified nodule, not entering the acetabulum. In the Discoglossidx the acetabulum remains open, as in the young of other Batrachians.

The femur is more or less strongly curved. The tibia and fibula are fused to a single nearly straight bone. The epiphyses of these bones remain cartilaginous in the Discoglossidæ and Pelobatidæ, calcify in the other families.

The tarsus is remarkable for the elongation of the astragalus and calcaneum, which form an additional 
segment to the limb, a sort of crus secondarium. This is especially striking in Pelodytes, where the two bones fuse, and resemble, but in length, the crus or tibia-fibula.

In the Bufonidx, Hylidx, and Panidx a calcified epiphysis unites the two bones at either extremity. In Rana and Bufo a small sesamoid bone is present on the inner side of the proximal extremity of the tarsus. A series of three or four small distal tarsals (Fig. 19) intervenes between the astragalus and calcaneum and the three inner metatarsals, whilst the two outer metatarsals are directly in contact with the calcaneum. The toes are five in number, with elongate metatarsals and 2, 2, 3, 4, 3 phalanges. A rudimentary inner digit, the so-called præhallux, consists of a

FIG. 19.

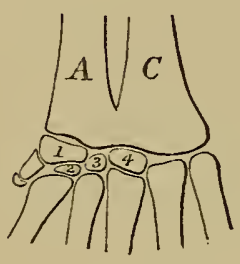

A

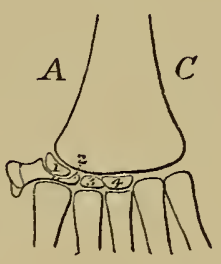

B

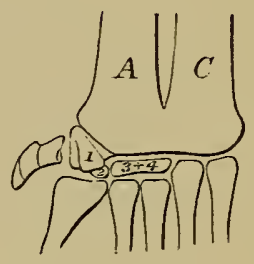

$\mathrm{C}$

Tarsus of-A. Bombinator pachypus. B. Pelodytes punctatus. c. Rana temporaria.

metatarsal and one or two phalanges, the development of which corresponds with that of the inner metatarsal tubercle. In Bombinator, Alytes, and Pelodytes the distal tarsals as well as the præhallux remain cartilaginous throughout life; in Discoglossus the præhallux ossifies, but the distal tarsals remain cartilaginous.

'The following is a Synopsis of the Genera and Species, based on the osteological characters:

I. Præcoracoid curved, connected with the coracoid by an arched (epicoracoid) cartilage overlapping its fellow (ARCifera). 
A. Vertebræ opisthocœlous, imbricate and completely covering the spinal cord above; autogenous ossified ribs attached to the anterior diapophyses; sacral vertebra with dilated diapophyses overlapping the ilia; urostyle with transverse processes at the base; omosternum cartilaginous or absent; sternum cartilaginous, with two posteriorly diverging limbs; eight elements in the carpus, two in contact with radius-ulna; four distal tarsal elements; long bones with cartilaginous epiphyses (DISCOGLOSSIDE).

1. Fronto-parietal fontanelle small, covered over in very old specimens; palatines present; zygomatic branch of squamosal forming a suture with maxillary; second rib with posterior process; dorsal vertebræ with a strong postero-median neural process; sacral vertebra with moderately dilated diapophyses and two condyles for urostyle . . . . . . Discoglossus.

2. Fronto-parietal fontanelle very large; palatines absent; second rib with posterior process ; postero-median neural process of vertebra absent or very short; sacral vertebra with very strongly dilated diapophyses and a single condyle for urostyle.

Bombinator.

Tibia shorter than femur . . . B. igneus. Tibia as long as femur . . . B. pachypus. 3. Fronto-parietal fontanelle large; palatines present; a cartilaginous supraorbital ; second rib without process ; postero-median neural process of vertebræ absent or very short; sacral vertebra with strongly dilated diapophyses and two condyles for urostyle . . . . Alytes. Fronto-parietal bones in contact only quite posteriorly, embracing a very large sole- 
shaped fontanelle; metacarpal and phalanges of fourth finger not more massive than the others . . . . . . A. obstetricans.

Fronto-parietal bones meeting in the middle, separating a large kite-shaped fontanelle in front from a very small one behind; metacarpal and phalanges of fourth finger very massive . . . . . . A.cisternasii.

B. Vertebræ procœlous, without autogenous ribs.

1. Vertebræ with imbricate arches completely covering the spinal cord above; diapophyses of sacral vertebra very strongly dilated, and sliding in a groove of the ilia; præcoracoid not entering glenoid cavity; omosternum cartilaginous; sternum with a bony style; long bones with cartilaginous, non-calcified epiphyses ; three carpal bones in contact with radius-ulna

(Pelobatider).

a. A fronto-parietal fontanelle; frontoparietals distinct; palatines absent; postero-median neural process of vertebræ very short or absent; sacral vertebra with two condyles for urostyle; astragalus fused with calcaneum; seven bones in carpus; four cartilaginous elements in distal tarsal row Pelodytes.

b. No fronto-parietal fontanelle; frontoparietal single, rugose; squamosal expanded, plate-like; dorsal vertebræ with a long postero-median neural process; sacrum usually fused with urostyle; astragalus and calcaneum distinct; eight bones in carpus, three in distal tarsal row . . . . . . . . Pelobates.

Squamosal not joining fronto-parietal; ethmoid reaching præmaxillaries . . P. fuscus. Squamosal forming with fronto-parietal a broad 
bridge over the prootic; ethmoid not reaching præmaxillaries . P. cultripes.

2. Vertebræ notched between the zygapophyses; diapophyses of sacral vertebra moderately dilated; sternum cartilaginous; præcoracoid entering the glenoid cavity; six bones in carpus, three in distal tarsal row; long bones with calcified epiphyses.

a. Distal phalanges obtuse; three carpal bones in contact with radius-ulna; omosternum absent (BUFONIDAR) . Bufo.

No fronto-parietal fontanelle; urostyle longer than the skull . . . . . . B. vulgaris.

A small fronto-parietal fontanelle, disappearing in old specimens; urostyle slightly longer than the skull . . . . . . B. viridis.

A large fronto-parietal fontanelle; urostyle as long as the skull . . . . . B. calamita. b. Distal phalanges claw-shaped; two carpal bones in contact with radius-ulna; omosternum cartilaginous (HrLID $\mathbb{E})$. Hyla.

II. Præcoracoid straight; no arched epicoracoid cartilage (FIrMISTERNIA).

Vertebræ procœlous, notched between the zygapophyses; no autogenous ribs; diapophyses of sacral vertebra cylindrical; omosternum and sternum with a bony style; six bones in carpus, two in contact with radius-ulna; three distal tarsal bones; long bones with calcified epiphyses (RANidE) . . . . . Rana.

A. Zygomatic branch of squamosal very long, nearly twice as long as the posterior; frontoparietals very narrow, grooved; second diapophysis not once and a half as long as the seventh . . . . . . R. esculenta.

B. Zygomatic branch of squamosal a little longer or a little shorter than the posterior; second 
diapophysis usually about once and a half as long as the seventh.

1. Fronto-parietals convex, narrow; nasals with straight or slightly concave posterior border.

Nasals widely separated from each other ; tibia nearly twice as long as the tarsus.

R. arvalis.

Nasals narrowly separated; tibia more than twice as long as the tarsus . R. camerani.

2. Fronto-parietals flat, broad.

Nasals with concave posterior border; tibia slightly longer than femur . R. temporaria. Nasals with straight or convex posterior border; tibia considerably longer than femur; distal phalanges with very distinct transverse expansion at the end* . . R. græec .

Nasals with concave posterior border; tibia considerably longer than femur . R. iberica.

Nasals with straight or feebly concave posterior border; tibia considerably longer than femur.

R. latastii.

3. Fronto-parietals grooved, moderately broad; nasals with straight or slightly concave posterior border; tibia considerably longer than femur. . . . . . R. agilis.

The above key, it must be observed, is drawn up from skeletons of adult, or at least half-grown specimens, and must necessarily often fail in its object if applied to young ones.

* Quite as much developed as in the species on which the genus Hylorana or Limnodytes has been founded. I have pointed out that certain Chinese and Burmese forms show a passage to exist from the Ranæ temporariæ to the Hyloranæ, and this view is further confirmed by a study of Rana græca. 


\section{VISCERA.}

A general sketch of the internal soft anatomy is not attempted here. We will merely indicate the principal differences in the structure of the lungs and urogenital apparatus which are of special importance from the point of view of the systematist. The following figure will suffice to show the position and relations of the various parts.

\section{FIG. 20.}

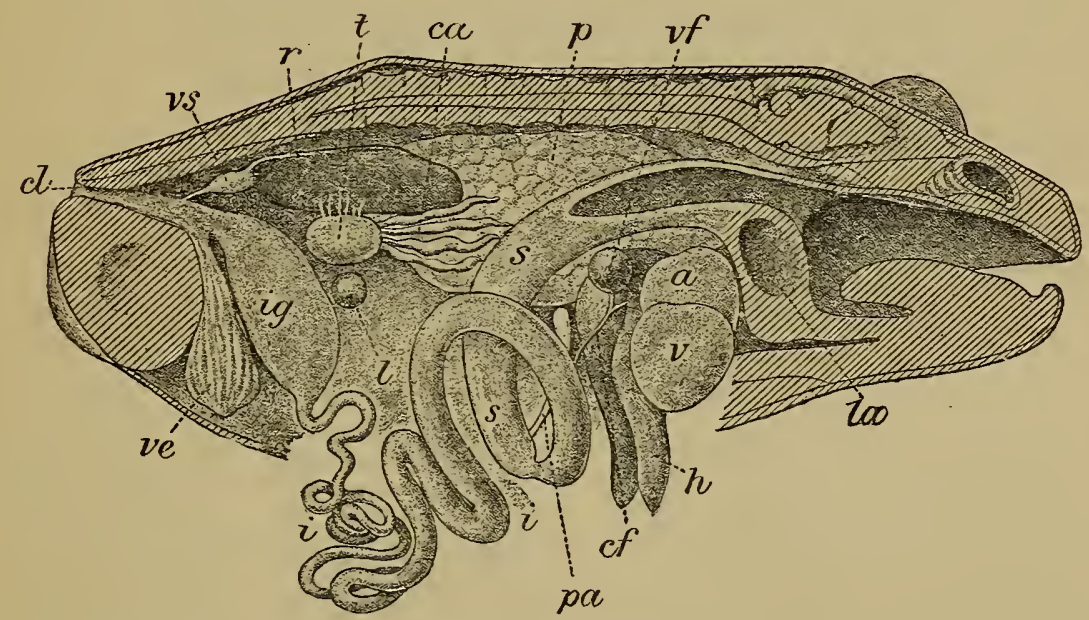

Longitudinal section through body of male Rana esculenta, showing the viscera.
a. Auricle of heart.
ig. Large intestine.
s. Stomach.
ca. Adipose bodies.
l. Spleen.
$c f$. Bile-duct.
la. Larynx.
cl. Cloaca.
p. Lung.
h. Liver.
pa. Pancreas.
i. Small intestine.
$r$ Kidney.
$t$. Testicle.
$v$. Ventricle of heart.
ve. Bladder.
$v f$. Gall-bladder.
vs. Vesicula seminis.

The lungs are a pair of sessile, or very shortly pedunculate, oval sacs, often more or less pointed posteriorly. Their walls are thick and spongy in Rana, thin and diaphanous in the other genera. Their periphery may be divided into numerous aircells, around which the ramifications of the pulmonary artery are distributed, as in most genera; or the cells may be few and the ramifications of the artery reduced 
to five or six, as in Bombinator pachypus (Fig. 21, A). Bombinator igneus and Hyla are intermediate between the tro extremes. Owing to the filling up of the abdominal cavity by the more voluminous genital organs, the lungs are usually smaller in females than in males. In the genus Rana (Fig. 21, c)

FIG. 21.
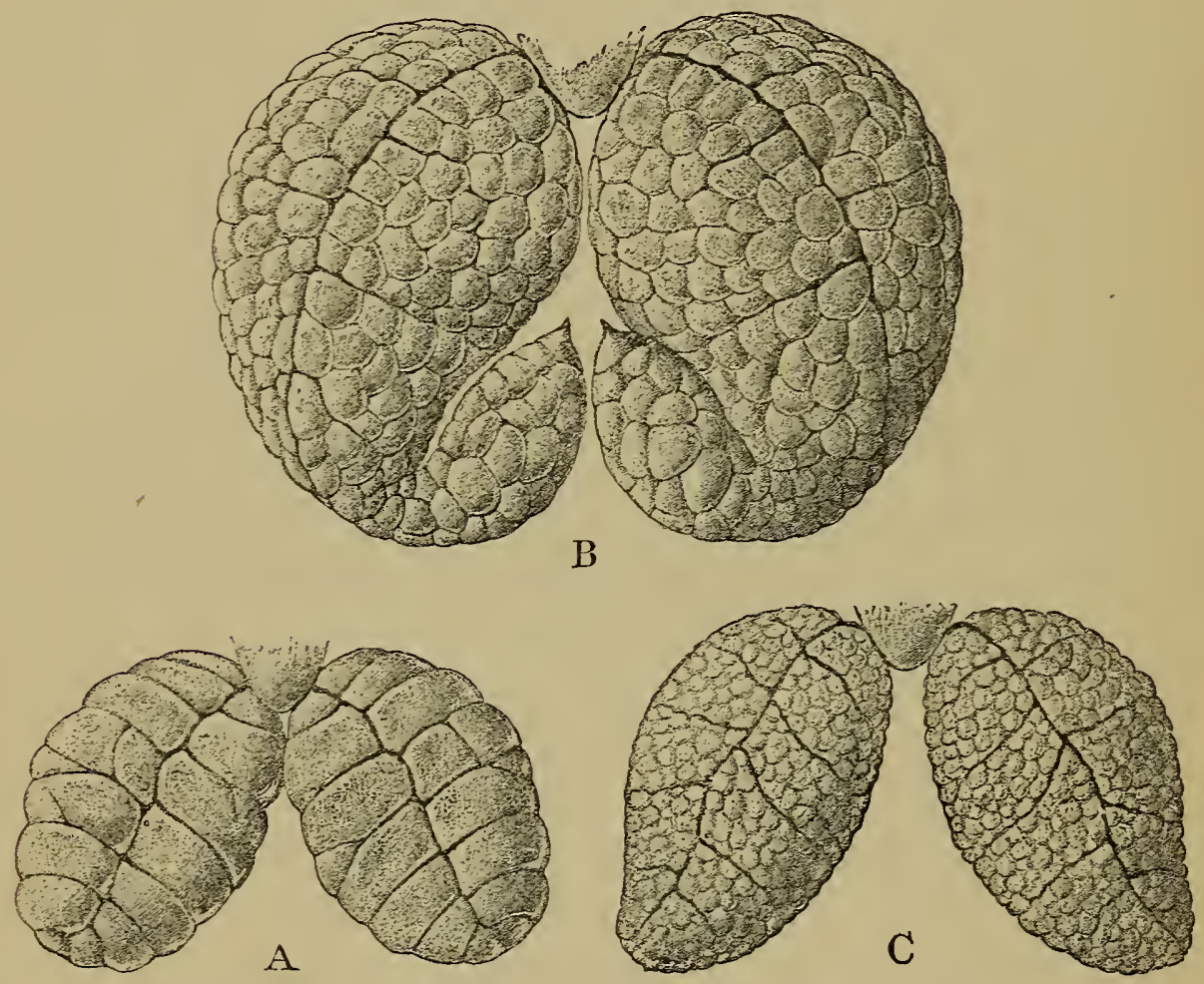

Lungs of-A. Bombinator pachypus. B. Pelobates fuscus. c. Rana temporaria.

the lungs, when fully distended, measure twothirds or more the length of the abdominal cavity in males, one-third to one-half in females. In Bombinator, Bufo, and Hyla they measure nearly three-fourths that length in males, two-thirds in females. In Pelobutes they are equally developed in both sexes, and larger than in any other genus, with a seemingly superadded narrower terminal portion bent inwards and forwards, tapering to a fine point (Fig. 21, в); the length of the inflated lung consider- 
ably exceeds that of the abdominal cavity. The lung's are smallest in Discoglossus, measuring only about half the length of the abdominal cavity in males.

The liver is divided into three lobes, one on the right side, two on the left.

The kidneys are elongate, flattened, red bodies attached to the dorsal body-wall, close to the middle line, below the vertebral column; from them the ducts or ureters proceed to the cloaca, into which they open by two small closely approximated apertures opposite the opening of the urinary bladder.

In the males the testes lie at the inner side of and ventrally to the kidneys, connected with them (except in the Discoglosside) by a number of delicate ducts, vasa efferentia, which convey the spermatozoa into the tubules of the kidneys, from which they escape by the ureter. The male reproductive organs differ considerably according to the species; and the testes, which are not always symmetrical, vary according to the season and the individual, so that little importance can be attached, from the systematic point of view, to their size, shape, and pigmentation.*

The ovaries in the female correspond to the testes in the male. The oviducts are long, much-convoluted tubes, with thick gelatinous walls, in which the ova as they descend become coated with their mucilaginous envelope; their open mouths are situated close to the roots of the lungs, and their lower ends, much dilated, have often been termed, improperly, uterus; the oviducts open, together with the ureters, into the cloaca.

In both sexes two tufts of flattened yellow or orange fatty appendages, the corpora adiposa, are attached above the genital glands. They vary much in size, according to the season, and are most developed just before the breeding period. I have seen them of a vermilion red in breeding specimens of Bufo calamita.

* I have examined a breeding male, Bufo vulgaris, whose right testicle was uniformly yellow, whilst the left was closely pigmented on about two-thirds of its surface. 
And finally, attention must be drawn to a problematic organ, peculiar to the males of the genus Bufo, termed by Spengel "Bidder's organ," situated

FIG. 22.

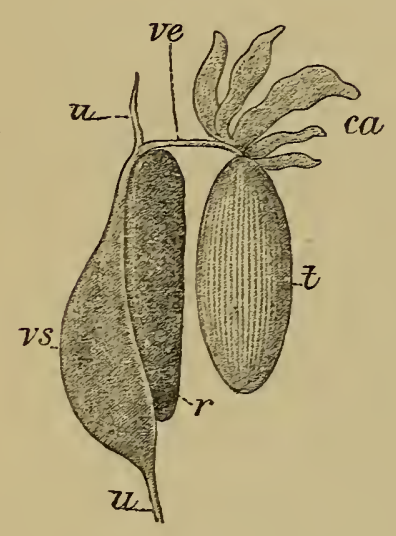

A

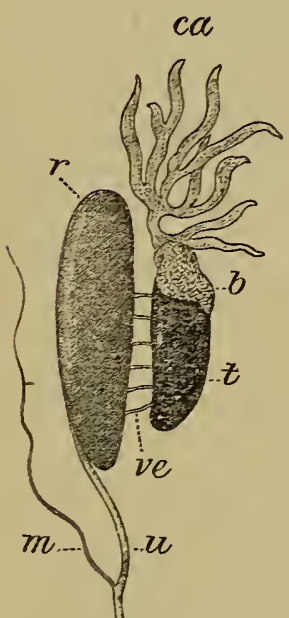

D

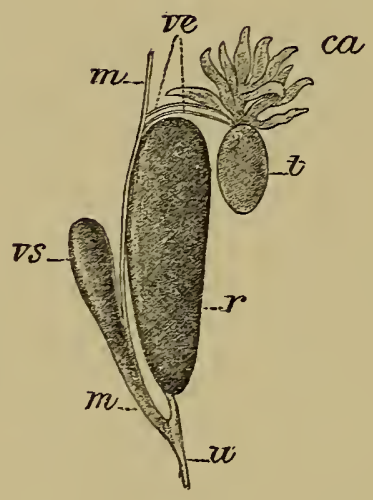

C

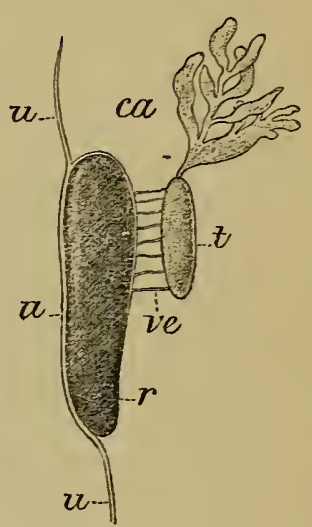

$\mathrm{B}$

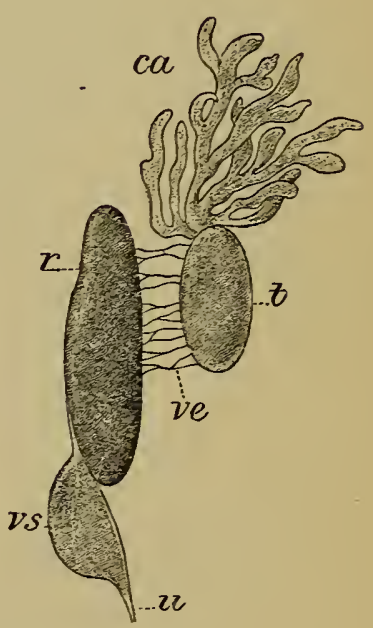

E

Right urogenital apparatus (ventral view, the testis shifted to the side) of-A. Discoglossus pictus. B. Bombinator pachypus. c. Alytes obstetricans. D. Bufo viridis. E. Rana temporaria.
b. Bidder's organ.
$t$. Testis.
ca. Corpora adiposa.
u. Ureter.
$m$. Müillerian duct.
$v e$. Vas efferens.
$r$ Kidney.
vs. Vesicula seminis. 
between the testicle and the adipose bodies. This has been considered by some anatomists as a rudimentary ovary, which it resembles in the ova-like nature of its contents. There is, however, no ground for regarding male toads as in any way normally hermaphrodite, for Spengel has actually observed a true hermaphrodite specimen of the common toad, in which the problematic organ was developed in addition to the ovary, and that author therefore regards it as a division of the testicle, endorsing the view of Bidder, its discoverer.

Rudimentary oviducts, the Müllerian ducts, occur in the males; most developed in Alytes, where, as we have seen above, they are functional, viz. act as seminal ducts, and in Bufo; absent in the Pelobatidx and Hylidx.

The following comparison is instituted on specimens examined during the breeding period:

In Discoglossus the testes are remarkably large, elongate, oval, ivory-white, longitudinally striated, measuring two-thirds to five-sixths the length of the kidneys. Contrary to what exist in all other Ecaudata, there is but one vas efferens, of large calibre, which does not open into the kidney, but is continued uninterruptedly into the seminal duct, which extends up to the front extremity of the kidney, terminating in a short blind process. The vesicula seminis is very large, and extends high up the side of the kidney.

In Bombinator pachypus the testes are yellow, unpigmented, twice to twice and a half as long as broad, slightly flattened and rounded at both ends, nearly half as long as the kidneys. The vasa efferentia open into a canal along the inner edge of the kidney. This canal communicates with the seminal duct at the anterior extremity of the kidney, beyond which the duct extends forwards as a blind process. A vesicula seminis is absent. B. igneus differs in having the testicles more or less pigmented, sometimes wholly black. They measure two-fifths to one-half the length 
of the kidney, and are nearly three times as long as broad.

In Alytes obstetricans the testes are subspherical or shortly oval, yellow, usually more or less sprinkled over with black pigment. There are two vasa efferentia, which do not open into the kidney but pass into the Müllerian duct, which functions as a seminal duct distinct from the ureter, and bears, as a diverticulum, a large strongly pigmented vesicula seminis.

In Pelobates fuscus the testes are oval, flattened, their length one-third to three-fourths that of the kidneys, the anterior extremity of which they nearly reach; they are yellow, rarely feebly pigmented. A vesicula seminis is absent.

Pelodytes punctatus agrees very closely with the preceding. The testes are small, measuring only onethird the length of the kidney, and much pigmented, nearly black.

In Bufo vulgaris the testes are yellow, sometimes more or less pigmented, elongate, cylindroid or flattened, two or three times as long as broad, onehalf to three-fourths the length of the kidney, to the anterior extremity of which they usually do not extend. A vesicula seminis is absent. In B. viridis the testes may be shorter, more oval, or cylindroid, and more than half as long as the kidney; they are more or less strongly pigmented, sometimes entirely black, and do not extend to the anterior extremity of the kidney. B. calamita has the testes elongate, and, as in B. viridis, they are situated opposite the middle of the kidney; they are so strongly pigmented as to appear entirely or nearly entirely black.

In Hyla arborea the testes are yellow, and resemble those of Bufo vulgaris in size, form, and position. A vesicula seminis is present.

In Rana esculenta the testes are yellow or orange, short, oval, not half the length of the kidneys, to the middle of which they are attached; the vesicula seminis is confounded with the ureter, which is of 
large calibre and tapers gradually towards the cloaca. R. temporaria has larger testes, measuring two-thirds to three-fourths the length of the kidneys, nearer the anterior than the posterior extremity of the latter, and often more or less strongly pigmented; the vesicula seminis is large and distinct from the ureter, immediately behind the kidney. In $R$. arvalis, $R$. græca, $R$. latastii, and $R$. agilis the testes are, as a rule, smaller, one-third to two-thirds the length of the kidneys, and not or but feebly pigmented. In R. temporaria, græca, latastii, the vesicula seminis is in contact with the kidney, whilst in $R$. arvalis and R. agitis it is a small sac, usually situated along the ureter midway between its attachment to the kidney and the cloaca. I have, however, dissected specimens of Ranc arvalis in which the vesicle was situated very near the kidney.

The chief differences in the male urogenital apparatus may be expressed in the following synopsis :

I. The spermatozoa are conveyed through the vasa efferentia direct to the seminal duct; the latter produced forwards beyond the kidney.

DisCOGLOSSIDA.

^. The ureter functions as seminal duct.

A single vas efferens; a vesicula seminis.

Discoglossus.

Several vasa efferentia opening into a canal along the outer edge of the kidney; no vesicula seminis

Bombinator.

в. The Müllerian duct functions as seminal canal distinct from the ureter; two vasa efferentia close together in front of the kidney; a vesicula seminis . . . . Alytes.

II. The spermatozoa are conveyed to the seminal duct (ureter) through the kidney, in which the anterior extremity of the duct is embedded. 
$\Lambda$. No vesicula seminis.

No ovary-like body in front of the testis

Pelobatides.

An ovary-like body (Bidder's organ) between the testis and the corpora adiposa. BuFonide.

B. A vesicula seminis formed by saccular enlargement of the ureter. Hylide, Ranide.

A table is added shorving the proportions of some of the principal viscera in different species, the measurements, in millimetres, being taken from males during the breeding season.

\begin{tabular}{|c|c|c|c|c|c|c|c|c|c|}
\hline Disc & $\begin{array}{c}1 . \\
59\end{array}$ & $\frac{2}{5}$ & $\begin{array}{l}3 . \\
8\end{array}$ & $\begin{array}{c}4 . \\
9\end{array}$ & $\begin{array}{c}5 . \\
19\end{array}$ & $\begin{array}{r}6 \\
18\end{array}$ & 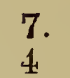 & $\begin{array}{l}8 . \\
15\end{array}$ & $\begin{array}{l}9 . \\
7\end{array}$ \\
\hline & 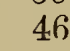 & 4 & 4 & 18 & 18 & 10 & 3 & $=$ & \\
\hline pus & $=1$ & 4 & 4 & 10 & 12 & 11 & 3 & 5.5 & $2 \cdot 5$ \\
\hline Alytes obsteiricans & 37 & 4 & 5 & 12 & 10 & 8 & $2 \cdot 5$ & 3 & 2 \\
\hline Pelobc & 5 & 5 & 6 & 34 & & 5 & & 0 & \\
\hline tatus & & 3 & 4 & 14 & & 9 & & $3 \cdot 5$ & \\
\hline Bufo? & & 9 & 8 & 2 & 25 & 21 & & 10 & 5 \\
\hline , v & & 9 & 7 & 2 & & & & 10 & 4 \\
\hline & & 9 & 7 & 2 & 23 & 16 & & 7 & \\
\hline Hyla as & & $\check{\jmath}$ & 5 & & & & 5 & 5 & 1.5 \\
\hline Rana esc & & 8 & 7 & & & & & 6 & \\
\hline$\Rightarrow a$ & & 6 & 6 & & & & & 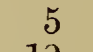 & \\
\hline „ten & & 6 & & & & 9 & 6 & 12 & \\
\hline & & & & & & 2 & & & $2 \cdot 5$ \\
\hline "latc & & & & & & & & & 25 \\
\hline $\operatorname{lggl}$ & & & & & & & & & \\
\hline
\end{tabular}

1. Length from snout to vent. 2. Length of ventricle of heart. 3. Breadth of ventricle of heart. 4. Length of inflated lung. 5. Length of longest lobe of liver. 6. Length of kidney. 7. Breadth of kidney. 8. Length of testis (in case of difference between the two testes, the longer is measured). 9. Breadth of testis. 10. Length of corpora adiposa. 


\section{Habit's.}

Frogs and toads were classified by the earlier authors into terrestrial, aquatic, and arboreal. It would be difficult now, nay impossible, to draw any sharp demarcation line between the three types, and all we can do is to emphasise the differences which exist between the extreme forms. Thus by opposing the extremes we can show examples among the European representatives of terrestrial and aquatic (Alytes obstetricansRana esculenta), fossorial and scansorial (Pelobates-

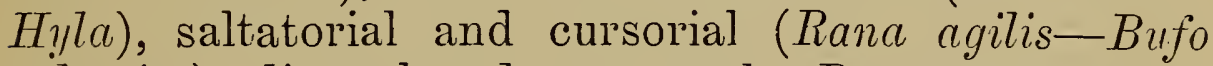
calamita), diurnal and nocturnal (Rana esculentaAlytes obstetricans) types, which are, however, connected by insensible gradations. These adaptations are revealed by certain structural characters, such as the development of the web between the toes to facilitate natation, the great development of the inner metatarsal tubercle to assist in burrowing, the adhesive digital disks for climbing, the relative length of the hind limbs for jumping, and the shape of the pupil, whether round or horizontal or vertical, as indicative of more or less diurnal or essentially nocturnal habits. But here and there we meet with exceptions; such are, for instance, the fully-webbed toes of Pelobates, which spends but a short time of the year in the water; the shovel-shaped metatarsal tubercle of Rana esculenta, var. lessonæ, which does not burrow; or the similarity in shape of the pupil in Rana and Bufo, which yet differ so much in their habits. Still, on the whole we may roughly incorporate the species outside the breeding season into the following categories:

Diurnal and aquatic: Rana esculenta, Discoglossus, Bombinator.

Diurnal and terrestrial : Rana temporaria and allies. Nocturnal and terrestrial: Bufo, Pelodytes, Alytes.

Nocturnal and fossorial: Pelobates.

Nocturnal and arboreal : Hyla.

That most, though not all, are aquatic during the 
breeding season is mentioned in the chapter on pairing and oviposition. All our species also spend a certain period of their existence as gill-breathing, fish-like larvæ: there are exceptional forms which entirely dispense with the larval life, and hop out of the egg in the perfect condition, but we have not to deal with them here, for they are only found between the tropics. Even our most aquatic species leave the water after metamorphosis, and young specimens of Rancesculenta and Bombinator are terrestrial, or live more on the border than actually in the water until able to breed. Sexual maturity is not attained before the third or fourth year in males, a year or two later in females-of the larger species, at any rate. The growth is slow, and so prolonged that of certain species, such as Rana and Bufo, one may say the older the specimen the larger; the gigantic size attained by some in secluded localities appears to be mainly due to the immunity they have enjoyed for a great number of years. Individuals of the common toad have been observed for very long periods, and it is probably no exaggeration to assess the possible duration of life in that species at a century. Among the smaller forms a tree-frog has been kept in confinement for twenty-two years.

The food consists exclusively of live prey; no insect or worm will be taken that has not moved in the presence of the consumer. But it is easy to deceive a Batrachian by agitating any object; the edible frog is thus captured in France by means of a red rag put on to a line. In fact, any moving object of commensurate size will be taken, to be afterwards rejected if distasteful. Discoglossus and Bombinator alone among our Batrachians are able to seize their prey under water. 'The thoroughly nocturnal forms cannot be induced to feed in the daytime. Frogs and toads occasionally display cannibal instincts, swallowing young of their own species. 'The prey is secured by throwing out the tongue, except in the Discoglossidx, which, not 
being provided with such a mechanism, simply seize it with their jaws, as does a newt; the hands often assist in pushing it into the mouth. A certain quantity of sand or fine gravel is usually found in the stomach and the large intestine, together with beetle elytra and other indigestible matter. As in many birds, the fæces are enveloped in a mucilaginous coating formed in the large intestine.

Although sensitive to cold and retiring at the approach of winter, Batrachians do not fall into complete lethargy. Hibernating specimens found in holes, under heaps of manure or dead leaves, or even buried in the mud under the water, are only sluggish, not dormant.

Salt is fatal to must Batrachians and to their eggs. A frog soon perishes when thrown into sea water. Yet Bufo calamita is in this respect exceptional, often breeding in brackish pools or burrowing in sand strongly impregnated with salt. The same toad is also remarkable in being less partial to moisture than any other of our Batrachians.

Among the species that remain concealed during the daytime or in inauspicious weather, Bufo vulgaris and Pelobates lead a solitary existence; whilst Bufo viridis and calamita and Alytes are of gregarious habits, two individuals or more being usually found in the same hole or under the same shelter.

Brief allusion should be made here to three popular beliefs, which, although often refuted, still crop up now and then, and, curiously, occasionally find champions in educated men.

The first, that toads squirt poison at their enemies, is explained by the fact that these Batrachians, when frightened and trying to escape, shoot out, to a considerable distance, liquid from the vent. But this liquid, tapped from the bladder, is as innocuous as pure water, and has nothing to do with the poisonous secretion of which toads are really possessed, but unable to squirt out spontaneously. 
The second is the supposed showers of frogs and toads, believed to fall with the rain, and to have been carried by a waterspout, some narrators of the phenomenon even stating to have received them on their hats or open umbrellas. But the fact that these so-called showers consist of young frogs, never of larvæ, and only occur at the time of the metamorphosis of the common species, when myriads leave the water and conceal themselves in holes and fissures in the soil, whence they suddenly emerge when the rain falls, sufficiently accounts for the phenomenon. Half blinded by the rain, people, startled at the sudden appearance of these legions of tiny Batrachians on the ground around them, actually fancy they feel them falling, the delusion being further enhanced in the case of baby tree-frogs, which, under the circumstances, climb up their clothes.

The third belief, in live frogs and toads enclosed in stones, hardly deserves refutation, when we know that air, moisture, and food are indispensable to these creatures. If every case could be properly investigated, it would be found that the quarry workman, from whom such tales invariably originate, has been the victim of a delusion, and that the Batrachian he fancied to have hopped out of the stone he was breaking lay concealed close to it unobserved, and jumped from its retreat at the blow of the bammer.

And, finally, it remains to observe that our Batrachians do not bite, although some exotic forms do. However, Pelobates, when irritated, assumes a very aggressive attitude, screaming and jumping with open mouth towards its tormentor, as if to snap at him. No doubt these antics, accompanied by a repulsive odour produced at the same time, must act as a protection against snakes and carnivores. The Bombinator are also believed to startle pursuers by turning over and suddenly exhibiting the brilliant coloration of their lower surfaces. 


\section{VoICe.}

All our male Batrachians are endowed with a voice, which they produce at least during the pairing season. Females are mute, or respond to the male by a mere grunt. The larynx is provided with vocal cords, which are set vibrating as the air is rapidly shifted from the lungs into the buccal cavity. In many species the sound is intensified by resonance in special vocal sacs situated in the gular region, or at the sides of the head behind the commissures of the jaws. The rocal sacs are called internal when

FIG. 23.

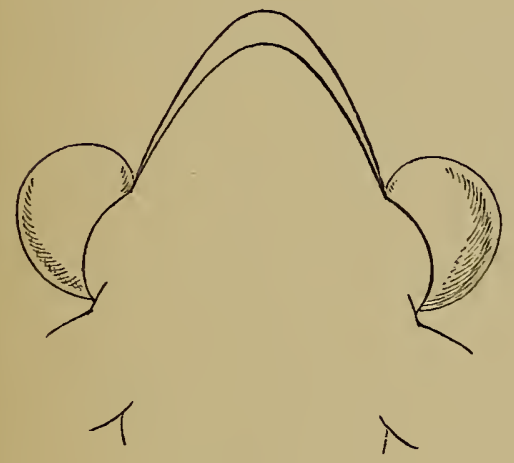

A

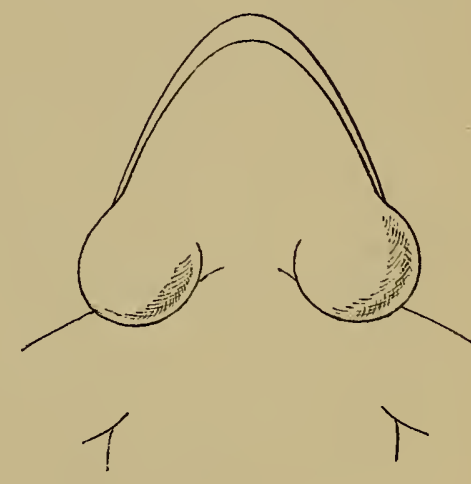

B

A. Rana esculenta, ठ, with inflated external vocal sacs (lower view).

B. Rano, temporaria, $\delta$, with inflated internal vocal sacs (lower view).

covered by the unmodified gular integument, however much this may be distended; external when their membrane, a diverticulum of the mylohyoid muscle, projects through slits at the sides of the throat, as in Rana esculenta, or when the skin is thinned and converted into a bladder-like pouch, as in Hyla arborea. In some forms there are two distinct sacs, in others but one. The air penetrates by one or two openings in the floor of the mouth, small, rounded, and situated near the commissures of the jaws, as 
in Rana, or slit-like, and situated at the side of the tongue, as in most other genera. Peloclytes and Hyla have two openings, whilst $B u f f o$ has commonly but one, either on the right side or on the left.

In Bombinator igneus internal vocal sacs are well developed, but are formed by the skin of the floor of the mouth, which is loose and plicate, and projects through a slit dividing the submaxillary muscle into an anterior and a posterior portion. Discoglossus has rudimentary vocal sacs of the same type, but they are confined to the sides of the throat, near the mandible. Bombinator pachypus, Alytes, Pelobates, Bufo vulgaris, and Rana græca, latastii, iberica, and agilis lack the vocal sacs.

The mode of inflation of the vocal sac is best observed in Hyla arborea, the bladder-like appendage when blown being of enormous size, nearly as large as the body, which, when the animal croaks, is much

FIG. 24.
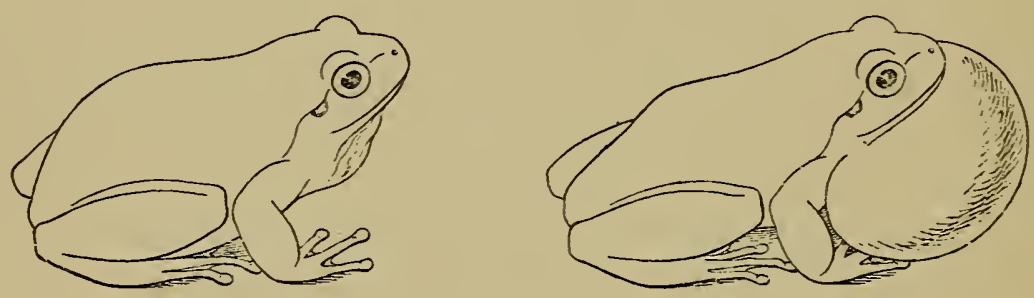

Hyla arborea, $\delta$, with the vocal sac in the collapsed and inflated conditions.

thinned by the emptying of the lungs, as shown in the accompanying figure (Fig. 24). This mechanism of the shifting of the air from the lungs into the throat, and vice ver'sa , explains the fact, paradoxical in appearance, of Batrachians being able to croak under water.

The voice varies very considerably according to the species, and the names bombina, sonans, campanisona, ridibunda, cachinnans, \&c., convey the impressions made on the ears of the earlier observers. It affords the trained collector one of the surest means of ascer- 
taining the Batrachian fauna of a district during the spring and early summer months; for although it may not lead at once to the discovery of the performer, owing to his most deceptive ventriloquial accomplishments, the whistling argentine note of Alytes obstetricans (often attributed by country people to the salamander), the hoo-hoo of Bombinator pachypus, the oonk-oonk of Bombinator ignens, the creck-creck-crecti of Pelodytes, the clock-clock-clocle of Pelobates fuscus, are so characteristic as to be surely recognised by whomsoever bas heard them before. The sound uttered by the breeding Bufo vulgaris may be compared to a feeble oft-repeated bark; that of Rana temporaria may be rendered by grook, grook, and that of Rana agilis and arvalis by co-co-co. But these are all comparatively feeble monotonous sounds. If we turn to the loud croakers, Rana esculenta, Hyla arborea, and Bufo calamita, all three of which are provided with external vocal sacs, we find a more varied performance, which when produced by a large number of individuals, as is usually the case, is simply deafening, and audible miles away. The croaking of Rana esculenta has been admirably rendered by Aristophanes in his chorus of

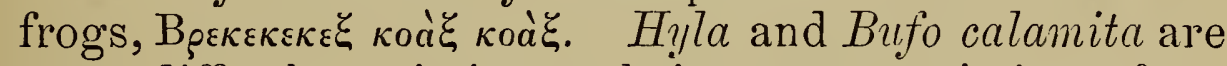
more difficult to imitate, their song consisting of an extremely rapid succession of highly sonorous vibrating notes, bra or cra.

These loud vocalists are in the habit of joining in choruses, ceasing suddenly at the approach of the listener. But they can easily be induced to resume the concert by an imitation of their croak either by the human voice or by strokes on a metal object. In confinement they can also be enticed to croak by being rubbed on the back.

Most frogs when seized by a snake or other enemy utter a shrill cry. That of Pelobates fuscus is most startling; and specimens of that species, when persistently teased, can be aroused to a fit of anger, accompanied by loud cries, lasting for several minutes. 


\section{Pairing and Oviposition.}

It is often stated in books that, in temperate climates at least, tailless Batrachians have a fixed annual period of reproduction, taking place in the end of winter or in spring. This statement, based on a generalisation of the familiar phenomenon presented by our two common Northern species, Rana temporaria and Bufo vulgaris, is erroneous, individuals of some species-those of the family Discoglossidæ, for instance-breeding several times a year, at distant intervals; and between these two extreme types we have almost every possible gradation.

In a first category, to which Bufo vulgaris, Rana temporaria, and Rana arvalis belong, the pairing season is of short duration, and although, with us, dependent on atmospheric conditions and regulated by the rise of the thermometer rather than by the calendar, coincides almost to a day for all the individuals under equal climatic conditions. The males are endowed with genesic fury to the extent of letting themselves be mutilated or even immersed in spirit without letting go their mate, to which they cling tightly with their powerful fore limbs, awaiting the expulsion of the ova to discharge on them their seminal fluid. In their blind frenzy they will clasp individuals of other kinds, even fishes, putrefied corpses of females that have succumbed to their embrace, or all sorts of floating objects. Common toads may be fished by holding out to thern a thick stick, to which they cling with their arms. As males of that species are always more numerous than females, great fights ensue, in which the latter sometimes perish under the pressure of several of their would-be possessors. 
Even in this category there are occasional exceptions. Such are the cases recorded by Martin and Rollinat and W. Evans, of single couples of the common toad found breeding near Argenton, in France, on the 18th June, and near Edinburgh on the 13th June, two or three months after the other individuals in the same localities had deposited their spawn and left the water. These exceptional cases are probably due to some accident having prevented the female from resorting to the breeding-place at the proper time. Males, we know, may long retain their genital ardour, so many of them, owing to their excess in numbers, being unable to find a mate.

We next find species which may also be said to have a short breeding season, but which do not congregate with the same ensemble, the condition of the genital products not being the same at a given time in all the individuals. In these species the female does not, as a rule, enter the water until ready to spawn, and the embrace is, in consequence, of short duration, often taking place only at night. To this category belong Pelobates, Pelodytes, Hyla, and Rana agilis. The males are not, as a rule, animated with the same frenzy as we observe in the first type, and will often let go the females when disturbed or handled.

A third category is represented by Bufo calamita, Bufo viridis, and Rana esculenta, which spawn but once a year, but the breeding season of which extends over a longer period, viz. two or three months, within the same district, with an ultimum mostly depending on the weather.

Lastly, all the species of the family Discoglossidx, and apparently also some individuals of Pelodytes, are able to breed twice or more every year. Bombinator spawns first in spring and again in summer, sometimes as late as Aug!ust or the beginning of September; Discoglossus and Alytes as often as three or four times at distant intervals during the warmer months, the 
former (inhabiting the extreme south) from January to October, the latter from the end of February or beginning of March to the beginning of September.

The time at which each species commences to pair varies, as we have seen, with the temperature, for the early breeders at least. Thus in the south of Europe these would start from January, whilst in the north or at corresponding altitudes in the mountains representatives of the same species would be compelled to wait until the thaw has set' in. Again, exceptionally prolonged winters may cause the individuals of a species to be retarded in this operation, so as to bring them together with other's which, under normal circumstances, do not breed until some weeks later. But, on the whole, our Batrachians may be arranged in the following order, beginning with the most precocious:

1. Discoglossus, Rana temporaria, R. arvalis.

2. Rana agilis, Alytes.

3. Bufo vulgaris, Pelobates, Pelodytes.

4. Bufo viridis, Bufo calamita, Hyla, Bombinator, Rana esculenta.

Taking the three British speeies as an example, Rana temporaria in normal years with us breeds in the beginning of March, Bufo vulgaris in the beginning of April, and Bufo calamita from the middle of May; their nuptial periods do not even overlap.

Leaving out the genus Alytes, which is altogether exceptional in its mode of parturition, all our Batrachians are compelled to resort to the water for the purpose of depositing their spawn. In some species, such as our common frog, the males precede the females, and may be found in winter in a semi-torpid condition, but already attired in their full breeding costume, at the bottom of pools thickly coated with ice. The common toad travels long distances on land, or following the course of brooks, in quest of suitable breeding-places; and if the sexes meet on the way the male often secures immediate possession of the female, accomplishing the rest of the journey on her back. 
The Natterjack toad, B. calamita, also often pairs on land, and being a bad swimmer, and only spawning at night, numbers in embrace may be found in the daytime in holes on the banks, their presence being revealed by their loud croak. The tree-frogs usually pair only at night or in the evening. Thoroughly aquatic species like Bombinator and Rana esculenta resort, of course, to the water before mating.

Alytes, the most terrestrial of European Batrachians, pairs and oviposits on land. The female never goes into the water, and the male contents himself with a hip-bath for the purpose of releasing his progeny from the egg-capsules entrusted to his care.

Species differ greatly in the choice of a site for their nursery. Alytes exercises the greatest judgment, avoiding ponds or pools already largely stocked with tadpoles of other species, or any water which is not permanent. 'The common toad and the treefrog, also, are judicious in their choice, and their offspring are never doomed through drying up of the site selected, an eventuality which the common frog and the Natterjack toad do not appear to be able to foresee. The latter species especially often spawns in roadside ditches and puddles of a most temporary nature, although suitable places may be near by, and we often find masses of their young tadpoles accumulated in a small hole with scarcely any water left, exposed to the sun-rays, where they must perish unless saved by a timely rainfall. Frost often destroys the brood of the common frog.

It has been observed by Héron-Royer, and I have more than once been able to verify the fact, that different species which breed in the same water somehow manage to keep clear of each other. In a pond near Paris the above-mentioned author found Rana temporaria occupying the north and west, Rana agilis and Bufo vulgaris the north-east, Pelodytes punctatus the south-east, and Hyla arborea the south, east, and west. In this country, where Rana temporaria and 
Bufo vulgaris often breed in the same place, we always find the tadpoles forming distinct colonies. A dip of the net will secure specimens of one species only.

Courtship does not take place in any of the tailless

FIG. 25.
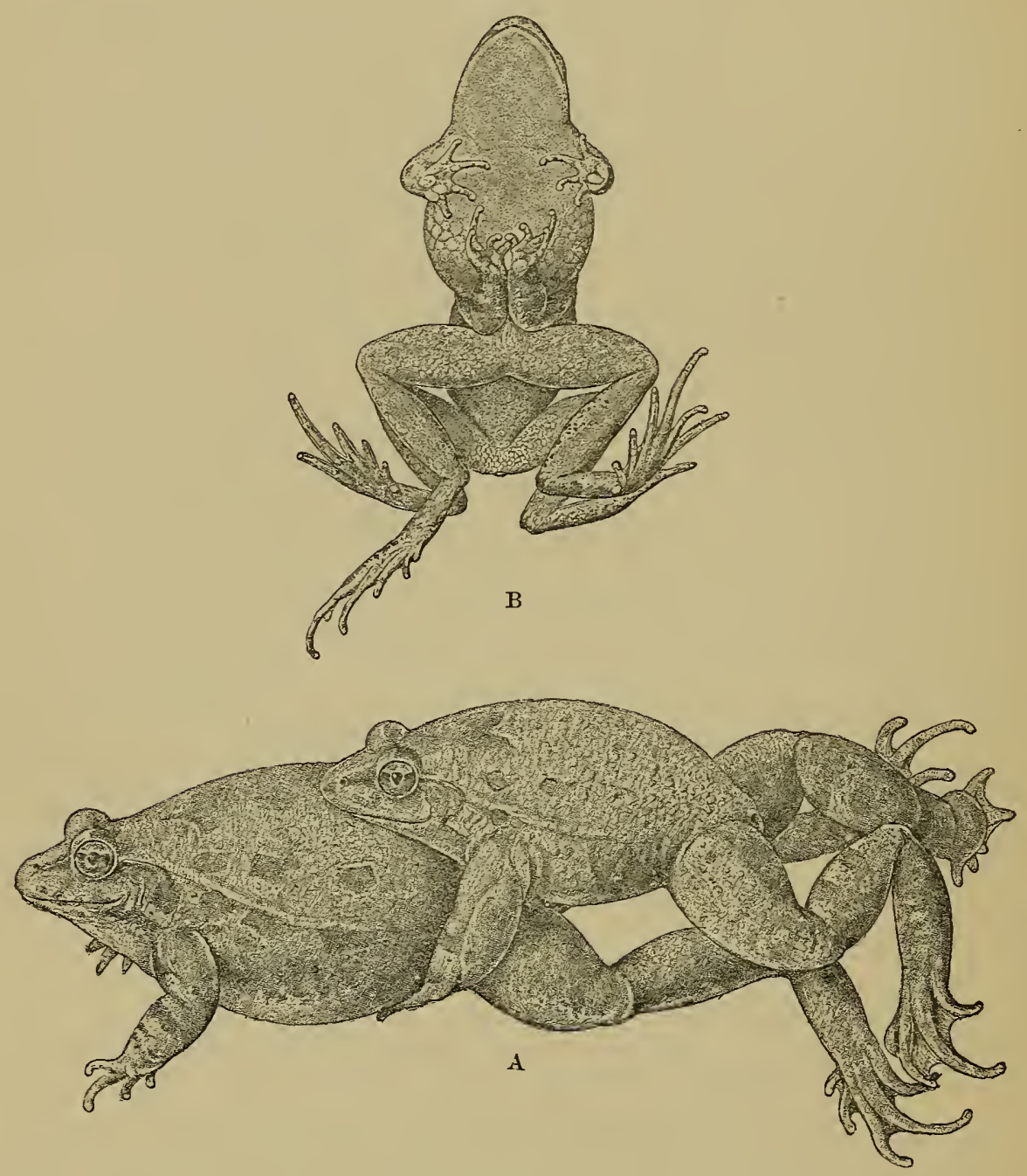

Pairs in embrace. A. Discoglossus pictus. в. Pelodytes punclatus.

Batrachians. The female is seized by the first comer, and when he has once secured his hold he will remain for a period varying between a few minutes and several days in possession until the evacuation of the ova, unless he be dislodged by a stronger competitor. 
Impregnation accompanies or immediately follows, in one or more emissions, the discharge of the eggs. The mode of embrace varies according to the species; it is axillary in all our genera with horizontal pupil, and lumbar in the others, as shown in the following synopsis :

\section{FIG. 26.}
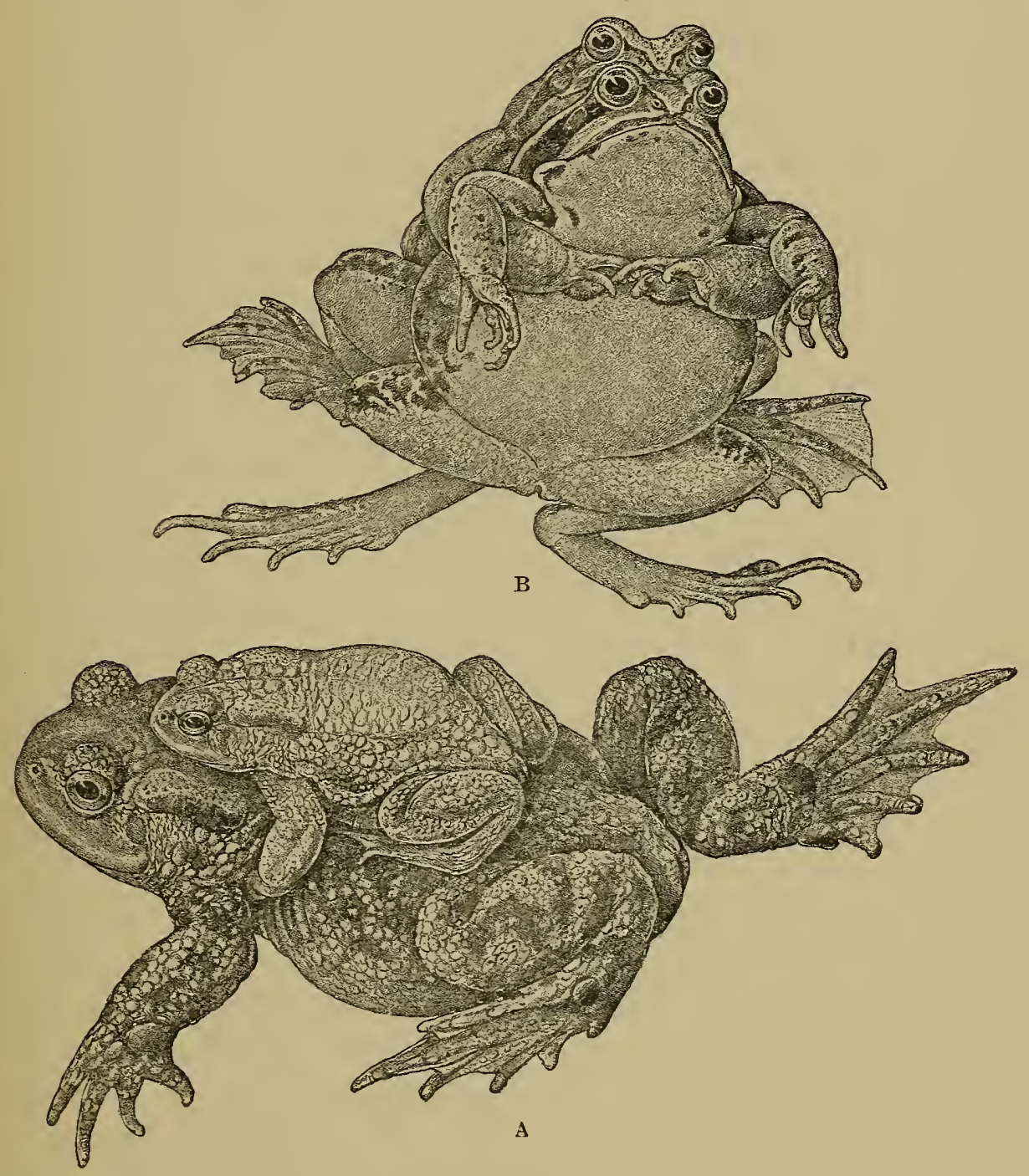

Pairs in embrace. A. Bufo vulgaris. B. Rana arvalis.

I. Male holding the female round the waist.

A. The hands joining on the pubic region (Fig. $25, \mathrm{~A})$.

Discoglossus, Bombinator, Alytes, Pelobates. 
B. The forearms meeting on the pubic region (Fig. 25, в) . . . Pelodytes,

II. Male holding the female behind or above the arms.

A. The hands dug into the axils or just above them (Fig. 26, A).

Bufo vulgaris, B. calamita, Hyla arborea.

в. The hands pressed against the breast (Fig. 26, в) . . . Bufo viridis, Rana.

Owing to the mode of embrace the fore limbs of the males are always stronger than those of the other sex, and in some species acquire about the breedingtime a great muscular development. The inner side of the inner finger may develop a thick pad, supported by a corresponding development of the bones of the rudimentary pollex and first functional finger, which, pressed against the breast or pubic region of the female, assists in maintaining the hold, often leaving a deep scar if the pairing has been of prolonged duration. There are developed in addition temporary horny excrescences, in the form of small granules or spines, which are present in most species, and afford useful characters for their distinction during the breeding season. When this is over the excrescences are shed in most species. They, however, often persist throughout the year in Bufo, Discoglossus, and Bombinator. These nuptial asperities are absent in Alytes and Pelobates, and scarcely distinguishable in our Hyla. When present, their shape and coloration, as well as their distribution on various parts of the limbs or even of the body, vary according to the species. With regard to distribution, we find them located in fully developed breeding individuals -

On the inner side of the two inner fingers, the antebrachium, the brachium, the breast at the base of the arm, the chin, the belly, and along the toes (Fig. 27, B)

Pelodytes.

On the inner and upper side of the three inner 


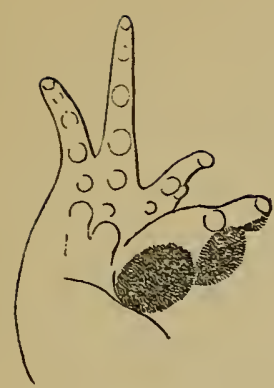

E
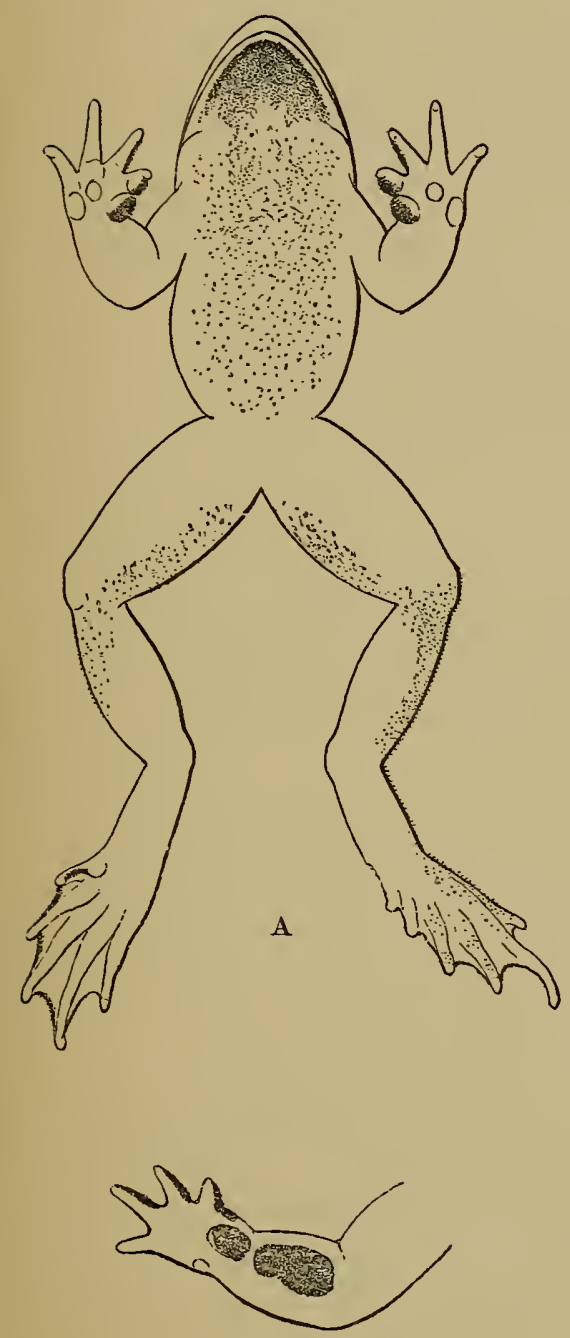

C
FIG. 27.

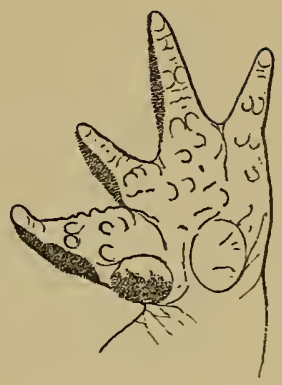

D
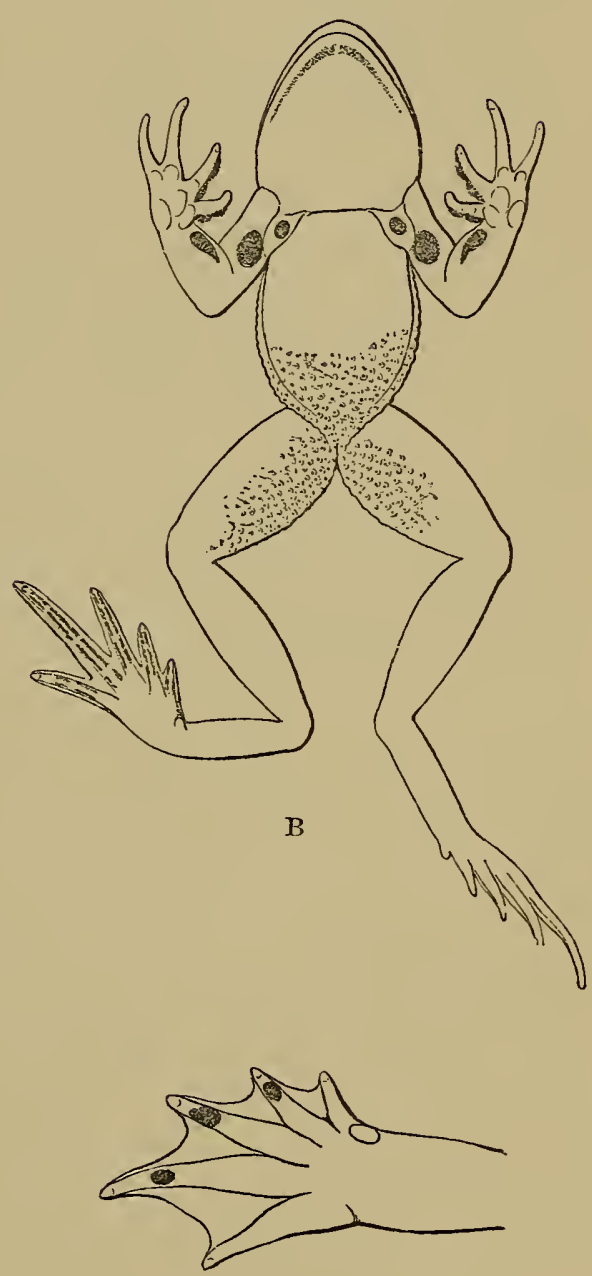

C

Nuptial excrescences of males. A. Discoglossus pictus. B. Pelodytes punctatus. c. Bombinator pachypus (hand and foot). D. Bufo vulgaris (hand). E. Rana temporaria (hand). 
fingers, on the chin, the belly, and on the free edge of the web between the toes (Fig. 27, A).

Discoglossus.

On the inner side of the three inner fingers and the antebrachium, and on the third, the second and third, or the second, third, and fourth toes (Fig. 27, c) . . Bombinator pachypus. On the inner side of the two inner fingers and the antebrachium . . Bombinator igneus. On the inner side of the three inner fingers (Fig. 27, D) . . . . . Bufo. On the inner and upper side of the inner finger (Fig. 27, E) . . . . . Rana. At the base of the inner finger . . Hyla. It sometimes happens that old females present at least traces of these organs, the appanage of the males. I have recorded such a case in a Rana temporaria with eggs in the oviducts; Boscá has found the same anomaly in a Pelodytes punctatus, and Méhely in five specimens of Bombinator pachypus. These horny productions are usually dark brown or black; they are greyish in Rana esculenta and agilis, colourless in Hyla arborea. Their aspect under the microscope, and the differences they present according to the species, have been studied by Lataste, who has shown that they are low and obtuse in Rana esculenta and agilis, erect and pointed in Rana temporaria and arvalis and Discoglossus, pointed and oblique or hooked in Bombinator and Pelodytes, pointed, erect, and crenulated in Bufo vulgaris and viridis, and obtuse and crenulated in Bufo calamita (Fig. 28).

As in all Batrachians in which no courtship takes place, the males are not distinguished by any ornamental appendages or more vivid colours, but in Rana temporaria and arralis they acquire during the pairing season a peculiar swelling of the skin, by which the back, and especially the gular region, take on a bluish tinge and a flabby texture, strongly contrasting with the aspect of the same parts later in the year. The 
females of the same species, on the other hand, develop on the back and limbs, during the breeding season, peculiar pearl-like structures of the epidermis, which are regarded as sensory, being provided with a special innervation, same as we find developed during the sparning season in the males of many Cyprinoid and Salmonoid fishes. These organs have been dealt with at great length by Huber and Maurer.

FIG. 28.

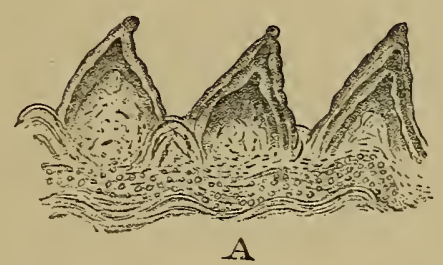

A

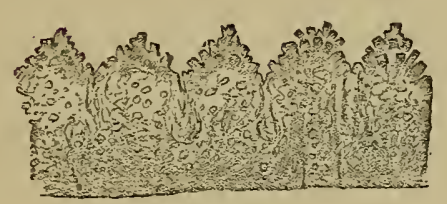

$\mathrm{C}$

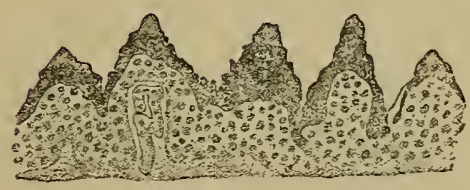

E

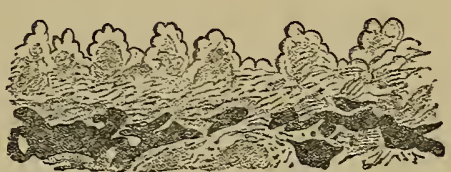

B

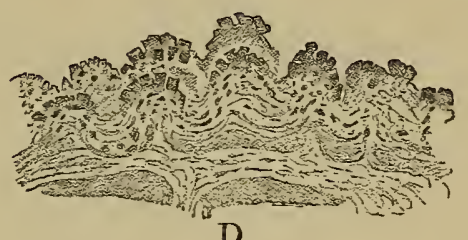

D

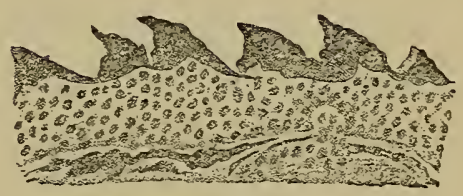

F

Sections through the nuptial asperities of males, much enlarged (after F. Lataste). A. Rana temporaria. B. Rana esculenta. C. Bufo vulgaris. D. Bufo calamita. E. Discoglossus pictus. F. Bombinator pachypus.

The males of most of our Batrachians make themselves conspicuous during the pairing time by their voice, whether they be provided with vocal sacs or not. Although there are some, Rana esculenta and Hyla, in which the clamour is not restricted to the breeding season, most others are comparatively mute outside that period, and the vocal sacs undergo a sort of regression, as is especially noticeable in Rana temporaria and Bufo calamita. 
Our larger species of toads and frogs do not appear to be able to propagate until four or five years old. But it has been ascertained on specimens kept in confinement that Alytes, Bombinator, Pelobates, and $H y / a$ - which are of proportionally larger size immediately after transformation-attain much sooner their full development, and may breed in the third year of their existence.

A curious fact, for which we can at present find no explanation, is the very considerable excess of males over females in the genera Pelodytes, Pelobates, and $B u f o$, when adult at least, as has been observed not only during the breeding season, but also at other times, and especially during the winter, when numbers congregate in holes. In other genera the proportion of both sexes appears about equal; Born and Yung have even ascertained that in the young of the genus Rana the females are in the proportion of 54 to 61 per cent. It is believed that in some lower animals abundance of food is an important factor determining sex. The two above-mentioned physiologists have conducted a series of experiments on tadpoles of frogs (Rana temporaria), and by giving them a more abundant or more artificial food have obtained a much higher ratio of females, viz. 70 to 95 per cent. A. von Griesheim, after examining the sexes of 440 specimens of the common frog captured immediately after the metamorphosis, found only 36 per cent. of males. It would be highly interesting to make a similar investigation on the young of some species, such as Bufo vulgaris or Pelobates fuscus, in which the number of adult males far exceeds that of females. 


\section{Speritat'ozoA.}

The seminal elements of tailless Batrachians have received a great share of attention, not only on the part of anatomists and physiologists, but even of systematic workers. This is due to the great amount of difference in structure and size between these elements in the various genera; and also to the fact that otherwise closely allied species of the genus Rana may differ in their spermatozoa more considerably from each other than from others morphologically more remote. The failure to obtain hybrids between such near allies as the male Rana temporaria and the female $R$. arvalis has been attributed principally to these differences; for other species of the genus $B u f o$, which stand very far apart, but which have almost identical spermatozoa-as, for instance, $B$. vulgaris and B. calamita, and B. vulgaris and B. viridis-cross with comparative facility under artificial fecundation.

One great source of errors in describing and comparing the spermatozoa has been due to the changes which these elements undergo in their development, and care should be taken to ascertain whether or not they are in a ripe condition. The safest way to avoid mistakes is not to extract the spermatozoa from the testicles, but to collect them in the seminal ducts from specimens in embrace. This is, however, difficult to do in species which are destitute of a seminal bladder.

Thanks to the investigations of Leydig, La Valette St. George, Spengel, and Pflüger, which I have been able to supplement for some of the less known species of Rana, we are now well acquainted with the spermatozoa of nearly all the European species.

Those of Discoglossus are remarkable for their great size, measuring three millimetres, whilst those of other species do not exceed one-tenth of a millimetre. The so-called bead is spirally wound like a corkscrew; the 
tail is about equally long, and provided with an extremely delicate, wavy, vibratile, hyaline membrane or crest. As in the newts, they are collected together in bundles, although devoid of a spermatophore.

FIG. 29.

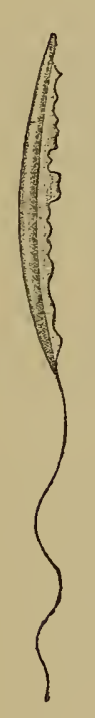

A

$B$

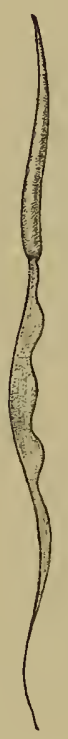

C

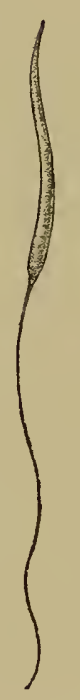

D

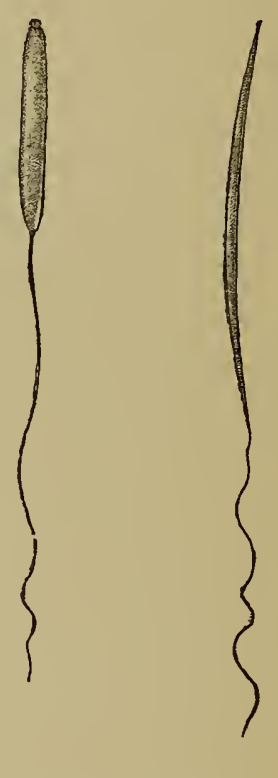

$\mathbf{E}$
F

A bates fuscus. C. Bufo vulgaris. D. Hyla arborea. E. Rana esculenta! F. Rana temporaria. (After La Valette St. George and Leydig.)

In Bombinator a crest is present along the side of the spindle-shaped head, and the tail is moderately long, filiform, and devoid of a crest. The crest may be partially detached from the head, and has been taken to belong to the tail.

In Alytes and Bufo the head is staff-shaped, pointed in front; the tail is about twice as long, with a delicate crest.

In Pelobates the head is long and thin, with strong spiral windings, corkscrew-shaped, passing gradually into the extremely long, delicate, filiform tail.

The spermatozoa of Pelodytes bear much resemblance to the preceding, but the head is less twisted; the tail is also extremely long and filiform. 
In Hyla arborea the head is spindle-shaped, acutely pointed in front, obtusely behind; the tail filiform, and about twice as long.

In Rana esculenta and arvalis the head is staffshaped and obtuse in front, and about half as long as the filiform tail; and in Rana temporaria and agilis the head is very long and thin, not or but scarcely longer than the tail, and attenuate into a fine point at both ends.

The spermatozoa of $R$. græca and latastii bear a greater resemblance to those of $R$. arvalis, but have a more elongate head, the diameter ten to twelve times in the length; the head is cylindrical, feebly attenuate, and quite obtuse at both ends.

The spermatozoa of $R$. camerani and $R$. iberica are still unknown.

Attention has been drawn above to the importance of securing for comparison the seminal elements in their fully ripe condition. La Valette St. George has shown that at certain stages of development these are almost identical in $R$. esculenta and $R$. temporaria; and that accumulations of protoplasm at certain points of the unripe element or spermatocyte, as he calls it, produce a shape which may be very unlike that of the true spermatozoon. So careful an observer as Leydig has unfortunately fallen into the error of figuring spermatocytes as spermatozoa in Bombinator, Bufo, and Hyla.

Pflüger has observed that spermatozoa with pointed heads possess a greater facility for penetrating the envelops of the ova of other species to reach the nucleus, a fact which explains the different results obtained in attempts at crossing in both directions, to which highly interesting experiments allusion will again be made in the chapter on hybrids. 


\section{EGGS.}

The eggs are spherical vitelline bodies, surrounded by a thin, elastic, cortical membrane or chorion and one or two gelatinous envelops, formed during their passage down the oviducts: the outer capsule swells out in the water after oviposition, and varies according to the families or genera; the inner is absent in the Pelobatidx. With the exception of Alytes, the upper pole of the vitelline sphere is always pigmented, varying from pale brown to black, and this coloration may extend on the whole sphere,-as, for instance, in Bufo vulgaris, or on the whole save a small whitish spot at the lower pole, as in Rana temporaria. The inner mucilaginous envelop is formed in the upper portion of the oviduct, and surrounds each ovum; the outer, which has been termed "adhesive enrelop," is formed lower down the oviduct, and either surrounds each single ovum, whether free or agglutinated in masses, or forms a common investment in which the ova are disposed irregularly or in files.

All eggs, except those of Alytes, are deposited in the water. If laid singly, each is fixed by its adhesive envelop to submerged bodies; if in strings or bands, these are twined round plants. Egg-masses are usually also fixed to plants, except those of Rana temporaria, which are endowed with a peculiar buoyancy, and simply float on the surface.

The eggs of some Batrachians have a strong odour of fish, this being most noticeable, among European forms, in Pelobates fuscus.

The amount of protection which the mucilaginous envelops afford the embryo varies considerably. In Discoglossus, Pelodytes, Pelobates, and Bufo they soon partly dissolve, so as to release the embryos almost before these are able to execute any spontaneous movements; the embryos, so to say, drop out and become fixed by their adhesive subbuccal apparatus to the 
outer surface of their remains. In Bombinator, Hyla, and Rana the embryo develops much further within the egg, and becomes liberated by its own action.

In Alytes, which is exceptional among European Batrachians in the eggs being laid on land in strings, taken charge of by the male parent, who carries them about twisted round the legs, all the embryonic stages are passed through within the egg, and the young is born as a true tadpole. Contrary to the other Batrachians, the food-yolk of which is in insufficient quantity to form an external appendage of the embryo, we find here a large yolk-sac. These egg's, which measure three and a half or four millimetres in diameter, are of a uniform yellow colour, and are protected and connected in rosary-like fashion by a comparatively tough but highly elastic transparent investment, which represents the adhesive envelop of the typical Batrachian ovum, and contracts thread- or hair-like between every two eggs.

The following synopsis shows the principal differences between the eggs of the European species, and will serve to their identification, the dimensions given being those of recently deposited ones.

I. With large unpigmented vitelline sphere, $3 \frac{1}{2}-4$. millimetres in diameter, laid on land in rosarylike strings, carried by the male twisted round his legs, the larva leaving the envelops in an advanced condition after the loss of the external gills and the formation of the spiraculum. Alytes.

II. With small vitelline sphere $(1-3$ millimetres in diameter), entirely or partially brown or black, deposited in the water, the embryo leaving the envelops with external gills or before their appearance.

A. Deposited singly or in small groups of two to tivelve; vitellus brown or black above, white or yellowish beneath, the embryo leaving the 
envelops with external gills or just before their appearance, with the tail more or less developed.

Vitellus $1-1 \frac{1}{2}$ millimetres in diameter, black above . . . . . . . . Discoglossus. Vitellus 2 millimetres in diameter, brown above.

Bombinator.

B. Irregularly disposed in a thick mucilaginous band (formed by fusion in the cloaca of the contents of the two oviducts); vitellus dark brown or black, with the lower pole white, $1 \frac{1}{2}-2 \frac{1}{2}$ millimetres in diameter, the embryo leaving the envelops before the appearance of the external gills and tailless.

Pelodytes, Pelobates.

c. In regular files in two long mucilaginous strings; vitellus entirely dark brown or black, or with a whitish lower pole, the embryo leaving the envelops before the appearance of the external gills and with a rudimentary tail . . . . . . . Bufo.

Vitellus $1 \frac{i}{2}-2$ millimetres in diameter; eggs, in each string, in three or four files when floating, in two when stretched. . . . .B. vulgaris.

Vitellus $1-1 \frac{1}{2}$ millimetres in diameter; egg's in three or four files when floating, in two when stretched . . . . . . . . B. vividis.

Vitellus $1-1 \frac{1}{2}$ millimetres in diameter, with whitish lower pole; eggs in two files when floating, in one when stretched . B. calamita.

D. In large lumps; upper pole brown or black, lower whitish or yellowish; the embryo leaving the envelops with external gills and a well-developed tail.

1. Envelop, when fully swollen out, measuring $3-4$ millimetres in diameter; vitellus yellowish white with brown upper pole, $1 \frac{1}{2}$ millimetres in diameter; embryo yellowish. 
Fig. 30.
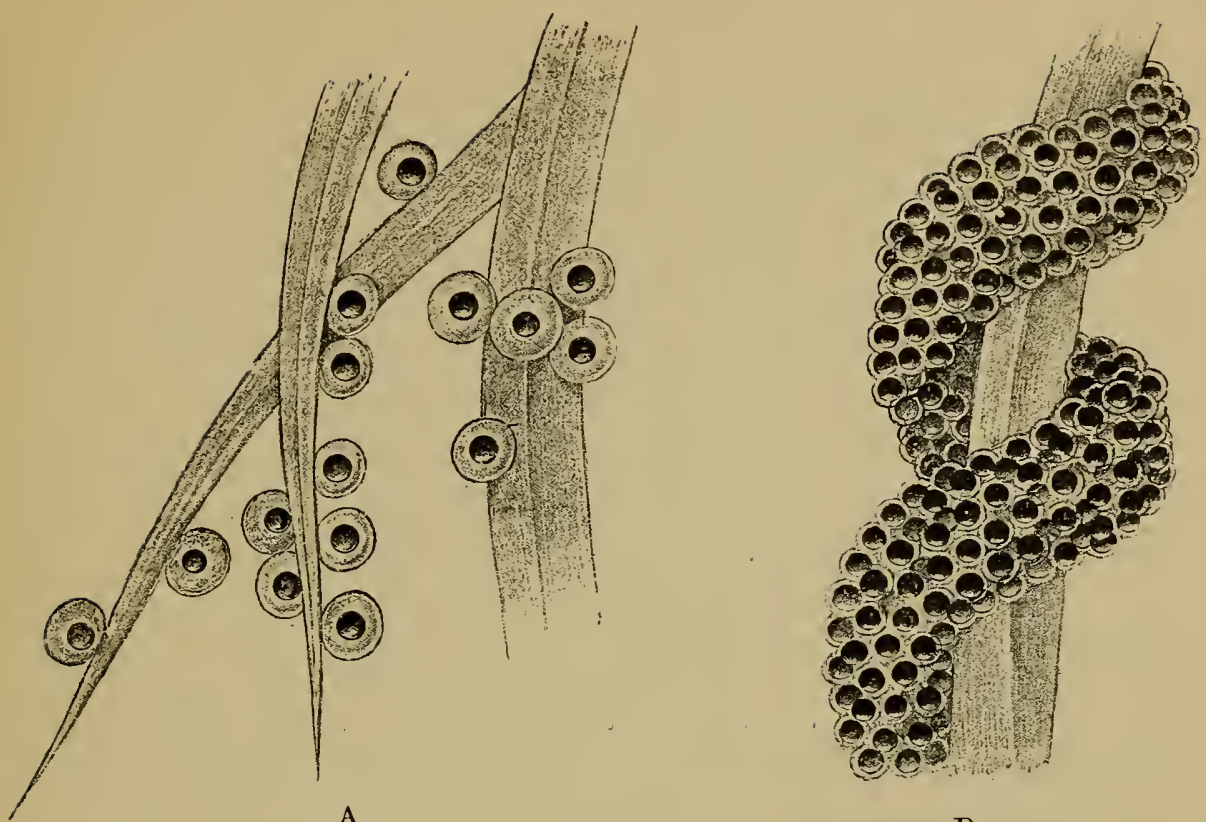

$\mathrm{D}$

(3)
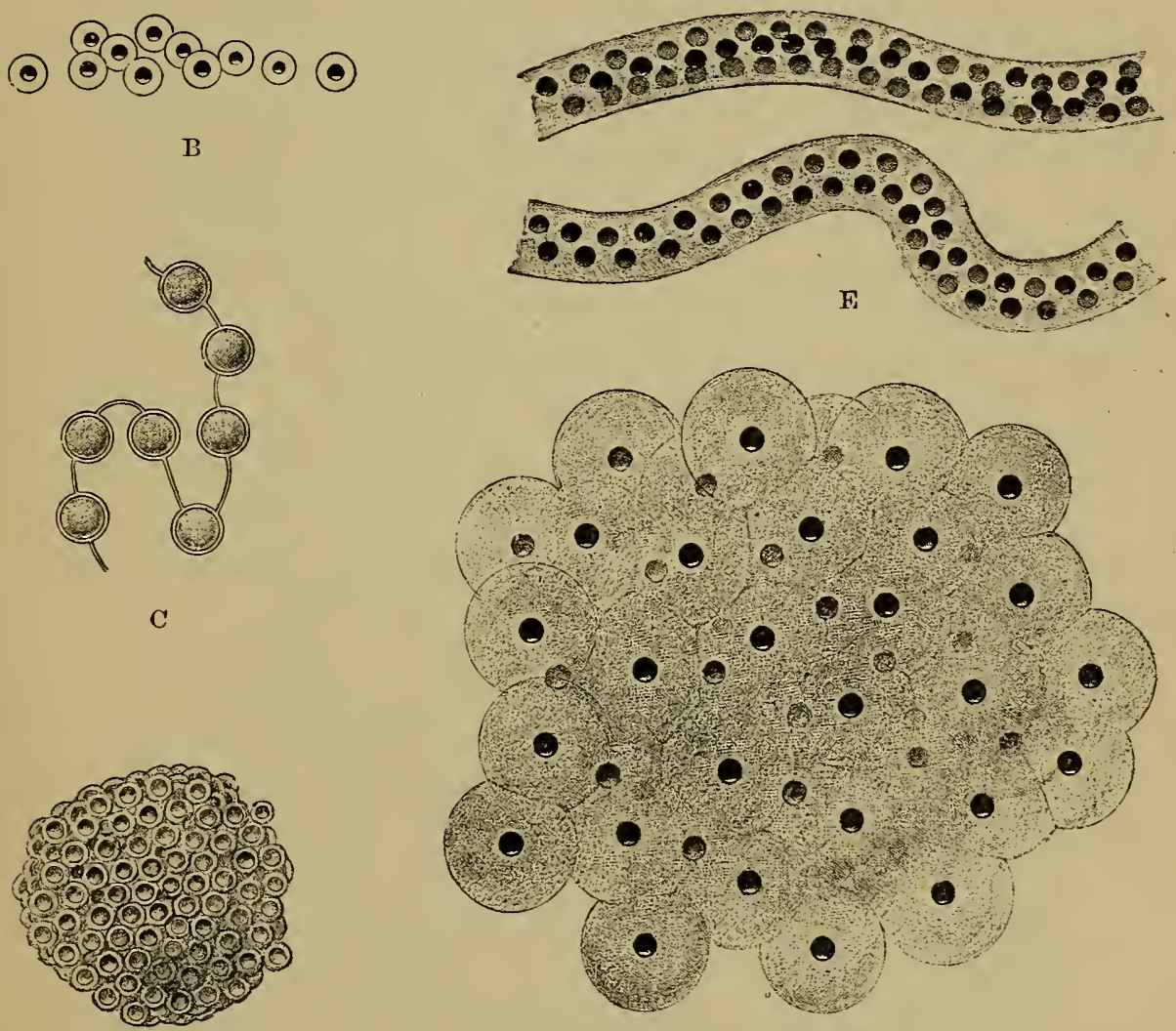

I"

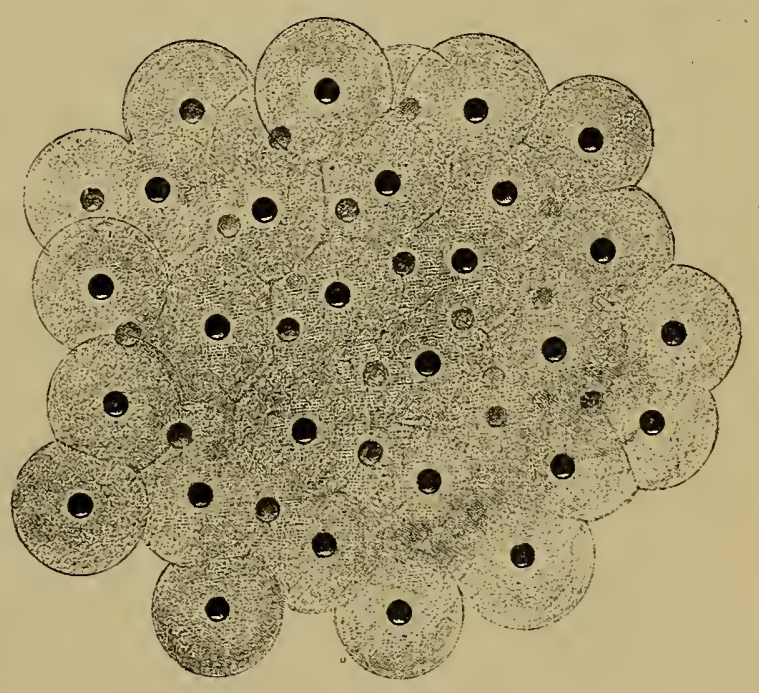

G

Eggs of-A. Bombinator pachypus. B. Discoglossus pictus. C. Alytes obstetricans. D. Pelodytes muctatus. E. Bufo vulgaris. F. Hyla arborea. G. Rana iemporaria. 
2. Envelop 7-10 millimetres in diameter; embryo brown or blackish . . . Rana. (a) Vitellus miparti, brown or blackish above, vellowish or white below, or the light spot covering at least the lower third; eggs submerged.

Diameter of vitellus $1 \frac{1}{2}-2$ millimetres.

$R$. esculenta, $R$. arvalis.

Diameter of vitellus $2-3$ millimetres . $R$. agilis.

(b) Vitellus nearly entirely black, with a small whitish lower pole.

Diameter of vitellus $2-3$ millimetres; eggs floating . . . . . . . . R. temporaria.

Diameter of vitellus $1 \frac{1}{2}-1 \frac{3}{4}$ millimetres; eggs submerged . . . . . . . R. latastii.

It may be noticed that, so far as species are concerned, the size of the egg stands in no relation to that of the parent, a fact which is also conspicuous in the tadpole. Thus the largest Batrachian, Bufo vulgaris, has eggs no larger than the smallest, Pelodytes punctatus; and in Rana temporaria they are considerably larger than in $R$. esculenta, which reaches both in the larval and perfect states to a much greater size. Héron-Royer has observed that young females produce eggs of a somewhat smaller size than those of full-grown specimens of the same species, and I have been able to verify his observation on Rana temporaria.

'I'he number of eggrs also varies according to the size of the female. Héron-Royer, who has counted them in most of the European species, gives the following numbers as the result of his computation :

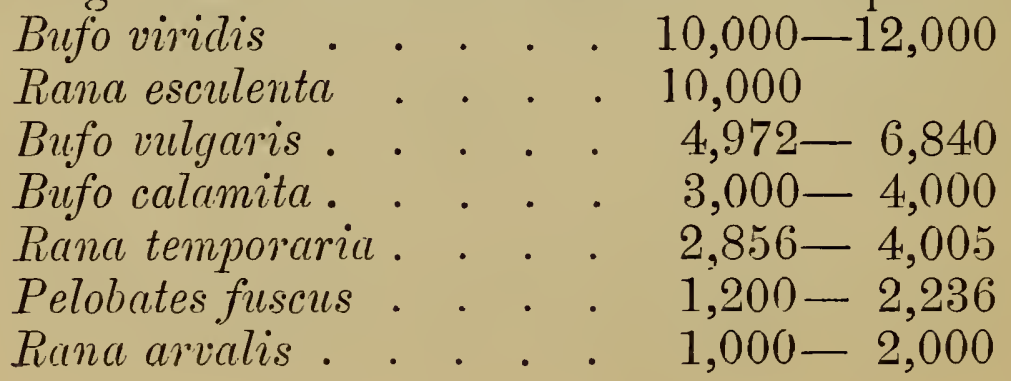




\section{Pelodytes punctatus . . . 1,000-1,630 \\ Rana agilis . . . . . 669-1,200 \\ Hyla arborea . . . . . 800-1,000}

These results, however, do not always agree with my own, as will be seen further on under the various specific headings.

In the Discoglossidx, which spawn two or three times a vear, each brood consists of 300 to 1000 eggs in Discoglossus pictus, 80 to 100 in Bombinator pachypus, and 20 to 90 in Alytes obstetivicans. This makes a probable maximum total of 3000 for the first species, 300 for the second, and 270 for the third. These numbers are, however, only approximative, for no observer has yet been able to follow the spawning of a given specimen throughout the year, and to record the total number of eggs produced.

Manipulating frogs' eggs is not easy, on account of the sticky mucilage which adheres to the fingers or instruments, and the counting is a very trying operation. Approximate computations are more easily arrived at with the egg-strings of toads, which can be divided into small portions, in which the eggs are counted and the result multiplied by measuring the length of the whole strings.

FIG. 31.
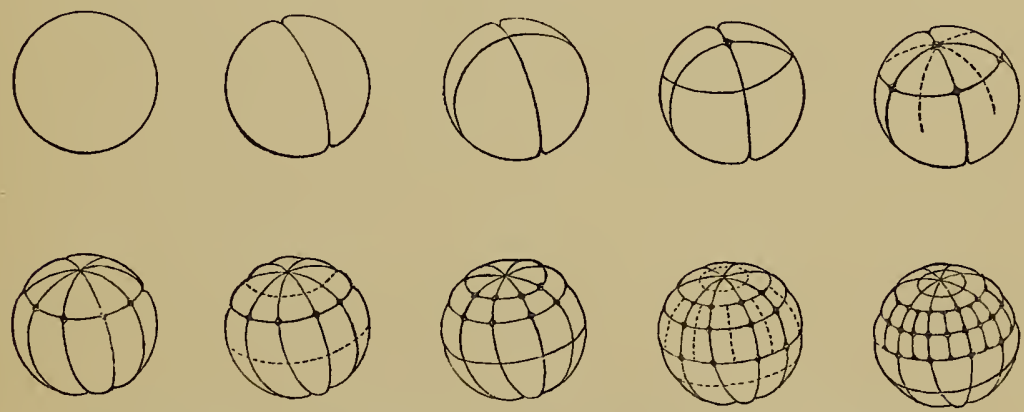

Cleavage of egg of Rana temporaria (after Ecker).

After fecundation the vitelline sphere undergoes a process of division, or segmentation, which can be readily observed under the microscope or an ordinary hand lens, and of which the above diagrammatic 
figure from Ecker's 'Icones Physiologicæ' will give an idea.

This type of segmentation, in which the first furrow completely cleaves the whole egg into two, each successive one again subdividing that cell with which it is related, the first two furrows vertical and the third horizontal, is termed complete or holoblastic. The first plane of division passes through the plane of symmetry of the future embryo, the tissues of which are formed from these cells. The egg of Alytes contains a much greater quantity of nutritive matter, and the segmentation is less regular and more limited; it belongs to the meroblastic type.

The time required for the eggs to hatch varies considerably, according to the species. Thirty hours may suffice for those of Discoglossus pictus, whilst those of Alytes obstetricans take at least, under the best conditions, nearly three weeks. The eggs of other species fall between the two extremes, the evolution being of course accelerated or retarded by the variable temperature with which early breeders have to contend, or even temporarily arrested when the thermometer descends to freezing-point or below. 


\section{XiI. Development and Metamorphosis.}

In the first condition, when the embryo has become distinct from the vitelline sac, the head is large and distinct from the elongate body, the tail absent or rudimentary. The head is usually cleft below by a median longitudinal groove, in the middle of which a transverse or rhomboidal depression represents the first rudiments of the mouth; on each side, in front of the mouth, a pit indicates the nostril ; behind it is a grooved fold, the cephalic crescent, which develops into a single or paired prominence, the holder"crochets" of Rusconi-acting as an adhesive apparatus by means of which the helpless embryo fixes itself at first to the outer surface of the mucilaginous envelop of the egg, and later to weeds or submerged objects. Eyes are absent. A small bud-like tubercle on each side of the posterior border of the head is the rudiment of the external gills, and vertical grooves in front and behind the bud represent the visceral clefts, the intervals between which will later become converted into the four branchial arches.

The adhesive apparatus mentioned above varies considerably, and its conformation affords the means of distinguishing genera or even species at a period when the tadpole characters are not yet developed. It is mainly through the observations of Héron-Royer and the more scientific researches of Thiele that we have become acquainted with its modifications in most of the European forms. Thiele has shown that the term "sucker," which has been bestowed on this organ by various authors, is a misnomer. There is no muscular suctorial apparatus developed in connection with it; it is glandular and secretory, producing a sticky mucus or slime, which serves to fasten the larva to its resting-place.* The mode of its development and

* From this apparatus the ventral adhesive disk of certain tadpoles living in mountain streams of the Himalayas, Burma, and the Malay Archipelago is no doubt developed. 
retrogression is shown in the following series of figures of Bufo vulgaris (after Thiele).

FIG. 32.

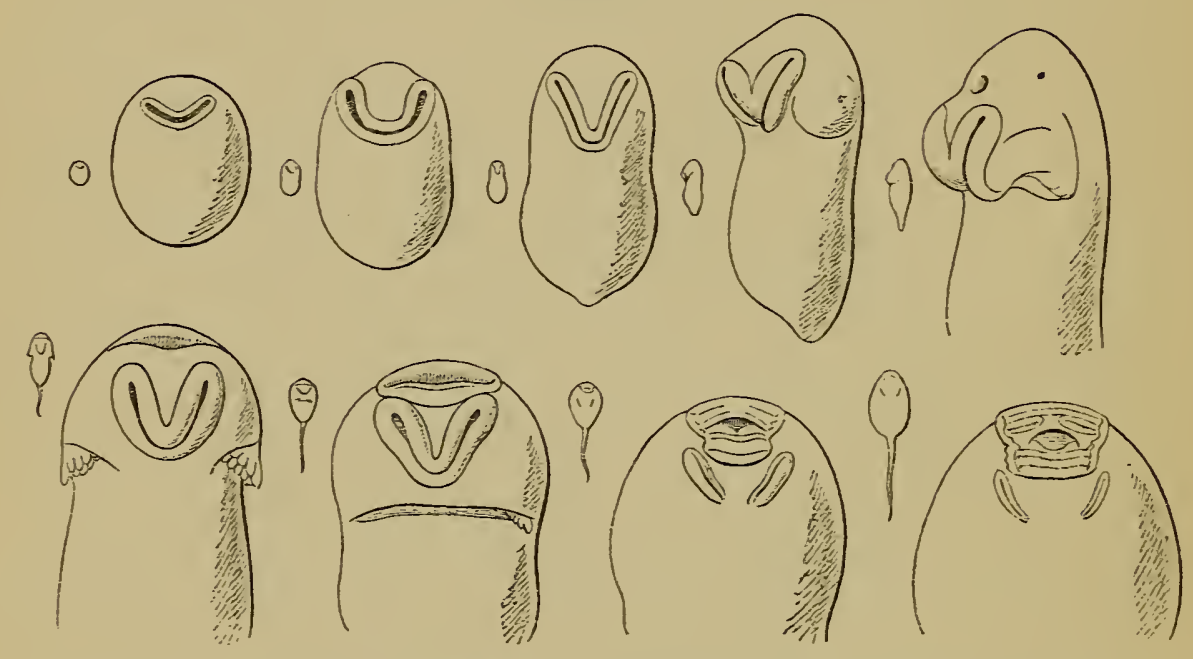

Development and retrogression of the subbuccal apparatus in Bufo vulgaris.

It appears as a crescentic groove very early, before any other organ, and disappears, after having undergone various changes, in the beginning of the tadpole period. Its fullest development coincides with that of the external gills. It is single and discoid, with a crescentic groove, in Discoglossus; single and $Y$-shaped in Pelodytes and Pelobates; single and V-shaped or crescentic in Bufo; and paired, forming two small disks, in Bombinator, Rana, and Hyla. These disks are close together in Bombinator, widely separated in Hyla and Rana temporaria and agitis, whilst they are connected by a fine transverse ridge in Rana esculenta, which thus affords a link between the single and paired types of holders. Hyla differs from all others in the disks shifting forwards so as to be, in the later stages, situated on a level with the mouth. The condition in Discoglossus appears to be the most primitive, from which those shown by Bombinator, Rana, and Fyla on the one hand, Pelobates and Bufo on the other hand, may be derived. The following 
diagram, copied from 'Thiele's memoir, shows roughly the shape of this organ, and its position with respect to the mouth at the close of the first larval period.

FIg. 33.

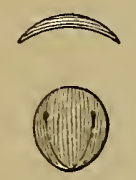

A

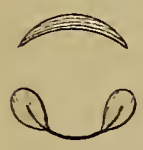

E

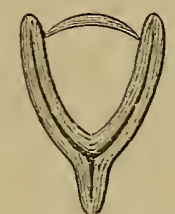

B

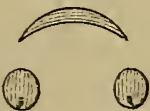

F

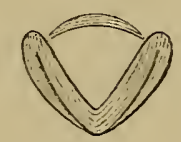

C

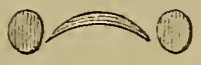

G
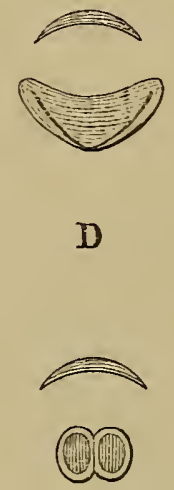

II

A. Discoglossus pictus. B. Pelobates fuscus. C. Bufo vulgaris.

D. Bufo viridis. E. Rana esculenta. F. Rana temporaria.

G. Hyla arborea. H. Bombinator pachypus.

As the embryo grows the tail elongates and shows a muscular portion with chevron-shaped myotomes, bordered above and below by a membranous crest. The gills become digitate or branched; the olfactory pits shift more forward, and become converted into functional nostrils communicating with the mouth; the eye may be detected at the side of the head, appearing first as a pigmented ring under the transparent epidermis; the mouth becomes bordered by fleshy lips; the anus is perforated; and the larva is able to feed, having thus far subsisted on the vitellus contained in the abdomen.

The external gills, two or three in number on each side, the second and third often rudimentary and concealed under the first, are largest and persist longest in Rana temporaria. In this species and in the toads they are strongly pigmented, like the body; in most others they are not, or but feebly, pigmented. A little smaller but likewise branched in Rana esculenta, Bufo vulgaris, and Discoglossus, they remain very short and 
unbranched or bifid in Bufo viridis and calamita and in Hyla arborea.

In Alytes, within the egg, the external gills are extremely developed, but single; and the very long and slender branches are confined to the ventral side, as in other tailless Batrachians.

On entering the second period,

FIG. 34 .

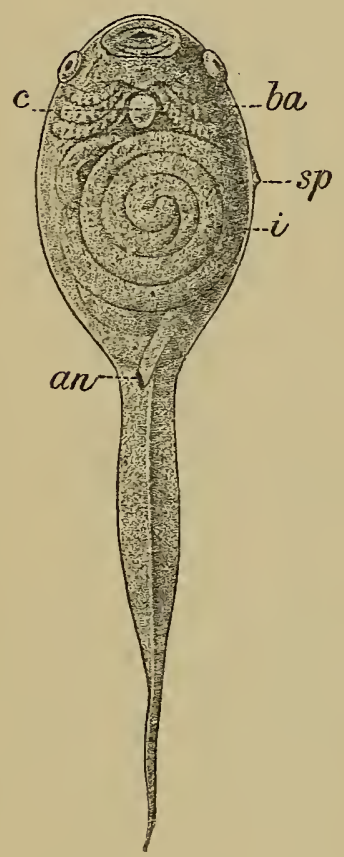

Young tadpole of Hyla arborea, seen from below, showing the branchial arches $(b a)$, the heart $(c)$, and the coiled-up intestine (i). $\times 3$. or true tadpole stage, the external characters of which will be more fully described in the following: chapter, an opercular fold covers the external gills (the right some time before the left in the forms with lateral spiraculum), which atrophy and are replaced by internal ones, small branched filaments disposed along four cartilaginous arches. The anal tube is developed; the mouth acquires horny mandibles and the lips horny teeth; the nostrils assume a more dorsal position; the subbuccal adhesive organ disappears; and the opercular fold having fused with the skin above the gill-arches, the head becomes confluent with the globular swollen belly, in which the extremely elongate intestine shows through the transparent abdominal membrane, coiled up like a watch-spring (Fig. 34).

In the third period the hind limbs appear as buds at the base of the tail, and gradually attain their full development during the tadpole life. The fore limbs grow simultaneously, and even more rapidly, but remain concealed within a diverticulum of the branchial chambers until fully formed, when they burst through the skin (unless the left spiraculum be utilised for the egress of the corresponding limb), leaving in 
front of them a small cleft, out of which the gillfilaments of the branchial arches in process of disappearance may often be seen projecting (Fig. 35).

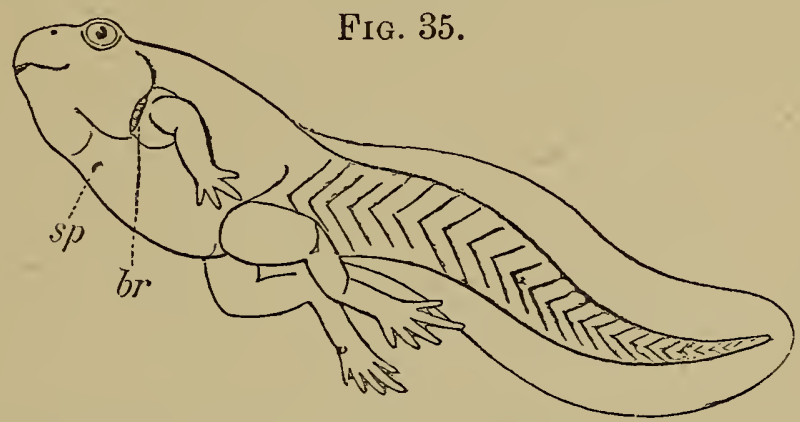

Alytes obstetricans, towards the end of the larval stage, showing the gills $(b r)$ protruding through the cleft in front of the arm, and the median spiraculum $(s p)$.

Then only the caudal crests become reduced and the tail gradually absorbed; the gill-arches entirely disappear; the lungs, which had co-existed as accessory respiratory and bydrostatic organs, assume alone (or, rather, together with the skin) the respiratory func-

Fig. 36.
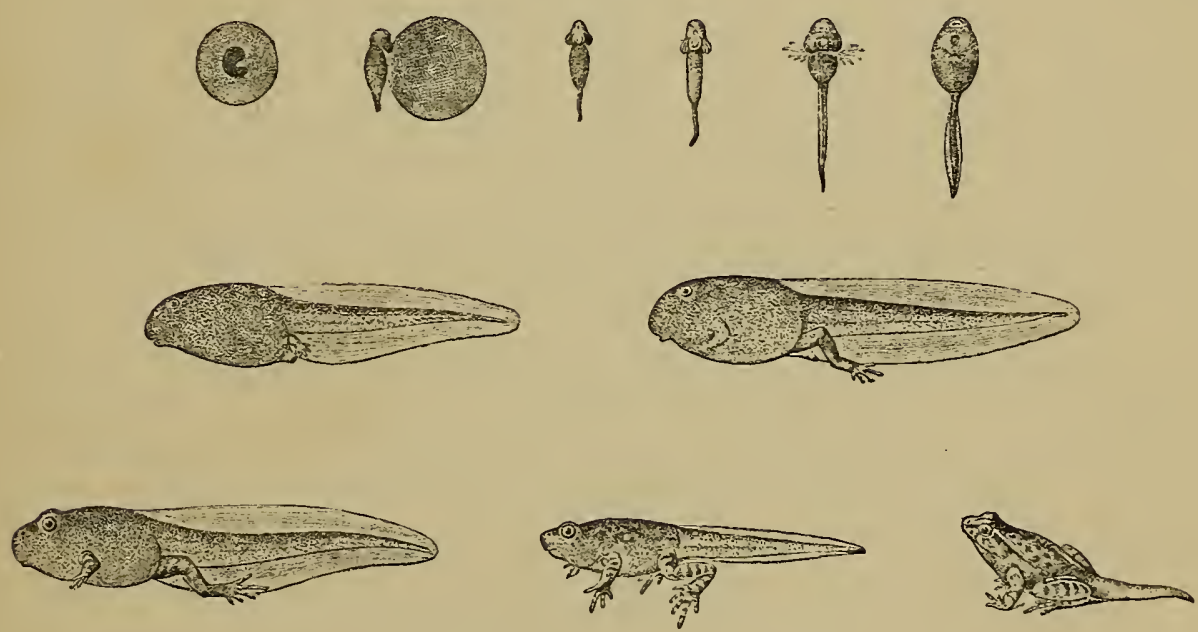

Development of Discoglossus pictus, $\times 1 \frac{1}{2}$.

tions; the horny armature of the mouth and lips is shed in pieces; the lips are absorbed and the buccal cleft extends; the eyes become free and acquire moveable lids; the lachrymal canal is shifted towards the 
eye and perforates the lower eyelid; the intestine shortens; the anal tube ceases to function, and disappears with the last vestiges of the caudal crest, which had become detached from the vent; and the young frog, usually still bearing a stumpy tail, leaves the water. The metamorphosis is completed.

The skull and its appendages also undergo very important changes. The cranium in the tadpole is a large undivided cartilage with narial openings and large suborbital fenestræ. The suspensorium of the lower jaw is extremely elongate, and sends up a strong process, connected with the cranium by a bridge, in front of the eye. The præmaxillaries are

\section{Fig. 37.}

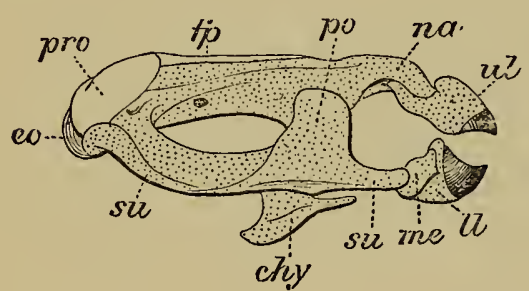

A

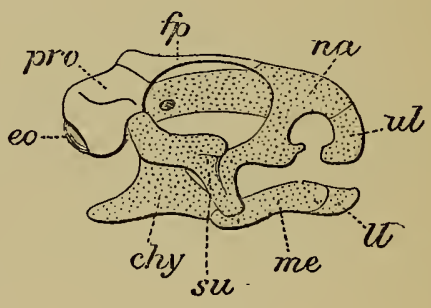

B

A. Skull of full-grown tadpole of Pelobates fuscus. B. The same at the end of the metamorphosis, after the loss of the horny beak. chy. Ceratohyal cartilage. eo. Exoccipital. $f p$. Frontoparietal. $l l$. Lower labial cartilage. me. Mandibular (Meckelian) cartilage. na. Nasal processes of chondrocranium. po. Præorbital process. pro. Prootic. su. Suspensorium (palatoquadrate). ul. Upper labial cartilage.

represented by a single or paired cartilage, the upper labial, loosely attached to the diverging anterior processes of the cranium, which supports the upper horny beak; and to this corresponds a pair of cartilages, the lower labials, ultimately the mento-Meckelian or symphysial bones, supporting the lower beak and attached to the short mandibular or Meckelian cartilage. In the transformation of the mouth this mandibular cartilage acquires a greater length, and the suspensorium becomes reduced in proportion and shifted backwards. 
The ceratohyal cartilage at first articulates by a condyle with the suspensorium below its præorbital process, and extends across the gular region towards its fellow, from which it is separated by a narrow space, with one or two small cartilaginous pieces (basithyals, Parker; copulx, Gaupp), behind which is a paired plate (hyobranchials, Parker; branchial plate, Gaupp). To each branchial plate the four cartilaginous arches bearing the tufted internal gills are attached by connective tissue, and ultimately fuse with it (in the third period). The homology of these branchial arches has been the subject of much discussion. According: to Parker, they are to be regarded as subcutaneous cartilages, and do not belong to the category of true visceral arches; they are called accordingly extrabranchials - the true branchial arches of fishes and tailed Batrachians being the ceratobranchials, represented by small styliform cartilages first attached to the outer border of the hyobranchial cartilage, with which they fuse, the fourth to persist throughout life, and ossify as the thyrohyal. This view is strongly refuted by the latest worker on the subject, Gaupp, whose conclusions are as follows:

The hyobranchial apparatus of the larva consists of two hyalia [ = ceratohyals] (Fig. 38, ch), connected mesially by a pars reuniens; continuous with it follows the copula [basihyal, bh], which connects the hyal with the branchial skeleton. The latter is made up of two branchial plates [hyobranchials, hbr] and four branchialia [ceratobranchials, cbr] on each side, which pass into the branchial plates with their inner extremities and into each other with their dorso-lateral extremities. The whole hyobranchial skeleton forms a cartilaginous continuum. For a time a cartilaginous piece is developed in front of the pars reuniens, which may be regarded as a first copula. During metamorphosis the larval apparatus is for the greater part lost; the pars reuniens and the anterior copula are absorbed; the branchialia disappear with- 
out a trace. 'The body of the hyoid cartilage of the transformed animal is composed of the two united branchial plates, the posterior copula, and of newly formed cartilage, constituting the manubria of the principal cornua, probably derived from the copula.

The alar and postero-lateral processes are new formations which only appear comparatively late. The so-called "processus thyroide $i$ " [thyrohyals, $t$ ] have nothing to do with the branchial processes (nor with the ceratobranchials of Parker, which Gaupp terms spicula), but are remains of the posterior portion of the larval branchial plates.

Thus, of the larval apparatus nothing is preserved but the hyal arch, and a portion of the copula and of the two branchial plates.

Dr. W. G. Ridewood has recently investigated the development of the hyobranchial skeleton of Pelodytes, and the careful figures he has drawn are reproduced here with his kind permission. He agrees with Gaupp in the main results, but shows the postero-lateral process to be the persistent proximal portion of the first ceratobranchial.

In Pelodytes as well as in Pelobates the anterior processes are expanded and bent inwards, and the cornua become broken, the anterior portion fusing with the alar processes, whilst the posterior becomes free from the byoid plate, as may be seen on Fig. 38.

In order to complete this rapid sketch of the evolution of the hyobranchial apparatus, which is of great importance for the correct understanding of the hyoid apparatus in the perfect form, it remains to notice that in the Discoglossidæ the first copula or basihyal is of much larger size than in other frogs, and persists longer; whilst the second extends farther back, and completely separates the hyobranchial plates from each other.

The ossification of the thyroid processes takes place only after transformation.

'The only cranial ossifications to develop during the 
Fig. 38.
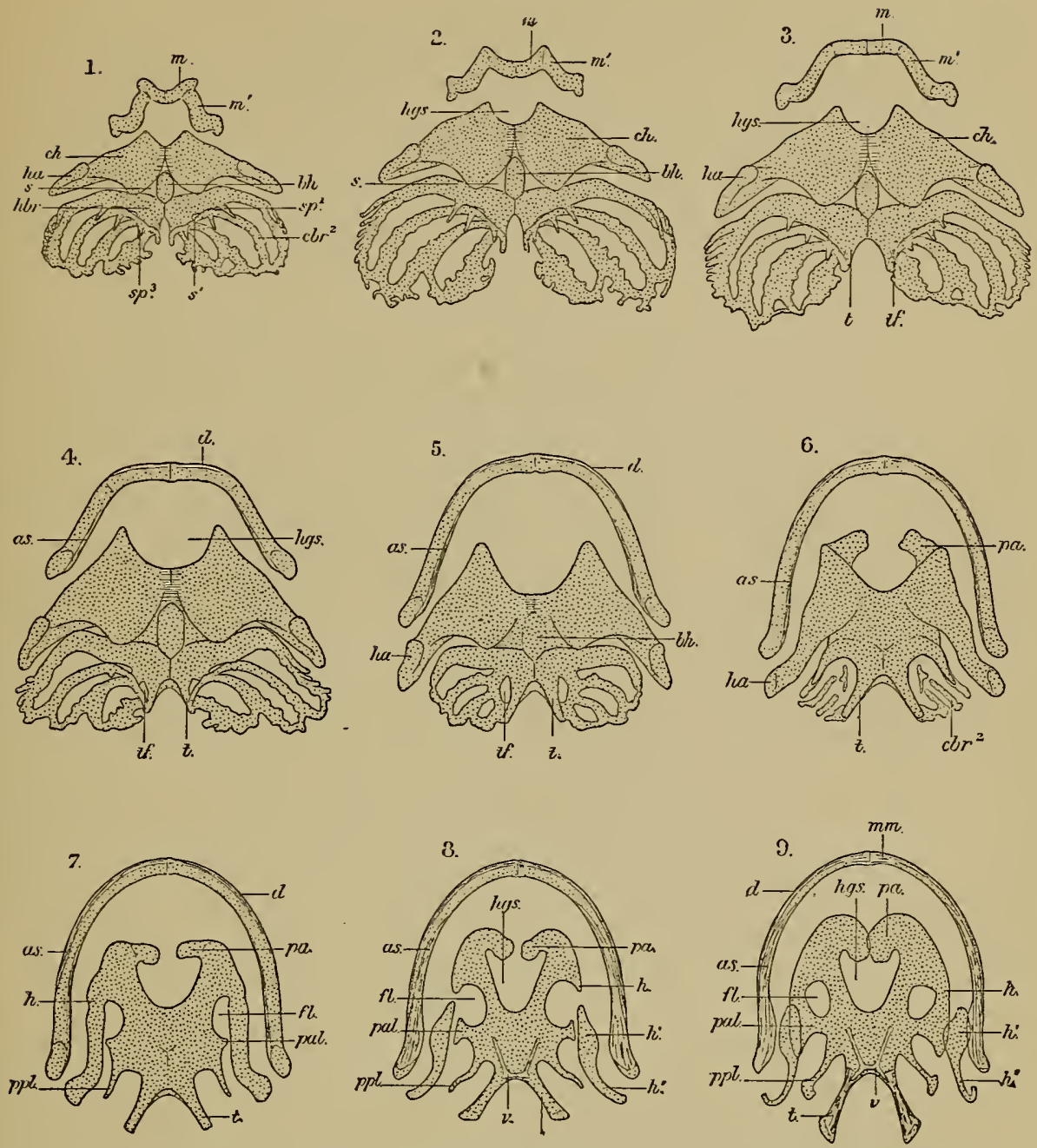

Transformation of the mandible and hyobranchial apparatus of Pelodytes punctatus. (After Ridewood, 'P.Z. S.,' 1897.) Nine different stages, No. 9 representing the adult. Figs. 1-7 dorsal view. Figs. 8 and 9 ventral view.

as. Angulo-splenial bone.

$b h$. Basihyal.

$c b r$. Ceratobranchial.

ch. Ceratohyal.

d. Dentary bone.

fl. Lateral foramen.

h. Hyoidean cornu.

ha. Convex surface by which the ceratohyal articulates with the palato-quadrate cartilage.

$h b r$. Hyobranchial plate.

$h g s$. Hyoglossal sinus.

$m$. Internal or mesial part of the mandibular cartilage. $m^{\prime}$. Lateral part of same. $m m$. Mento-Meckelian (symphysial) bone.

pa. Anterior process.

pal. Antero-lateral process.

$p p l$. Postero-lateral process.

s. Space enclosed between the hyobranchial plate and the proximal ends of the first and second ceratobranchials.

$s p$. Spicules of branchial arches.

$t$. Thyrohyal.

tf. Thyroid foramen.

$v$. Ventral splint-bone. 
tadpole condition are the exoccipitals and prootics (cartilage bones) and the fronto-parietals, or frontals and parietals if these ossify from distinct centres, and parasphenoid (membrane bones). The præmaxillaries, maxillaries, and squamosals, next in order, appear only some time after the loss of the suctorial or larval mouth.

Whilst the fore limbs are enclosed, each moiety of the shoulder-girdle is widely separated from the other; the scapula is directed upwards, and the coracoid and præcoracoid form a loop turned downwards and inwards. At the same period the ilium is perpendicular to the vertebral column.

The tail proper of the tadpole remains in a notochordal condition, no cartilage being ever formed in that region. But both dorsal and ventral cartilages are developed in the basal portion of the caudal region, and ossify as two dorsal elements or arches and a single ventral strip behind the ninth or sacral vertebra; they gradually fuse to a continuous cylinder, the urostyle or coccyx, from which both chorda and spinal cord ultimately disappear, to form in the adult a solid bony rod.

The vertebræ of the trunk are formed, as first discovered by Dugès, on two different plans. In the Discoglossidx, Pelobatidx, and Hylidæ the chorda remains for a long time exposed along the ventral surface, and, owing to the absence of cartilaginous formation around it, disappears without ever becoming invested otherwise than by a thin elastic membrane; it can easily be stripped off below the vertebræ in specimens on the point of metamorphosing. This has been termed by Gegenbaur the epichordal type. In the Bufonidx and Ranidx, which represent the perichordal type, the greater share of the formation of the whole vertebra falls to the (paired) dorsal cartilage, but there is in addition a narrow ventral or hypochordal cartilage which fuses with the dorsal or becomes connected with it by calcified tissue; the 
notochord is thus completely surrounded by a thick sheath in tadpoles with imperfectly developed limbs. This mode of formation of both the arch and the greater part or whole of the so-called centrum from the same cartilage explains why there is never a neuro-central suture in these Batrachians.

FIG. 39.

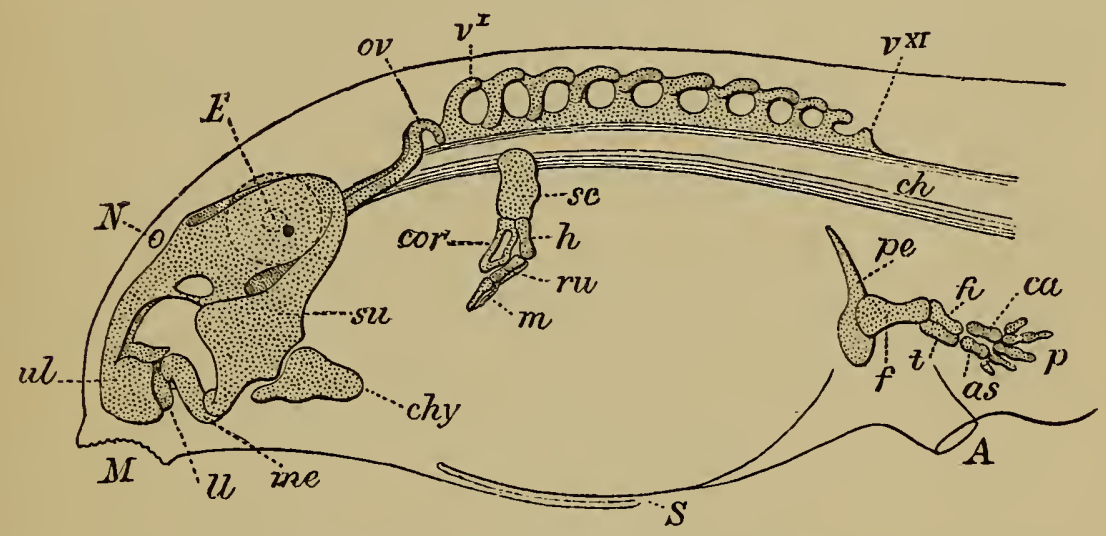

Side view of cartilaginous skeleton of tadpole of Bombinator pachypus, - with outlines of the external parts. (After Goette.)

A. Anus.

E. Eye.

M. Mouth.

$N$. Nostril.

S. Spiraculum.

as. Astragalus.

cr. Calcaneum.

ch. Chorda.

chy. Ceratohyal. cor. Coracoid and

f. Femur.

fi. Fibula.

$h$. Humerus.

ll. Lower labial.

$m$. Manus.

me. Meckelian. $o v$. Occipital vertebra.

p. Pes.

pe. Pelvis.

$\vartheta$. Radius-ulna.

sc. Scapula.

su. Suspensorium.

$t$. Tibia.

ul. Upper labial.

$v$. Vertebra.

During segmentation of the dorsal cartilages mentioned above, which send out the transverse processes or diapophyses, there appears between each two centra an intervertebral cartilage, out of which the articulating knob of the centrum is formed, and becomes attached either to the vertebra anterior (procœlous type) or posterior (opisthocœlous type) to it, if not remaining as an independent, intervertebral, ossified sphere, as we sometimes find in specimens of Pelobatidx. Ossification appears first in the neural arch, next descends to the centrum, and sets in last in the articulating condyle. 
The annexed figure (40) of the vertebral column (ventral aspect) of a recently transformed Pelobates cultripes shows well the independence of the intervertebral spheres and the three elements which enter into the formation of the urostyle.

FIG. 40.

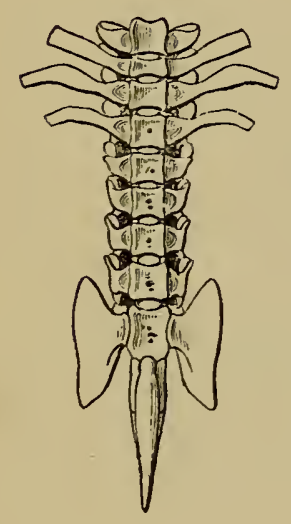

A glance at this figure will also show to what extent the importance of the mode of articulation of the vertebræ has been overrated by those systematists who have proposed to divide the tailless Batrachians primarily into procœlian and opisthocœlian types. As a matter of fact, both occur in the family Pelobatidx, some of the exotic genera of which are normally opisthocœlian.

During larval life the habits vary considerably according to the species. Thus Hyla is always on the move, swimming about in every direction like a fish; Bombinator, Alytes, Pelobates, and Rana keep more to the bottom, approaching the borders of the ponds or pools during the hotter part of the day to sun themselves in shallow water ; Discoglossus, Pelodytes, and Bufo are in the habit of coming frequently to take air on the surface, where they swim about with upturned bellies.

The notion that tadpoles are exclusively herbivorous has long been exploded; they feed on both vegetable and animal substances, and usually show a preference for the latter, in addition to the microscopical organisms contained in the ooze, which they swallow in large quantities. Their carnivorous or even cannibal habits are only too noticeable in confinement, and they have been utilised for making small and delicate skeletons. The tadpoles of Bombinator and Alytes are almost exclusively carnivorous, the real difference between them and the perfect animal being that the former feed readily on dead or even decomposing matter, 
whilst the latter takes only living prey. Nevertheless the intestine in all tadpoles is exceedingly elongate, being several times louger and of a greater calibre than after the metamorphosis. Bataillon has ascertained by direct experiment that the abbreviation of the gut is not localised to any special region. Tadpoles of Alytes obstetricans having been anæsthetised a fer days before the egress of the fore limbs, the abdominal cavity was cut open, and the intestine, after having been slightly uncoiled, marked at regular distances by silk threads tied round it. The abdomen was then sewn up, and the tadpoles, having recovered, continued their evolution. At the close of the metamorphosis the gut was again examined, and it was found that the threads, which were tied at intervals of twenty millimetres, were then only seven or eight millimetres apart.

I have measured the uncoiled digestive canal in fully developed tadpoles and in recently transformed young of the three following species. It will be seen from the measurements, in millimetres, how considerable the range of variation between different forms may be, both in the larval and perfect conditions. Thus in Rana esculenta the length of the intestine of the tadpole is nearly ten times that of the perfect form, whilst in Alytes obstetricans its length is only as $4: 1$; Pelodytes punctatus, with $6: 1$, is intermediate. This difference is correlated with the diet, Rana esculenta being the most herbivorous, and Alytes obstetricans, as noticed above, almost exclusively carnivorous in the tadpole condition.

Length of intestine in tadpole (I) and young (II) of-

I. II.

Alytes obstetricans (25 mm.body-length) 23560

Pelodytes punctatus (20 ,, :, ) 19432

Rana esculenta

(23,

) 4.745

Before closing this chapter on Development, the highly interesting fact remains to be alluded to that 
whereas the transformed tailless Batrachians, unlike their tailed precursors, occupy too high a position in the zoological scale to be able to regenerate amputated extremities, the hind limbs reproduce without difficulty during the larval existence, a fact first observed by Spallanzani in the last century, and since verified by Günther and Barfurth. In order to be regenerated it is, however, necessary that the limb be not completely removed. A basal fragment of the femur must remain to give off the cartilagecells which, most curiously, will become differentiated into the various segments, proceeding from the distal to the proximal; and the mutilation must have taken place some time before the close of the third larval period or true tadpole stage. It has been stated that reproduction of the limbs can only be obtained in young larvæ, long before they have reached their full size. This is, however, contrary to my own experience on large, full-grown tadpoles of Alytes obstetricans, in which the well-developed hind limb, after having been amputated below the knee-joint, was regenerated with the greatest facility.

FIG. 41.
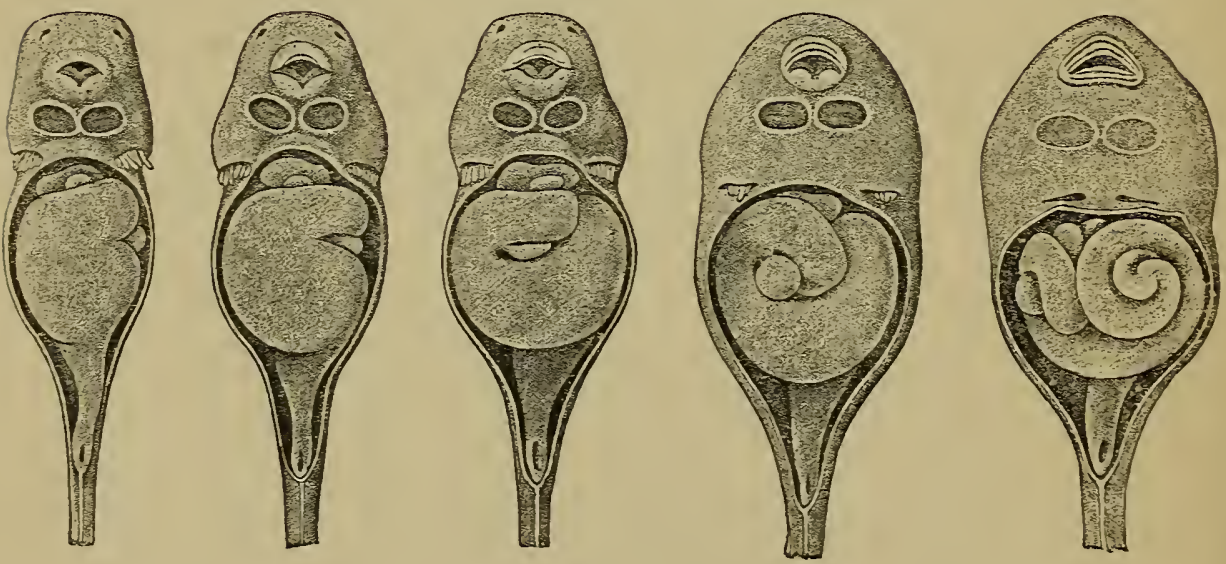

Series of embryos of Bombinator pachypus. (After Goette.) Showing the formation of the larval mouth, together with the atrophy of the adhesive disks; the gradual disappearance of the external gills, and the formation of the median spiraculum by approximation of the two opercular slits; and the development of the gut (the abdominal membranes being removed). 


$$
a^{a^{4}}
$$



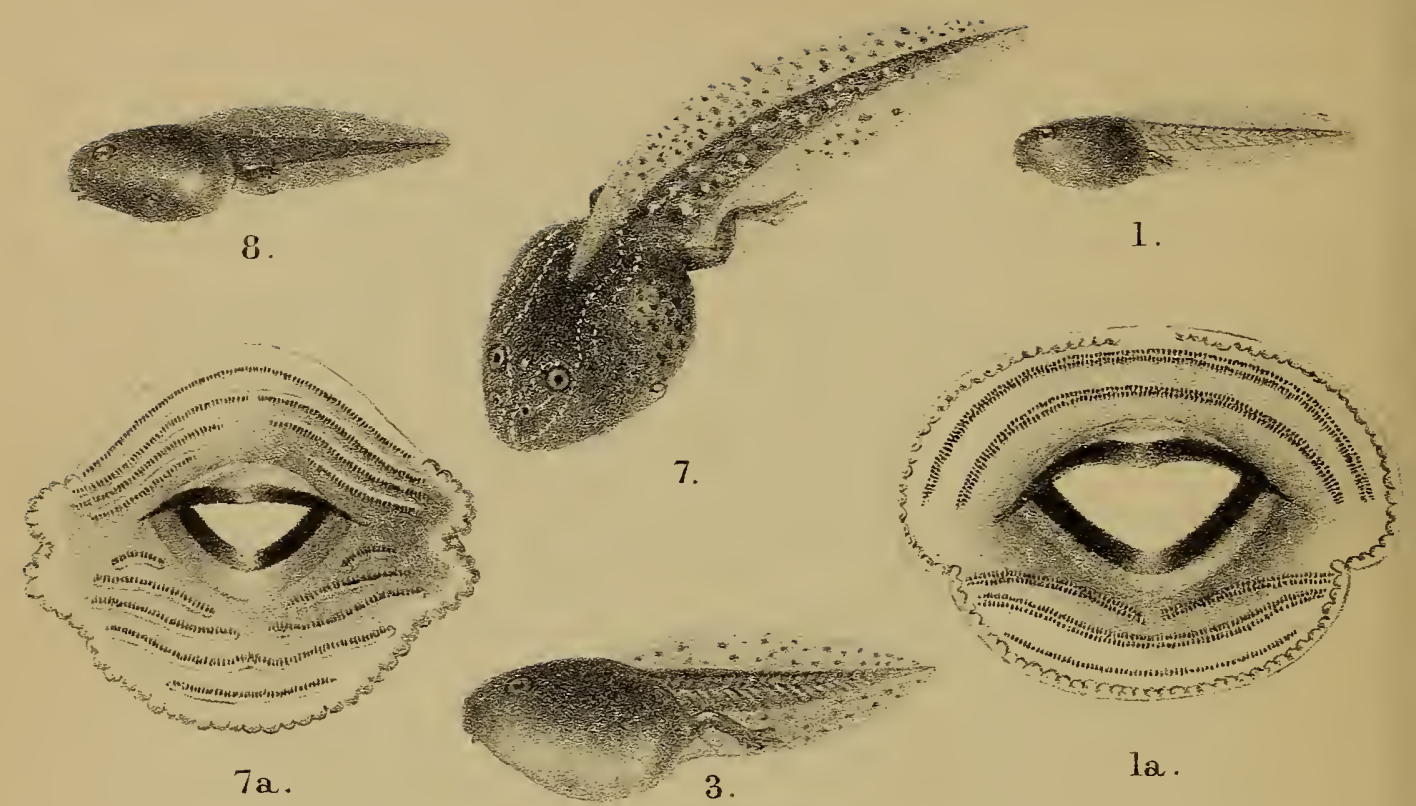

7 a.

3.
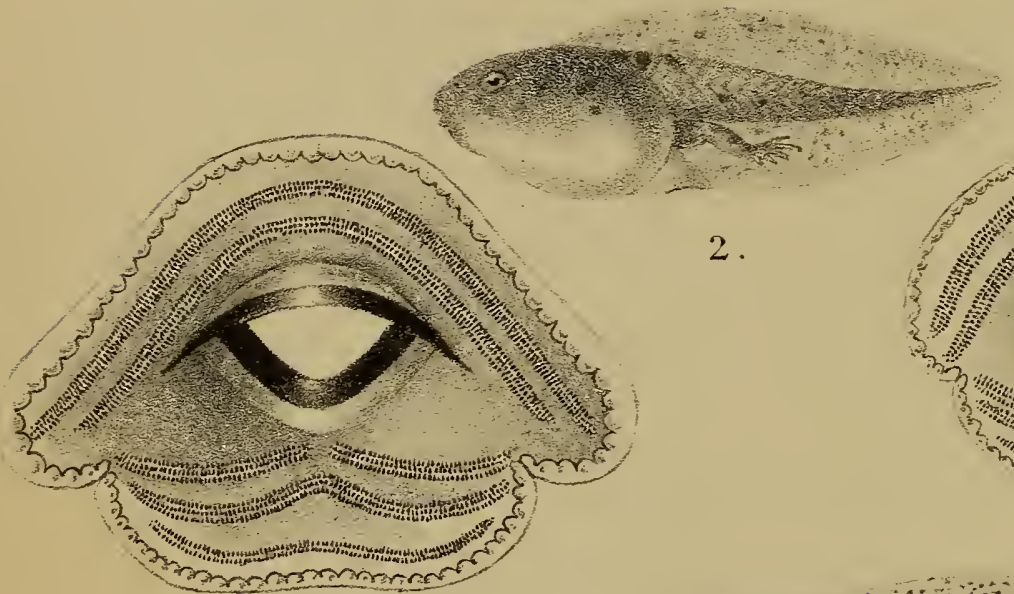

2 .

2 a.

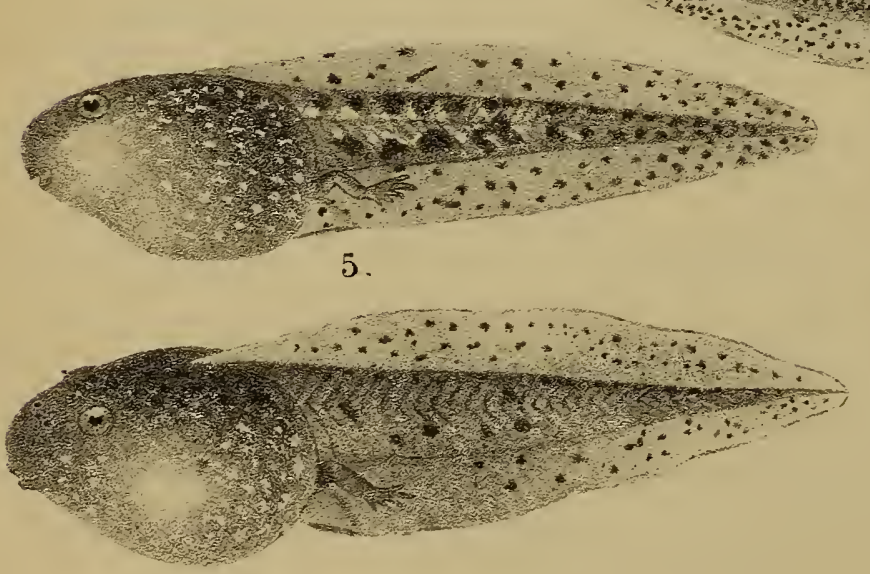

4.

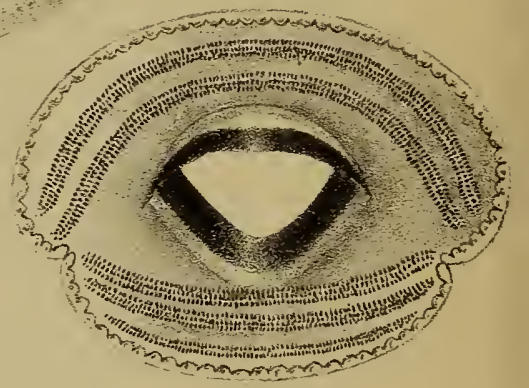

$3 \mathrm{a}$

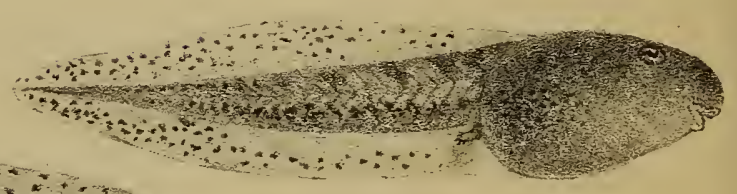

6.

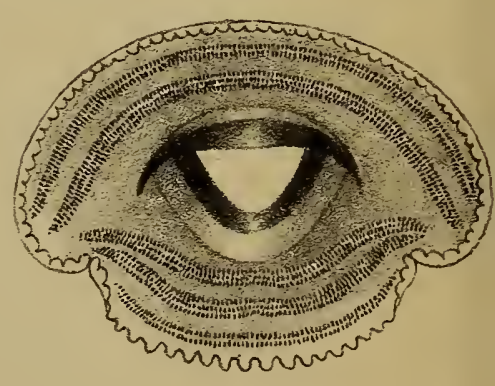

$4 a$.

\section{\%udpolies.}

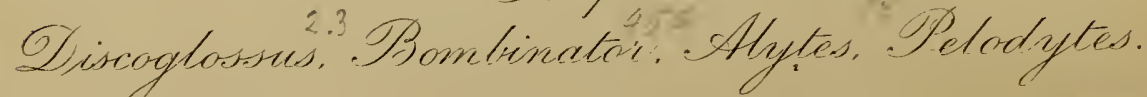




\section{TADPoles.}

The term tadpole is restricted to the developmental stages between the formation of the spiraculum and the egress of the fore limbs, and corresponds to the second and third periods of Dugès. Descriptions are preferably drawn up from specimens in the third period, which begins with the budding of the bind limbs.

Form. - The head and body are so fused that it is

FIG. 42.

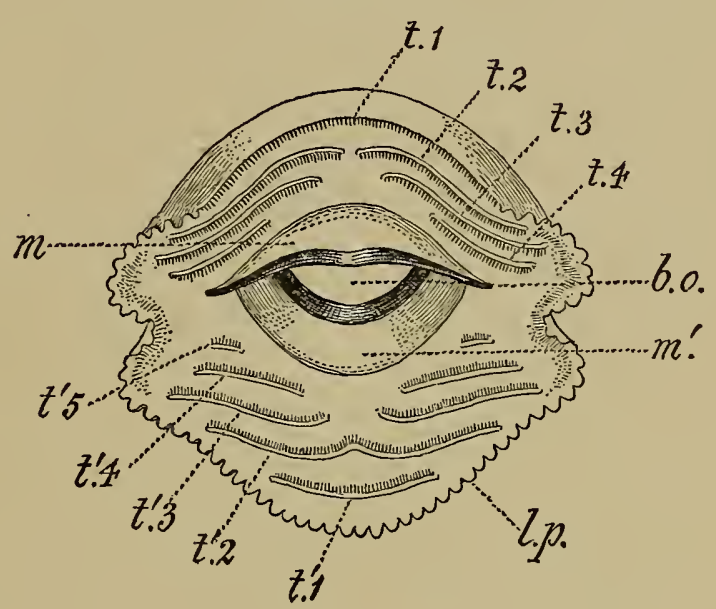

A

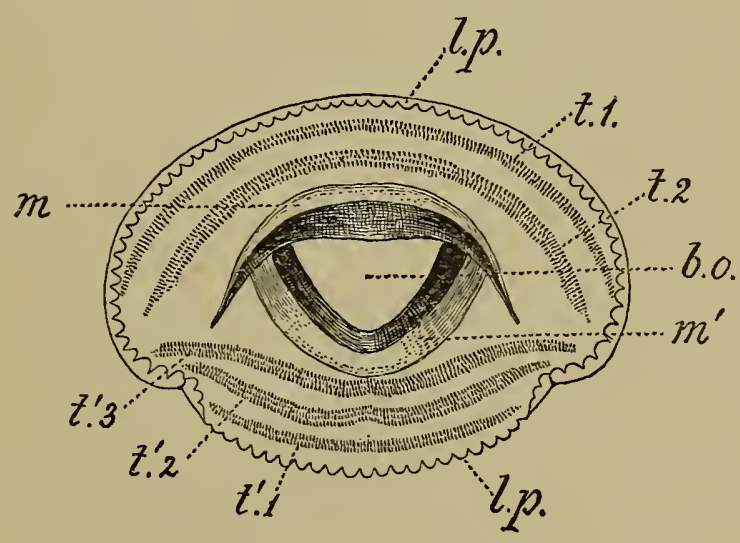

B

Open mouth of-A. Pelodytes punctatus. B. Alytes obstetricans. b.o. Buccal orifice. l.p. Labial papillæ. m. Mandibles. $t$. Series of labial teeth. (From 'P. Z. S.,' 1891.) 
extremely difficult to discern the limit between the two. The term "body" is, therefore, used in the description as meaning both head and body. Its longitudinal measurement is taken to the origin of the hind limbs. The tail consists of a flesby muscular portion bordered above and below by membranous expansions, termed respectively the upper and lower crest. By depth of the tail is meant its greatest depth, crests included, and the length is measured from the posterior extremity of the body.

Mouth (Fig. 42). - This term is used in its wider sense, $i$.e. to include the much-dereloped lip surrounding, like a funwel directed downwards, the horny beak, not unlike that of a cuttle-fish, which forms the entrance to the mouth proper. The character's offered by this circular lip are among the most important for the distinction of species. The lip may be entirely bordered by fleshy papillæ (7.p.), or these may be re-

FIG. 43 .
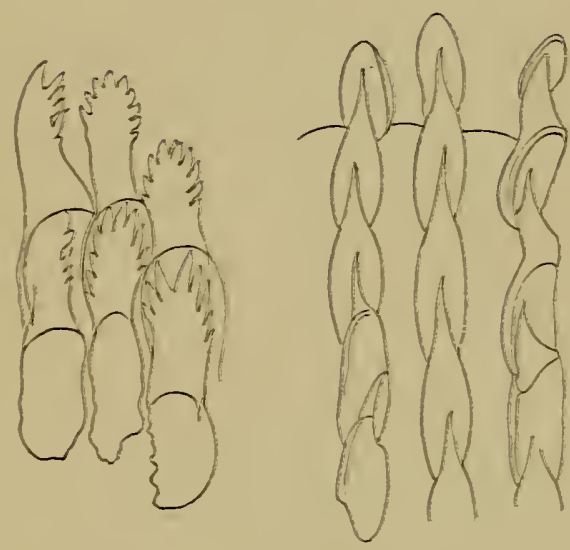

A

$\mathrm{B}$ stricted to the sides, or to the sides and the lower border. Its inner surface is furnished with ridges armed with series of minute bristle-like erect horny teeth $(t)$, each of which, when strongly magnified, is seen to be formed of a column of superposed cones, hollowed out at the base and capping each other (Fig. 43); the summit or cromn of each of these cones is expanded, spatuHorny teeth of Rana agilis (i) and Pelobates fuscus (B). (After Van Bambeke.)

late, hooked backwards, and usually multicuspid. The denticles are absent in Pelobates and Pelodytes, and present in all the other genera. The number of these columns is rery great. F. E. Schulze has counted as many as 1100 in the lip of Pelobates fuscus. 
By drawing an imaginary line across between the mandibles the lip may be divided into an upper and a lower portion, the series of teeth above the upper mandible being termed upper labial, those below the lower mandible being lower labial. These are described as first, second, third, \&c., proceeding from the outer border towards the beak in both the upper and lower sections of the lip, as shown in the accompanying figures (p. 99). Each series is reckoned as one, whether continuous or more or less interrupted in the middle; this method being far more simple, and at the same time more correct, considering the great amount of individual variation, than those used by some authors who distinguish between "median" and "lateral" series, according as to whether or not the. series is broken up in the middle. The first series, either in the upper or lower division of the lip, may be marginal (Fig. 42, A, t.1), or it may be within the border, which is then occupied by fleshy papillæ (Fig. 42, B). The arrangement of the series is expressed by a formula- $\frac{2}{3}$, for instance, indicating the number in the upper and lower divisions, the figures being separated by a transverse line corresponding to the position of the horny beak. The labial teeth are usually arranged in a single row on each ridge (Fig. $42, \mathrm{~A})$; in the Discoglossidre, however, each ridge, or at any rate the second, bears two or even three rows of teeth (Fig. 42, B). The beak itself is made up of horny elements like the labial teeth; its edge, when sufficiently magnified, is seen to be denticulate, each denticle representing the cusp of a single tooth.

The inside of the mouth and the pharynx (Fig. 44) are beset with long pointed mucous papillæ, "tasteorgans" of F. E. Schulze, the longest of which border the choanæ $(c h)$, one in front and one behind, and are followed by a pair with a denticulate fold between them ; a cushion-like, hemispherical swelling $(t)$ represents the tongue, on the anterior border of which a pair of papillæ are inserted. A broad cleft with 
denticulate anterior fold leads into the branchial chambers $(b r)$, which contain the four branchial arches.

FIG. 44.

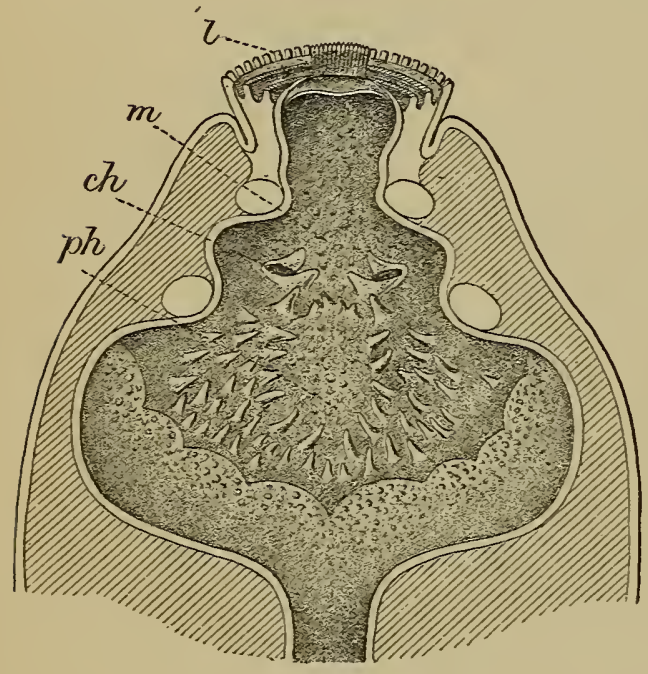

A

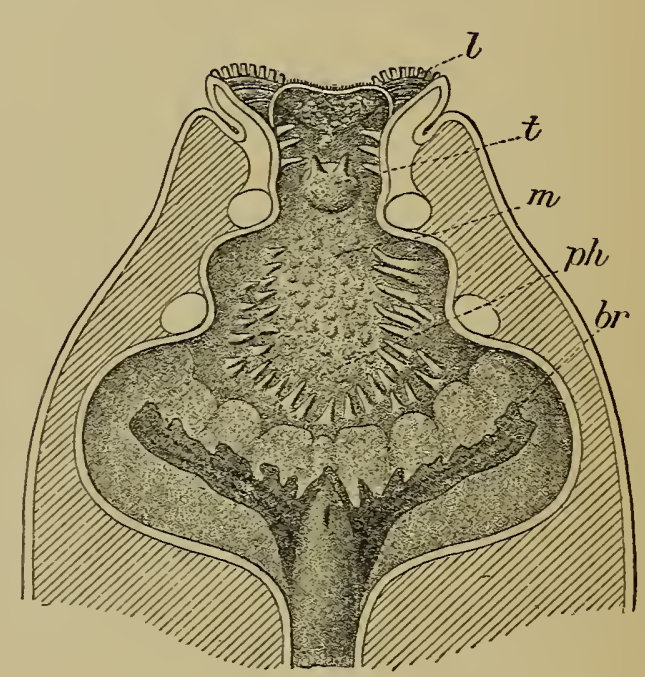

B

Transverse section through the head of larval Pelobates fuscus.

(After Schulze.) A. Upper part. B. Lower part. br. Bran-

chial chambers. ch. Choanæ. l. Lip. m. Mouth. ph. Pharynx.

$t$. Tongue.

These arches bear on the convex outer side the delicate arborescent gills, and on the concave inner side develop a membranous septum with vermicular perforations, a special sifting or filtering contrivance through which the water absorbed by the mouth has to pass before reaching the respiratory organs of the branchial apparatus.

Spiraculum.-The water is expelled from the branchial chambers by one or two tubes opening by one orifice in all European Batrachians. This orifice is the spiraculum. In the Discoglossidæx two tubes are present, which gradually converge towards each other at the end of the first period of development, as shown on Fig. 41, p. 98, and in the tadpole proper discharge through one transverse, slit-like or crescentic opening, situated in the middle of the breast (Fig. 45, A, sp.). In all other tailless Batrachians the tube is single, and 
opens on the left side, straight backwards in Bufo, backwards and upwards in the other genera (Fig. 45, в, sp. ; Fig. 46, А, в).

FIG. 45.

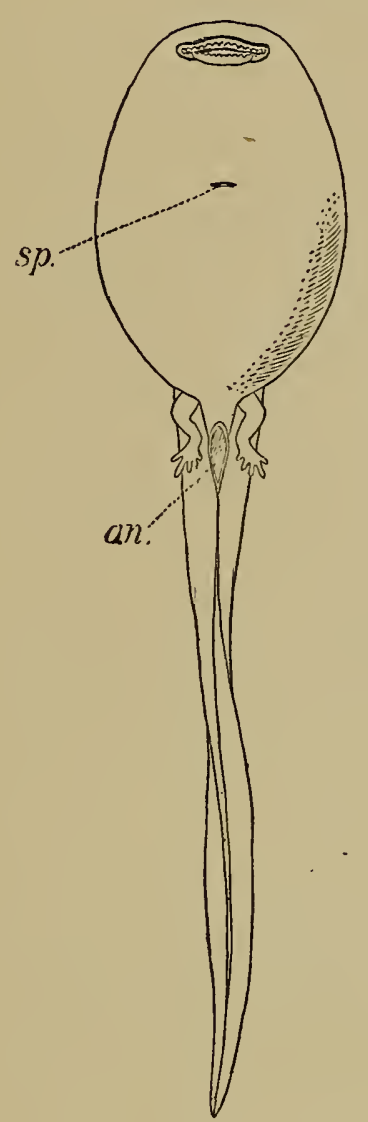

A

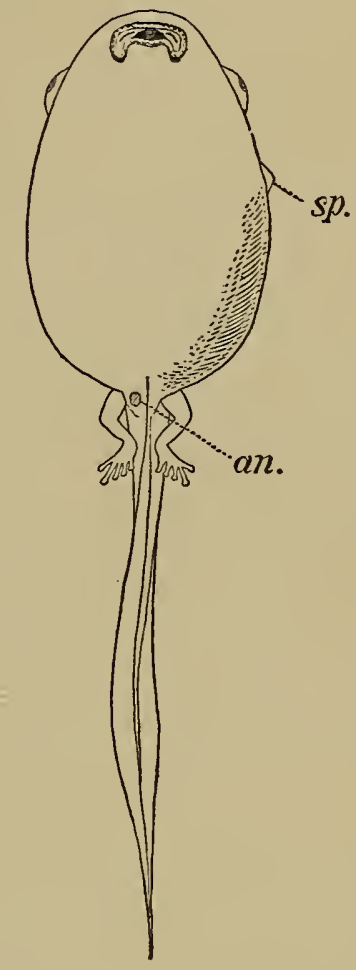

B

Lower view of tadpoles of-A. Alytes obstetricans. B. Hyla arborea. (From 'P. Z. S.,' 1891.)

The Lines of Muciferous Crypts or Sensory Canals.All tadpoles are provided with these organs, the homologues of the lateral line in fishes ; they stand in immediate relation to the nerve branches, and are regarded as organs of a special sense possessed by aquatic animals, feeling, in its broadest sense, having been admitted as their possible use, and the function of determining waves of vibration in the aqueous medium having been suggested. The surface openings of these tubules or canals form lines which may differ greatly 
as regards their degree of development in individuals of the same species, and their arrangement also varies, within certain limits, irrespective of the species. I

FIg. 46.
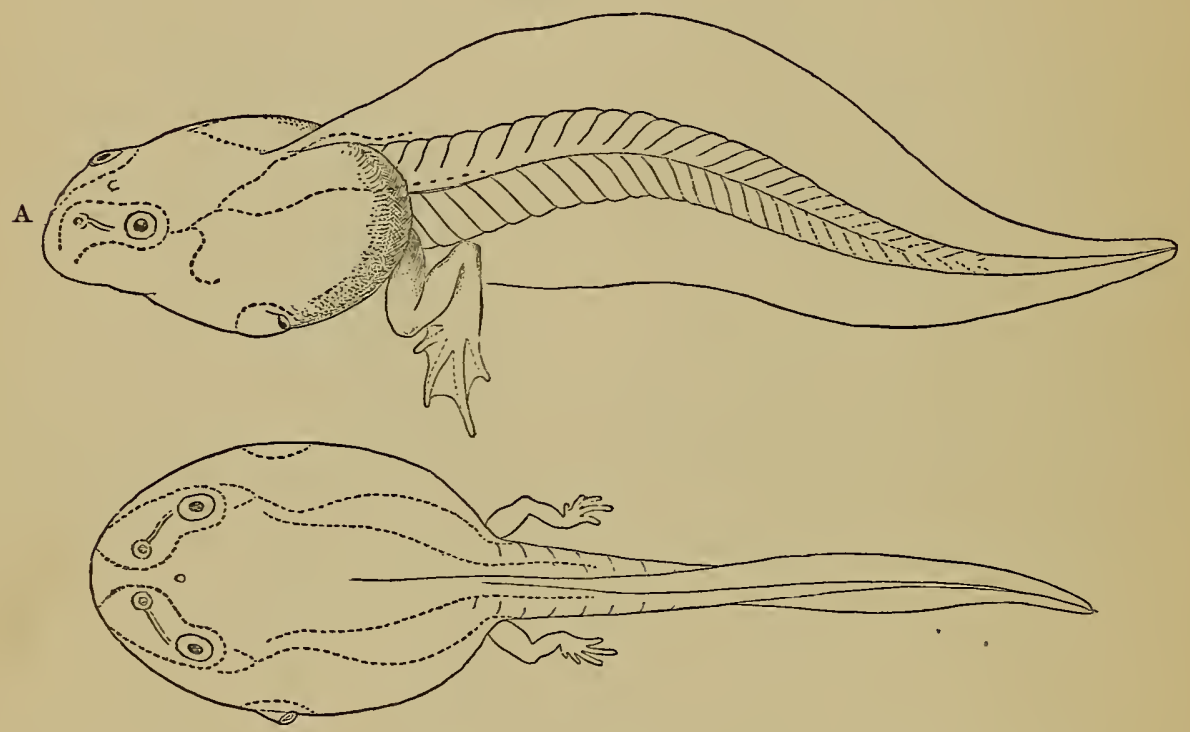

B
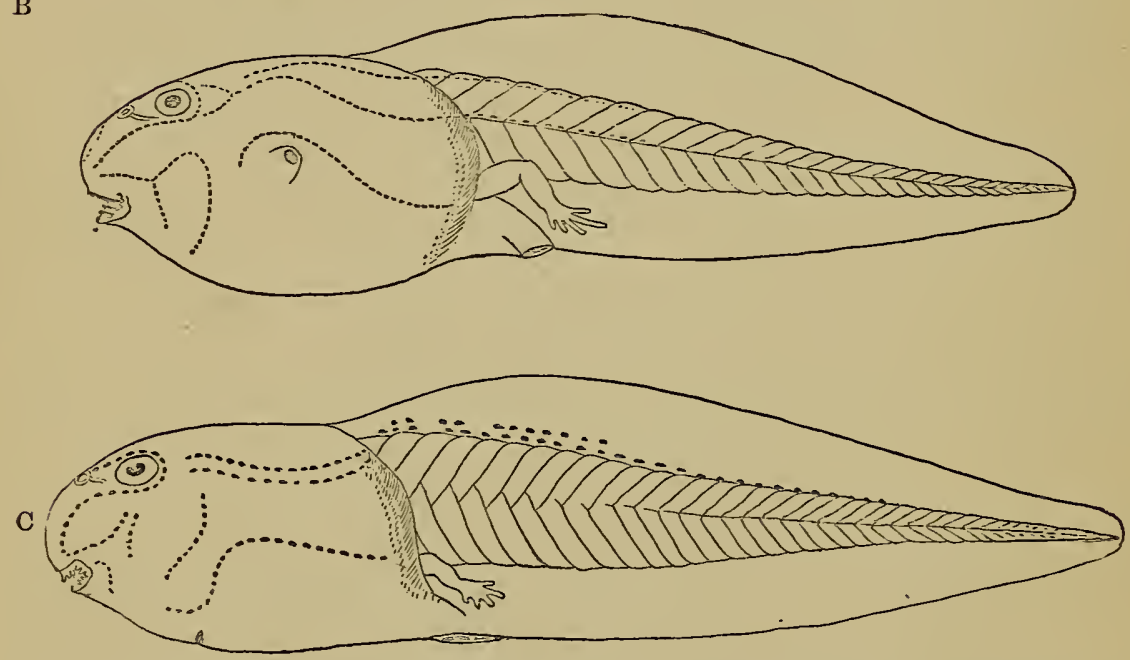

Tadpoles showing sensory canals. A. Rana agilis. B. Pelodytes punctatus. c. Alytes obstetricans. (From 'P. Z. S.,' 1891.)

have found them usually most distinct in Pelodytes, Pelobates cultripes, Rana agilis, R. latastii, and Bombinator igneus; least in Bufo. I append figures (Fig. 46) of tadpoles of Rana agilis, Pelodytes punctatus, 



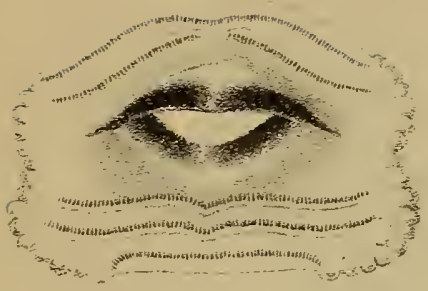

$4 a$.

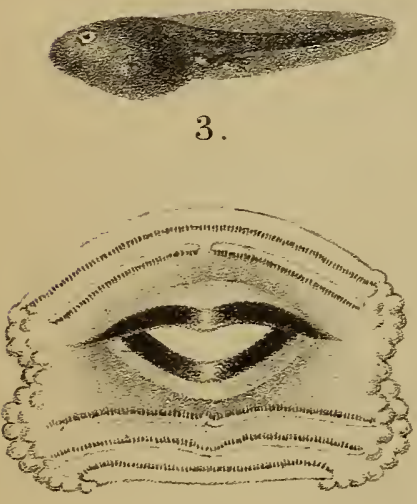

$3 a$.

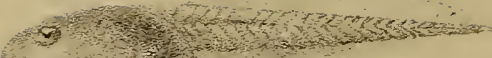

4.

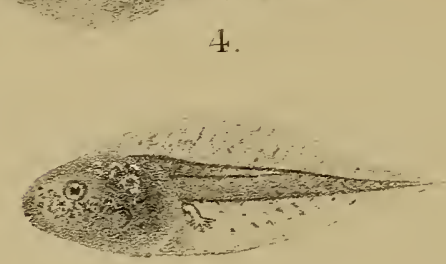

8

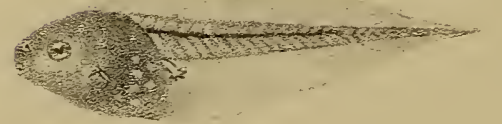

7.

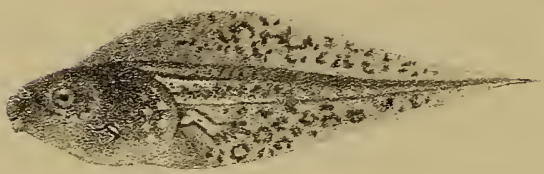

6.

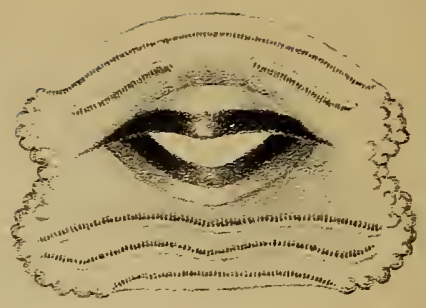

52.

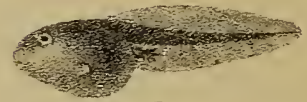

5.

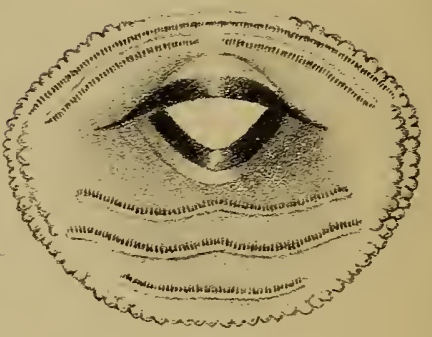

$6 a$.
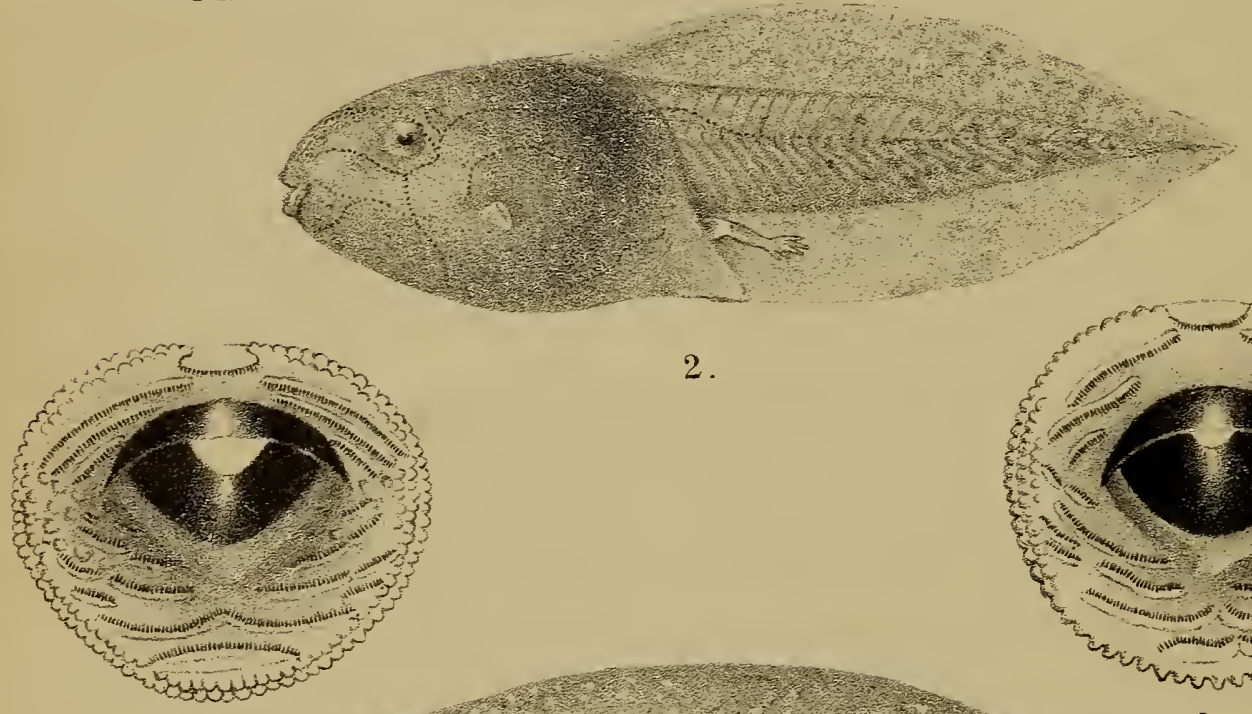

2.

12.
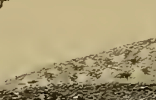

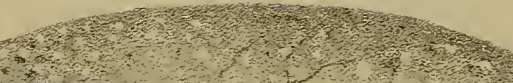

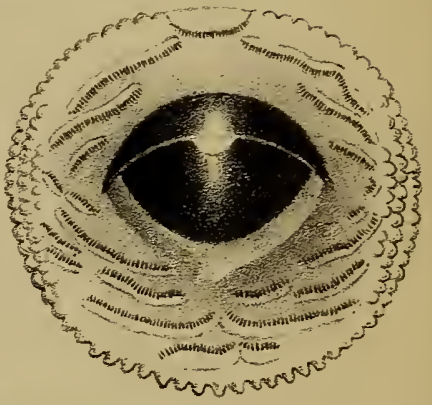

$2 a$.

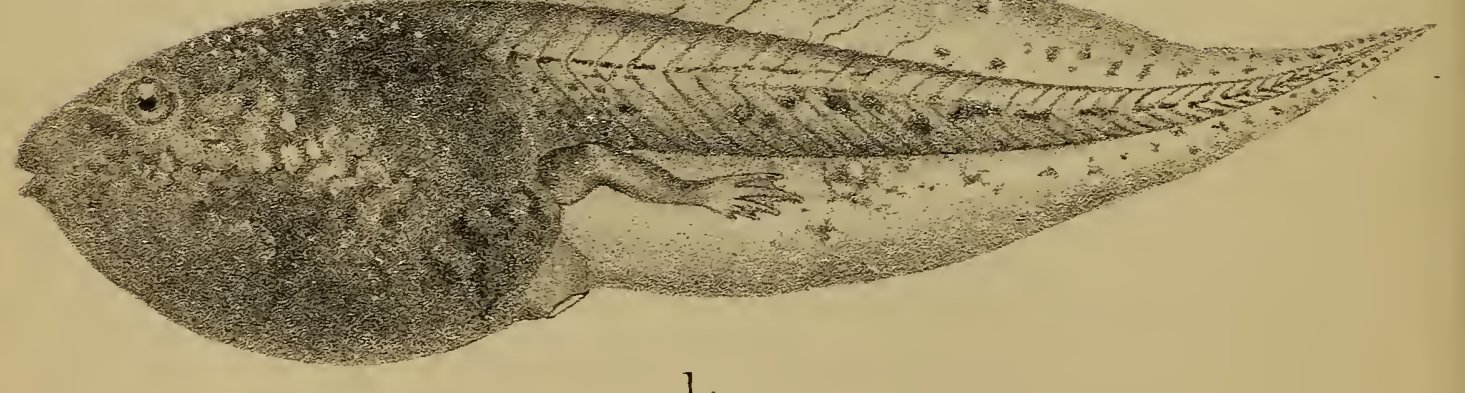

1.

Tadpotes.

Pelotates BBufor Honyta. 
and Alytes obstetricans, in which these organs are represented by dotted lines. In addition to these lines, all tadpoles show more or less distinctly a small whitish gland in the middle of the head between the eyes, the so-called frontal gland or pineal gland, which in early stages is connected with the brain. A glandular streak extending from the nostril towards the eye is the lachrymal canal.

The presence of a number of pulsating lymph-sacs has lately been discovered by Weliky on each side of the dorsal caudal crest.

Pigmentary Netuork. - In addition to the ordinary pigment-cells, the tadpoles of a few genera (Discoglossus, Bombinator, Pelodytes) present a system of fine black lines, most apparent on the caudal crests and the more feebly pigmented parts of the body, which afford excellent characters for their identification. It is a fact worthy of notice that when the end of the tail has been injured these pigmentary lines are not reproduced on the regenerated portion. Their aspect is shown in the following figures (from 'P. Z. S.,' 1891), representing much-enlarged pieces of the upper caudal crest of Pelodytes (A) and Discoglossus (в).

FIG. 47.

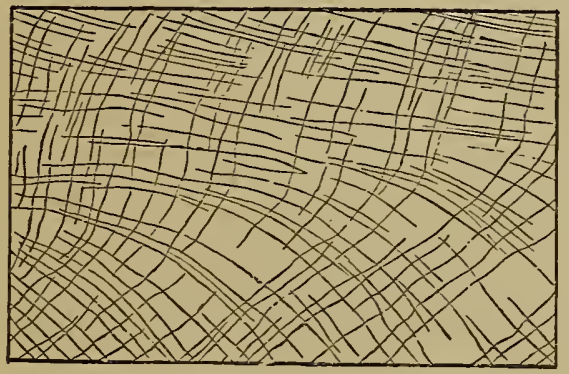

A

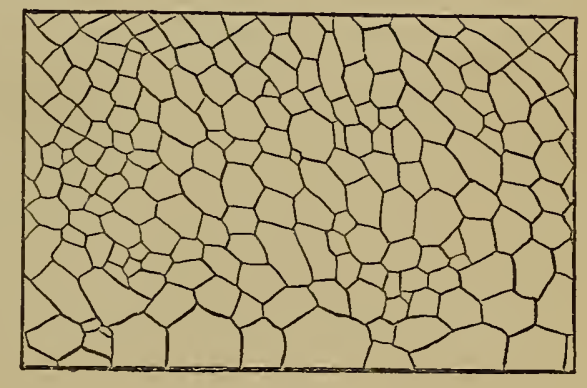

B

The following key has been drawn up to facilitate the identification of the genera and species in the tadpole condition.

I. Spiraculum median; anus median; tail rounded or obtuse at the end; a papillose edge all round 
the lip, sometimes narrowly interrupted above; labial teeth in $\frac{2}{3}$ series, disposed in two or three rows, at least in the second series.

A. Spiraculum equally distant from the anterior and the posterior extremity of the body; tail at least once and a half the length of the body, and three and a half or four times as long as deep; caudal crests with a polygonal network of fine black lines . . Discoglossus.

B. Spiraculum nearer the posterior than the anterior extremity of the body; tail not more than once and a half the length of the body, twice to twice and a half as long as deep; caudal crests with fine black decussating lines.

BuMBINATOR.

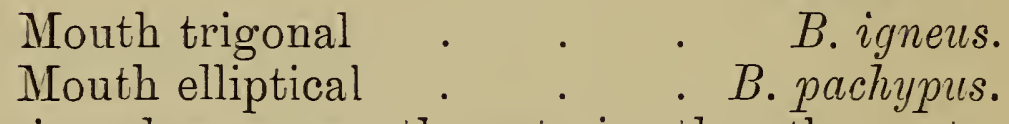

c. Spiraculum nearer the anterior than the posterior extremity of the body; tail at least once and a half the length of the body, twice and two-thirds to thrice and a half as long as deep; no black network . . Aurtes.

II. Spiraculum sinistral; labial teeth disposed in a single row in each series or ridge.

A. Anus median.

1. Spiraculum directed upwards and backwards; lower lip bordered with papillæ; series of labial teeth $\frac{4}{4}$ or $\frac{5}{5}$.

a. Tail obtusely pointed, with fine black decussating lines; an inverted fold on each side of the lip, the upper edge of which bears a long series of teeth; beak white with black edge . . PelodY'tes.

b. T'ail acutely pointed, without black lines; first series of upper labial teeth short; beak entirely black. . Philobates. T'ail once and a half to twice as long as the body . . . P.fuscus. 
Tail not more than once and a half as long as the body . . . P. cultripes.

2. Spiraculum directed straight backwards, tail rounded at the end; both upper and lower lip with toothed edge; series of labial teeth $\frac{2}{3}$. . . . Bufo. Mouth at least as wide as the interocular space, which is twice as great as the distance between the nostrils; second upper series of labial teeth very narrowly interrupted in the middle. $B$. vulgaris. Mouth nearly as wide as the interocular space, which measures once and a half the distance between the nostrils; second upper series of labial teeth more or less interrupted in the middle . . B. viridis. Mouth considerably narrower than the interocular space, which is nearly twice as great as the distance between the nostrils; second upper series of labial teeth very widely interrupted in the middle.

B. calamita.

B. Anus dextral ; spiraculum directed backwards and upwards; lower lip bordered with papillæ.

1. Anus opening above the lower edge of the tail; upper caudal crest extending far forwards on the back, almost to between the eyes, which are lateral and visible from the ventral as well as from the dorsal aspect of the body; series of labial teeth $\frac{2}{3}$

HyLa.

2. Anus opening close to the lower edge of the tail; upper caudal crest not extending forwards beyond the vertical of the spiraculum; eyes on the upper surface. RaNa. a. Series of labial teeth $\frac{2}{2} \frac{\text { or }}{3} \underline{3}$.

Interocular space at least twice the distance between the nostrils, and much greater 
than the width of the mouth; tail acutely pointed, at least nearly twice as long as the body . . . . R.esculenta. Interocular space but little wider than the distance between the nostrils or the width of the mouth; tail once and two-thirds to trice as long as the body . R. arvalis.

$b$. Series of labial teeth $\frac{3 \text { to } 5}{4}$.

$a$. Tail obtusely pointed, once and a half to twice as long as the body.

Second series of upper labial teeth widely interrupted in the middle; first series of lower labial teeth at least two-thirds the length of the second; width of mouth a little less than the interocular width, which equals about once and a half the distance between the nostrils. R. temporaria. Second series of upper labial teeth continuous or narrowly interrupted; first series of lower labial teeth at least two-thirds the length of the second; width of mouth quite as great as the interocular space, which equals about once and a half the distance between the nostrils . R. græca.

Second series of upper labial teeth widely interrupted in the middle; first series of lower labial teeth hardly half as long as the second; width of mouth much less than the interocular space, which equals nearly twice the distance between the nostrils . . . . R. iberica. $\beta$. Tail acutely pointed or submucronate, at least nearly twice as long as the body.

Interocular space once and a half the width of the mouth or the distance between the nostrils; no tubercle on the upper mandible. . . . . R. latastii.

Interocular space at least twice the width of 
the mouth or the distance between the nostrils; usually a black tubercle on the upper mandible . . . R. agilis.

With regard to size, the tadpoles rank as follows:

Maximum length on record. Millimetres.

1. Pelobates fuscus . . . . . . 175

2. " cultripes. . . . . . 120

3. Rana esculenta. . . . . . . 111

4. Alytes obstetricans . . . . . . 90

5. , cisternasii . . . . . . 69

6. Pelodytes punctatus. . . . . . 65

7. Rana agilis . . . . . . . . 59

8. Bombinator igneus . . . . . . 50

9. Hyla arborea . . . . . . . 49

10. Rana iberica. . . . . . . . 49

11. „, græca. . . . . . . . . 48

12. " temporaria . . . . . . 46

13. Bomlinator pachypus . . . . . 45

14. Bufo viridis . . . . . . . . 44

15. Rana latastii . . . . . . . 44

16. ", arvalis . . . . . . . 43

17. Discoglossus pictus . . . . . . 33

18. Bufo vulgaris . . . . . . . 32

19. , calamita . . . . . . . 30

But if we compare the maximum length of the tadpole with the maximum length of the adult, we obtain the following order :

$$
\begin{aligned}
& \text { Maximum } \\
& \text { length of adult from } \\
& \text { snout to vent. } \\
& \text { Millimetres. }
\end{aligned}
$$

1. Pelobates fuscus . . . . . . . 80

2. Alytes obstetricans . . . . . . 54

3. ", cisternasii. . . . . . . 40

4. Pelobates cultripes . . . . . . . 88

5. Pelodytes punctatu.s . . . . . . 45

6. Bombinator igneus . . . . . . 50 
Millimetres.

7. Hyla arborer. . . . . . . . 50

8. Rana iberica . . . . . . . . 50

9. Bombinator pachypus . . . . . 50

10. Rana esculenta . . . . . . . 125,

11. „, græea . . . . . . . . 66

12. ,, agilis . . . . . . . . 90

13. , latastii. . . . . . . 65

14. ", arvatis. . . . . . 75

15. ,, temporaria . . . . . . 95

16. Bufo viridis . . . . . . . . 90

17. Discoglossus pictus . . . . . . 75

18. Bufo calamita. . . . . . . . 80

19. ,, vulgaris. . . . . . . . 180

It may be noticed that the fire species which head the list as having proportionally the largest tadpoles are the only ones in which the pupil is vertical.

The structural differences which separate the genera and species in their tadpole condition reflect, on the whole, pretty accurately the system based upou the perfect animals, although here and there the modifications are of unequal importance. We must bear in mind, however, that such a correspondence, if existing in the European Batrachians, is not universal. Larval forms such as the tadpoles are outside the eycle of recapitulation, the ontogeny being broken by the intercalation of the larval phasis. The horny beak, the circular lip with its horny armature, the spiraculum, the enclosure of the fore limbs in diverticula of the branchial chambers, and such special adaptations as the ventral disk or sucker of certain exotic mountain forms, clearly point to tadpoles having had a developmental history of their own. We need, therefore, not be surprised at occasionally finding, within the same genus, very different types of tadpoles, or even a total suppression of the free larval stages, as is actually the case in the large and widely distributed genus Rana. 



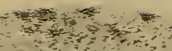

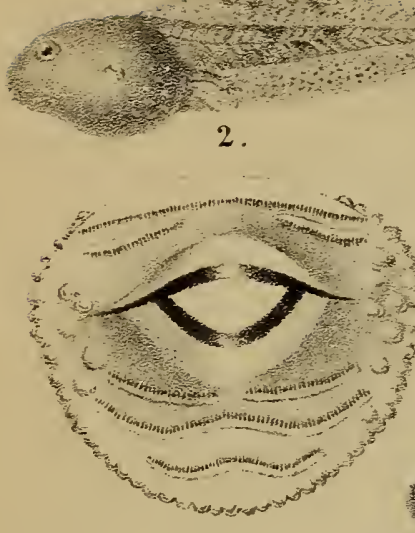

2 a.

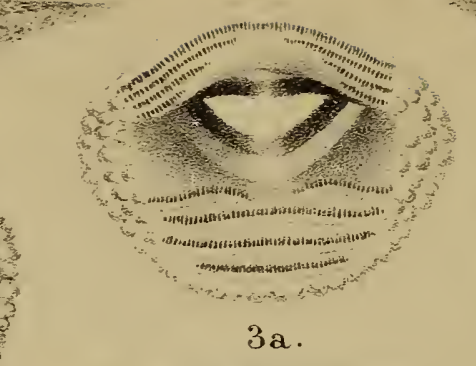

$3 a$.

3. (4) 1 2) (3)

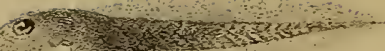

H.

3.

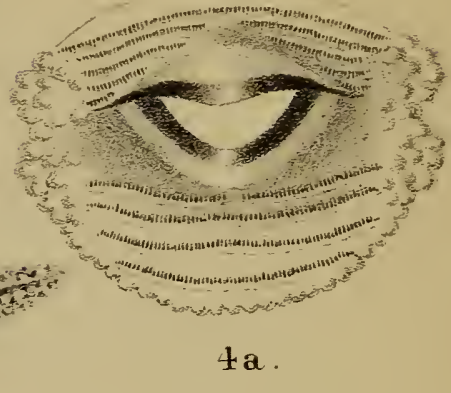

4 .

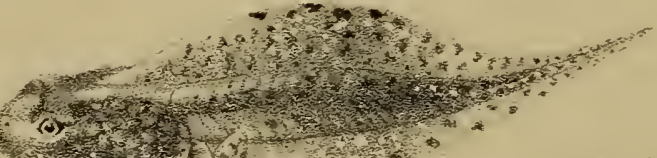

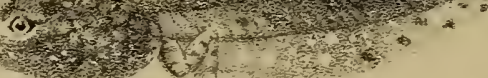

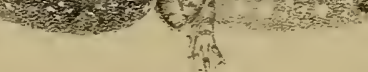

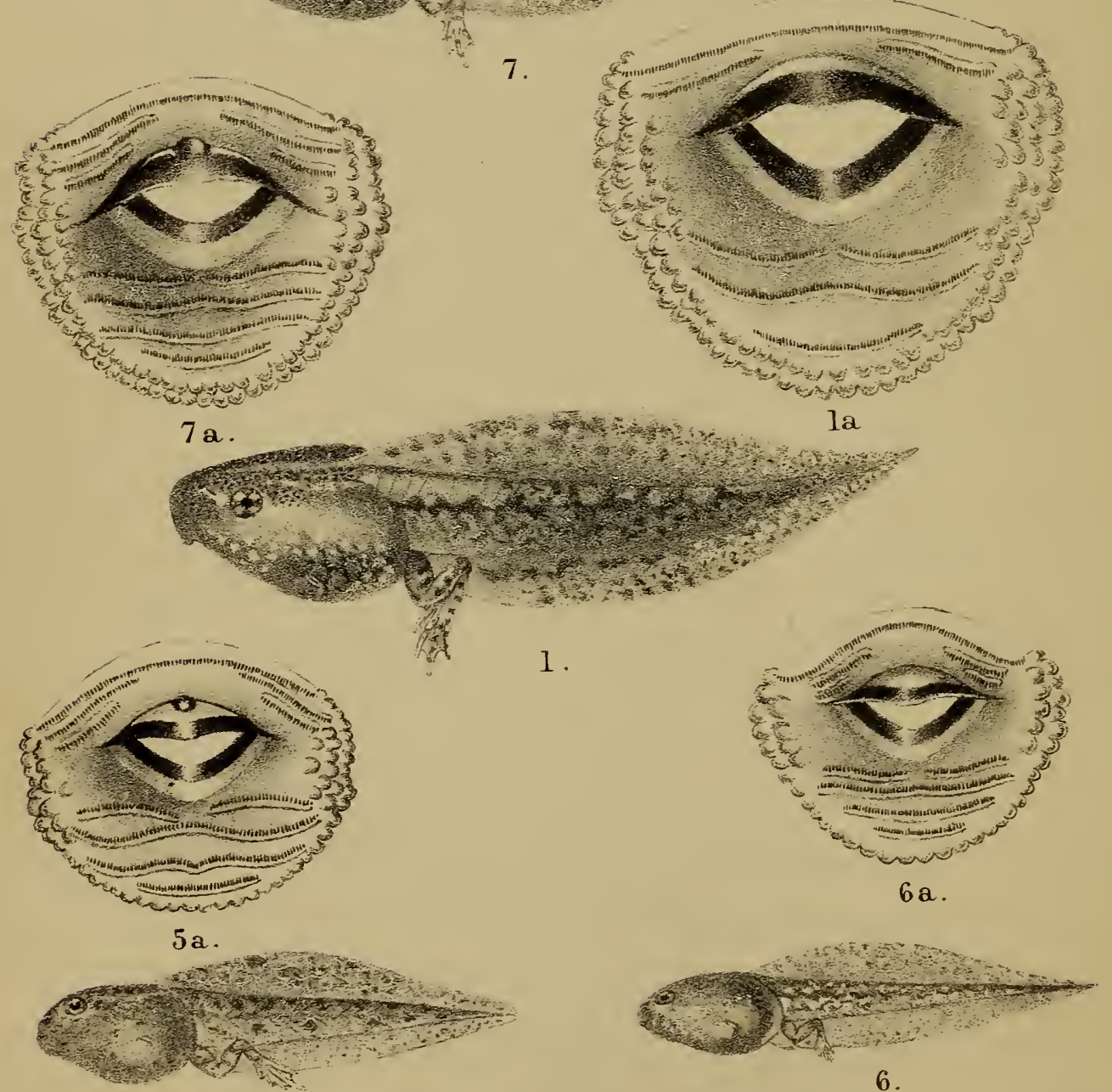

5 . 
The tadpoles are represented, of the natural size, on Pls. I, II, and III. The mouth $(a)$ is enlarged five diameters in figs. 1 and 2, Pl. II ; seven diameters in fig. 4, Pl. I; fifteen diameters in figs. 3 and 5, Pl. II, and fig. 1, Pl. I; ten diameters in the rest.

\section{PLATE I.}

Fig. 1. Discoglossus pictus. Montecristo.

, 2. Bombinator igneus. Seelaud, Denmark.

"3. - pachypus. Mondorf, Luxemburg.

„4. Alytes obstetricans. St. Germain, near Paris.

" 5. - - var. boscæ. Sierra Estrella.

, $6 . \quad$ - cisternasii. Sierra Morena.

„7, 8. Peloclytes punctatus. Near St. Malo.

\section{PLATE II.}

Fig. 1. Pelobates fuscus. Prague.

"2. - cultripes. Near Bordeaux.

" 3. Bufo vulgaris. Near London.

"4. - viridis. Breslau.

" 5. - calamita. Near St. Malo.

"6, 7. Hyla arborea. Near St. Malo.

$\therefore$ 8. - - var. meridionalis. Near Nice.

\section{PLATE III.}

Fig. 1. Rana esculenta. Near St. Malo.

, 2. - arvalis. Breslau.

", 3. - temporaria. Near London.

"4. - græca. Parnassos.

"5. - iberica. Coimbra.

, 6 . - latastii. Italy.

"7. - agilis. Near St. Malo. 


\section{Hybrids.}

The fact, so often observed, that pairing takes place between different species-as, for instance, between Rana temporaria and Bufo vulgaris, Rana temporaria and Pelobates fuscus, Pelodytes punctutus and Hyla arborea - has long ago given rise to the supposition that hybrids are occasionally produced. At the end of the last century, Spallanzani, after his successful experiments on artificial fecundation, attempted to raise hybrids between species of Rana, Bufo, and Hyla, but without results.

Experiments were again instituted, from 1867 to 1872 , by A. de l'Isle, who tried to hybridise the French species of Rana and Bufo. The difficulty of such experiments is rery great, owing to the diversity in the breeding season of the different species. Nevertheless de l'Isle succeeded in procuring suitable examples of three species of Rana, and artificially impregnated ova of Rana esculenta and $R$. agilis with the semen of $R$. temporaria, and ova of Rana temporaria with the semen of the two others. The experiments, several times repeated, gave a negative result, which the author attributes to the very considerable difference between the genital organs of even so closely allied species as $R$. temporaria and $R$. agilis. But with Bufo vulgaris and B. calamita, which, although morphologically more widely separated, have almost identical genitalia, positive results were obtained, although the development did not proceed beyond the tadpole condition.

A few years later, in 1877 and 1878, the subject was again taken up by Lataste, who succeeded in fertilising eggs of Pelobates fuscus with the semen of $P$. cultripes. But the few tadpoles obtained were monstrous or dropsical, and not one survived to develop the limbs. 
Experiments, conducted with the greatest care, were instituted by Pflïger in 1882 . He was able to show that different degrees exist in the action of the spermatozoa upon the ova of different species. Thus the spermatozoon of a newt (Molge alpestris, M. vulgaris) acted upon the ovum of Rana temporaria to the extent of producing a very irregular segmentation; other cross-fertilisations between various frogs and toads extended to the formation of an embryo, of a tadpole, or finally of a perfect Batrachian. These interesting experiments were continued by Pflüger and W. J. Smith in 1883, and by Born in 1883 and 1884.

At first Pflüger absolntely failed in crossing Rana temporaria and $R$. arvalis, but ultimately both he and Born succeeded in obtaining a few perfect hybrids $(R$. temporaria os $\times R$. arvalis of). Born also obtained perfect hybrids of Bufo vulgaris and B. viridis crossed in both directions; and, what is more extraordinary, a ferw embryos, which did not develop beyond the hatching period, from eggs of Rana esculenta fecundated by Bufo viridis.

More extraordinary still is a case mentioned by Héron-Royer. In March, 1881, he found a male Rana temporaria pairing with a Pelobates fuscus which had begun to spawn. Having brought home the short band of eggs, he was much surprised to see them develop quite normally, and ultimately produce larræ which were indistinguishable from those of Rana temporaria; and two that survived transformed into normal specimens of $R$. temporaria. I cannot help thinking that some confusion must have taken place: may not, somehow or other, embryos of $R$. temporaria have been substituted whilst Héron-Royer was observing their development?

Hybrids between two closely allied species, Bombinator igneus and B. pachypus, were obtained by Héron-Royer, and a second generation was produced by crossing these hybrids with individuals of the latter species. It also appears from remarks made 
by v. Méhely that, in the few localities where the two species co-exist, intermediate specimens occur which are no doubt to be regarded as hybrids.

As to the supposed hybrids between Rana esculenta and temporaria, noticed by Schlotthauber and others, they are nothing but $R$. arvalis, a species which is in many respects intermediate between the two supposed parents, and with which the authors in question do not seem to have been well acquainted.

Hybrid embryos between Rana esculenta and $R$. arvalis appear to have been recently obtained by $\mathrm{W}$. Gebhardt.

So-called hybrids between Hyla arborea and $H$. meridionalis (barytonus), and Bufo viridis and $B$. arabicus, obtained by Héron-Royer, are only mongrels, as I do not consider the specific distinctions justified. 
XV. Geographical Distribution.

'The Western Palæarctic sub-region, to which Europe, together with South-western Asia north of the 30th parallel, and Africa north of the Sahara, belongs, is characterised by the development of the Discoglossidx and Pelobatidx, the former family being represented outside its limits by a single species in Manchuria, Corea, and Northern China (Bombinator orientalis), and another (Liopelma hochstetteri) in New Zealand, of which it is the only Batrachian representative; whilst the latter, absent from the Eastern Palæarctic sub-region, is again abundant in Southern China, the Eastern Himalayas, Further India, the Malay Archi. pelago and Papuasia, North America, and Mexico.

The Bufonidx, Hylidx, and Ranidre, of each of which the type genus is represented in Europe, are families of very extensive distribution. The first is found all over the world except in Madagascar and Australia; the second is absent from Africa south of the Sahara, Madagascar, India, and the Malay Peninsula and Archipelago west of the Moluccas and Sumba; and the third is absent from Australia (with the exception of a single Papuan species found at Cape York) and the greater part of South America.

Five species have a very wide range in the Palæarctic region. Three extend from Western Europe and North Africa to China and Japan, viz. Bufo vulgaris, Hyla arborea, Rana esculenta; Rana temporaria ranges from Western Europe to the Pacific coast of Northern Asia and Yesso, and Bufo viridis from the Rhine and Alps, and North-west Africa to Mongolia, Western China, and the Himalayas.

Of the species which are known to inhabit more than one country, three may be regarded as strictly Western, viz. Discoglossus pictus, Pelodytes punctatus, and Pelobates cultripes. Bufo calamita and Alytes obstetricans may also be described as Western forms, 
generally distributed over France and the Spanish Peninsula, becoming gradually more local and scarcer east of the Rhine, and not extending into Russia nor south of the Alps.

As Eastern forms we may regard Bombinator igneus, Bufo viridis, and Rana arvalis, which do not extend to Belgium and France, although in North Africa Bufo viridis reaches the Atlantic coast of Morocco, Rana camerani (Caucasus, Armenia, North-west Persia), and Rana græca (Greece, Bosnia, Italy). Pelobates fuscus is characteristic of Central Europe.

Bombinator pachypus and Rana agitis have an extensive but somewhat irregular distribution, being absent from the north aud north-east and the Pyrenean Peninsula.

Three species have a very restricted range, viz. Alytes cisternasii (Pyrenean Peninsula), Rana iberica (Pyrenean Peninsula), and Rana latastii (Italy).

Rana temporaria may be regarded as a northern species, reaching the extreme north and disappearing, or confined to the mountains, in the south; whilst Rana esculenta and Hyla arborea extend very far south, and are absent from the extreme north.

With regard to the range from north to south, the twenty species may be classed in the following order:

1. Rana temporaria.

Northern limit.

2. Bufo vulgaris . . . . . . . . 65

3. Rana arvalis . . . . . . . . 60

4, 5. \{Rana esculenta. . . . . . . 59

, Pelobates fuscus . . . . . . 59

$6,7\{$ Bufo vividis . . . . . . . 58

6,7. Bufo calamita. . . . . . . 58

8. Hyla arborea . . . . . . . . 57

9. Bombinator igneus . . . . . . 56

10. Bombinator pachypus . . . . . 53

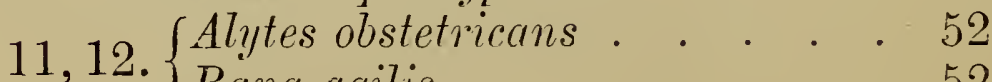

Rana agilis . . . . . . . 52

13. Pelodytes punctatus . . . . . . 51 
14. Pelubates cultripes . . . . . . $48^{\circ}$

15. Rana latastii. . . . . . . . 46

16. Rana camerani . . . . . . . 45

17. Rana græea . . . . . . . . 44

18, 19. $\{$ Discoglossus pictus . . . . . 43

18,19. Rana iberica. . . . . . . 43

20. Alytes cistemasii. . . . . . . 41

From south to north the following order obtains:

Southern limit.

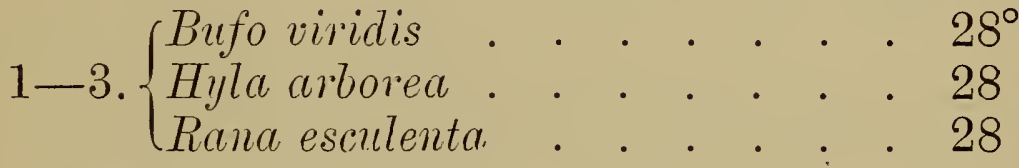

4. Discoglossus pictus . . . . . . 31

э. Bufo vulgaris . . . . . . . . 34

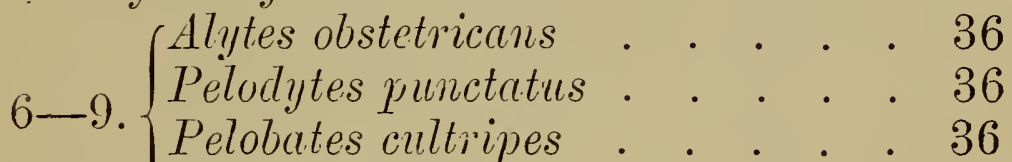

Pelobates cultipes • • • . . 36

Bufo calamita. . . . . . . 36

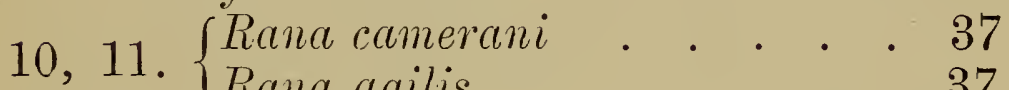

10, 11. Rana agilis. . . . . . . 37

12. Pelobates fuscus . . . . . . . 38

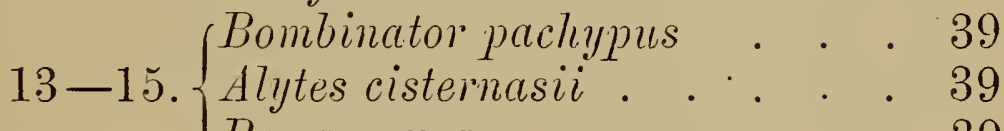

Rana græca . . . . . . . 39

16. Rana iberica . . . . . . . . 40

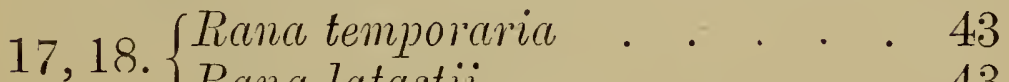

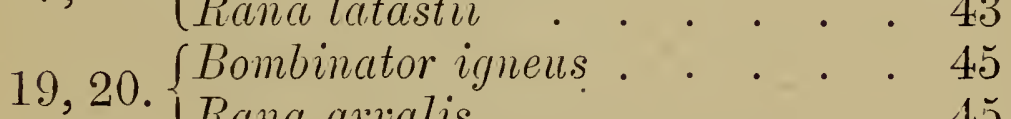

19, 20. TRana arvalis. . . . . . . 45

With regard to the vertical range, the species may be arranged in the following order:

Maximum elevation reached.

Feet.

1. Rana temporaria . . . . . 10000

2. Rana camerani . . . . . . 8000

3. Bufo vulgaris . . . . . . . 7000 
Feet.

4, 5. $\left\{\begin{array}{l}\text { Alytes obstetricans } \\ \text { Bufo viridis }\end{array}\right.$

6500

6. Rana græca

6500 *

7. Bombinator pachypus

5800

8. Runa iberica

5.500

9. Rana agilis .

4500

10. Bufo calamita . . . . . . 4000

11. Rana esculenta . . . . . 3500

12. Hyla arborea . . . . . . . 3300

The other species do not ascend to 3000 feet.

The following table shows the distribution in the different countries of Europe :

1. Discoglossus pictus

$\begin{array}{llllllllll}1 . & 2 . & 3 . & 4 & 5 & 6 & 7 & 8 & 9 & 10\end{array}$

2. Bombinator igneus

$\begin{array}{llllllllll}1 . & 2 . & 3 . & 4 & 5 & 6 & 7 & 8 & 9 & 10 . \\ \ldots & \ldots & \ldots & \ldots & \ldots & + & + & & & \\ \ldots & + & \ldots & \ldots & + & \ldots & \ldots & + & \ldots & + \\ \ldots & \ldots & + & + & + & \ldots & + & + & + & \\ \ldots & \ldots & + & + & + & + & \ldots & + & & \\ \ldots & \ldots & \ldots & \ldots & \ldots & + & & & & \\ \ldots & \ldots & + & \ldots & \ldots & + & + & & & \\ \ldots & + & + & + & + & \ldots & + & + & \ldots & + \\ \ldots & \ldots & + & \ldots & \ldots & + & & & & \\ + & + & + & + & + & + & + & + & + & + \\ \ldots & + & + & \ldots & + & \ldots & + & + & + & + \\ + & + & + & + & + & + & \ldots & \ldots & \ldots & + \\ \ldots & + & + & + & + & + & + & + & + & + \\ + & + & + & + & + & + & + & + & + & + \\ \ldots & + & \ldots & + & + & \ldots & \ldots & + & \ldots & + \\ \ldots & \ldots & \ldots & \ldots & \ldots & \ldots & \ldots & \ldots & \ldots & + \\ \ldots & + & + & + & + & + & + & + & + & + \\ \ldots & \ldots & \ldots & \ldots & \ldots & + & & & & \end{array}$

" pachypus.

Alytes obstetricans

6. Pelodytes punctatus

7. Pelobates fuscus

8. " cultripes.

9. Bufo vulgaris

10. ", viridis .

11. ., calamita

12. Hyla arborea

13. Rainc esculenta

14. ", arvalis.

15. " camerani

16. " temporaria.

17. „, græeca.

18. " iberica.

19. ", latastii.

20. " agilis.

1. Great Britain and Ireland.

2. Scandinavia and Denmark.

3. France.

4. Belgium and Holland.

5. Germany and Switzerland.

6. Spanish Peninsula.

7. Italy.

8. Austria-Hungary and Roumania.

9. Dalmatia, Bosnia, and countries south of the Danube.

10. Russia.

* 15,000 feet in the Himalayas. 
It may also not be without interest, in order to bring out their associations, to enumerate the species occurring in the environs ( $i . e$. a radius of about fifteen miles) of some of the principal towns the Batrachian fauna of which has been thoroughly searched by competent workers. It will be seen, then, that no district can boast of possessing more than ten out of the twenty recognised species, and that, in spite of their northern position, Paris and Bonn yield to no other and are richer than many more southern localities.

1. London (three species).

Bufo vulgaris, B. calamita, Rana temporaria.

2. Copenhagen (nine species).

Bombinator igneus, Pelobates fuscus, Bufo vulgaris, B. viridis, B. calumita, Hyla arborea, Rana esculenta, R. arvalis, R. temporaria.

3. Paris (ten species).

Bomlinator pachypus, Alytes obstetricans, Pelodytes punctatus, Pelobates fuscus, Bufo vulgaris, B. calamita, Hyla arborea, Rana esculenta, R. temporaria, R. agilis.

4. Bordeaux (nine species).

Bumbinator pachypus, Alytes obstetricans, Pelodytes punctatus, Pelobates cultripes, Bufo vulgaris, B. calamita, Hyla arborea, Rana esculenta, $R$. agilis.

כ. Brussels (five species).

Bufo vulgaris, B. calamita, Hyla arborea, Rana esculenta, R. temporaria.

6. Berlin (nine species).

Bombinator igneus, Pelobates fuscus, Bufo vulgaris, B. viridis, B. calamita, Hyla arborea, Rana esculenta, $R$. arvalis, $R$. temporaria.

7. Bonn (ten species).

Bombinator pachypus, Alytes obstetricans, Pelobates fuscus, Bufo vulgaris, B. viridis, B. calamita, Hyla arborea, Rana esculenta, $R$. arvalis, $R$. temporaria. 
8. Geneva (eight species).

Bombinator pachypus, Alytes obstetricans, Bufo vulgaris, B. calamita, Hyla arborea, Rana esculenta, $R$. temporaria, $R$. agilis.

9. Coimbra (ten species).

Discoglossus pictus, Alytes obstetricans, A. cisternasii, Pelodytes punctatus, Pelobates cultripes, Bufo vulgaris, B. calamita, Hyla arborea, Rana esculenta, $R$. iberica.

10. Turin (seven species).

Pelobates fuscus, Bufo vulgaris, B. viridis, Hyla arborea, Rana esculenta, $R$. latastii, $R$. agilis.

11. Palermo (five species).

Discoglossus pictus, Bufo vulgaris, B. viridis, Hyla arborea, Rana esculenta.

12. Vienna (ten species).

Bombinator igneus, B. pachypus, Pelobates fuscus, Bufo vulgaris, B. viridis, Hyla arborea, Rana esculenta, $R$. arvalis, $R$. temporaria, $R$. agilis.

13. St. Petersburg (three species).

Bufo vulgaris, Rana avealis, $R$. temporaria.

14. Moscow (eight species).

Bombinator igneus, Pelobates fuscus, Bufo vulgaris, $\dot{B}$. viridis, Hyla arborea, Rana esculenta, $R$. arvalis, $R$. temporaria.

And finally, in order to complete the sketch of the Geographical Distribution, a list is appended of all the tailless Batrachians known from other parts of the Palæarctic region in its widest sense, viz. North Africa and Asia north of the 30th parallel. Column A stands for North-western Africa, B for North-eastern Africa, C for South-western Asia, D for Northwestern and Central Asia, E for Eastern Asia with Tibet, and $\mathrm{F}$ for Japan. The names of species occurring also in Europe are prefixed with an asterisk. 
DISCOGLOSSIDE.

*Discoglossus pictus, Otth

Bombinator orientalis, Blgr.
A. B. C. D. E. F.

\section{$+$}

... $\quad \ldots \quad+$

\section{Pelobatide.}

Pelodytes caucasicus, Blgr.

*Pelobates fuscus, Laur.

, syriacus, Bttgr.

BUFONIDA.

*Bufo vulgaris, Laur.

", formosus, Blgr.

* ", viridis, Laux.

, raddii, Strauch

" mauritanicus, Schleg.

" regularis, Reuss

HYLID ж.

*Hyla arborea, L. . . . . . +++++ , stepheni, Blgr.. . . . . . . $\quad \ldots \quad \ldots \quad \ldots \quad \ldots++$

RANID五.

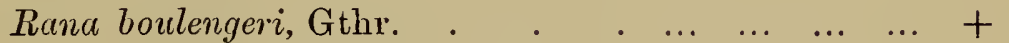

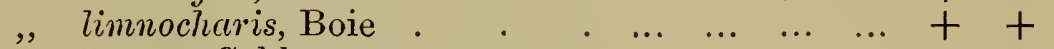

, rugosa, Schleg.

, esculenta, L.

, plancyi, Lat. provalis, Nilss.

* ,, comerani, Blgr.

,, macrocnemis, Blgr. .

"temporaria, $\mathrm{L}$

" cumurensis, Blgr.

, martensii, Blgr.

,, japonica, Blgr.

* ", agilis, Thom. .

, mascareniensis, D. \& B. .

, schmackeri, Bttgr.

Rhacophorus buergeri, Schleg. .

\section{"} davidi, Sauv.

, schlegelii, Gthr.

$$
\begin{array}{llllll}
+ & \ldots & + & + & + & + \\
\ldots & \ldots & \ldots & \ldots & \ldots & + \\
+ & + & + & + & + & \\
\ldots & \ldots & \ldots & \ldots & + & \\
+ & & & & & \\
\ldots & + & & &
\end{array}
$$




[At page 123.

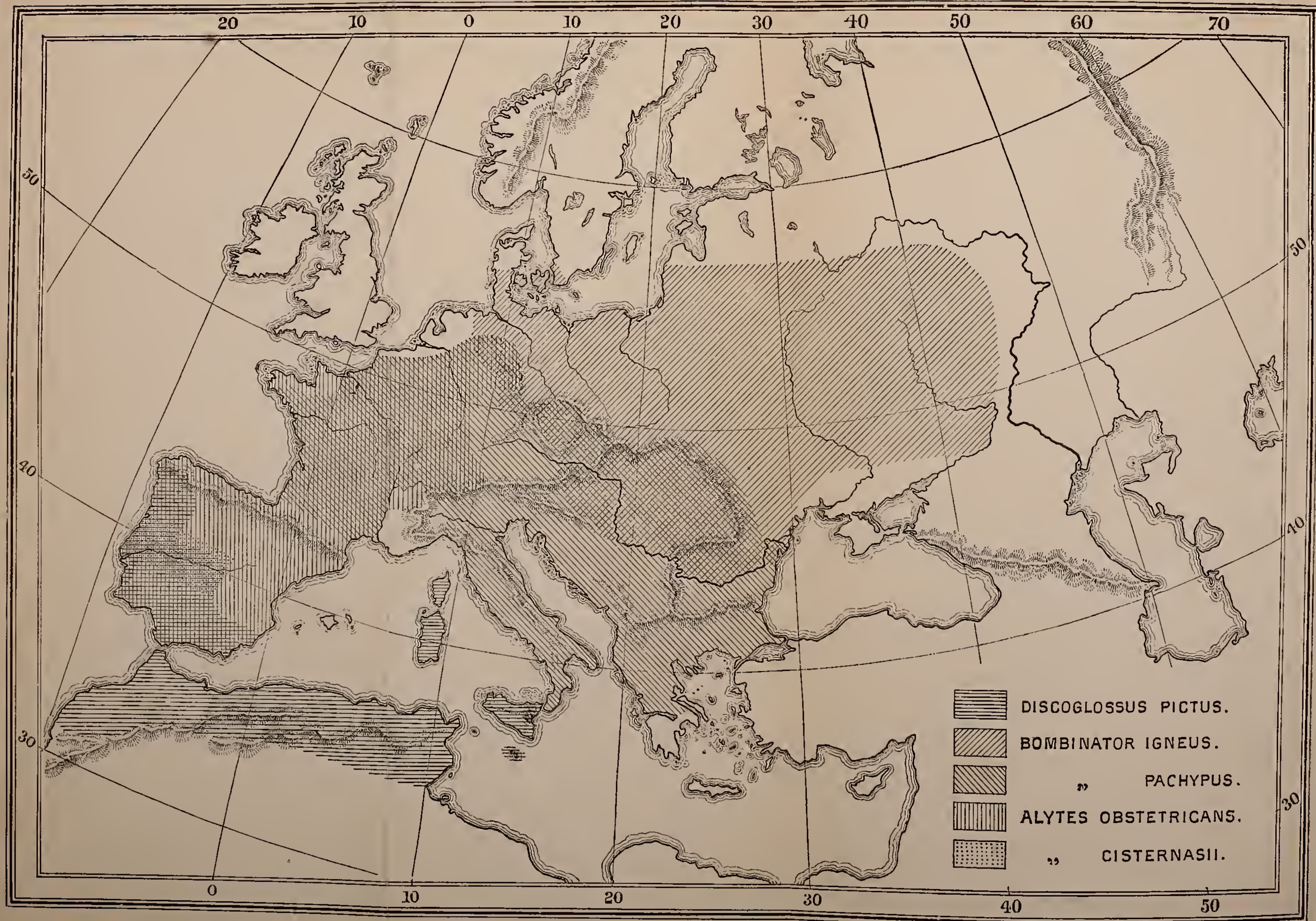

DISTRIBUTION OF EUROPEAN DISCOGLOSSIDAE. 

age 123.

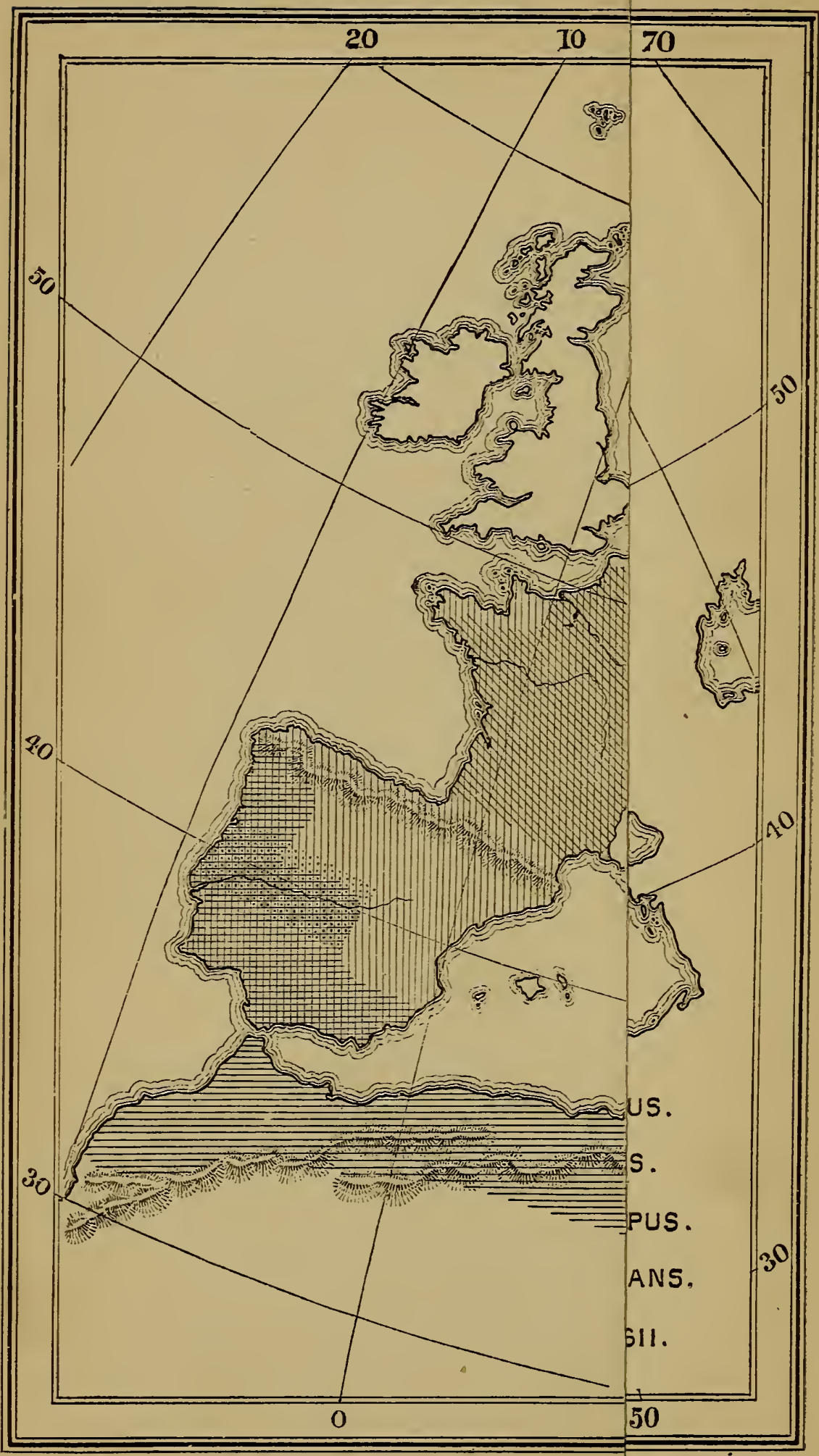




\section{Order ECAUDATA.}

Four limbs and no tail. Radius and ulna, and tibia and fibula confluent; tarsus (astragalus and calcaneum) elongate, forming an additional segment in the hind limb. Frontal bones confluent with parietals.

\section{Sub-order PHANEROGLOSSA.}

Eustachian tubes separated; tongue present.

\section{Series A.-ARCIFERA.}

Pectoral arch with the opposite halves moveable, the coracoids and præcoracoids connected by an arched cartilage (the epicoracoid), that of the one side overlapping that of the other.

\section{Family 1.-DISCOGLOSSID A.}

Vertebræ opisthocœlous; short ribs articulated to the anterior diapophyses; diapophyses of sacral vertebra dilated. Upper jaw toothed.

The genera combined under this family constitute a most interesting and perfectly natural group, as is abundantly evidenced by the bony structure, the larval characters, \&c.

That they occupy the most lowly position among the Ecaudata, and show the nearest approximation to the Caudata, is another point on which there can be no question. The opisthocœlous vertebræ with distinct ribs, the increased number of carpal and tarsal elements, the non-extrusible tongue, the presence of the azygos (posterior cardinal) vein discovered by Hochstetter in Bombinator, and since shown by Howes to be 
fairly distinctive of the whole family, the structure of the urogenital apparatus, together with other characters, give ample foundation to this proposition.

This family comprises only four genera. Three are confined to the Palæarctic region and represented in Europe ; the fourth, Liopelma, Fitzinger, closely allied to Alytes, is the only representative of the Batrachians in New Zealand. The range of the species dealt with in this work is shown on the accompanying map.

The European genera are distinguished as follows:

Tympanum present,. distinct or hidden; pupil roundish or triangular; diapophyses of sacral vertebra moderately dilated . 1. Discoglossus. Tympanum absent; pupil roundish or triangular ; diapophyses of sacral vertebra very strongly dilated . . . . . . . 2. Bombinator.

Tympanum distinct; pupil vertical; diapophyses of sacral vertebra strongly dilated.

3. Alytes.

The relationships of these three genera cannot be well expressed in a linear arrangement Discoglossus is unquestionably the most generalised, and Bombinator and Alytes are almost equally related to it, the latter being, on the whole, more affine to Discoglossus than to Bombinator, especially with regard to the osteological characters.

\section{Discoglossus.}

Otth, Neue Denkschr. allgem. Schweiz. Naturf. Ges., i, 1837, p. 6.

Pupil roundish or triangular. Vomerine teeth in long transverse series behind the choana. Tongue circular, entire, scarcely free behind. Tympanum more or less distinct or concealed under the skin. Fingers free, toes webbed; outer metatarsals separated by web. Diapophyses of sacral vertebra moderately dilated. Urostyle articulated to two condyles.

A single species, confined to the western parts of the Palæarctic region. 

S

$\because x^{2}+4$

$x^{2}-4$ का

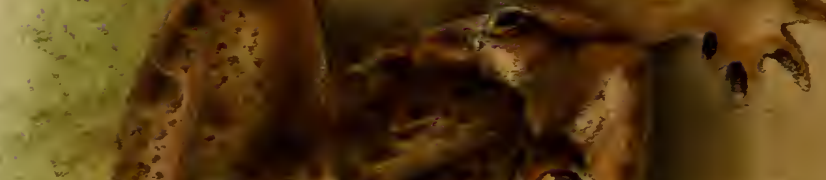

w 20

s

항

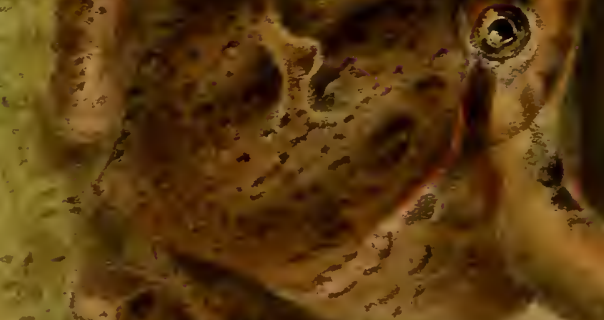

$-i x^{2}+2$

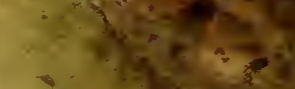

$2 \log ^{2} \mathrm{x}$

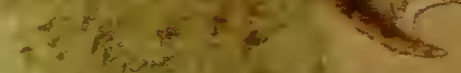

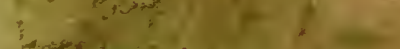

$3+\log ^{2}=$

9 9 * 42003 aropes ats

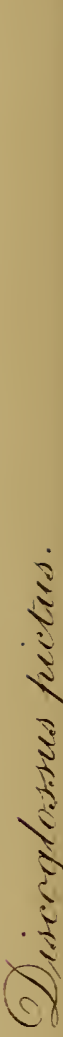
$x+2 \times+2=$ कु

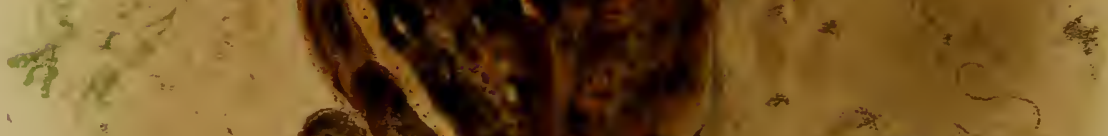
$\therefore$ Cxyocos is

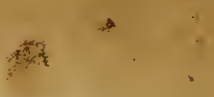




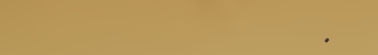



The pupil is described as roundish or triangular; in its contracted condition it varies considerably according to individuals. It is never absolutely round, for it forms an angle below, whence a subtriangular form results. I have seen specimens in which the vertical diameter somewhat exceeds the horizontal, so that the fully contracted pupil might be termed vertically pear-shaped, or, the upper border forming an open angle, kite-shaped.

\section{Discogrossus pictus. (Plate IV.)}

Cetti, Anf. e Pesc. Sard., iii, p. 38 (1777).

Rana temporaria (non L.), Rozet, Voy. Alg., i, p. 230 (1833).

Discoglossus pictus, Otth, N. Denkschr. allgem. Schweiz. Nat. Ges., i, 1837, p. 6, figs.; Tschudi, Class. Batr., p. 80 (1838); Bonaparte, Icon. Faun. Ital., Rett. Anf. (1838); Duméril \& Bibron, Erp. Gén., viii, p. 425 (1841); Günther, Cat. Batr. Sal., p. 35 (1858); Strauch, Erp. Alg., p. 77 (1862); De Betta, Atti Ist. Venet. (3), xiii, 1868, p. 77, and Faun. Ital., Rett. Auf., p. 67 (1874); Schreiber, Herp. Eur., p. 112 (1875); Camerano, Atti Acc. Torin., xiv, 1879, p. 443, pl. -, figs. 6-8; Lataste, Act. Soc. Linn. Bord., xxxiii, 1879, p. 275 , pls. iii-v; Bedriaga, Bull. Soc. Nat. Mosc., 1881, p. 292; Bonlenger, Cat. Batr. Ecand., p. 445 (18\&2); Camerano, Mem. Acc. Torin. (2), xxxv, 1883, p. 204; Bedriaga, Arch. f. Nat., 1883 , p. 254; Héron-Royer, Bull. Soc. Zool. France, 1885, p. 565, pl. xiv ; F. E. Schulze, Sitzb. Ges. Naturf. Fr. Berlin, 1886, pp. 5 and 31; Héron-Royer \& Van Bambeke, Arch. Biol., ix, 1889, p. 280; Bedriaga, Bull. Soc. Nat. Mosc, 1889, p. 54.5, and Amph. Rept. Portug., p. 22 (1889); HéronRoyer, Bull. Soc. Et. Sc. Angers (2), xix, 18s9, p. 160, pls. i and ii ; Boulenger, Trans. Zool. Soc., xiii, 1891, p. 160, and Proc. Zool. Soc., 1891, p. 620, pl. xlvii, fig. 3; Anderson, Proc. Zool. Soc., 1892, p. 24; Bedriaga, Suppl. Amph. Port., p. 13 (1893); Minà-Palumbo, Nat. Sicil., xii, 1893, p. 262.

Discoglossus sardus, Tschudi, in Otth, l. c., and Class. Batr., p. 80 ; Bonaparte, l. c.; Camerano, Atti Acc. Torin., xiv, 1879 , p. 437, pl. - , figs. 4 and 5.

Pseudis sardoa, Gené, Syn. Rept. Sard., p. 24, pl. v, figs. 1-3 \& 6 (1839).

Rana picta, Schlegel, in Wagner, Reisen Alg., iii, p. 134 (1841).

Colodactylus crevilescens, Tschudi, Faun. Per., Herp., p. 68, pl. xi, fig. 2 (1845); Peter's, Mon. Berl. Ac., 1873, p. 414, pl. iii, fig. 1.

Discoglossus scovazzii, Camerano, Atti Acc. Torin., xiii, 1878, p. 548 , and xiv, 1879, p. 447 , pl. - , figs. 1-3.

Discoglossus auritus, Héron-Royer, Bull. Soc. Zool. France, 1888, pp. 205 and 220 , and Bull. Soc. Et. Sc. Angers (2), xix, 1889, p. 177 , pls. $\mathrm{i}$ and ii. 
Vomerine teeth in a long, straight or slightly curved series, narrowly interrupted in the middle, behind the choanæ, and extending outwards to the

Fig. 48.

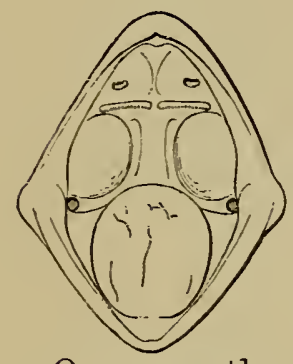

Open mouth. vertical of their outer borders or even a little beyond. Tongue moderately large, circular, thick, adherent, scarcely free behind.

Head much depressed, a little broader than long; snout rounded or obtusely pointed, projecting considerably beyond the mouth, as long as or a little longer than the diameter of the orbit; no canthus rostralis; dorsal region slightly grooved; nostril a little nearer the tip of the snout than the eye; eye moderate; interorbital space as broad as or a little narrower than the upper eyelid, and equal to the distance between the nostrils; tympanum measuring three-fifths to two-thirds the diameter of the eye, sometimes feebly distinct, often completely hidden.

Fig. 49.

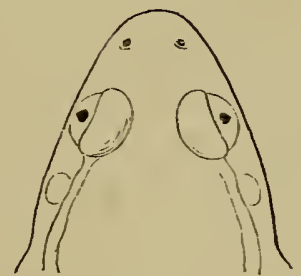

A

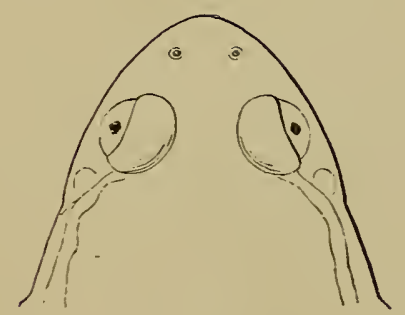

C

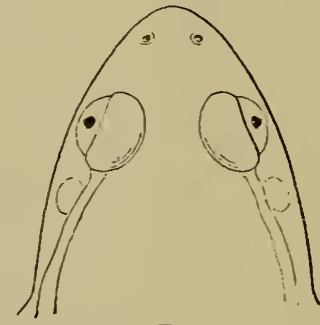

B

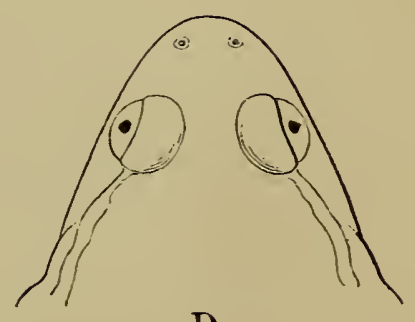

$\mathrm{D}$

Heads of males, upper views. A. Corunna. B. Oran. c. Tlemsen. D. Sardinia. 
Fingers rather short, obtusely pointed, first shortest, third longest, second and fourth equal; no subarticular tubercles; three palmar tubercles, the inner (rudiment of pollex) largest and very prominent, the two others flat and close together, at the base of the third and fourth fingers.

Hind limb rather long; the tibio-tarsal articulation reaches the tympanum, the eye, or the nostril ; tibia longer than the femur, the heels overlapping when the legs are folded at right angles to the rhachis. Foot a little shorter than the tibia; toes rather slender, one-fourth or one-third webbed in females and young, three-fourths or nearly entirely in adult males; no subarticular tubercles; no tarsal fold; a small rounded inner metatarsal tubercle, the length of which equals one-third to one-half the length of the inner toe.

Skin remarkably shiny in life, smooth or with small warts or short glandular folds on the back; a more or less developed glandular lateral fold from the eye to above the shoulder, often prolonged on the side of the body to the inguinal region; a fold of the skin may be present across the occiput behind the eyes. Lower parts smooth except the thighs, which are granulate near the vent; throat and belly sometimes with isolated small granules.

Coloration very variable. Pale brown, grey, greyish olive, yellowish or red above, uniform or with dark, often light-edged spots; some specimens with a broad yellow vertebral stripe, which may be bordered on each side by one or two dark stripes; the lateral glandular fold light, often reddish or golden; a dark streak on each side from the tip of the snout to the eye, and a dark temporal blotch or streak; limbs with transverse dark spots, sometimes forming regular cross-bands; a more or less distinct light triangular or heart-shaped spot often present on the middle of the back between the fore limbs, and another, more in the form of a streak, on the coccygeal region. The dorsal spots sometimes small and irregular, some- 
times forming handsome symmetrical markings; a large triangular, heart-shaped, or chevron-shaped marking is usually present between the eyes. Lower parts ivory-white, uniform or closely speckled with brown, yellowish or more or less carneous under the limbs. Iris golden in its upper portion, dark bronzy in its lower two-thirds, the dark lateral streak of the head passing through the eye; sometimes entirely bronzebrown, as in Bombinator, with a fine golden border to the pupil, interrupted at the lower angle.

FIG. 50.

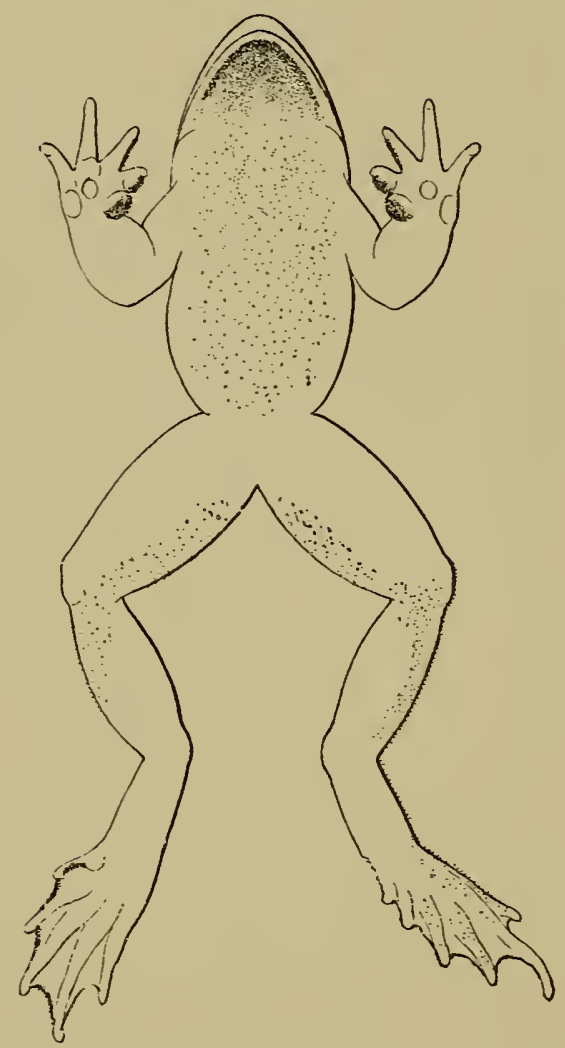

Lower view of male with nuptial excrescences.

Male distinguished from the fernale by much stronger muscular fore limbs, more developed inner carpal tubercle, a great enlargement and flattening of the inner finger, and more fully webbed toes, the web even extending to the inner metatarsal tubercle. Vocal sacs are in a rudimentary condition, and do not com- 
municate by any openings with the floor of the mouth. Horny blackish excrescences are largely developed and distributed as isolated minute spines over the ventral surfaces and on the hind limbs; they form large groups on the inner palmar tubercle and the two inner finger's, a band round the chin, and often border the web of the foot. These excrescences usually persist longer than in most other Batrachians, being found, more or less developed, in adult specimens all the year round.

GEOGRaPhical Varia'ions.-The polymorphism of this species has given rise to the establishment of various species and sub-species, which were believed to be restricted to certain parts of the habitat of the genus. Thus a Discoglossus sardus, Tschudi, was stated to be peculiar to Sardinia and Corsica, and a D. scovazzii, Camerano, was described from Morocco.

Lataste, in his monograph of 1879 , had, it seemed, disposed once for all of these supposed species by showing the inconstancy of the characters adduced for their separation; and, for my part, after examining a very large material from almost every part of the habitat, I fully agree with him. But, since 1879, the $D$. sardus has been maintained, no longer as a species, but as a sub-species, by Camerano, and the $D$. scovazzii, or a form very closely agreeing with it, has been revived by Héron-Royer under the name of $D$. auritus; it may therefore be well to explain in a few words why I take no notice of them even as varieties. According to Camerano's latest definition, D. sardus, from Sardinia, Corsica, and neighbouring small islands, differs from the typical D. pictus from Sicily, Malta, and the Spanish Peninsula in having a less acuminate snout, more robust limbs, and the length of the tibia contained twice, or a little over twice, in the length of head and body. The two former characters are really too slight to be easily appreciable; and besides, I find Maltese, Algerian, and Portuguese specimens with the snout 
quite as short and broadly rounded as in the Sardinian form. As already observed by Lataste, this difference is no greater than that between specimens of Rana temporaria, and is certainly not more constant. With regard to the third character, I need simply refer to my tables of measurement and to Camerano's own table, where Sardinian as well as Sicilian specimens are shown to have the tibia less than half the length of head and body.

Bedriaga also is inclined to retain D. sardus as a distinct form, although admitting that the existence of annectant specimens renders a precise definition impossible. On the whole, he finds the body shorter in proportion to the head and limbs in Corsican and Sardinian specimens than in those from Algeria and Portugal. That there is nothing constant in that supposed difference may be seen from the following measurements (in millimetres) of four adult males, the heads of which are figured above (p. 126), - a from Corunna, $b$ from Oran, $c$ from Tlemsen, prov. Oran, and $d$ from Luras, Sardinia :

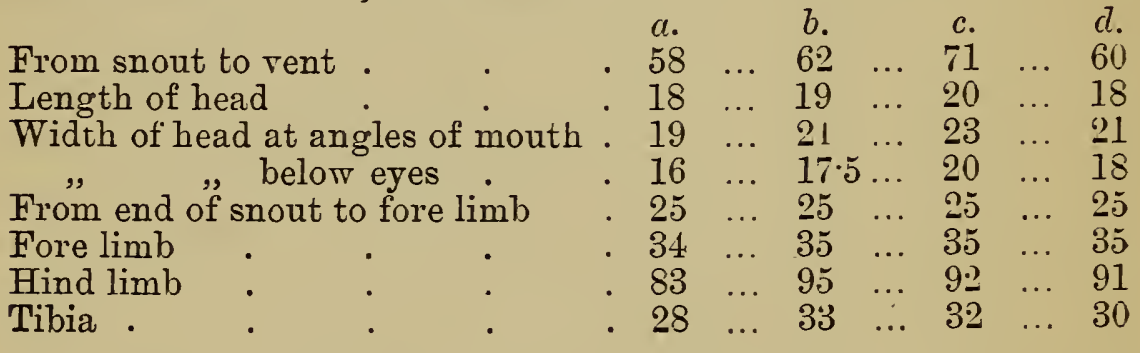

It will be noticed that the Spanish and Algerian specimens $a$ and $b$ have the head a little longer in proportion to the body than in the Algerian $c$ and the Sardinian $d$; that the width of the head below the eyes is as great in proportion in the Algerian $c$ as in the Sardinian $d$; and that the hind limb is shorter in proportion in the Algerian $c$ than in the Sardinian $d$.

Héron-Royer's D. auritus is founded on Algerian specimens (which had been previously referred by Camerano to D. scovazzii), supposed to differ from the Europeans in having the tympanum distinct, the tem- 
poral spot larger, and the inner metatarsal tubercle smaller. But a male specimen from Algiers, collected by Mr. Sclater, has the tympanum completely concealed; and, on the other hand, the organ is perfectly distinct in a male from Corunna and in another collected by M. Boscá on the Sierra Morena; whilst a number of specimens from Europe and Africa are intermediate between the two extremes. I have now before me a large number of living specimens from Oran. In some the tympanum is very apparent, whilst in others its presence can hardly be detected. The shape and extent of the dark temporal band and the size of the metatarsal tubercle are subject to variation in specimens from the same locality, and I have failed to find any constancy in the other very trivial distinctive characters pointed out by Héron-Royer. Dr. Anderson, who has collected specimens in Algeria, some of which show no trace of a tympanum externally, concurs with me in rejecting $D$. auritus even as a local form.

Specimens from Sardinia, Corsica, Montecristo, and Giglio, it has been observed, never show the striped form so frequent in Spain and Africa; but neither do the Maltese specimens, which are referred by Camerano to D. pictus.

Measurements (in millimetres).

From snout to vent

Length of head

Width of head

Diameter of eye

Interorbital width

From eye to nostril

Fore limb

Hind limb

Tibia

Foot .

1, 5. Corunna: Seoane.

2,6. Coimbra: Gadow.

3. Luras, Sardinia : Camerano.

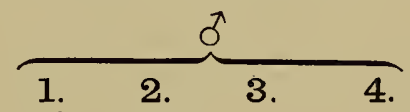

$\overbrace{5.6 . \quad 7 . \quad 8 .}^{q}$. $\begin{array}{rrrrrrrrr}58 & \ldots 55 & \ldots 60 & \ldots & 73 & \ldots 55 \ldots 54 \ldots 43 & \ldots 76\end{array}$

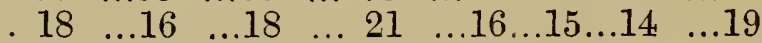

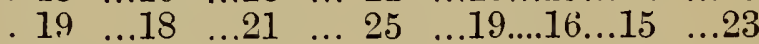

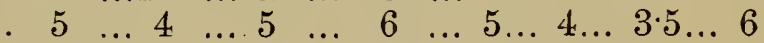

. $35 \ldots 3 \cdot 5 \ldots 4 \ldots 4.5 \ldots 3 \ldots 3 \ldots 3 \ldots 5$

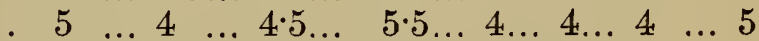

. $8 \ldots \ldots 7 \cdot 5 \ldots 8 \cdot 5 \ldots 10 \ldots 7 \ldots 7 \ldots 6 \ldots$

$\begin{array}{lllllllll}.34 & \ldots 29 & \ldots 35 & \ldots & 40 & \ldots 27 \ldots 26 \ldots 24 & \ldots 35\end{array}$

$\begin{array}{llllllll}.83 & \ldots 80 & \ldots 91 & \ldots 95 & \ldots 84 \ldots 75 & . .644 & \ldots 95\end{array}$

$\begin{array}{llllllll}28 & \ldots 26 & \ldots 30 & \ldots & 35 & \ldots 26 \ldots 25 & \ldots 20 & \ldots 33\end{array}$

$\begin{array}{llllllll}26 & \ldots 25 & \ldots 26 & \ldots & 32 & \ldots 24 \ldots .22 \ldots 18 & \ldots 30\end{array}$

4. Oran: Chevreux.

7. Giglio: Florence Mus.

8. Algiers: Hóron-Royer. 
Skeleton.-Ethmoid short, not extending posteriorly beyond the anterior third or two-fifths of the parasphenoid, embracing above a large fontanelle which extends to the line of the anterior borders of the orbits, and which remains exposed between the diverging anterior borders of the fronto-parietals except in very old specimens; its upper lamina obtusely pointed and partly covered by the nasals, which are large and form a long suture in the median line. Fronto-parietals large, in contact along their posterior two-thirds or more. Zygomatic branch of the squamosal joining by suture an ascending process of the maxillary. Vomers large, their posterior toothed border nearly straight, and covering the feeble palatines, narrowly separated from each other in the median line; pterygoids regularly trifurcate, with a small round outer wing-like expansion at the meetingpoint of the three branches, joining a corresponding process of the angular bone of the mandible; the inner branch of the pterygoid in contact with the parasphenoid, which is $\perp$-shaped, obtuse or truncated, or indentated anteriorly, and not quite reaching the vomers. Mento-Meckelians quite indistinct.

Hyoid a large, broad cartilaginous plate with rounded lateral wings, small postero-lateral processes, and proximally slender, mesially broad and lamellar ceratohyal cornua without forward processes ; in addition to the rather large thyrohyals, which meet with their inner angles, there is a V-shaped, slender, ventral ossification, which is in contact with the latter at its apex, and reaches forward to the anterior notch of the cartilaginous plate; this ossification often paired, the two branches being disconnected at the apex.

Vertebral column twice to twice and one-third as long as the skull. Vertebræ imbricate and completely covering the spinal cord above, with a long posteromedian neural process. Second, third, and fourth vertebræ with short diapophyses, to which short ribs are attached. The first rib is the shortest, horizontal 


\section{DISCOGLOSSUS.}

FIG. 51.
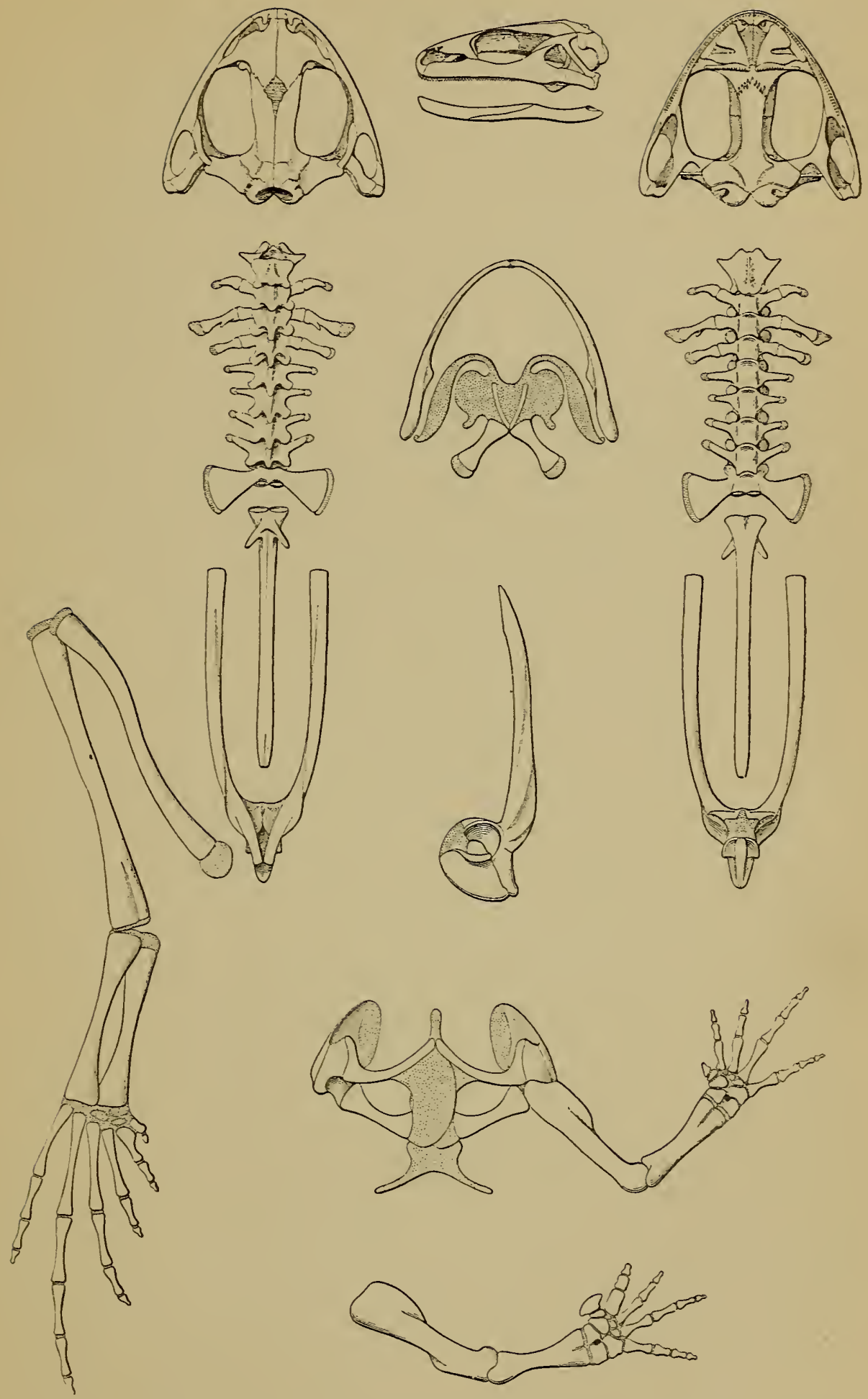

Whole skeleton of female and fore limb of male. 
or directed a little forwards ; the second is the longest, nearly horizontal or directed a little backwards, and sends off from the middle of its upper border a short, slender process, directed outwards and backwards; the third rib, which may be somewhat curved, is directed slightly backwards, and in length is intermediate between the first and second. The following vertebræ have no distinct ribs, but the diapophyses are longer and more slender, the last two or three being turned more or less distinctly forwards. The diapophyses of the sacral vertebra, which cover the anterior extremities of the ilia, on which they may shift forwards and backwards to some extent, are moderately dilated, their diameter at the free extremity being somerwhat less than their length. Two condyles for articulation with the urostyle. The latter is a little longer than the rest of the vertebral column, and bears on each side at its base a short, slender, transverse process directed obliquely backwards.

Præcoracoids slender, curved, entering the glenoid cavity; coracoids stronger, feebly curved; suprascapula ossified; omosternum cartilaginous; sternum produced into two long, slender, diverging processes. Humerus once and a half to once and two-thirds as long as radius-ulna. Carpus with eight bones, two of which are in contact with radius-ulna; a single bone in the pollex, very large in the male; metacarpal of inner digit enlarged in the male, with strong inner crest.

Pelvis nearly two-thirds the length of the vertebral column; pubis cartilaginous ; acetabulum open. Femur and tibia with the epiphyses cartilaginous, the former strongly sinuous and shorter than the latter; astragalus a little longer than calcaneum, from which it is perfectly distinct throughout, owing to the absence of calcified epiphyses, and one-half or rather more than half the length of tibia-fibula; three tarsalia in the distal row, one or two of which may ossify; and two bones to the præhallux. Distal phalanges obtuse, slightly expanded at the apex. 
Measurements of Skeleton (in millimetres).

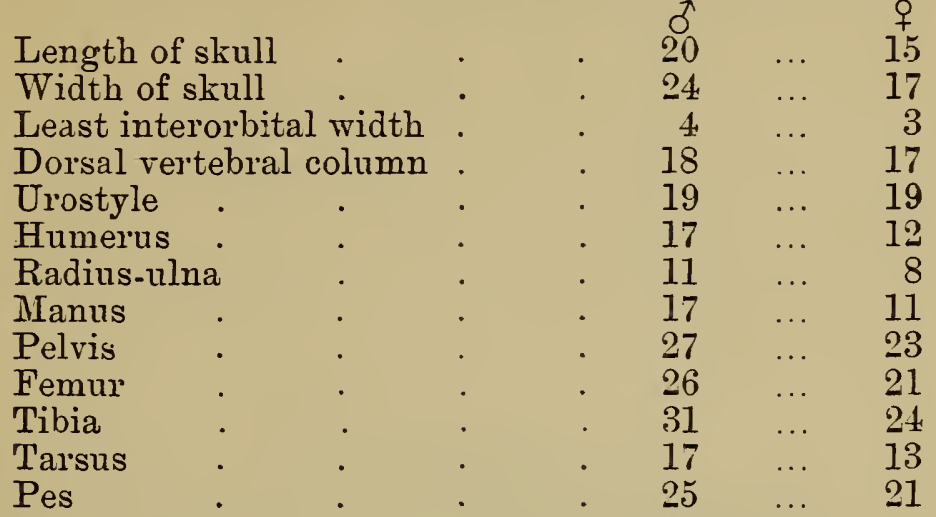

HaBiTs.-Discoglossus pictus resembles the true frogs in the quickness of its movements. It is active by day as well as by night, and usually found in or about water, objecting neither to brackish pools nor to cold running mountain streams. Like its relative Bombinator, and unlike all other European Ecaudates, it is able to seize its prey under water, in the same manner as newts do, and is therefore easily fed in confinement with earthworms dropped into the tank with which the terrarium must be provided. Although particularly shy when handled, it does well in captivity, and will usually take food immediately on arriving after a long journey in a small box. When seized it becomes covered with a slimy secretion, which renders it very difficult to handle, but which has no special odour nor any irritating action on our mucous membranes, so far as I can judge from experiments upon myself. Like Lataste, who was the first to study the habits in captivity, and who later had the good fortune to observe this Batrachian in a wild state in Algeria, I have never heard the rutting male produce more than a feeble note, sounding to my ear as $h a-a, h a-a-a$, or $w a, w a, v a-v v a-v v a$, issued in rapid succession, although specimens have repeatedly paired and bred in my terrarium. But according to HéronRoyer, specimens under his observation uttered at night a constantly repeated $r a-a, r a-a$, loud enough to disturb him when produced in a yard outside his 
window. Discoglossus cannot be described as mute, but its voice is certainly the feeblest among all our members of the tailless tribe.

The pairing season extends from January, in Algeria, to September and October, and the female is able to spawn three times in the year. The embrace, which never lasts long, is lumbar, the

FIG. 52.

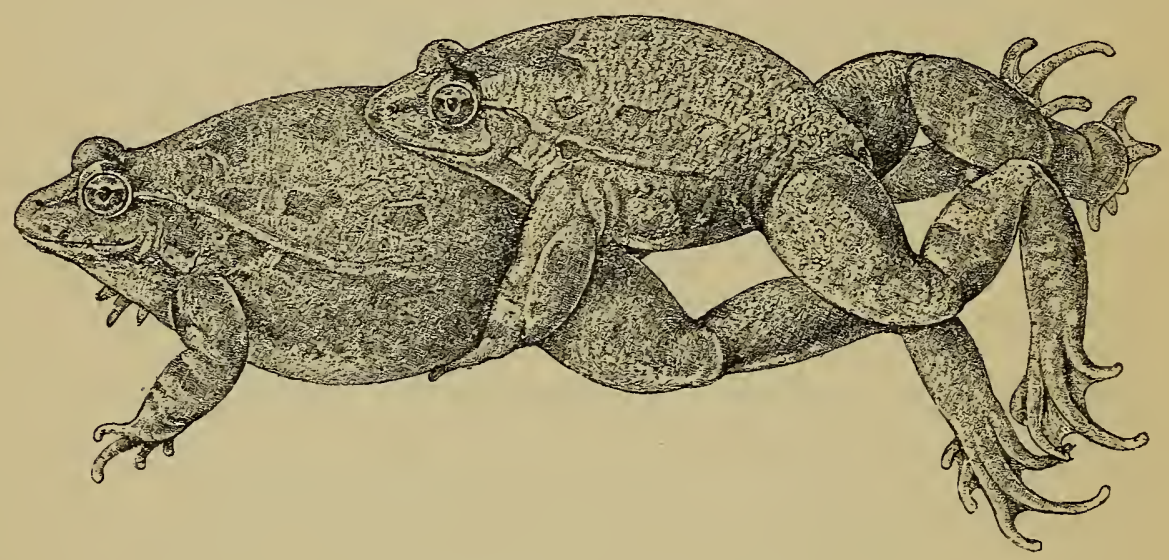

Male and female pairing.

male's hands joining on the pubic region. The remarkably small eggis are produced slowly, one at a time, and feebly adhere to the bottom of the pool or tank, where they form a single layer, more or less closely set. Only exceptionally have I found eggs attached to the weeds with which I had furnished the small tank in the terrarium, the pair keeping to the bottom during oviposition. The spermatozoa, which from their large size can be detected with the naked eye, are ejaculated in several bundles.

The larvæ, as a rule, live only from one to two months before transforming, and keep small, being in this respect comparable to those of the common toad; but tadpoles born late in the summer may remain for nine or ten months in that condition.

Specimens which I received from Algeria in January and February, 1897, although in apparently excellent health and readily feeding on worms and insects, did 
not begin to pair, so far as I could observe, until the beginning of June. The first eggs, about 400 in number, I found on the bottom of the tank on the morning of June 7 th, the embryos emerging on the 10th; whilst on the 14th, or exactly a week later, the young had lost their external gills and entered the tadpole stage, measuring $11 \mathrm{~mm}$. total length, buds of the hind limbs being discernible on the $17 \mathrm{th}$. On the 23rd the largest specimens measured $21 \mathrm{~mm}$., and on the 3rd July some had reached their full length, viz. 25 to $30 \mathrm{~mm}$. On the 5th July some had put on the striped livery. The fore limbs first appeared on the 6th, and the metamorphosis was completed by the 8th, when the first specimens left the water with a reduced caudal appendage, and measuring 8 to $10 \mathrm{~mm}$. from snout to vent, the last metamorphosing as late as August 6th. Striped specimens were in the proportion of one to four spotted or immaculate.

On the morning of June 14th the tank again contained eggs, 895 in number, which, from their condition, must have been deposited in the night of the 12th-13th (I was absent on Sunday, 13th), and the embryos of which were liberated in the afternoon of the 14th, thus less than forty-eight hours after the deposition of the eggs-a process of development more rapid than has been observed in any other species of Batrachians. The young from this brood began to leave the water on July 20th, whilst others retained the larval condition until October 5th. None were of the striped form. A third lot of $936 \mathrm{eggs}$ were deposited during the night of July 6th-7th; they hatched in the night of 8th-9th, and the young completed their metamorphosis between August 16th and October, a few being still in the tadpole condition whilst these lines are passing through the press. About two-thirds of them belonged to the striped form. In all these cases I was struck by the extremely small proportion of eggs that did not develop, 
and the very slight amount of mortality that took place among the embryos; whilst of the tadpoles all except such as I killed for study went through the metamorphosis. In fact, the success in rearing these broods of Discoglossus has been greater than I have experienced in dealing with any other kind of tailless Batrachians under similar conditions. I had no difficulty in feeding the tiny young on aphides.

On the 17th July egg's had again been produced during the night, but they numbered only 306 . They hatched on the 18th; most of them were destroyed shortly after by a fungus. A further oviposition took place under my eyes in the afternoon of July 31st, 341 egg's being produced. The male was spotted, the female striped. The same pair remained in the tank, which, on the morning of August 2nd, contained a further lot of eggs, 543 in number-laid, I have every reason to believe, by the same female. Both these broods hatched in less than thirty-six hours. The first went through their evolution without mishap, metamorphosis beginning on September 11th; whilst the second perished wholesale as embryos through a fungus. Among the former, contrary to my expectation, not one developed into the striped form, but I had the pleasure of obtaining an albino tadpole, fleshcolour with large pale golden spots; the so-called pigmentary network was distinguishable, of an opaque white. The albinism was, however, not perfect, for the pupil of the eye was black instead of red, and later in life a small quantity of brown pigment appeared on the back. Further ovipositions took place at night on August 18-19, 20-21, 23-24, and 2627 , the number of eggs being $314,830,598,360$. All these broods did well, and at the time this account of them is written I have a large number of tadpoles, which will probably not transform until the coming spring. They differ greatly in their degree of development, irrespective of age, measuring from 11 to 30 millimetres total length. 
EGGS.-Small, 1 to $1 \frac{1}{2} \mathrm{~mm}$. in diameter, dark brown or black, with the lower third or fourth white or grey, in isolated capsules measuring not more than 3 or $4 \mathrm{~mm}$. in diameter. The number of eggs does not seem ever to exceed

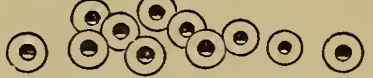

Fra. 53. 1000 , and may be as few as 300 . Eclosion takes place on the second to sixth day. The embryo, which then measures 3 or $4 \mathrm{~mm}$., is blackish-brown; it has a very short tail, but the external gills have not yet appeared.

'I'ADPOLE (Pl. I, fig. 1).-Length of body once and two-thirds its width, one-half to two-thirds the length of the tail. Eyes on the upper surface of the body, the distance between them about once and a half the distance between the nostrils, equal to or slightly less than the width of the mouth. Spiraculum in the mid-ventral line, equally distant from either extremity of the body. Anal opening median, larger than the spiraculum. Tail three to four times as long as deep, broadly rounded at the end, both upper and lower crests but very feebly convex, the former not extending upon the back; the depth of the muscular part at its base one-half to two-thirds the total depth.

Mouth elliptical. Beak white, edged with black. Lips bordered by a single series of papillæ, which are usually narrowly interrupted in the middle of the upper lip; a well-marked chink on each side of the lower lip. Series of labial teeth $\frac{2}{3}$, occupying the whole width of the lips, the third lower interrupted in the middle; the first upper and the first lower series formed of one or two rows of teeth, the others constantly of two.

The ordinary lines of crypts on the head are distinguishable, and often also one running along each side of the back.

Brown or olive above, grey or whitish below, speckled with gold ; caudal crests whitish, uniform or with small brown dots. Colour-dimorphism is discernible some time before the egress of the fore limbs; 
advanced tadpoles may be marked with a light, darkedged vertebral stripe, whilst this is absent in other specimens out of the same brood. The whole body and tail with a network of fine brown lines forming polygonal meshes; this network most easily traceableon the tail.

Total length, $33 \mathrm{~mm}$; body, $12 \mathrm{~mm}$.; width of body, $7 \mathrm{~mm}$.; tail, $21 \mathrm{~mm}$.; depth of tail, $6 \mathrm{~mm}$.

Hавт'тат. -Discoglossus pictus inhabits South-western Europe and North-west Africa. It is found nearly all over Central, Western, and Southern Spain and Portugal, but appears to be absent from the east coast as well as from the Balearic Islands, a fact which is the more surprising since the species is again abundant in Corsica, Giglio, Montecristo, Sardinia, Sicily and small neighbouring islands, Malta and Gozo. In Africa its habitat extends all over Morocco, Algeria, and Tunisia north of the Sahara; also on Galita Island, off the coast of Tunisia. It inhabits the coasts and plains as well as the hills, having been found by Bedriaga in Corsica from sea level to an altitude of 2450 feet.

The occurrence of Discoglossus in Santa Maura, Ionian Islands, whence a single specimen is stated by De Betta to have been obtained by the late A. Ninni in 1863, has not been confirmed by more recent explorers of those islands, and Bedriaga informs us that the specimens put up under that name in the Athens Museum belong to Rana esculenta.

A few years ago the late Héron-Royer introduced the species into France near Amboise, in Touraine, where it appears to have become perfectly acclimatised. Several thousands of young specimens have also been turned loose in the neighbourhood of Argenton, dep. Indre, by M. Rollinat in 1892 and 1893.

Pl. IV shows specimens from Oran, for which I am indebted to the kindness of Messrs. E. Chevreux and Doumergue. The right-hand figure represents a fullgrown male in nuptial costume; the two others represent females of the spotted and striped forms. 



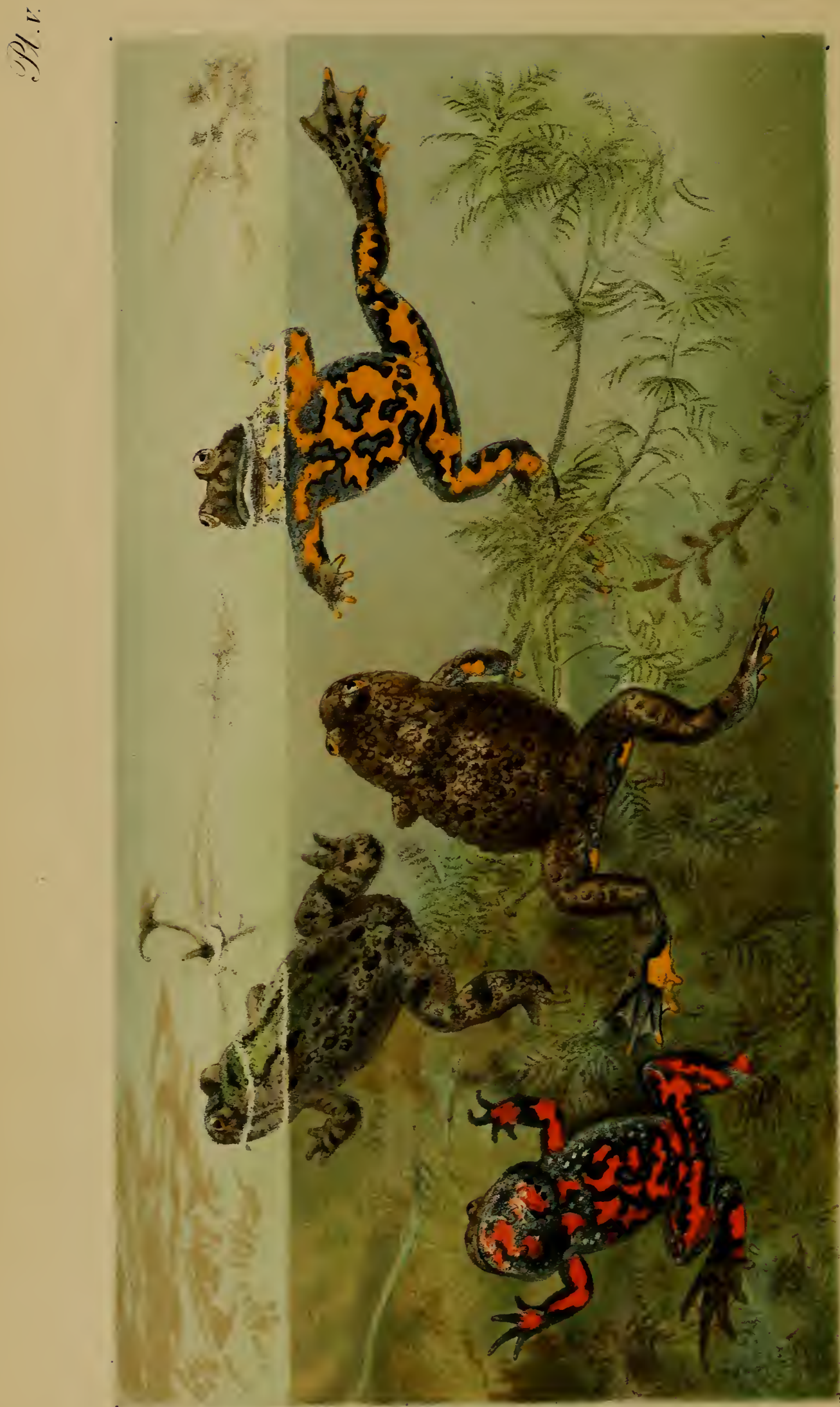




2. BOMrBINA'TOR.

Merrem, Tent. Syst. Amph., p. 178 (1820), partim.

Pupil roundish, triangular, or cordiform. Vomerine teeth in two short transverse groups behind the choanæ. Tongue circular, entire, adherent. No tympanum. Fingers free, toes webbed; outer metatarsals separated by web. No palatine bones. Diapophyses of sacral vertebra very strongly dilated. Urostyle articulated to a single condyle.

This genus includes three closely allied species. Two are European; the third, Bombinator orientalis, Blgr., inhabits North-eastern Asia, from Manchuria to Northern China.

Apart from the coloration, the two European species are easily distinguished by the length of the tibia or crus, which is shorter than the foot, measured from the base of the inner metatarsal tubercle, in $B$. igneus, and as long as the foot or even a little longer in $B$. pachypus. Males are besides distinguished by the presence in the former and the absence in the latter of internal vocal sacs; during the breeding season the third finger and one or several of the toes are provided with plates of black horny asperities in B. pachypus, which are never present on those parts in B. igneus.

Although nearly allied, and actually known to produce fertile hybrids, * the right to specific distinction of the two European forms, so long confounded under the name of $B$. igneus, is now established beyond contest.

* That this affords no absolute criterion in matters of specific distinctions is shown, among Batrachians, by the two newts, Molge cristata and $M$. marmorata, producing the hybrid known as $M$. blasii, which proves to be fertile for one or two generations at least. 


\section{Bombinator igneus.}

\section{(Plates V and VI.)}

Linnæus, Faun. Suec., p. 94 (1746).

? Rana variegata, Linnæus, Syst. Nat., ed. 10, p. 211 (1757).

Rana boinbina, Linnæus, Faun. Suec., ed. 2, p. 101 (1761), and Syst. Nat., ed. 12, i, p. 355 (1766).

Bufo igneus, Laurenti, Syn. Rept., pp. 29 and 129 (1768); Schneider, Hist. Amph., i, p. 187 (1799).

Bufo ignicolor, Lacépède, Quadr. Ov., i, Syn. Méth., and p. 595 (1788).

Rana rubeta. Lindaker, Abh. Böhm. Ges. Wiss., i, 1791, p. 112.

Bombinator igneus, Merrem, Tent. Syst. Amph., p. 179 (1820); Gravenhorst, Delic. Mus. Vratisl., p. 67 (1829); Schulz, Faun. March, p. 470 (1845) ; Nilsson, Skand. Faun., Amf., p. 94 (1842); Collin, Naturh. Tidsskr (3), vi, 1\$69, p. 307 ; Boulenger, Proc. Zool. Soc., 1886, p. 500, pl. l, fig. 2 ; HéronRoyer, Bull. Soc. Zool. France, 1887, p. 640, pl. xii; Boulenger, Bull. Soc. Zool. France, 1888, p. 174; Wolter'storff, Zeitschr. f. ges. Naturw., lvi, 1889, p. 29, and Jahrb. Ver. Magdeb., 1590, p. 318; Héron-Royer, Bull. Soc. Et. Sc. Anyers (2), xx, 1891, p. 201; Méhely, Zool. Anz., 1891, p. 269, and Math. Term. Közl. (Budapest), xxiv, 1591, p. 558, pl. i; Erwin Schulze, Schr. Nat. Ver. Harz, vi, 1891, p 40; Boulenger. Proc. Zool. Soc., 1891, p. 621, pl. xlvii, fig. 4; Méhely, Math. Nat. Ber. Ungarn, x, 1892, p. 61, pl. iv; Werner, Rept. A mph. Oesterr.-Ung., p. 109 (1897).

Bombinator igneus, part., Bonaparte, Icon. Faun. Ital., Rett. Anf. (1838); Schreiber, Herp. Eur., p. 95 (1875).

Bomoinator bombinus, Glückselig, Lotos. i, 1851, p. 224 ; Bedriaga, Bull. Soc. Nat. Mosc., 1889, p. 581; Sasserno, Boll. Mus. Torin., iv, 1889, No. 68; Dürigen, Deutschl. Amph., p. 552, pl. ii, figs. 3 and 4 (1S97).

Vomerine teeth in two roundish or transversely oval groups, close together just behind the level of the

FIG. 54.

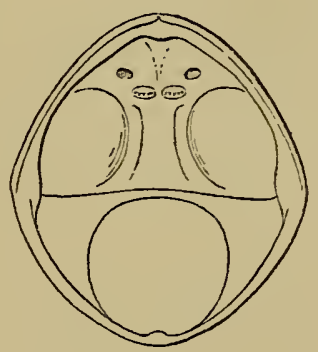

Open mouth.
FIG. 55.

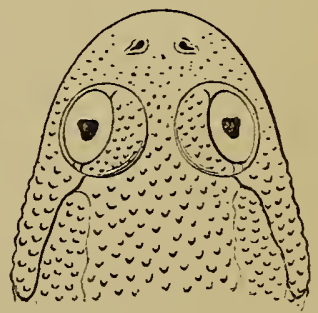

Upper view of head.

choanæ. Openings of the Eustachian tubes minute. Tongue moderately large, circular, comparatively thin, entirely adherent. 
Head depressed, as long as broad, or slightly broader than long; snout rounded, scarcely projecting, as long. as the diameter of the orbit; no canthus rostralis; no loreal groove; nostril a little nearer the eye than the tip of the snout; eye rather small, very prominent, directed upwards and outwards; interorbital space narrower than the upper eyelid and nearly equal to the distance between the nostrils.

Fingers short, obtuse, first shortest, third longest, fourth a little longer than second; no subarticular tubercles ; two or three round palmar tubercles, inner usually largest and more prominent.

Hind limb stout, little longer than head and body; the tibio-tarsal articulation reaches the axil or the shoulder, the tarso-metatarsal the commissure of the jaws or the eye ; tibia a little shorter than the femur, the heels not meeting when the legs are folded at right angles to the rhachis. Foot longer than the tibia; toes short, obtuse, flattened, at least two-thirds webbed in the adult, sometimes nearly entirely webbed, but the membrane always with deep crescentic emargination; in young specimens the toes may be barely half webbed; no subarticular tubercles; a very small and feebly prominent round inner metatarsal tubercle.

Upper parts covered with more or less prominent, round or oval, distinctly porous warts; each may be tipped with closely set black asperities, none of which, as a rule, are developed into true spines, although there is sometimes a conical central eminence. Some of the warts may run together and form short chains, particularly an oblique, posteriorly converging pair between the shoulders, and a parotoid-like one on each side behind the eyes; a distinct fold usually extends below the latter, from the eye to the base of the arm. Lower parts smooth, or with small scattered granules, each of which is tipped with black horny matter as on the dorsal warts; lower surface of thighs with larger flat granules; a more or less strong gular fold separating the head from the body. 
Grey, olive, or rarely bright grass-green above, with distant symmetrical blackish or dark bottle-green spots disposed on the larger warts. Usually, in German specimens, a pair of pale green or bright green roundish spots between the shoulders. Austrian specimens often lack the green colour, and Méhely found it in two specimens only, out of fifty collected in Hungary. A dark streak from the end of the snout to the eye; upper lip with dark vertical bars; limbs, including the digits, with more or less regular dark cross-bars. Lower parts biuish-black, usually with white dots, and more or less numerous, insuliform or vermicular, bright orange to vermilion markings, the most constant of which are a pair of pectoral spots and a pair of lumbar cross-bars; the latter sometimes nearly continuous, like a belt across the præpubic region; the spots sometimes absent on the throat and belly, which then are entirely black, dotted with white; a small white spot sometimes present on the chin. A large bright spot on the inner side of the palmar, and another on the inner side of the plantar surface; these spots are not confluent with those on the forearm and tarsus, and do not extend to the tip of the inner digit; one specimen, from Vienna, is exceptional in having the plantar and tarsal spots confluent on the right side. The tips of all the digits black or yellowish-white, never bright orange or red.

Iris golden, much sprinkled over with brown, or bronzy brown with a golden circle round the pupil; the golden border broader above than below and at the sides; the pupil round with a lower angle, or subtriangular, rarely notched above as in the following species, - in fact, perfectly similar to that of Discoglossus.

Male distinguished from the female by a usually somewhat shorter body, a rather broader head, stronger fore limbs, and especially by the presence of a pair of internal vocal sacs formed by the skin of the floor of the mouth, which is loose and plicate, and projects through a slit dividing the submaxillary 
muscle into an anterior and a posterior portion; when these sacs are fully inflated the throat is globular and larger than the rest of the head. During the breeding season black horny excrescences form a band along the inner side of the forearm, and cover the inner carpal tubercle as well as the inner side of the first and second fingers.

\section{Measuremlents (in millimetres).}

From snout to vent

Length of head

Width of head

Diameter of eye

Interorbital width

From eye to nostril .

, to end of snout

Hind limb

Tibia

Foot

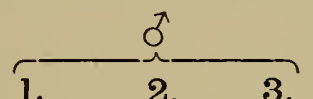

$1.2 \quad 2.3$.

$\begin{array}{lllll}-49 & \ldots & 46 & \ldots & 42\end{array}$

$\begin{array}{lllll}15 & \ldots & 14 & \ldots & 13\end{array}$

$\begin{array}{lllll}16 & \ldots & 15 & \ldots & 14\end{array}$

$\begin{array}{lllll}3 & \ldots & 3 & \ldots & 3\end{array}$

$\begin{array}{lllll}2 & \ldots & 2 & \ldots & 1 \cdot 5\end{array}$

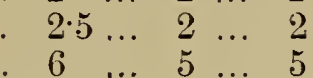

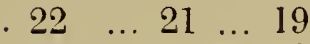

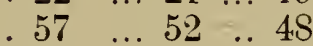

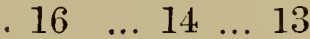

$\begin{array}{lllll}19 & \ldots & 16 & \ldots & 16\end{array}$

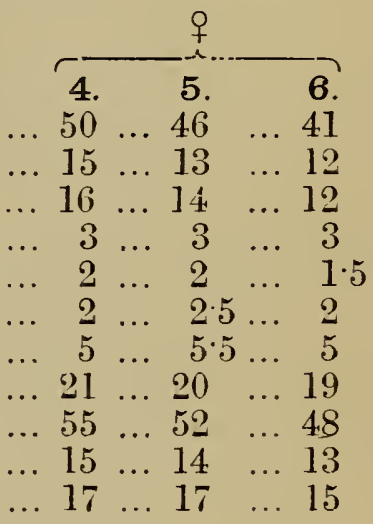

1, 4. Kullen, Sweden: Lilljeborg.

2, 5. Berlin: Boulenger.

3, 6. Holics, Hungary: Méhely.

Skeleton.-Skull very flat and feebly ossified, the enormous fontanelle being but narrowly bordered at the sides, or at the sides and behind, by the muchreduced fronto-parietal bones; ethmoid short and nearly entirely exposed, its upper lamina with convex anterior border, and in contact with or narrowly separated from the nasals; the latter bones have a concave anterior and a convex posterior border, and are in contact with each other in the median line. Squamosal feeble, with short zygomatic, and no posterior branch. Vomers thin ossifications narrowly separated in the middle line; no palatine bones; the anterior branch of the trifurcate pterygoid much elongate, extending to the anterior border of the orbit, where it curves inwards to make up for the missing palatine, the inner branch short and widely separated from the parasphenoid; latter shaped like a dagger with very short handle, obtuse or truncated anteriorly, 
not reaching the vomers, leaving the ethmoid uncovered, or covering but a small portion of it. Stapes absent. No well-defined mento-Meckelian bones.

Hyoid a large broad plate with two pairs of ossifications ; ceratohyal cornua broad and without forward processes ; postero-lateral process large, ossified at the base, this ossification extending to the body of the hyoid and sometimes nearly meeting its fellow in front of the likervise ossified but slender thyrohyals.

Vertebral column twice and one-third to twice and a half as long as the skull. Vertebræ imbricate, the column closed above. Second, third, and fourth vertebræ with short diapophyses and small distinct ribs, the second of which is the longest, and bears a small posterior process as in Discoglossus. The first diapophysis is directed forwards, the second, third, and fourth are nearly horizontal, and the three following are again directed forwards. The diapophysis of the sacral vertebra are very strongly dilated, and cover the anterior third of the pelvis; their longitudinal diameter, without the cartilaginous epiphysis, equals about twice the transverse diameter; this vertebra has a single condyle for articulation with the urostyle. As in Discoglossus, the latter bone has a posteriorly directed, slender transverse process on each side at its base, but usually more developed, its length often exceeding that of any of the processes of the præsacral region; it is sometimes followed by a second similar process; the length of the urostyle equals that of the skull, or of the six or seven anterior vertebræ.

Præcoracoids moderately slender, strongly curved, entering the glenoid cavity; coracoids little stronger, feebly curved; supra-scapula cartilaginous, or partially ossified; sternum cartilaginous, produced into two long, slender, diverging processes. Humerus once and one-third as long as radius-ulna. Carpus with eight elements, as in Discoglossus, two of which are in contact with radius-ulna; two bones in the pollex.

Pelvis measuring three-fiftbs to two-thirds the 
length of the vertebral column; no pubis, ilium and ischium meeting in the acetabulum. Femur slightly curved, a little longer than the tibia; calcaneum slightly longer than the astragalus, two-thirds to three-

Fig. 56 .
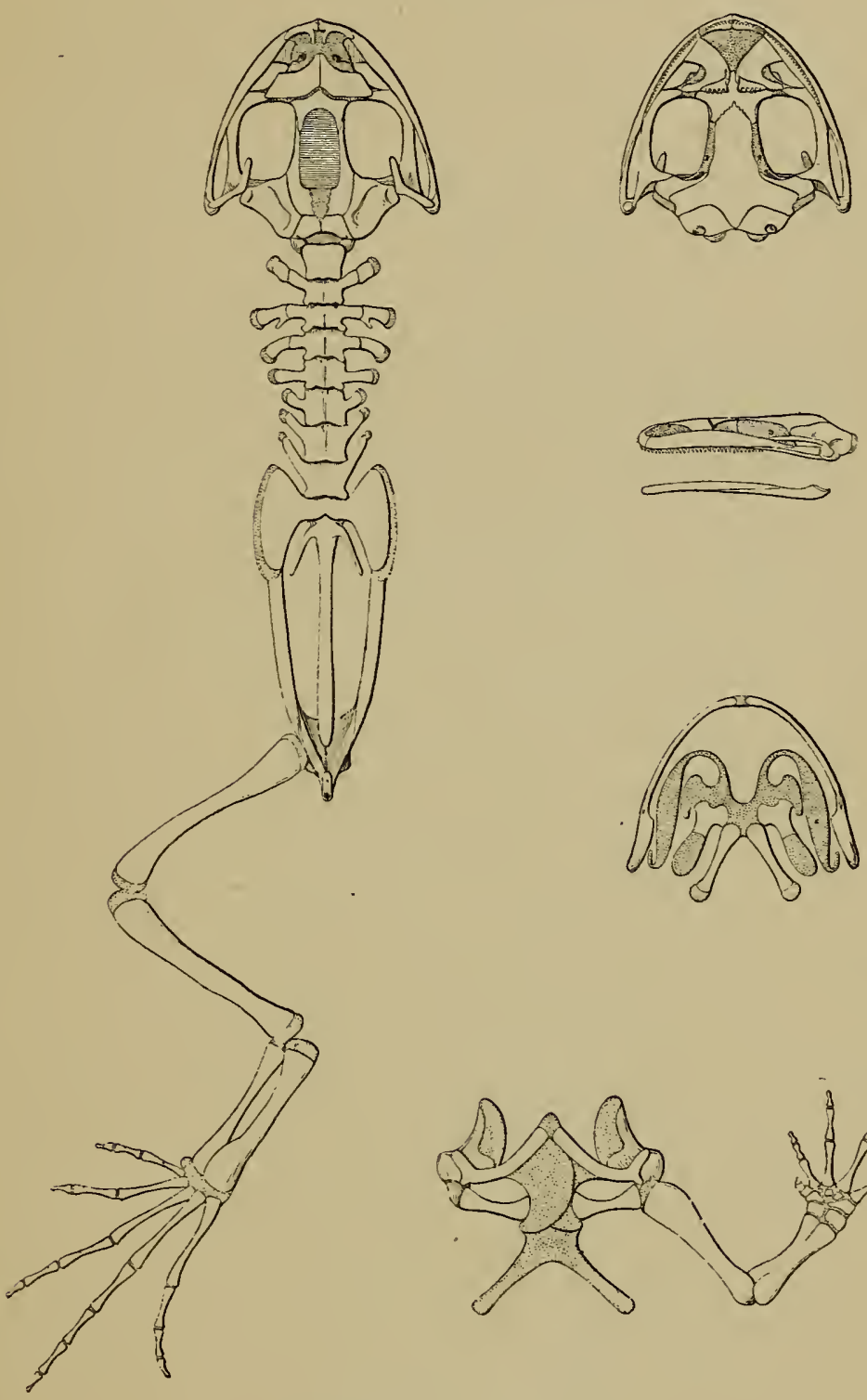

Skeleton of male.

fourths the length of the tibia; three cartilaginous tarsalia, and one or two minute cartilages in the præhallux. Distal phalanges obtuse, slightly expanded at the apex. 'The epiphyses of all the long bones uncalcified. 
Measurements of Skeleton (in millimetres).

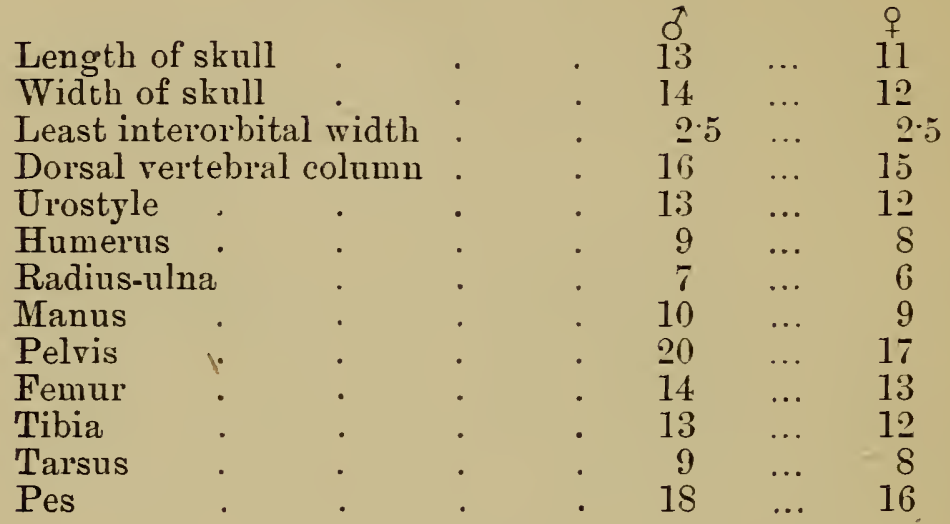

HaBITs.-'I'his species is diurnal and thoroughly aquatic during its period of activity, being found in small ponds or pools or among the grass on the borders. It is very agile in the water, and proceeds by small leaps on land. It likes to rest near the surface of the water with spread-out limbs, nothing but the eyes and nose emerging, and dives to conceal itself in holes or under stones or bury in the mud when disturbed. I found it pairing near Berlin in the latter half of May. The male embraces the female round the waist, and, swelling out its throat, utters at short intervals a somerwat porverful and melancholy note, hook, hook, or hoonk, hoonk, whence the name "Unke" by which it is generally known in Germany. The pairing season extends over two or three months, and Héron-Royer has ascertained that the female spawns two or three times in the year at distant intervals. The eggs are produced singly or a few at a time, and become fixed by their gelatinous capsules to submerged grass or other weeds; this operation is performed slowly, and may last from one to three days, with several bours' interruption.

Males appear to reach sexual maturity much sooner than females. I have found pairing male specimens not more than $28 \mathrm{~mm}$. long from snout to vent, although the joung that have just completed the metamorphosis measure as much as 15 to 20 . 
The skin of the upper parts produces an acrid secretion, very similar to that of the crested newt, fresh-caught specimens becoming covered with white froth when handled; and this exudation causes great irritation to our mucous membranes, fits of sneezing and running of the eyes being the usual consequence of simply looking into the bag in which the captives are being brought home. When surprised on land, and unable to escape in the water, this Batrachian, in common with its congener $B$. pachypus, makes ridiculous contortions, ultimately feigns death, and concavely bending its spine turns up the head and hind part of the body, as well as the limbs which are folded over, thus exposing the brilliantly coloured lower surfaces; at the same time covering its eyes with its hands as if not to see the danger.

EGGs.-C'l'he vitellus measures about $2 \mathrm{~mm}$. in diameter; the upper hemisphere is dark brown, the lower yellowish-white. There are two gelatinous capsules, the outer of which measures 7 or $8 \mathrm{~mm}$. in diameter. The eggs being laid singly or in small groups of seldom more than ten at intervals of several hours, the exact number produced by one female has not yet been ascertained with absolute certainty, but appears to be from 80 to 100 for each brood. The embryo escapes from its envelop after a week in a more advanced condition than Discoglossus, provided with small external gills and a well-developed tail, and more or less distinctly striped as in that of Alytes.

Tadpole (Pl. I, fig. 2).-Length of body once and one-fourth to once and one-third its width, two-thirds to four-fifths the length of the tail. Eyes on the upper surface of the body, the distance between them trice and a half to three times as great as that between the nostrils, equal to or slightly less than the width of the mouth. Spiraculum in the mid-ventral line, nearer the posterior than the anterior extremity of the body. Anal opening median, much larger than the spiraculum. Tail twice to twice and a half as long 
as deep, ending in an obtuse point; the upper crest convex, not or but slightly deeper than the lower, and extending upon the back; the muscular part at its base two-fifths to one-half the total depth.

Mouth triangular. Beak white, edged with black. Lips bordered by a series of papillæ; a well-marked chink on each side of the lower lip; series of labial teeth $\frac{2}{3}$, occupying the whole width of the lips, all uninterrupted, or the third lower broken up in the middle; the first upper and the first lower series formed of two or three rows of teeth, the others of two, three, or four.

Well-marked series of muciferous crypts; one on each side of the head, from above the upper lip, passing above the nostril and bordering the eye, then descending towards the upper lip, where it curves and ascends to below the eye; two on each side of the back, beginning at some distance behind the eye, the upper extending to the dorsal portion of the muscular part of the tail, the lower very short and parallel to the upper; and finally a short curved one on each side of the belly.

Brown above, greyish-white below; the series of crypts whitish; tail greyish, with or without small brown spots. A network of fine blackish lines crossing each other at right angles is spread over the whole tadpole.

Total length $50 \mathrm{~mm}$; ; body, 20 ; width of body, 16 ; tail, 30 ; depth of tail, 15.

Навітат.-Bombinator igneus must be regarded as an Eastern species, essentially bound to the plain. It inhabits Russia, west of the Volga, between lat. $47^{\circ}$ and $56^{\circ}$, Southern Sweden (Scania), Denmark, North Germany (as far west as the Weser and Oldenburg), Austria-Hungary, and Moldavia. As pointed out by Wolterstorff and confirmed by v. Méhely, it avoids hilly districts, where it is replaced by its congener B. pachypus; only in a few places in Thuringia, Lower Austria, and Transylvania are the two species to be 


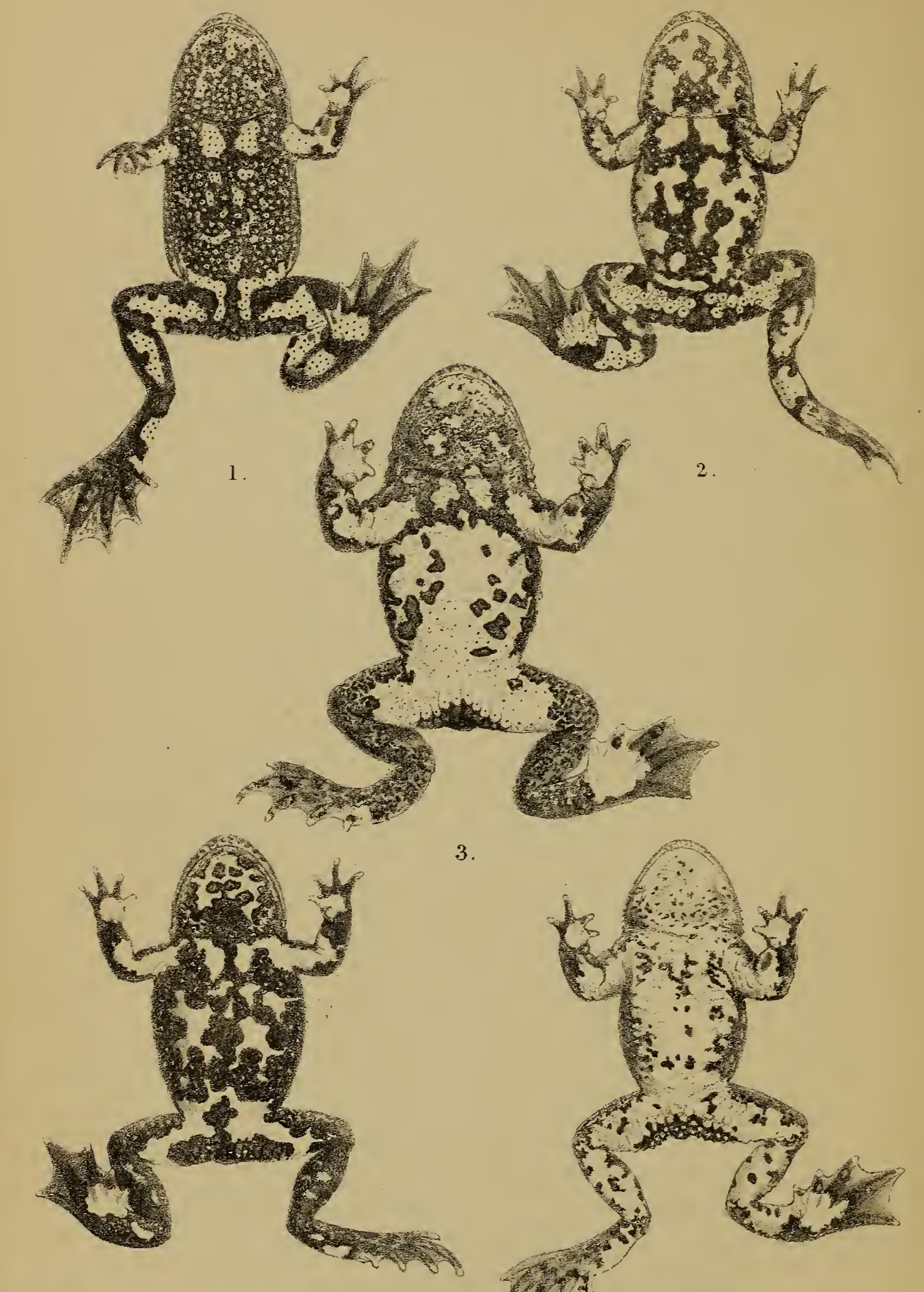

4.

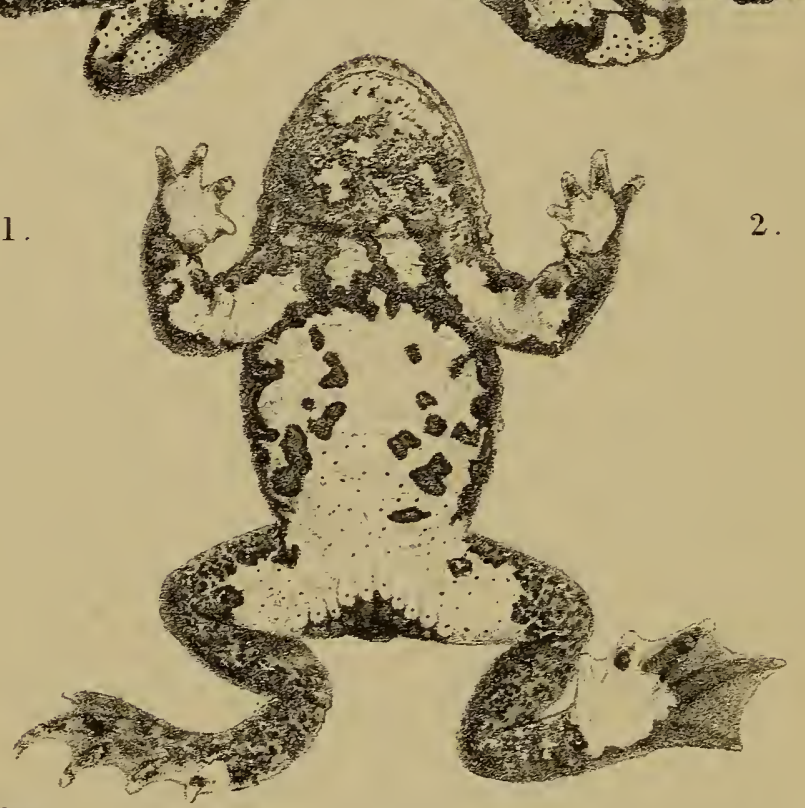

3.

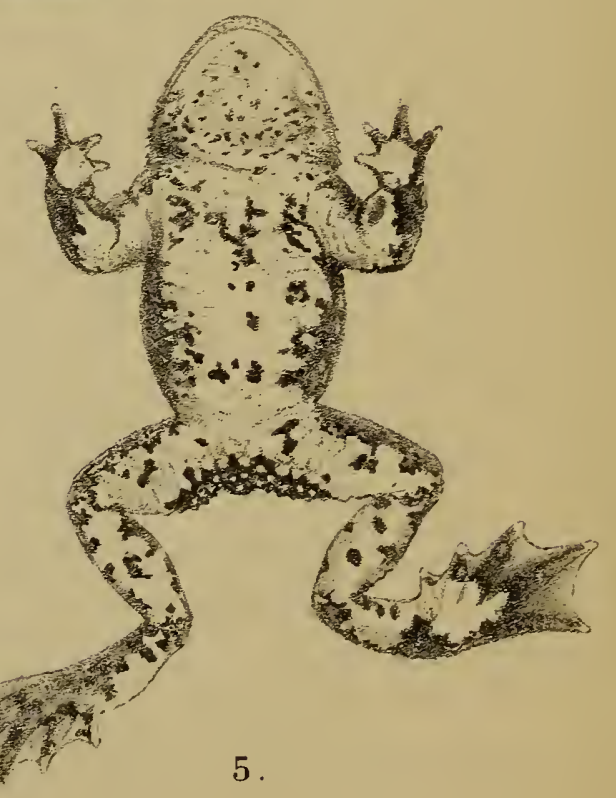

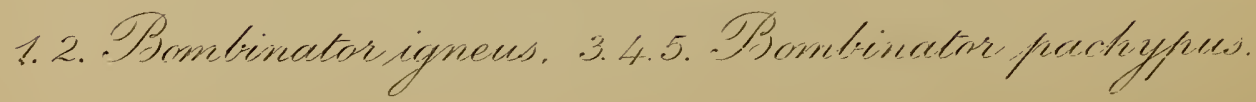


found together. The highest altitude at which it has yet been found is about 800 feet in Transylvania.

The two specimens represented on Pl. V, left hand, are from Magdeburg, kindly sent me by Mr. W. Wolterstorff. The male shows the ventral aspect and the inflated gular sac; the other specimen is a female.

'I'wo more specimens, both males, are figured, lower aspects, on Pl. VI; fig. 1 from Vienna, fig. 2 from Holics, Hungary.

\section{Bombinator pachypus. (Plates V and VI.)}

Roesel, Hist. Ran., p. 97, pls. xxii and xxiii (1758).

Bufo salsus, Schrank, Naturhistor. Briefe, i, p. 308 (1785) ;

Schneider, Hist. Amph., i, p. 213 (1799).

Rance salsa, Gmelin, Syst. Nat., i, p. 1049 (1789).

Rana sonans, Lacépède, Quadr. Ov., i, Syn. Méth., and p. 535, pl. xxxvii (1788).

Rana bombina, Sturm, Deutschl. Faun., iii (1797).

Rana ignea, Shaw, Gen. Zool., iii, p. 116, pl. xxxv (1802).

Bufo bombinus, Daudin, Hist. Rain. Gren. Crap., p. 75 (1803), and Hist. Rept., viii, p. 146 (1803).

Bufo pluvialis, Daudin, Hist. Rain., \&c., pl. 1xxxvi.

Bombina ignea, Oken, Lehrb. Naturg., iii, p. 207 (1816); Koch, in Sturm, Deutschl. Faun., iii (1828); Reider \& Hahn, Faun. Boic., iii (1832).

Bombinator igneus, part., Bonaparte, Icon. Faun. Ital., Rett. Anf. (1838); Schreiber, Herp. Eur., p. 95 (1875); Boulenger, Cat. Batr. Ecaud., p. 447 (1882).

Bombinator pachypus, Fitzinger, in Bonaparte, 1. c. ; Boulenger, Bull. Soc. Zool. France, 1888, p. 175; Héron-Royer \& Van Bambeke, Arch. Biol., ix, 1889, p. 282 ; Bedriaga, Bull. Soc. Nat. Mosc., 1889, p. 566 ; Sasserno, Boll. Mus. Torin., iv, 1889, No. 68; Héron-Royer, Bull. Soc. Et. Sc. Anger's (2), xx, 1891, p. 211; Méhely, Zool. Anz., 1891, p. 269, and Math. Term. Közl. (Budapest), xxiv, 1891, p. 563, pl. ii ; Boulenger, Proc. Zool. Soc., 1891, p. 621, pl. xlvii, fig. 5 ; Méhely, Math. Nat. Ber. Ungarn, x, 1892, p. 68, pl. v; Martin \& Rollinat, Vert. Dép. Indre, p. 352 (1894); Boutenger, Boll. Mus. Torin., xi, 1896, No. 261 ; Werner, Rept. Amph. Oesterr.-Ung., p. 106 (1897); Dürigen, Deutsehl. Amph., p. 543, pl. ii, figs. 1 and 2 (1897).

Bombinator brevipes, Blasius, Isis, 1839, p. 667, and Ber. 19. Ver's. Deutsch. Naturf. Brunswick, p. 81 (1841); Erwin Schulze, Schr. Nat. Ver. Har"z, vi, 1891, p. 40.

Bombinator igneus, Duvernoy, Règne Anim., Rept., pl. xxxix, fig. 1 (1836); Duméril \& Bibron, Erp. Gén., viii, p. 487 (1841); Bruch, Würzb. Nat. Zeitschr , iv, 1863, p. 96 ; Fatio, 
Vert. Suisse, iii, p. 368 (1872); Koch, Ber. Senck. Ges., 1872, p. 162; De Betta, Faun. Ital., Rett. Anf., p. 70 (1874); Lataste, Herp. Gir., p. 275 (1876); Leydig, An. Batr., p. 50 (1877); Bedriaga, Zool. Anz., 1879, p. 664; Camerano, Atti Acc. Tor. (2), xxxv, 1883, p. 211, figs.

Bombinator variegatus, Bedriaga, Bull. Soc. Nat. MLosc., 1881, p. 291.

Bombinator bombinus, Bonlenger, Proc. Zool. Soc., 1886, p. 499,

pl. 1, fig. 1; Héron-Royer, Bull. Soc. Zool. France, 1887, p. 640; Woltersturff, Zeitschr. f. ges. Naturw., lvi, 1888, p. 28; Eivin Schulze, Zool. Anz., 1891, p. 161.

Although closely allied to the preceding, with which it has long been confounded, this species is easily distinguished by several important characters.

The general habitus is stouter still. Head constantly broader than long; snout more broadly rounded, as long as or slightly shorter than the diameter of the orbit; eye rather larger; nostril equally distant from the end of the snout and the eye, or slightly nearer the latter. In some males the tarso-metatarsal articulation reaches a little beyond the eye. Tibia as long as the femur, and as long as or slightly longer than the foot; the heels usually meet when the legs are folded against the thighs. The foot is usually rather swollen, the digits shorter, and the web fuller, often with rectilinear border in the males. Warts on the upper surfaces usually more prominent and more crowded, not forming symmetrical chains; parotoid gland very rarely distinct.

FIG. 57.

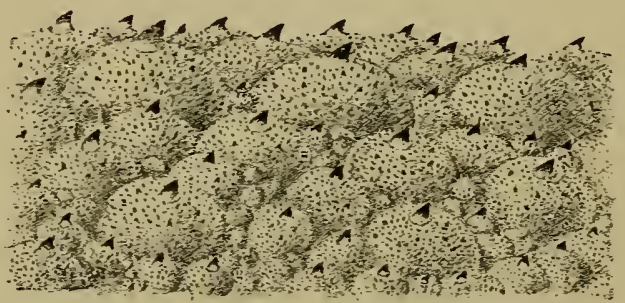

Piece of dorsal skin of male $(\times 8)$.

The black horny excrescences on the warts consisting in the males of regular spines, distinguishable with the aid of an ordinary hand lens, surrounded with very small points (Fig. 57); in female specimens, 
however, these excrescences are often not different from those of $B$. igneus, which in the males may exceptionally assume the form of spines. Gular fold usually absent or rather indistinct; sometimes, however, as well marked as in $B$. igneus.

Upper parts yellowish, greyish-brown, or olive, as if powdered with metallic bronzy dust, uniform or with dark spots disposed as in B. igneus; usually a pair of more or less distinct, light yellowish or whitish, round spots between the shoulders, and another pair further back in the middle of the body. Black has been assigned as the ground colour of the lower surfaces in $B$. igneus; in this species in most cases these parts should be described as yellow, varying from pale straw-colour to orange, with greyish-blue or black spots or marblings, which may be lighter in the centre. In some specimens, however, the black is more diffused, and might be regarded as the ground colour on which small yellow blotches are irregularly distributed, in addition to white dots, as in $B$. igneus; such is the specimen from Basle figured on Pl. VI, fig. 4, and I have seen similar ones from Belgium and Normandy.

The yellow of the lower surface of the thigh sends up a process which is well visible from behind when the animal swims, as a patch halfway between the vent and the leg, and the bright colour of the lower. surface of the arm often extends uninterrupted across the breast, which it never does in $B$. igneus. The fingers and toes are tipped with bright yellow, and the yellow palmar and plantar spots involve the whole of the inner digit, unless interrupted by a small black spot, sometimes the whole of the second, and may even extend on their upper surface; the plantar spot is often, but by no means always, confluent with the tarsal. In specimens from the peninsula of Italy (the typical B. pachypus of Fitzinger), such as the one from Calabria figured on Pl. VI, fig. 3, the yellow tarsal spot is absent or reduced to a few small marblings, and the lower surface of the tibia may also 
be uniform black, or grey spotted with black. In these peninsular specimens, which strongly contrast with those from north of the Po, the yellow of the under surface of the arm does not extend across the breast as usual in the individuals from North Italy, Austria-Hungary, and Germany (var. brevipes), and as shown by the example from Schemnitz, Hungary, figured on Pl. VI, fig. 5; but the breast is either uniform blue, grey, or blackish, or bears a pair of isolated spots as in B. igneus. In France, Belgium, and Switzerland we find individuals bridging over the two forms. Specimens, eight in number, obtained by M. Lataste at Boulay-les-Trous, near Paris, are very interesting in this respect. In all the plantar spot is completely separated from the tarsal, which may be large or broken up and reduced to a few marblings; in some the spots on the breast are completely detached from those of the fore limbs, and the inner digits of both hand and foot are not completely involved in the palmar or plantar spot. Detached spots on the breast and tarsus also occur in Belgian examples. In 25 from near Dinant I count 16 with the plantar spot separated from the tarsal on both sides, 3 with the two confluent, and 6 in which the right side belongs to the one, and the left to the other of the two categories. In 25 from Mondorf, Luxemburg, 7 belong to the first category, 12 to the second, and 6 to either. A specimen from Goslar, Harz, has also the plantar and tarsal spots disconnected.

Some of the principal variations observed in the markings of the lower parts are represented on Pl. VI.

Iris more uniformly bronzy than in the preceding species, with the golden edge to the pupil finer, less distinct; pupil roundish, with lower angle triangular, or, more frequently, cordiform, Y-shaped when fully contracted.

Very young specimens bluish-white or greyish beneath, with black spots and large yellow blotches on the limbs (Bufo salsus, Schrank). In the second 
year the yellow pigment extends to the other parts of the under surface. The bright colours are never fully developed in specimens under $20 \mathrm{~mm}$. body-length.

The male of this species differs from that of the preceding in the total absence of vocal sacs, the submaxillary muscle being undivided; and in the presence, during the breeding season, of a band of black horny excrescences on the inner side of the third finger as well as on the first and second, and of small round or oval groups of similar excrescences under the penultimate phalanx of the third, the second and third, or the second, third, and fourth toes, as first pointed out

FIG. 58.
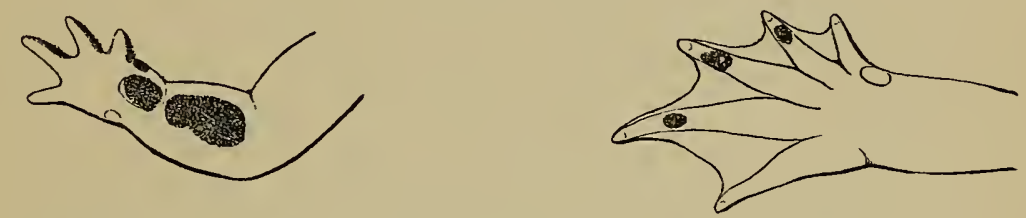

Lower view of fore limb and foot of male, showing nuptial excrescences.

by Bruch in 1863, although their discovery is usually attributed to Leydig, who first gave a figure of them. The spiny horny excrescences of the upper parts are more developed in the males than in the females, the difference being most marked during the breeding season, the development of these excrescences being correlated with that of the so-called copulatory or clasping plates which arm the fingers and toes.

Geographical Variations.-As we have seen above in dealing with the markings of the lower parts, it is possible to correlate some of the variations with the habitat. Thus I think I can in every case recognise specimens from the mountains of the Italian Peninsula, which represent the typical $B$. pachypus, by the predominance of orange or yellow on the belly and the lower surface of the thighs, its absence or its reduction to spots on the breast, and its absence on the tarsi ; the habitus is particularly massive, and the size larger. Specimens from other parts of Europe may be 
grouped together as a var. brevipes, Blasius, in which we notice a gradual predominance of yellow together with an attenuation in its intensity as we proceed from west to east. There is yet a third form, from Montenegro, with which I am only acquainted through Schreiber's description, and which perhaps deserves to rank as a variety; the lower parts are black, without or with small and jolated yellow spots. The skin is described as comparatively smooth, with widely separated warts covered with a black horny layer.

Measurenen's (in millimetres).

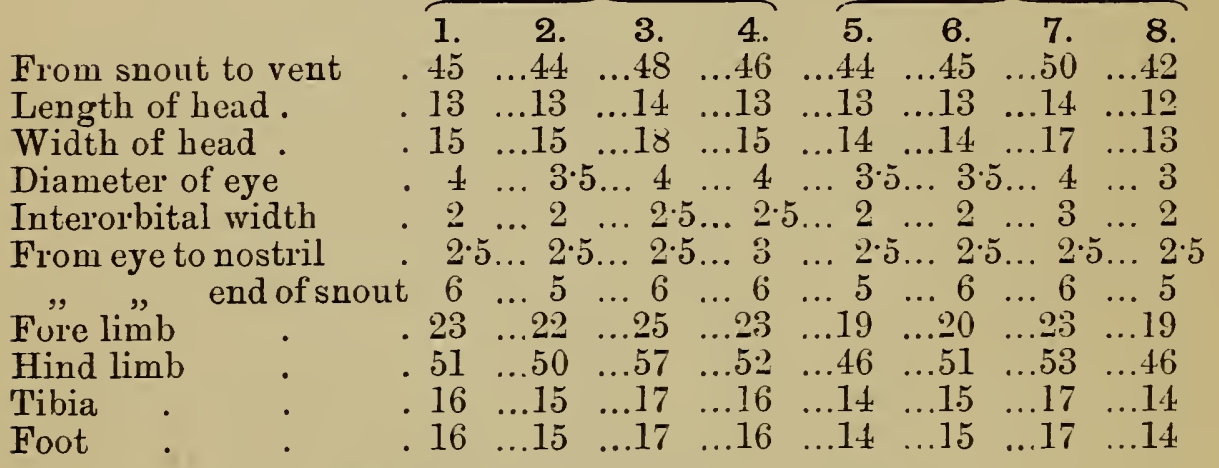

1, 5. Mondorf, Luxemburg: Boulenger.

2, 6. Marcellise, Prov. Verona: De Betta.

3. S. San Bruno, Calabria: Giglioli.

4, 8. Parnassos : Krüper.

7. Arsoli, Rome: Vinciguerra.

SkzLeron.-The osteological differences between this and the preceding species are very slight indeed. The most constant is found in the length of the tibia, which equals that of the femur. The sacral diapophyses are usually not quite so strongly dilated, and the bones are nearly white instead of yellow as usual in the allied species.

As has been shown by Goette, whose great work 'Entwickelungsgeschichte der Unke' deals with this species, by Camerano ('Atti Acc. 'Torin.,' xv, 1880, p. 445) and by Sasserno (op. cit., xxiv, 1889, p. 703), there often occur curious individual anomalies in the posterior vertebræ, which may result in asymmetry of 
the sacrum or in the presence of two sacral diapophyses, the second of which is produced by enlargement of the process at the base of the urostyle, and connected distally with the one in front of it by a common cartilaginous epiphysis. Both Camerano (loc. cit.) and Howes ('Proc. Anat. Soc. Gr. Brit.,' 1890 , p. xvi) have recorded a curious anomaly similar to that observed by Lataste in an Alytes obstetricans : the sacral process on the right side is normal, whilst that on the left side is formed by the tenth vertebra, or base of the urostyle. - The latter bone is sometimes provided with two processes on each side instead of one. I have examined a specimen from Amboise, preserved in M. Lataste's collection, which is remarkable for having nine præsacral vertebræ, and perfectly normal sacral vertebra and urostyle.

Measurements of Skeleton (in millimetres).

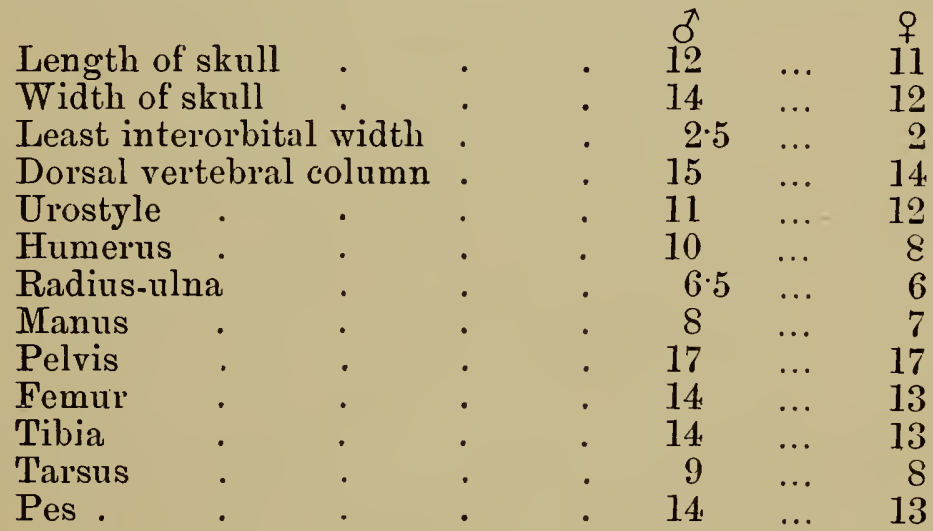

Habits. - B. pachypus has much the same habits as its congener, but is less particular in the choice of the localities. Any sort of pools, warm or cold, clear or dirty, with or without vegetation, even the merest puddles, appear a satisfactory resort to this lively little Batrachian, which may be heard in spring and summer uttering its low and mournful note, hoo, hoo. This sound is often produced by large numbers in a small pool exposed to the full rays of the sun. Pairing takes place two or three times in the year, and spawn is mostly found from the end of May to the middle 
of July, sometimes as late as September, as observed by Pflüger near Bonn. Specimens from Belgium kept by me in confinement were still pairing on August 18th, and Mr. A. Pam informs me that some brought home by him this summer from Switzerland were observed in embrace as late as October 13th.

Méhely found spawn as early as the 2nd of May in Transylvania. Spallanzani, in the last century, observed it pairing in May in the mountains near Modena, and he tells us that during his journey to Switzerland in 1779 the same species was pairing in July and August. I have myself observed it in embrace in the end of May near Salzburg and near Bordeaux, and spawning in Belgium in June and July. Two years ago, around Freiburg in Baden, the breeding seemed to be over in the beginning of August. On the whole, as observed by Werner, this species appears to breed a little later than its congener ; near Vienna, where the two occur, the season has been observed by that authority to begin in the first half of May for B. igneus, in the second half of the same month for $B$. pachypus. The eggs are usually attached to weeds as in the other species; but as they are sometimes laid in puddles without any trace of vegetation, they then simply drop to the bottom. The lack of vegetation is no hindrance to the development of the larvæ, which are mainly carnivorous. Recently transformed young were found by Schrank in the last century in the salt water of the saline caves of Berchtesgaden, Austria.

These Batrachians hibernate on land in holes or under stones. In early spring, in Belgium, I have found several specimens together in their winter quarters-deep recesses between stones, which they shared with Salamandra maculosa. They do not appear to emerge before the end of April, when they travel considerable distances in search of suitable breeding localities, breaking the journey in any small temporary puddle they come across. I much doubt 
their ever spending the winter in the mud at the bottom of pools, as they are believed by Fatio occasionally to do.

EGGs.-Do not differ materially from those of the preceding species. Upper hemisphere pale brown, lower yellowish-white. The figure here given is a copy of Héron-Royer's.

FIG. 59.

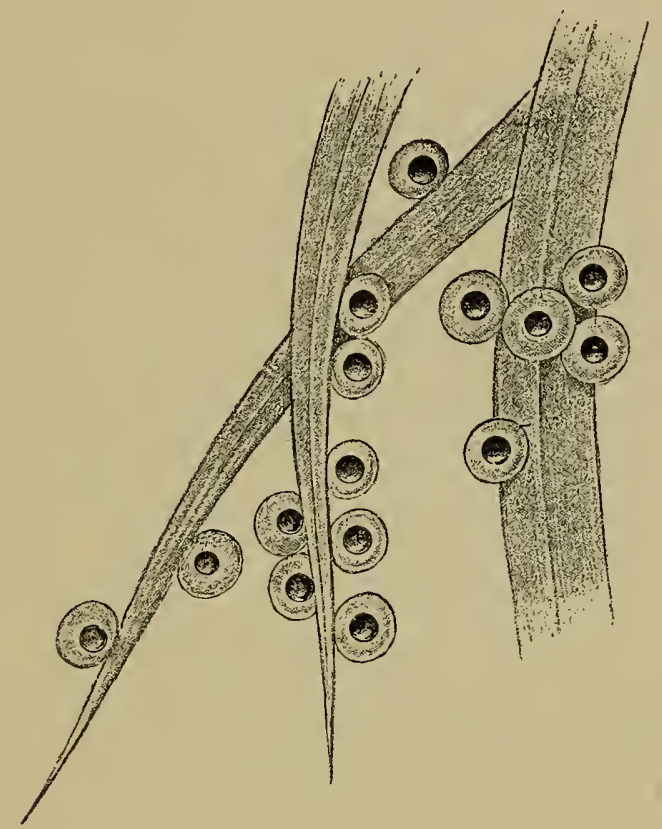

TADPOLE (Pl. I, fig. 3).-One very striking character distinguishes this tadpole from the preceding, viz. the shape of the mouth, which is elliptical as in other genera of Discoglossidx. The tail is, as a rule, rather shorter, and the muciferous crypts are hardly distinguishable in the tadpoles obtained by me; however, it is very probable that the latter difference would not prove constant if tested on more extensive material.

Body $17 \mathrm{~mm}$.; width of body 14; tail 20; depth of tail 10 .

Haвin'at.-Bombinator pachypus has a very extensive range in Europe. It is found nearly all over France with the exception of the north coast of 
Brittany, in the plains as well as in the hills, but very local in many parts, and does not ascend the Pyrenees ; South-eastern Holland; Belgium south of the Sambre and the Meuse, and in the calcareous localities near Tournay; Germany all along the Rhine, but not higher up than 2000 feet in Baden; South Germany, Switzerland, in the valleys as well as on the mountains up to 3900 feet. East of the Weser in Germany this species enters into competition with $B$. igneus, and, as first pointed out by Wolterstorff, becomes restricted to the hills; this being the case wherever the two species co-exist, as in AustriaHungary and Moldavia. Its highest recorded occurrence in Transylvania is at 3900 feet, as in Srvitzerland, whilst in the 'Tyrol it reaches to 4850 feet, and in Bosnia to 5500 feet. In Italy the species is found in Lombardy and Venetia," in the Apuan Alps up to 4500 feet, and along the chain of the Apennines from Emilia to Calabria, between 600 and 3600 feet, as I am informed by Prof. Gighioli. It is on record from the Etna, but not from other parts of Sicily. East of the Adriatic it occurs in Dalmatia, Bosnia, Herzegovina, Montenegro, Turkey (Adrianople), and Greece (Parnassos, 3000 feet).

Méhely has recently expressed the opinion that $B$. pachypus is to be regarded as a typical hill or mountain form, which only descends to the plain in the cooler northern regions, like Rana temporaria. This is certainly not the case. In the south-west of France the species is quite abundant at sea level; I have myself collected it on the banks of the Garonne, in the immediate vicinity of Bordeaux, where it is plentiful in small ditches bordering the vineyards; and E. de Betta found it numerous in the plains of Venetia.

* The species is absent from Piedmont. Some hundred specimens from Venetia were turned loose in the neighbourhood of Turin by Count Peracca about ten year's ago. 
Male (ventral view) and female (dorsal view) specimens from near Dinant, Belgium, are figured on the right side of $\mathrm{Pl}$. V. Ventral views of specimens from the Serra San Bruno, Calabria (fig. 3), Basle, Switzerland (fig. 4), and Schemnitz, Hungary (fig. 5), are given on Pl. VI.

Hybrids.-Mélely has pointed out that in the few places in Hungary where the two species occur together, intermediate specimens are found such as are not to be procured from other localities. These specimens are no doubt hybrids. Héron-Royer succeeded in crossing the two species in both directions, and four nearly adult hybrids are described and figured by him in 'Mém. Soc. Zool. France,' 1891, p. 81. 'These hybrids, which proved fertile, and produced a second generation, were nearly intermediate between the parent forms, but somewhat nearer $B$. igneus, whether the latter was the father or the mother: the ventral spots were lemon-yellow on a black ground; the digits were not tipped with bright yellow; the inner finger and the inner toe were yellow in one specimen, in the others the inner finger was black, but the inner toe yellow. 


\section{ALYTES.}

Wagler, Syst. Amph., p. 206 (1830).

Pupil vertical. Vomerine teeth in transverse or slightly oblique series behind the choanæ. 'Tongue circular, entire, slightly free behind. Tympanum distinct. Fingers free, toes webbed; outer metatarsals separated by web. Diapophyses of sacral vertebra strongly dilated. Urostyle articulated to two condyles.

Two species, both of which inhabit Europe. The presence of three palmar tubercles in A. obstetricans, and of two in $A$. cisternasii, and the short swollen outer finger in the latter easily distinguishes them, in addition to several other characters, external and osteological.

The characters in which the latter species differs from the former are adaptations to more burrowing habits, and of too slight importance, in my opinion, to justify the genus Ammoryctis, proposed by Lataste in 1879 for the then newly discovered Alytes cisternasii, which has since proved to be endowed with the same extraordinary nursing habits as its long known and famous congener. It may be added, as a further argument against generic distinction, that the tadpoles of the two species resemble each other so closely as to be almost indistinguishable before the limbs have made their appearance; this being the only instance that I know among Batrachians of wellmarked species not being differentiated in their larval condition. The contrary would, however, in my opinion, be no valid objection to generic association, for reasons explained in the Introduction, p. 110. 



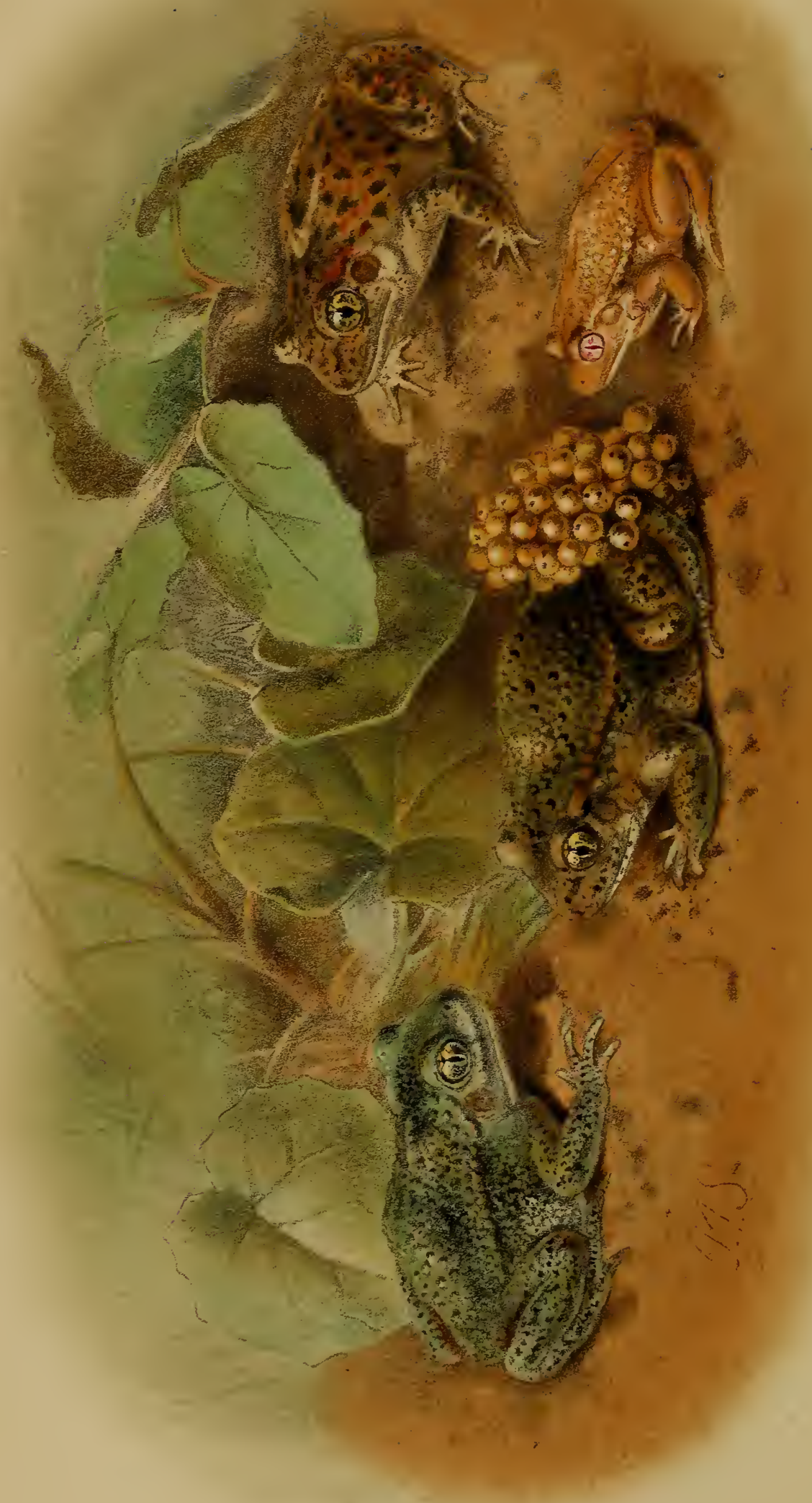




\section{Alytes obstetricans.}

\section{(Plate VII.)}

Demours, Hist. Acad. Sc., 1741, p. 28, and Mém. Ac. Sc., 1778, p. 13.

Bufo obstetricans, Laurenti, Syn. Rept., pp. 28 and 128 (1768); Brongniart, Bull. Soc. Philom., ii, 1801, p. 91, pl. vi, fig. 4; Dandin, Hist. Rain. Gren. Crap., p. 87, pl. xxxii, fig. 1 (1803), and Hist. Rept., viii, p. 176 (1803) ; Zawadski, Faun. Gal.-Bukow. Wirbelth, p. 156 (1840).

Rana campanisona, Laurenti, 1. c., p. 30.

Rana obstetricans, Wolf, in Sturm, Deutschl. Faun., iii, Heft 4 (1805).

Bombinator obstetricans, Merrem, Tent. Syst. Amph., p. 179 (1820); Gravenhorst, Delic. Mus. Vratisl., p. 68 (1829).

Bufo campanisonus, Goldfuss, Handb. d. Zool., p. 484 (1820).

Alytes obstetvicans, Wagler, Icon. Amph., pl. xxii, figs. 3-5 (1830); Schinz, Faun. Helv., p. 145 (1837); Tschudi, Isis, 1837, p. 702 ; Bonaparte, Icon. Fann. Ital., Rett. Anf. (1838); Duméril \& Bibron, Erp. Gén., viii, p. 467 (1841); Günther, Cat. Batr. Sal., p. 38 (1858); Bruch, Würzb. Nat. Zeitschr., iv, 1863, p. 92, and Ber. Offenb. Ver., v, 1864, p. 51, fig.; Fatio, Vert. Suisse, iii, p. 358 (1872); Koch, Ber. Senck. Ges., 1872, p. 155; Schreiber, Herp. Eur., p. 102 (1875); De l'Isle, Ann. Sc. Nat. (3), xx, 1876, No. 7 ; Lataste, Herp. Gir., p. 249 (1876); Leydig, An. Batr., p. 64 (1877); Lataste, Bull. Soc. Zool. France, 1877, p. 281; F. Müller, Verh. Nat. Ges. Basel, vi, 1877, p. 420; Boulenger, Cat. Batr. Ecaud., p. 448 (1882) ; Héron-Royer, Bull. Soc. Zool. France, 1883 , p. 417, pl. xiii, and 1886, p. 671; Nehring, Sitzb. Ges. Nat. Fr. Berlin, 1887, p. 48; Heller, Zool. Gart., xxix, 1888, p. 180; Héron-Royer \& Van Bambeke, Arch. Biol., ix, 1889, p. 285; Bedriaga, Bull. Soc. Nat. Mosc., 1889, p. 596; Fatio, Vert. Suisse, v, App., p. 7 (1890); Wolterstorff, Zool. Anz., 1891, p. 65; Er'win Schulze, Schr. Nat. Ver. Harz, vi, 1891, p. 42; Boulenger, Proc. Zool. Suc., 1891, p. 622, pl. xlvii, tigs. 6 \& 7; Wolterstorff, Zool. Auz., 1893, p. 151 ; Oudemans, Tijdschr. Dierk. Ver. (2), iv, 1893, Vers]., p. xlii ; Martin \& Rollinat, Vert. Dép. Indre, p. 356 (1894); Werner, Rept. Amph. Oesterr..Ung., p. 111 (1897); Dürigen,

Deutschl. Amph., p. 558, pl. i, fig. 4, and pl. ii, fig. 6 (1897). Obstetricans vulyaris, Dugès, Rech. Ostéol. Batr., p. 7 (1834). Alytes obstetricans delislei, Lataste, Rev. Int. Sc., iv, 1879, p. 543. Alytes obstetricans boscai, Lataste, l. c., and Act. Soc. Linn. Bord., xxxiv, 1880, p. 181, pl. xi ; Bedriaga, Amph. Rept. Portug., p. 25 (1889), and Larves Batr. Portug., p. 12 (1891). Alytes boscai, Héron-Royer \& Van Bambeke, 1. c., p. 289.

Vomerine teeth in a transverse series, interrupted in the middle, behind the choanæ; the series extends 
outwards to the vertical of the inner or of the outer border of the choanæ. Tongue large, thick, circular, slightly free behind.

FIG. 60.

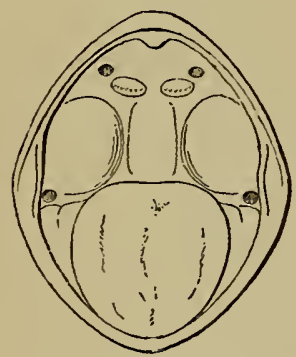

Open mouth.

Head large, moderately depressed, broader than long; snout rounded, slightly projecting, as long as the diameter of the orbit; canthus rostralis rounded; loreal region grooved, nostril a little nearer the eye than the tip of the snout; eye large, very prominent; interorbital space as broad as the upper eyelid, and as broad as or a little broader than the distance between the nostrils; tympanum circular, three-fifths to four-fifths the diameter of the eye.

Fingers rather short, depressed, obtuse, first shorter than second, as long as fourth or slightly shorter, third longest; no subarticular tubercles; Fig.61. three prominent palmar tubercles, corresponding in position to the base of the first, third, and fourth fingers, inner oval, outer round and largest, median round and smallest.

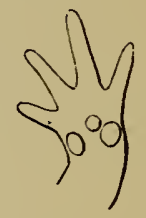

Hind limb short; the tibio-tarsal articulation reaches the shoulder in the female, the tympanum in the male; the tarso-metatarsal

Lower view of left hand. articulation reaches the eye in the female, the tip of the snout or between the eye and the tip of the snont in the male; tibia as long as the femur, the heels meeting when the legs are folded at right angles to the rhachis. Foot as long as or a little shorter than the tibia ; toes short, depressed, obtusely pointed, onethird to one-half webbed, and bordered; no subarticular tubercles; a small, rounded, inner metatarsal tubercle.

Upper parts covered with small smooth warts, limbs nearly smooth, with a glandular thickening on the forearm and another on the calf ; a small, more or less distinct parotoid gland behind the eye above the tympanum, usually followed by a series of smaller glands 
along each side of the body; a more or less distinct round gland behind the angle of the mouth. Throat, belly, and lower surface of thighs, or belly and pubic region granulate; a strong gular fold separating the throat from the breast.

Greyish or pale brown above, speckled with darker or with small greyish-olive or greenish spots, sometimes with red or reddish centres; an ill-defined dark canthal streak sometimes present; a light band across the anterior half of the interocular space, and a triangular, cordiform, or $\Lambda$-shaped light marking between the shoulders are often distinguishable, and between these two light markings a dark triangle or $\mathbf{X}$; the glands of the lateral series often orange or red. Lower parts dirty white or greyish, with the granules of a pure white; limbs carneous; throat and breast often speckled with grey, especially on the sides. Iris pale golden, rarely silvery, veined with black.

Male difficult to distinguish from the female. The body is, however, somewhat shorter, and the fore limbs are a little stronger.

Geographical Variations.-'This species varies very little in France, Germany, and Switzerland. But the specimens from the Spanish Peninsula show less uniformity; the more divergent may be distinguished at a glance, and have been named var. boscx, Lataste. The skin is usually smoother, the parotoid glands are smaller, and the dorsal spots are generally larger and better defined, sometimes forming marblings; these characters combine to produce a physiognomy somewhat suggestive of a young Pelobates cultripes. I am, however, unable to confirm the absolute constancy of the various structural differences by which this variety is to be distinguished from the typical form; measurements of the skull and vertebral column of some Rhenish and Spanish specimens show me that the proportions may, exceptionally, be the same. 


\section{Measurements (in millimetres).}

From snont to rent

Length of head

Width of head

Diameter of eye

Interorbital width .

From eye to nostril

Diameter of tympanum

Fore limb

Hind limb

Tibia

Foot

1. Paris: Lataste.

2. French Jura: Ling Roth.

3. Hameln, Weser; Wolterstorff.

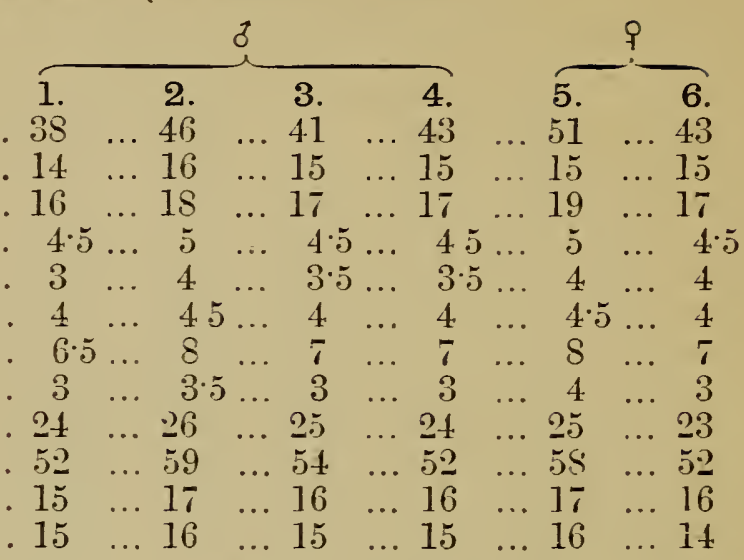

4, 6. Valencia, Spain: Boscá (rar. bosce).

5. Paris: Héron-Royer.

According to Fatio the female reaches a length of $54 \mathrm{~mm}$.

Skeleron.-Ethmoid short, embracing above a large foutanelle which extends nearly to the line of the anterior borders of the orbits; fronto-parietals very narrow, in contact with each other only quite posteriorly, with an inward process in the middle which gives the fontanelle the shape of the sole of a shoe; ethmoid rounded or somewhat produced anteriorly, exposed between the posteriorly diverging inner borders of the nasals, which are large and in contact with each other in front or along the greater part of their length; a cartilaginous supra-orbital plate is articulated to the nasal and the anterior third of the fronto-parietal. Zygomatic branch of the squamosal very short. Vomers large, narrowly separated from each other on the median line, their posterior toothed borders partly covering the feeble palatines ; pterygoid regularly triradiate, the anterior branch joining the maxillary and the slender palatine; parasphenoid $\perp$-shaped, obtuse or truncated in front, not quite reaching the vomers, and separated from the pterygoids. Mento-Meckelians very indistinct.

Hyoid a large, broad, cartilaginous plate with rounded lateral wings, small postero-lateral processes, and long cornua; a pair of diverging, ossified stylo- 
hyals, apart at the base, in front of which a slender $\mathbf{V}$ or $\mathrm{Y}$-shaped ossicle is developed on the ventral side.

Vertebral column trice or a little more or a little less than twice as long as the skull. Spine closed

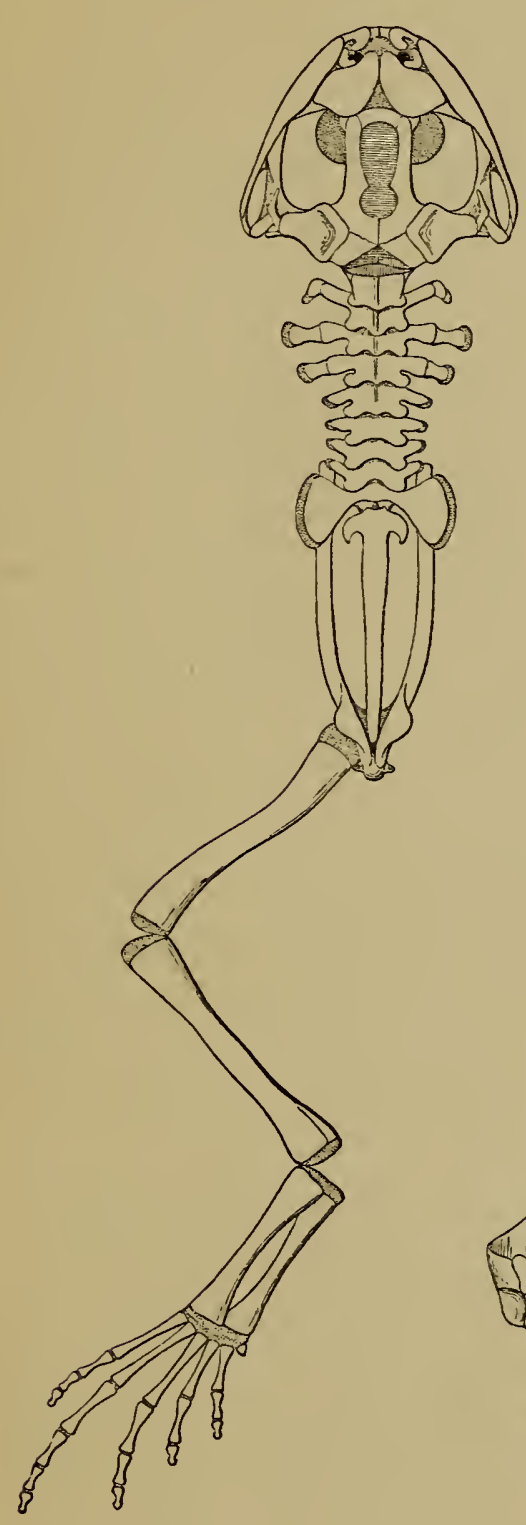

FIG. 62.
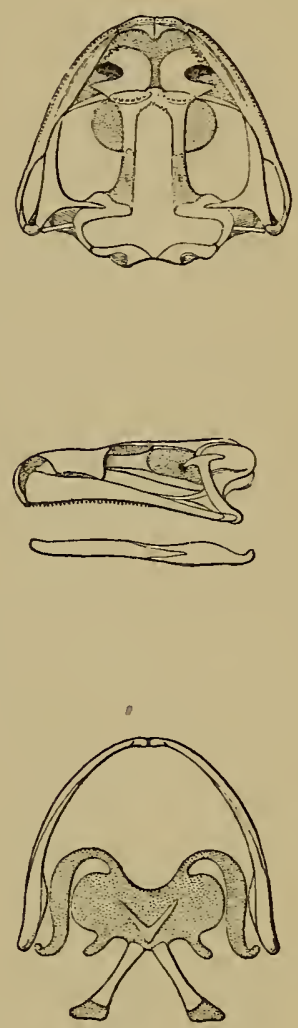

Skeleton of male.

above, the neural arch without or with a very short postero-median process. Second, third, and fourth vertebræ with short diapophyses, with short antogenous ribs. The first rib the shortest and directed 
a little forwards ; the second the longest, nearly horizontal ; the third intermediate in length between the other two, and horizontal or directed slightly backwards; the fourth or fourth and fifth diapophyses nearly horizontal, the sixth and seventh, sometimes also the fifth, directed forwards. Diapophyses of the sacral vertebra triangular, their distal diameter equalling or slightly exceeding their length; two condyles for articulation with the urostyle. Latter nearly as long as or a little shorter than the eight anterior vertebræ taken together, with a rather strong, curved or posteriorly hooked transverse process at the base.

Præcoracoids slender, curved, meeting at an acute angle, entering the glenoid cavity; coracoids stronger, nearly straight; supra-scapula ossified; omosternum absent; cartilaginous sternum with two feebly calcified posteriorly diverging styles. Carpus with eight elements, two of which are in contact with radiusulna; a single bone in the pollex.

Pelvis three-fifths to two-thirds the length of the vertebral column; pubis cartilaginous; acetabulum open. Femur and tibia equal in length, the former strongly curved; astragalus nearly two-thirds the length of the tibia; three small cartilaginous tarsalia; one cartilaginous element to the præhallux. Distal phalanges obtuse, slightly expanded at the apex.

Measurements of Skeleton (in millimetres).

Length of skull

Width of skull

Least interorbital width

Dorsal vertebral column

Urostyle

Humerus

Radius-ulna

Manus

Pelvis

Femur

Tibia

Tarsus

Pes
F. typica.

$\overbrace{0}^{+1}$

. 13 ... 14

. $16 \quad \ldots \quad 17$

. 4 ... 4

$\begin{array}{lll}13 & \ldots & 15\end{array}$

$\begin{array}{lll}12 & \ldots & 12\end{array}$

$\begin{array}{lll}10 & \ldots & 10\end{array}$

1
.$\quad 7 \quad 7$

- 12 ... 11

$\begin{array}{lll}16 & \ldots & 18 \\ 15 & \ldots & 15\end{array}$

- $15 \quad \ldots \quad 15$

. $15 \quad \ldots \quad 15$

. $10 \quad \ldots \quad 10$

. 17 ... 16
Var. bosce.

$\begin{array}{rlc}\overbrace{0}^{3} & & 9 \\ 12 & \ldots & 13 \\ 1+ & \ldots & 16 \\ 3 \cdot 5 & \ldots & 3 \cdot 5 \\ 11 & \ldots & 12 \\ 11 & \ldots & 13 \\ 9 & \ldots & 10 \\ 6 & \ldots & 7 \\ 10 & \ldots & 11 \\ 16 & \ldots & 18 \\ 13 & \ldots & 15 \\ 13 & \ldots & 15 \\ 8 & \ldots & 10 \\ 13 & \ldots & 15\end{array}$


Habi's. - The life-history of this Batrachian is one of great interest, but difficult to observe owing to its nocturnal habits and shy disposition. First discovered in the act of parturition by Demours, in the middle of the last century, on the border of a small pond in the Jardin des Plantes, we have had to wait until the year 1876 for a truly scientific account, based on exact observations, of the mode of oviposition of the so-called "crapaud accoucheur de sa femelle."

This we owe to that most excellent and patient naturalist, Arthur de l'Isle du Drénenf, who, residing near Nantes, in a locality where the species is exceptionally abundant, spent in three consecutive years more than fifty nights in the open in order to unravel the mystery, and whose notes taken on the spot cover 250 foolscap pages of small handwriting. 'I'he account given hereafter of the pairing and oviposition is compiled from that source. Although I have stayed at places where Alytes is not uncommon, and have made nocturnal excursions with a lantern in order to witness the operation, I have, in common with most herpetologists, hitherto failed in my object.

Alytes is nocturnal and slow in its movements; it progresses mostly crawling, but sometimes by short leaps, even when embarrassed with the eggs. It is able to burrow chiefly by means of the fore limbs, but usually selects for its retreat holes made by small mammals, or interstices between stones. Turning. over large stones in the vicinity of the water where its tadpole attracts notice, is the surest means of securing specimens in the daytime. Towards evening it reveals its presence by a clear whistling note, which has often been compared to the sound of a little bell, or to a chime when produced by numerous individuals.

The breeding season lasts throughout spring and summer, and the female is able to spawn two, three, or even four times in the year. The season seems', however, at its height in May and June in the plain; later, of course, in the mountains. 
Pairing and oviposition take place on land. The male seizes the female round the waist; but during impregnation, or when he proceeds to lade himself with the ova, he clasps her round the head in front of the fore limbs. Males are more numerous, and often dispute about the females. When he has secured undisturbed possession the male strongly bends the body so as to bring his heels close to the cloacal region of the female, which he proceeds to lubrify by rapid movements of the inner toes, at times introduced into the cloaca, the two feet working alternately. This sort of raking consists of 1100 to 1300 strokes for the two feet, divided into 15 to 21 periods of 45 to 103 strokes, with intervals of two or three minutes' rest, and lasts about twenty-five minutes. Then the movements suddenly stop, the female extends her hind limbs, tightly embracing those of the male, which are bent at angles at the knees, the tarsi erect and pressed close together; the eggs are suddenly expelled, with noise, as if by explosion, and fall into the rhomboidal receptacle formed between the pelvic limbs and bounded behind and beneath by the tarsi and feet of the male. The yellow eggs, as if threaded together by elastic filaments, form a large mass, two to four layers of about ten, in this receptacle.

The very moment the eggs are emitted the male unclasps the waist of the female and shifts his hold to the base of the head; the body then stretched out, but the legs remaining in the same position as before, fecundation commences; it takes place in two or three emissions at short intervals. 'T'he seminal fluid is much diluted with the contents of the urinary bladder, which soaks the envelops of the eggs. An interval of ten to fifteen minutes' rest follows before the male proceeds to attach the eggs to his legs. This is done in the following manner:- Still holding his mate round the head, he draws out the legs so as to stretch the elastic connections between the eggs sticking to his tarsi ; then, folding one of the limbs, bringing the 
knee to the level of the sacrum, and stretching it out again, he passes it, toes first, into the egg-mass; the other limb follows in like manner. These movements are repeated several times, and accompanied by one or two seminal ejaculations. Thus the strings of eggs come to be fastened round the legs, where they will remain until eclosion. All the time this operation has lasted, about ten minutes, the female has remained motionless, still connected with the eggs by the last elastic filaments from the oviducts. 'l'hese two threads stretch to a length of 4 to 12 inches before breaking when the pair separates.

'Thus laden, and yet so little impeded in his movements as to occasionally resort again to hymen during the nursing period, and successfully add on a second burden, the male retires to his usual retreat, going about at night in order to feed himself and to keep up the moisture of the eggrs, even resorting to a short immersion in the water during exceptionally dry nights. The development within the egg takes about three weeks, sometimes a little less, often a little more. The male enters the water with his burden; the larvæ, in the full tadpole condition, measuring 14 to $17 \mathrm{~mm}$., bite their way through the tough envelop, which is not abandoned by the father until all the young are liberated.

'The tadpole is found in spring and summer, at all stages of development, in small reservoirs, cow-ponds, flooded quarries, pits in brick-fields, \&c. The tadpoles of the late broods hibernate under the ice, concealed in recesses but not torpid. Some specimens, at least in confinement, remain nearly two years before transforming, but, as a rule, larvæ born early in the spring accomplish their metamorphosis within three to five months. The duration of the larval life varies, however, in individuals of the same brood; and as such as have not sufficiently developed their limbs to take to the land in the autumn have necessarily to postpone the metamorphosis until the following spring, it 
follows that whereas some may have spent only three or four months in the water, their brothers will sojourn for a whole year or more in that element. Young reared by me measured, immediately after metamorphosis, from 18 to $22 \mathrm{~mm}$. from snout to vent.

EGGs.-Large, the vitellus measuring $3 \frac{1}{2}$ to $5 \mathrm{~mm}$. in diameter, varying in colour from pale straw-yellow to bright yellow. They are coated with

Fig. 63. two transparent gelatinous envelops, the outer of which is tough and elastic, and forms the threads by which the eggs are connected in two rosary-like series as they issue from the cloaca. These connecting threads measure, without great tension, from 4 to $7 \mathrm{~mm}$., and according to the number of eggs, which varies between 18 and 54 , the whole rosary has a length of $70 \mathrm{~cm}$. to $2 \mathrm{~m}$. Males observed by Geisenheyner and Melsheimer with 126 and 150 egg's were no doubt nursing double or treble broods.

When fresh laid the eggrs are nearly spherical, but they soon acquire a more transversely oval shape. Through the transparent capsules the whole development can be easily followed. An enormously large vitelline sac is present, and the embryo develops uncommonly long, unpigmented gills, one only on each side, with a large number of slender branches along the ventral side of the trunk. These gills are absorbed and replaced by internal ones, and the transformations which accompany the passage from the first or embryonic to the second or tadpole period are all effected within the ego-capsules. The embryos are at first uniform yellowish-white; the pigment, when it appears, forms two brown stripes, but before hatching the little tadpole has put on his grey, more or less spotted coloration.

TADPOLE (Pl. I, figs. 4 and 5).- -Length of body once and one-third to once and a half its width, two-fifths to one-half the length of the tail. Nostrils nearly 
halfway between the end of the snout and the eyes. Eyes on the upper surface of the body, the distance between them about twice as great as that between the nostrils, and equal to or slightly greater than the width of the mouth. Spiraculum in the mid-ventral line, a little nearer the anterior than the posterior extremity of the body. Anal opening median, very much larger than the spiraculum. Tail twice and two-thirds to thrice as long as deep, ending in an obtuse point; the upper crest convex, usually a little deeper than the lower, and extending but very slightly upon the back; the depth of the muscular portion, at its base, about half the total depth.

Beak white, with a broad black margin. Lip entirely surrounded by a series of papillæ. Labial teeth in $\frac{2}{3}$ series, occupying nearly the whole width of the inner surface of the lip, all continuous, or the third lower narrowly broken up in the middle; the first upper and the first lower series composed of one or two rows of teeth, the others of two or three.

Lines of crypts usually very indistinct; all that can be distinguished being the usual lines from the end of the snout between the nostrils, bordering the eyes above, behind and below, and forming a loop on each side of the upper lip, a line beginning at a considerable distance behind the eye along each side of the back to the upper border of the muscular part of the tail, and another very short line close to and parallel with the anterior extremity of the latter. But in a fine specimen from Bellaigues, Switzerland, I find the lines much more distinct and blackish; in addition to the series described above, it shows the second dorsal line prolonged to the base of the tail, which also bears two lines, the upper being on the supra-caudal crest; a short series descends vertically from below the centre of the eye, another, curved, from below the anterior extremity of the dorsal lines, a third on each side of the mouth, and a fourth extends on each side of the belly, from the level of the spiraculum nearly 
to the origin of the lind limbs, its anterior extremity bent downwards and forwards. This specimen is figured above (p. 104, Fig. 46, c).

Lead-grey to blackish above, uniform or with round blackish spots; sides with large silvery or pale golden spots; tail with numerous dark brown dots or round black spots, which are very apparent on the greyishwhite crests. Nearly black tadpoles as well as albinos are on record.

Total length $80 \mathrm{~mm}$. ; body, 28 ; width of body, 21 ; tail, 52 ; depth of tail, 19 . Exceptionally grows to $90 \mathrm{~mm}$.

Habita's. - The midwife toad is common in France nearly everywhere; it is also found in Belgium (provinces Namur, Liége, and Luxemburg), South-eastern Holland (Limburg), Luxemburg, Sivitzerland, Vorarlberg, in Germany along the Rhine, and locally in hilly districts as far east as Brunswick and Thuringia (Hameln on the Weser being the northernmost, Nordhausen and Eisenach the easternmost points of its ascertained distribution), and all over Spain and Portugal. It ascends to 5000 feet in the Alps of Sivitzerland, and to 6500 feet in the Pyrenees (Lac Bleu, Hautes-Pyrénées), where the snow is not absent for more than three months.

Specimens have been introduced by Knauthe near Schlaupitz, in Silesia, some years ago, and appear to have established themselves there. 'T'he species is stated to occur in Bukowina, whence it was described by Zawadski in 1840. It would be highly interesting to ascertain whether it does really extend so far to the east; for the present the statement can only be accepted with caution.

In France the midwife toad is found in the plains as well as in the mountains; common at Biarritz, close to the sea, it extends high up the Pyrenees. I have also found it on the coast of Normandy, and, as Prof. Bavay informs me, it occurs on the coast of Finistère. East of the Rhine, however, its habitat, like that of 
Bombinator pachypus, becomes restricted to the hills. It by no means avoids the divellings of man, and may be found in great numbers in old walls of villages as well as in gardens and waste grounds of towns. It is still to be met with in the Jardin des Plantes, where it was first discovered in the middle of the last century.

Four specimens are figured on Pl. VII, viz. a male from Paris, laden with eggs; a female from Liége, on the left hand; a young albino from Génevilliers near Paris, reared by M. Lataste; and on the right hand a specimen from Valencia, Spain (var. bosce).

\section{Aly'tes oisterernasil.}

\section{(Plate VIII.)}

Alytes cisternasi, Boscá, An. Soc. Esp., viii, 1879, p. 217 ; Boulenger, Cat. Batr. Ecaud., p. 449 (1882); Héron-Royer \& Van Bambeke, Arch. Biol., ix, 1889, p. 289; Bedriaga, Bull. Soc. Nat. Mosc., 1889, p. 617, Amph. Rept. Portug., p. 27 (1889), and Larves Batr. Portug., p. 141 (1891); Boulenger, Proc. Zool. Soc., 1891, p. 624, pl. xlvii, fig. 8.

Ammoryctis cisternasi, Latiste, C. R. Ac. Sc., lxxxviii, 1879, p. 983 ; Boscá, Bull. Soc. Zool. France, 1880, p. 252, and An. Soc. Esp., x, 1881, pl. ii, figs. 1-6.

Vomerine teeth in two transverse series, widely separated from each other in the middle, behind the choanæ;

FIG. 64.

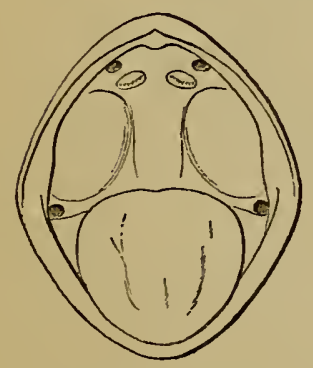

Open mouth. these series often slightly oblique, forming together an angle pointing forwards. T'ongue large, circular, slightly free behind.

Head large, moderately depressed, much broader than long; snout rounded, projecting, shorter than the diameter of the orbit; canthus rostralis rounded, loreal region grooved; nostril nearer the tip of the snout than the eye; eye large, very prominent; interorbital space broader than the upper eyelid, as 
broad as the distance between the nostrils; tympanum three-fifths to two-thirds the diameter of the eye.

Fingers rather short, depressed, obtuse, first shorter than second, third a little longer than second, fourth shortest; fourth finger very thick, stumplike, brown and horny at the end; no subarticular tubercles; two prominent palmar tubercles, inner small and oval, outer very large, oval, oblique. Brachium nearly entirely embedded in the skin of the body.

Hind limb short; the tibio-tarsal articulation reaches the axil or the shoulder; the Lower view tarso-metatarsal articulation reaches the tym- of right panum or the eye; tibia as long as the femur, FIG. 65. the heels meeting when the limbs are folded. Foot as long as or a little shorter than the tibia; toes short, depressed, obtusely pointed, one-third webbed; no subarticular tubercles; a small, oval inner metatarsal tubercle.

Upper parts covered with very small smooth warts ; snout smooth; a series of enlarged warts along the upper eyelid; a very small parotoid gland. Lower parts coarsely granulate; a strong gular fold.

Greyish or brownish above, with small dark spots; a light cross-bar between the eyes, and three light spots on a line between the shoulders; the enlarged warts on the eyelids whitish or orange; some of the warts on the sides also whitish or orange. Some specimens have the markings better defined, and a light triangular or cordiform spot between the shoulders is accompanied by an oblique, curved light band on each side of the back, beginning from the supra-temporal fold. These markings, which may also be observed, though less defined, in the preceding species, are highly suggestive of those of certain specimens of Discoglossus pictus, and afford further evidence of the close relationship, so long overlooked, which exists between the two genera. Lower parts whitish. Iris golden. 
Measurements (in millimetres).

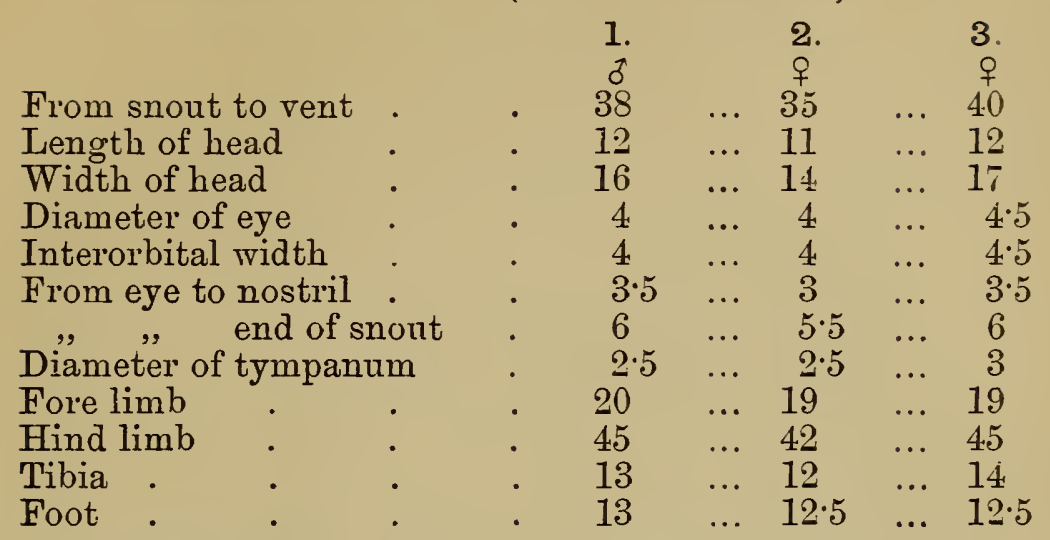

1, 2, Merida, Spain: Boscá. 3. Badajos, Spain : Boscá.

Skele'ron.-Apart from the stouter and shorter limb-bones, the skeleton of this species differs from that of the preceding in the larger nasals, which overlap the ethmoid and the inner borders of which meet along their entire length, in the constricted frontoparietals, and in the shape of the fronto-parietal fontanelle, which is divided into two portions between which the fronto-parietals form a bridge; the anterior fontanelle is large and kite-shaped, the posterior very small, a mere foramen between the fronto-parietals.

FIG. 66.
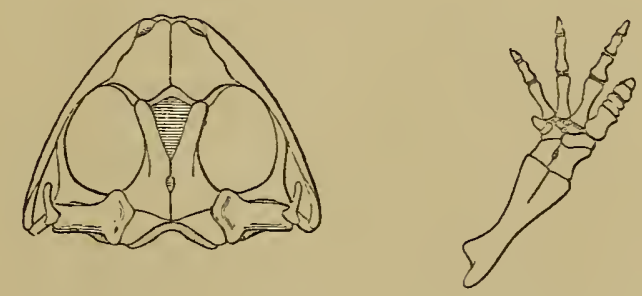

Upper view of skull and lower view of left forearm and hand.

The coracoids and præcoracoids are more flattened and more robust, and the metacarpal and phalanges of the outer finger are shorter and more massive; the terminal one in particular being extremely short, nearly hemispherical. The femur is slightly longer than the tibia.

The more strongly ossified cranium is correlated 
with the burrowing habits of this species, and the differences noticed between this species and $A$. obstetricans are merely of degree.

Measurements of Skeleton (in millimetres).

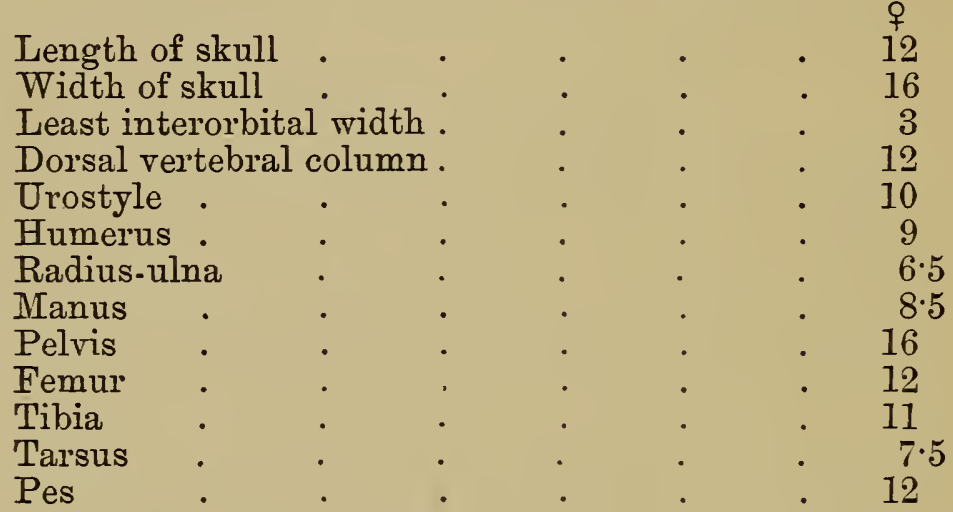

HaBITS.-This species is a burrower in sandy localities, digging by means of the outer edge of the hands. In accordance with these habits its lungs are more developed than in the allied species. Boscá having found the male carrying the egg's, in April, there is no doubt the breeding habits are much the same as in A. obstetricans, although the pairing has not yet been actually observed. The tadpole is to be found all the year round.

TADPOLE (Pl. I, fig. 6).-I am not able to detect any character by which this tadpole may be surely distinguished from that of $A$. obstetricans. The spots on the tail are, however, smaller, more crowded, and forming vermiculations on the muscular portion, the space occupied by the lateral groove being usually free from spots.

Length of body, $20 \mathrm{~mm}$; width of body, $15 \mathrm{~mm}$.; tail, $42 \mathrm{~mm}$.; depth of tail, 14.

Habitat.-Spain (Aragon, New Castille, Estremadura) and Portugal (Douro, Beira, and Alemtejo).

The specimen figured on Pl. VIII is a female, one of the types from Spain, preserved in M. Lataste's collection. 
[At page 179 .

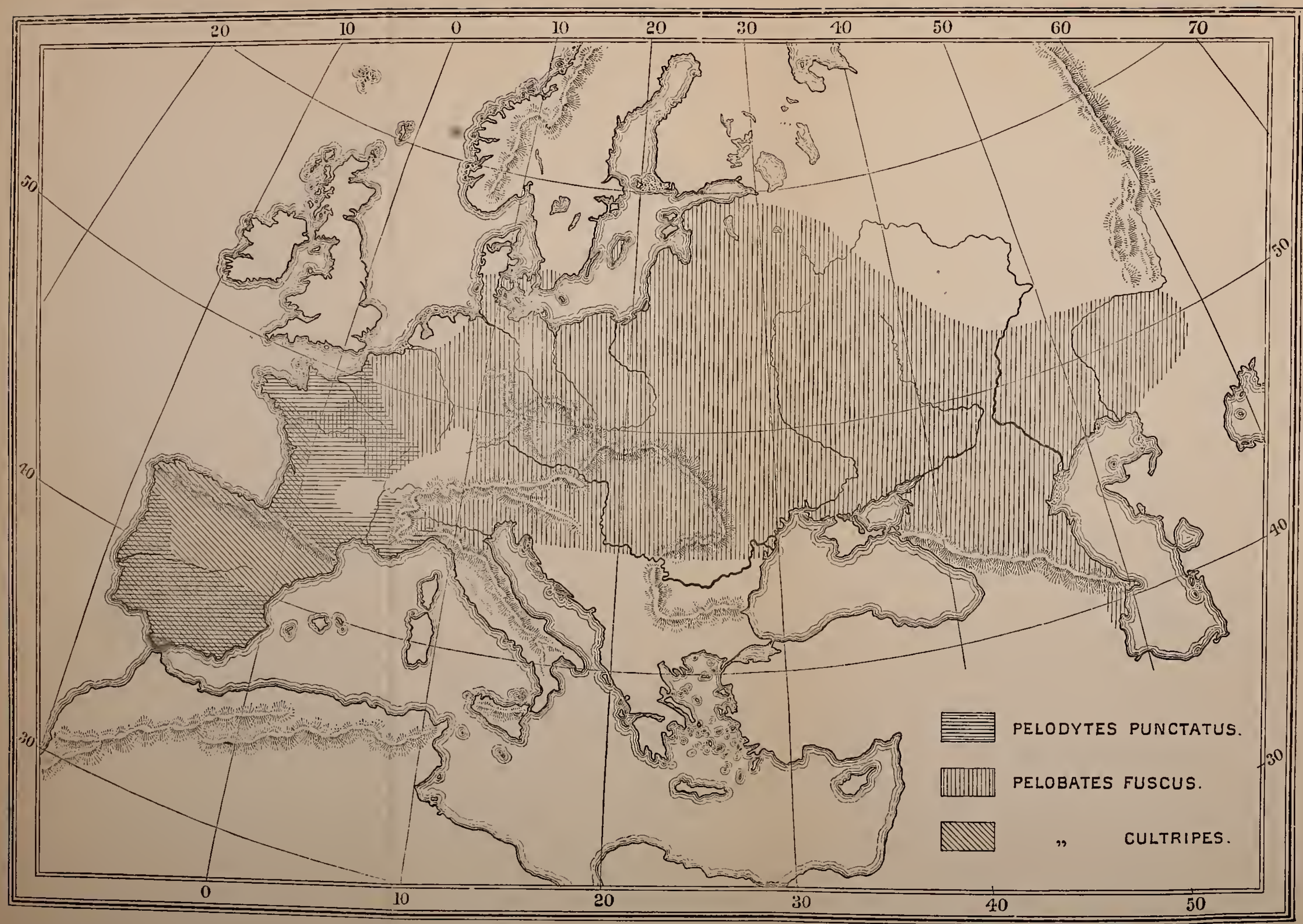

DISTRIBUTION OF EUROPEAN PELOBATID瓜. 



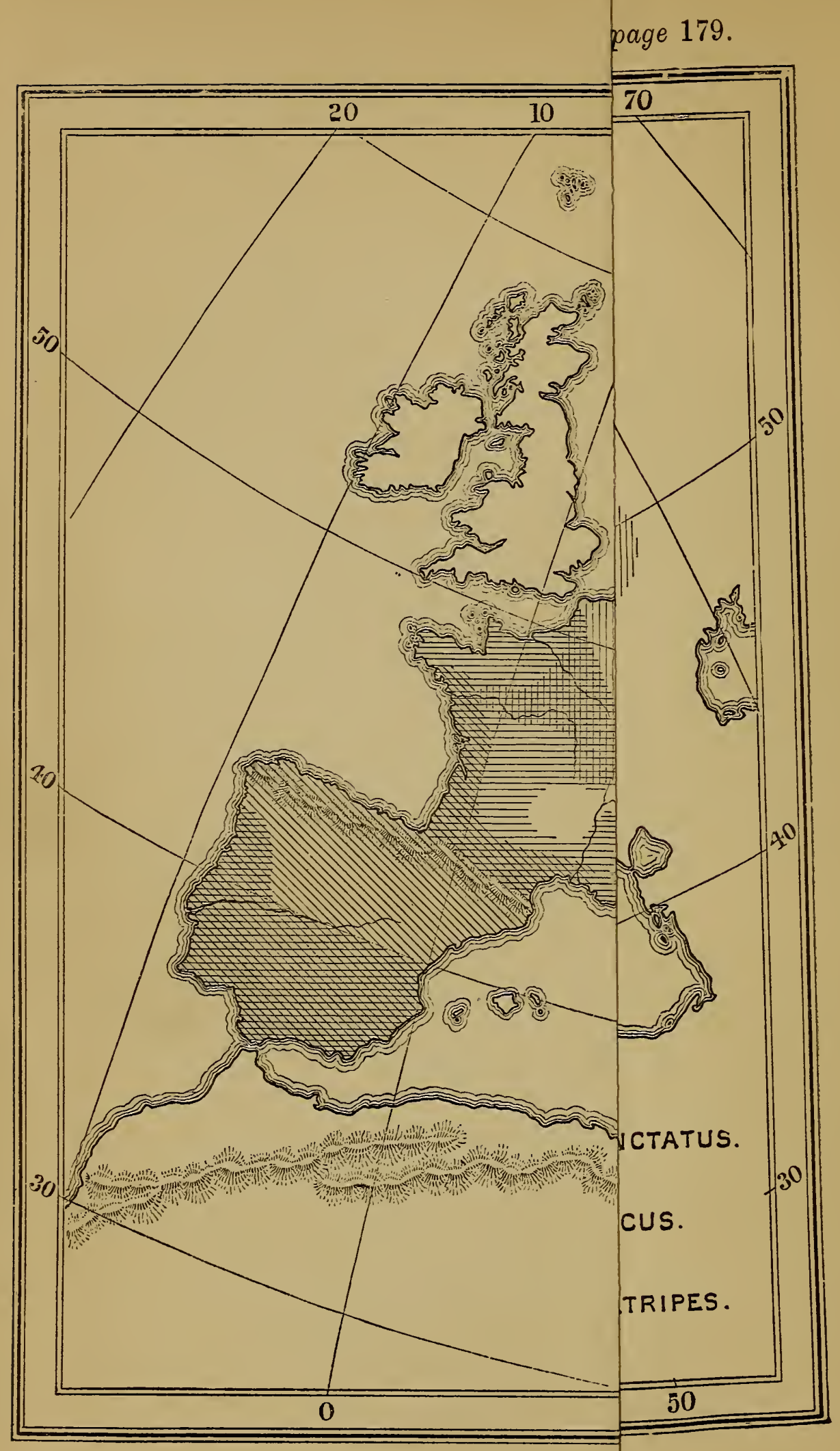




\section{Family 2.-PELOBATID卌.}

Vertebræ procœlous (in the European genera), without autogenous ribs; diapophyses of sacral vertebra very strongly dilated. Upper jaw toothed.

The Pelobatidæ occupy an intermediate position between the Discoglossidæ and the Bufonidæ. Seven genera are known, inhabiting Europe and Southwestern Asia, South-eastern Asia and New Guinea, and North America and Mexico.*

The two European genera are easily distinguished:Pelodytes, slender and frog-like, with deeply cleft toes, and a more or less distinct tympanum; Pelobates, stout and toad-like, with broadly webbed toes, no tympanum, the skin of the head adherent to the skull, and a large, sharp-edged, shovel-shaped tarsal tubercle.

Both genera must be looked upon as highly specialised forms of a group which has, in all probability, sprung up from the Discoglossidx, with which some of the exotic genera are nearer connected through a character to which great importance has been attached, viz. the opisthocœlous rertebræ.

A map is here given showing the range of the three European species of this family.

\section{Peludytes.}

Fitzinger, in Bonaparte, Icon. Faun. Ital., Rett. Anf. (1838).

Pupil vertical. Vomerine teeth in two small groups between the choanæ. Tongue subcircular, entire or slightly nicked, and free behind. Tympanum present,

* Exotic genera:

Scaphiopus, Holbu. E. and S. United States, Mexico.

Batrachopsis, Blgr. New Guinea.

Leptobrachium, Tsch. S. China, Further India and Malay Archipelago.

Megalophrys, Kuhl. Malay Peninsula and Archipelago.

Asterophys, Tsch. New Guinea.

The last two have opisthocœlous vertebræ. 
more or less distinct or hidden under the skin. Fingers free, toes webbed at the base and more or less distinctly bordered; outer metatarsals separated by web. Proximal tarsal bones fused. Vertebræ procolous; diapophyses of sacral vertebra very strongly dilated; two condyles for articulation with urostyle. Omosternum cartilaginous; sternum with a bony style.

This genus includes two species:-P. punctatus, Fitz., of Western Continental Europe, and $P$. caucasicus, Blgr., recently discovered on the Asiatic side of the Caucasus at an altitude of 7000 feet. The latter has been made the type of a distinct genus, Pelodytopsis, by Nikolski, on grounds too trivial to deserve recognition.

Perhaps this Pelodytes caucasicus may yet be found in Cis-Caucasia, and yield a further addition to the European fauna. It is distinguished from its congener in the longer hind limbs, the tibio-tarsal articulation reaching the tip of the snout, and the somewhat more posterior position of the groups of vomerine teeth; the toes are not so strongly fringed in the male, the fore limbs are more robust, and the black horny nuptial excrescences are much more strongly developed on the warts and ridges of the upper surfaces.

\section{Pelody'tes punctatus.}

\section{(Plate VIII.)}

Rana punctata, Daudin, Hist. Rain. Gren. Crap., p. 51, pl. xvi, fig. 1 (1803), and Hist. Rept., viii, p. 100 (1803).

Rana plicata, Daudin, ll. cc., pp. 53, 102.

Rana daudinii, Merrem, Tent. Syst. Amph., p. 177 (1820).

Bombinator plicatus, Fitzinger, N. Class. Rept., p. 65 (1826).

Obstetricans punctatus, Dugès, Rech. Ostéol. Batr.. p. 7 (1834). Alytes punctatus, Tschudi, Class. Batr., p. 84 (1838).

Pelodytes punctatus (Fitzinger), Bonaparte, Faum. Ital., Rett. Anf. (1838); Duméril \& Bibron, Erp. Gén., viii, p. 463 (1841);

Thomas, Ann. Sc. Nat. (4), i, 1854, p. 290 ; Günther, Cat. Batr. Sal., p. 35 (1858); Fatio, Vert. Suisse, iii, p. 353 (1872);

De Betta, Faun. Ital., Rett. Anf., p. 68 (1874); Schreiber, Herp. Eur., p. 99 (1875); Lataste, Herp. Gironde, p. 242 



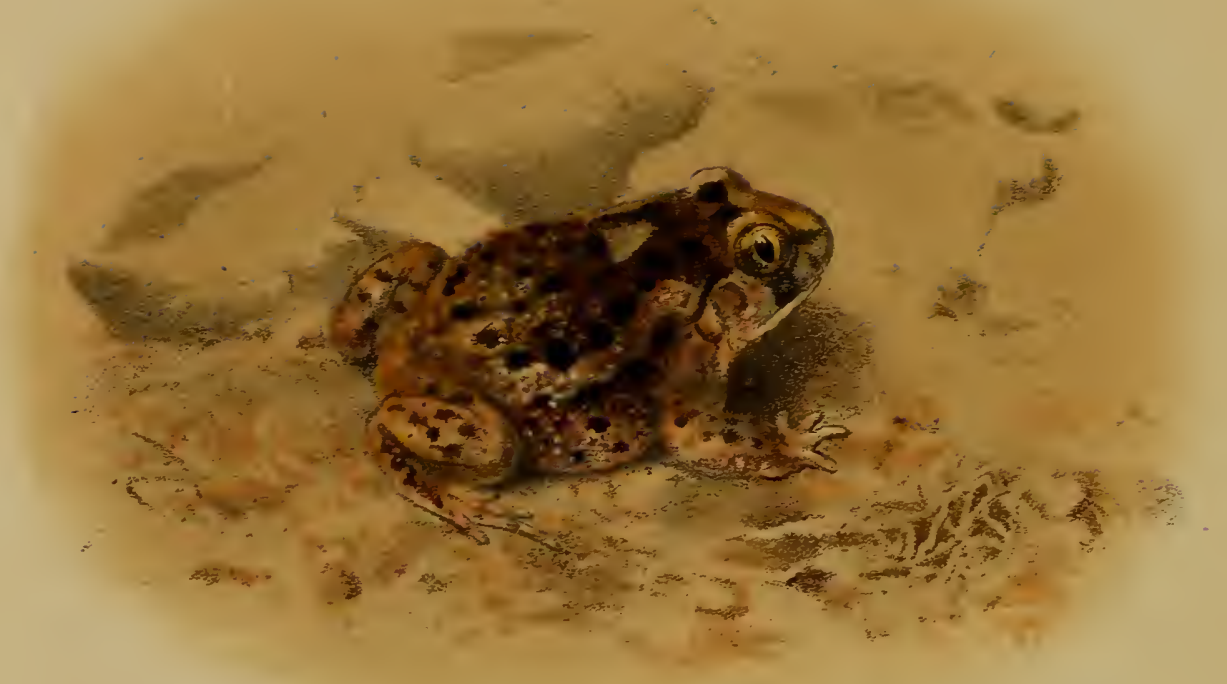

- Alytes cisternarie.

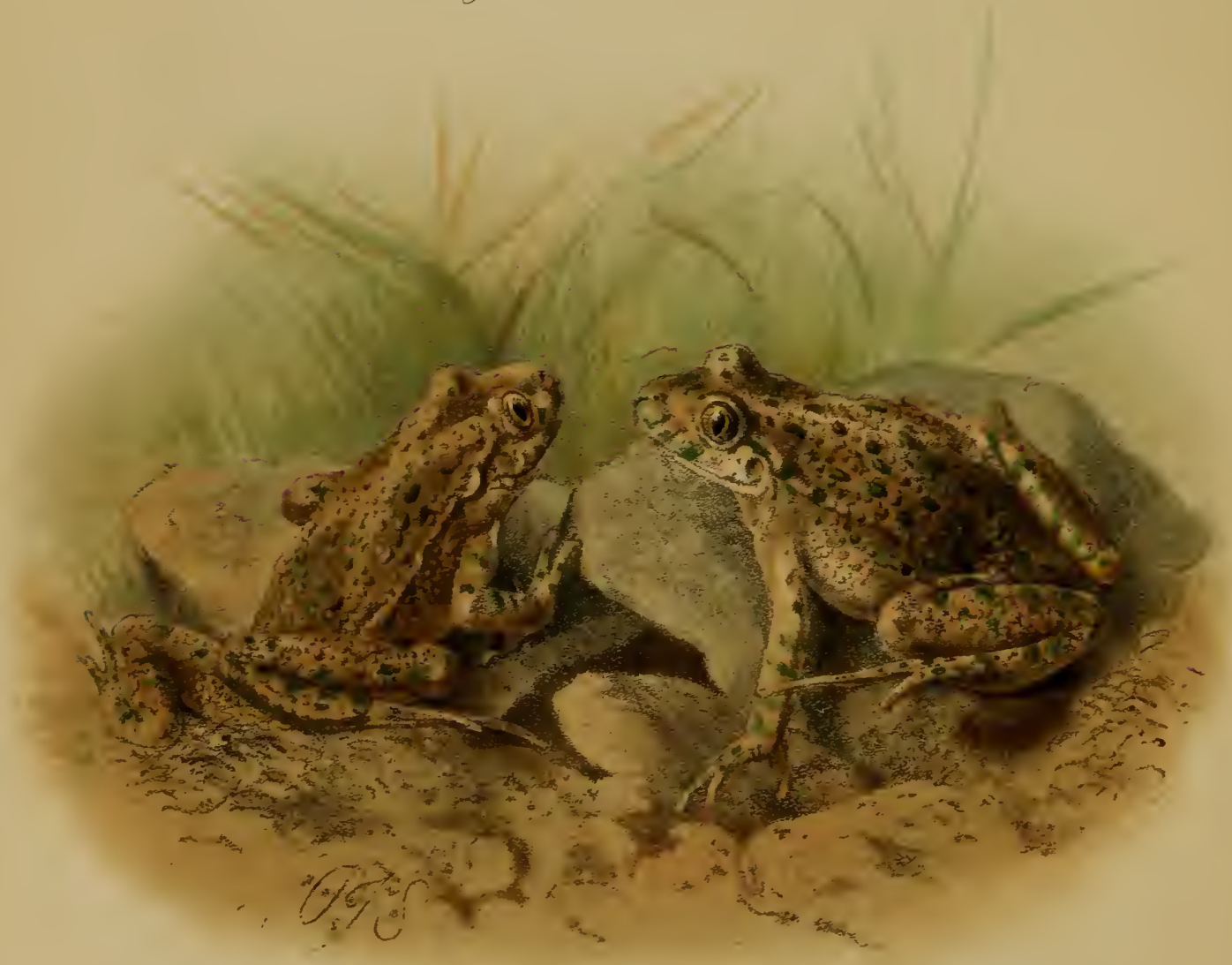

Pelodytes fuenctatus. 


(1876); Héron-Royer, Bull. Soc. Zool. France, 1878, pp. 128 \& 299, pl. iii, and 1879 , p. 229, pls. $x$ and xi; Boulenger, Bull. Soc. Zool. France, 1880, p. 225, and Cat. Batr. Ecaud., p. 438 (1882); Peracca, Boll. Mus. Torin., i, 1886, No. 1; Héron-Royer, Buil. Soc. Et. Sc. Angers, xv, 1886, p. 91; Héron-Royer \& Van Bambeke, Arch. Biol., ix, 1889, p. 277, pl. xx, figs. 5-12 ; Bedriaga, Bull. Soc. Nat. Mosc., 1889, p. 533, and Amph. Rept. Portug., p. 20 (1890); Boulenger; Proc. Zool. Soc., 1891, p. 617, pl. xlvii, figs. 1 \& 2 ; Bedriaga, Amph. Rept. Portug., Suppl., p. 11 (1893); Martin \& Rollinat, Vert. Dép. Indre, p. 349 (1894).

Pelodytes daudini, Boscá, Bull. Soc. Zool. France, 1880, p. 255.

Vomerine teeth in two short transverse or slightly oblique series on a line with the anterior borders of the choanæ; these series either close together or nearer the choanse than each other. 'Tongue large, circular, entire or feebly nicked behind.

Head much depressed, as long as broad or slightly broader than long; snout rounded, projecting beyond the mouth, as long as the diameter of the orbit; canthus rostralis rounded; loreal region grooved; nostril midrway between the eye and the tip of the snout or a little FIG. 67. nearer the latter ; eye large, prominent; interorbital space as broad as or a little narrower than the upper eyelid, and equal to the distance between the nostrils; tympanum usually moderately distinct, sometimes hidden, one-half to three-fifths the diameter of the eye.

Fingers rather elongate, somewhat swollen at the end, third much the longest, first a little shorter than second, which is a little shorter than fourth; basal subarticular tubercles distinct; three palmar tubercles, median smallest and circular.

Hind limb rather slender; the tibio-tarsal articulation reaches the eye or between the eye and the nostril; tibia a little longer than femur, the heels overlapping when the legs are folded at right angles to the rhachis. Foot as long as or a little longer than the tibia; toes slender, webbed at the base, the web extending as a fringe along each side to the 
tips, which are slightly swollen; subarticular tubercles feeble or indistinct; no tarsal fold; a small, rounded inner metatarsal tubercle.

Upper surfaces covered with more or less prominent porous warts of unequal size; the larger warts on the back sometimes disposed in wavy longitudinal series; a strong glandular fold from the eye to above the shoulder, passing above the tympanum, and sometimes followed along each side of the body by a chain of large warts. Lower surfaces smooth except the posterior part of the belly and the thighs, which are coarsely granulate.

Greyish or pale greyish-olive above, with small irregular dark olive, bottle-green, or bright green spots (whence the name "Persille"' by which this Batrachian is known in some parts of France), which may be confluent into more or less regular cross-bars on the limbs; between the eyes two oblique streaks of the dark colour, converging backwards, are usually distinct; a dark streak extends from the tip of the snout to the eye, involving the nostril, and often reappears behind the eye along the supra-temporal fold; two or three dark vertical bars, sometimes broken up into spots, on the upper lip; the larger warts on the sides sometimes orange or rusty red; a light $\mathbf{X}$-shaped marking on the ground colour is usually more or less distinct on the anterior part of the body, the anterior branches extending to the upper eyelids, the posterior to the sacral region. Lower parts white, often yellowish on the limbs and rosy about the inguinal region. Iris golden, more or less pigmented with brown on the lower half, or bronzy-brown with a fine pale golden border to the pupil.

Male distinguished from the female by a shorter body, longer and more robust fore limbs, a greater development of the dermal borders of the toes, and the presence of an internal vocal sac which communicates with the mouth through a long slit on each side of the tongue; owing to the pigmentation of the vocal 
sac the throat appears pale purplish-grey. During the breeding season horny excrescences are much developed on the lower surfaces, and similar productions of small size are sometimes also scattered on the upper surfaces, the largest crowning the principal warts; no trace of them being found normally in the females. These excrescences, which are of a dark purplish-brown or black colour, are disposed as follows on the lower surfaces :-A rounded group on each side of the breast, at the base of the arm; another on the arm; a band along the inner side of the fore-arm; and a band along the inner side of the two inner fingers; there FIG. 68.

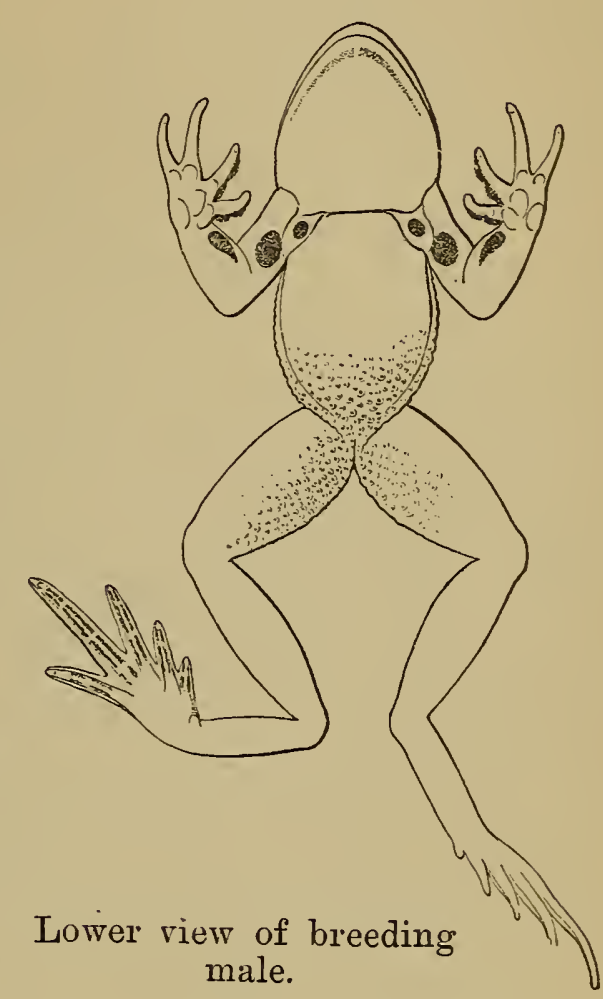

are besides, very often, a band on the chin, isolated points on the abdominal granules, and two linear series along the toes, interrupted at the articulations.

\section{Measurements (in millimetres).}

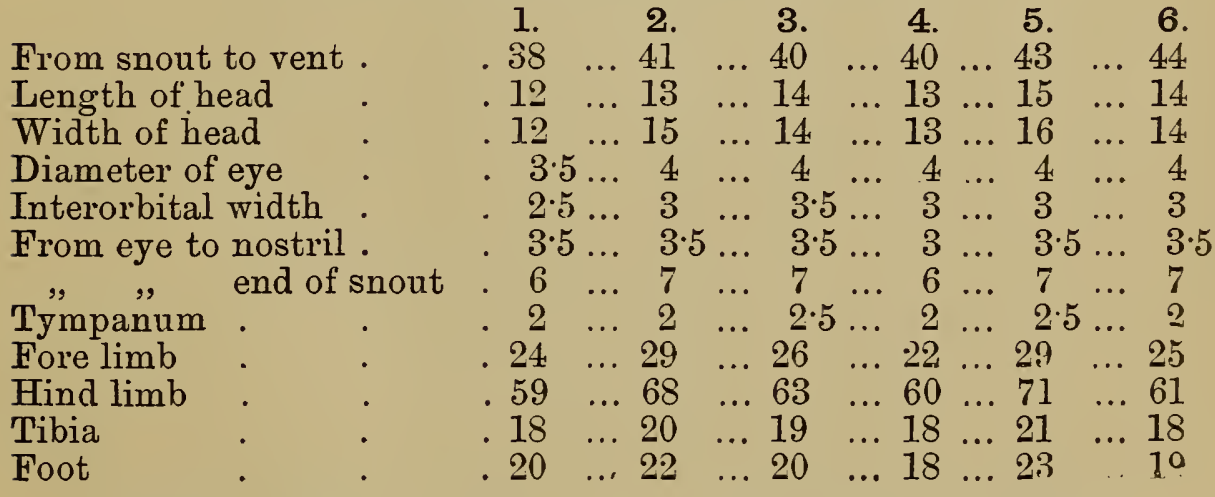

1, 4. Paris: Héron-Royer.

2, 5. Nice: Bedriaga.

3,6. Valencia: Lilford 
Sheleton.-The skull, so far as the shape and the extent of ossification are concerned, is intermediate between that of Discoglossus and that of Bombinator, agreeing with the latter in the absence of palatine bones. Etbmoid short, not extending posteriorly beyond the anterior two fifths of the basisphenoid; the lower anterior lamina rounded or truncate, and extending nearly to the posterior border of the vomers; the upper obtusely pointed and extending to between the nasals. The large chondrocranial fontanelle is only partially covered by the fronto-parietals, these bones being in contact with each other to but a small extent either behind or in the middle. Nasals moderately large, tear-shaped, not meeting on the median line. Zygomatic branch of the squamosal short. Vomers moderately large, narrowly separated from each other on the median line; pterygoids rather slender, the anterior branch longest and joining the maxillary; parasphenoid dagger-shaped, sharply pointed in front, and extending forwards to the line of the anterior borders of the orbits, separated from the pterygoids. Mento-Meckelian bones distinguishable only from the inner side of the mandible.

Hyoid a large cartilaginous plate with slender postero-lateral processes; anterior processes much expanded, turned inwards and closely approximating. in front, and confluent with the lateral wings, enclosing a small fenestra; thyrohyals slender, diverging, narrowly separated from each other at the base; a pair of slender ossifications in front of the thyroidals on the ventral side, distinct and L-shaped or united

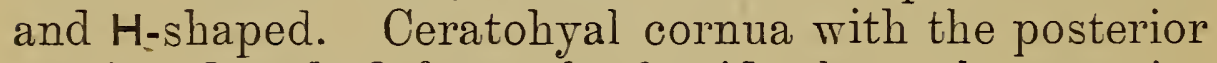
portion detached from the hyoid plate, the anterior portion being included in the hyoid plate.

Vertebral column twice or a little less than twice as long as the skull. Spine closed above; neural arch without or with a very short postero-median process. First diapophysis obliquely directed forwards ; second, third, and fourth horizontal; second longest, 
fourth small; fifth, sixth, and seventh small, slender, and directed forwards.

FIG. 69.

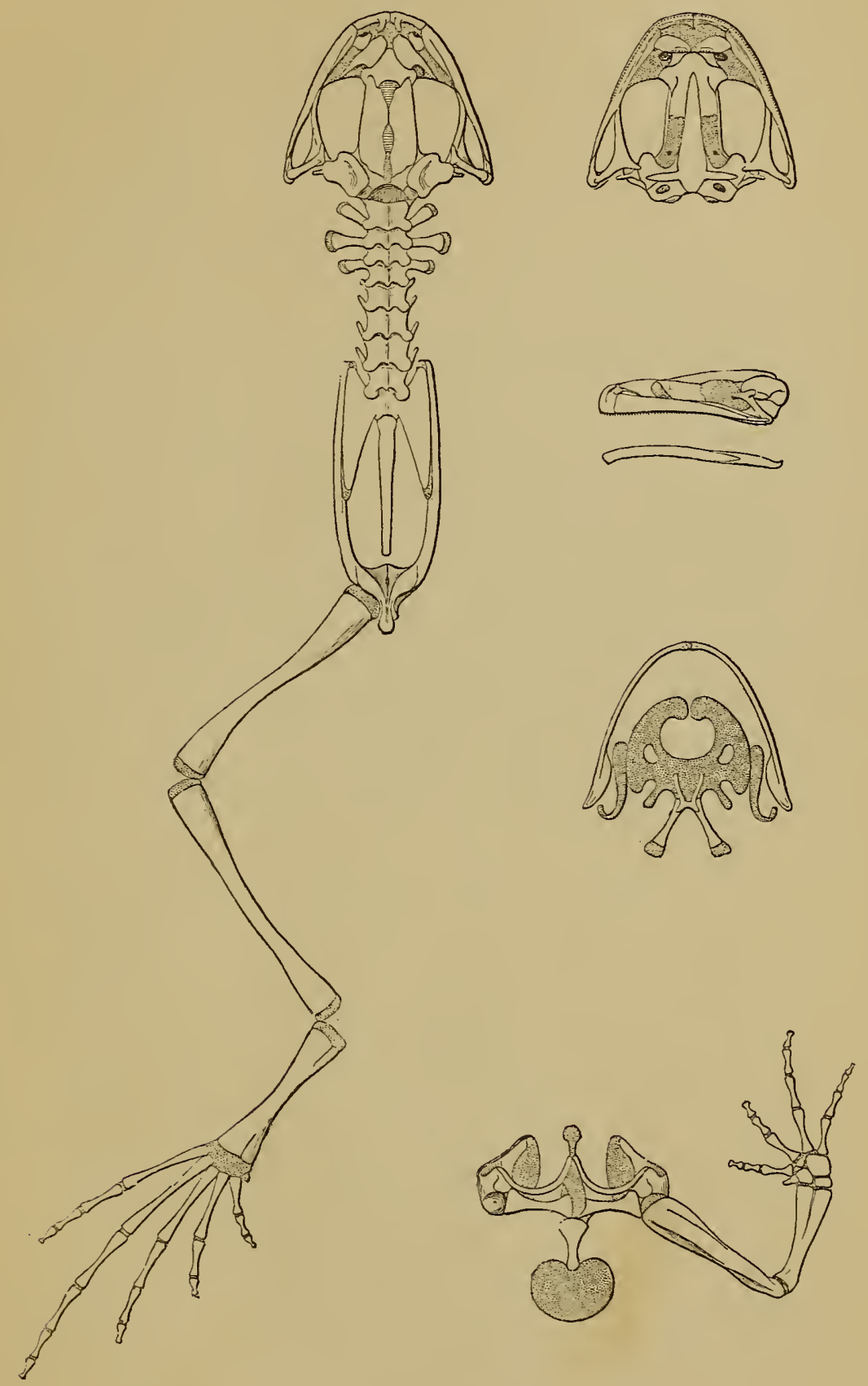

Skeleton of male.

Sacral vertebra with very strongly dilated diapophysis, the transverse diameter of which is nearly 
three times in the longitudinal, but little shorter than the urostyle, which articulates by two sockets, and measures three-fifths to two-thirds the length of the remainder of the vertebral column.

Præcoracoids slender, strongly curved; coracoids nearly straight, dilated at both ends; a cartilaginous omosternum; sternum with a bony style dilated proximally, and a large discoid cartilage. Humerus considerably longer than radius-ulna. Carpus with seven elements, three of which are in contact with radiusulna; a single bone in the pollex.

Pelvis three-quarters the length of the vertebral column; ilia with an inner groove, embracing the sacral processes; the pubis does not ossify. Femur and tibia with the epiphysis cartilaginous; tibia a little longer than the femur, nearly as long as the pelvis; calcaneum and astragalus completely fused into a single slender bone with a minute foramen in the middle, resembling the tibia, of which it measures three-fifths the length; the elements of the distal row of the tarsus are not ossified, and the præhallux contains two cartilages. Distal phalanx of all digits slightly expanded at the apex.

\section{Measurements of Skeleton (in millimetres).}

\begin{tabular}{|c|c|c|}
\hline Length of skull & ${ }_{11}^{\delta}$ & \\
\hline Width of skull & & $\ldots$ \\
\hline Least interorbital width & 2 & $\cdots$ \\
\hline $\begin{array}{l}\text { Dorsal vertebral column } \\
\text { Urostyle }\end{array}$ & 12 & $\cdots$ \\
\hline $\begin{array}{l}\text { Urostyle } \\
\text { Humerus }\end{array}$ & $8 \cdot 5$ & \\
\hline Radius-ulna & 6 & . \\
\hline $\begin{array}{l}\text { Manus } \\
\text { Pelvis }\end{array}$ & $\begin{array}{r}9 \\
15\end{array}$ & $\cdots$ \\
\hline Femur & 14 & \\
\hline Tibia & 16 & .. \\
\hline Tarsus & $7=$ & $\cdots$ \\
\hline Pes & & \\
\hline
\end{tabular}

HaBITs.-This small and graceful Batrachian is essentially nocturnal; only during the breeding season is it met with in the daytime. Its long limbs enable it 
to jump in the manner of the true frogs, covering 14 or 15 inches at one leap, and it is besides a good climber, ascending smooth vertical surfaces by adhesion of the abdominal surface. Nor, in spite of its nearly free toes, is it a bad swimmer, often frequenting deep ponds during the pairing time. Its dermal secretion bears a strong smell of garlic As often heard in the evening, its voice is feeble, a sort of creck-crecticreck, which cannot be better compared than to the creaking of a leather shoe. But during the pairing the male produces, under water, a more sonorous and very different note-co-ack, to which the female responds by a feeble coo.

As a general rule, Pelodytes punctatus breeds, in France, between the end of February and the beginning of April; but instances of its breeding in May, July, August, September, October, and November have been placed on record by A. Thomas, Lataste, Bedriaga, and myself. Thomas, who first observed the breeding habits of this Batrachian, near Nantes, stated that it spawns twice in the year, in the spring and in the autumn. According to HéronRoyer, another French observer who devoted special attention to the habits of the same animal, Pelodytes breeds only once a year, in the spring. Bedriaga has observed the spawning to take place in the south of France in the spring and again in the autumn. On the 30th of October, 1896, he was so kind as to send me from Nice a large number of breeding specimens, - among them, however, only two females, one of which spawned on the way and the other reached me with eggs in the oviducts. Having, besides, myself found Pelodytes pairing on the north coast of Brittany at the end of August, I have no doubt Héron-Royer was wrong, and that the autumnal hymen will also be found to take place near Paris, where the species is so plentiful.

The mode of embrace, which falls in the lumbar type, is peculiar. Owing to the thin waist of the 
female the elbows of the male join on the pubic region, and the forearms are carried forwards, pressed against the middle line of the belly, the hands meeting without intercrossing the fingers. Sometimes, however, the embrace is less close, the elbows fitting into the groins, and the forearms forming an angle on the belly. The pairing is usually of short duration, a few hours only,

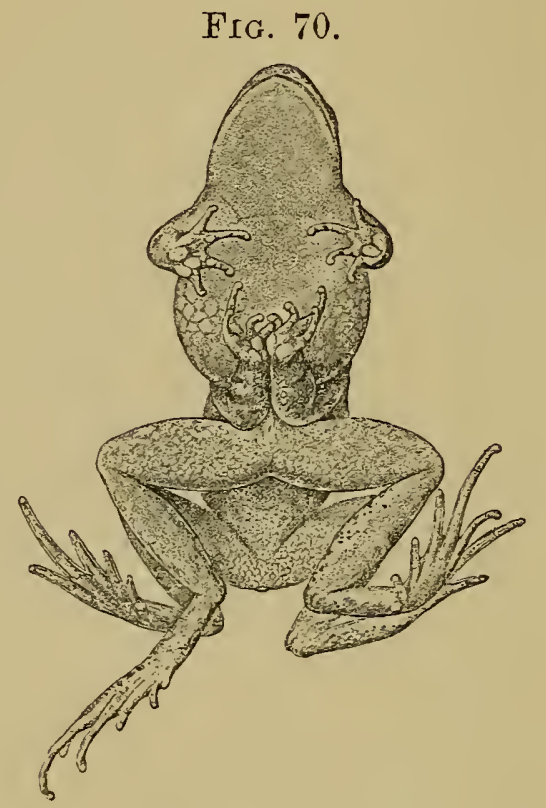

Lower view of male and female pairing.

and the male will, as a rule, let go if handled. Specimens kept in confinement by me last winter paired in January, and remained together for nearly three weeks.

Stagnant water of all sorts is resorted to for the purpose of spawning, provided it be furnished with vegetation, preferably Graminacea, round the stems of which the bands of ora are twined.

The larvæ of the spring broods transform in July and August; but late offspring of course hibernate in the larval condition, and tadpoles may therefore be found throughout the year.

Males are more frequent than females; out of 150 specimens collected by Lataste in the Gironde during the spring of 1877 , only 20 were female. 
EGGS.-Small, measuring $1 \frac{1}{2}$ to $2 \mathrm{~mm}$. in diameter; blackish, with the lower pole white. Laid in two strings which coalesce in the cloaca, thus forming a single lengthened band, often broken into several pieces, twined round the stalks of small reeds or grass below the surface of the water. The mucilaginous capsule surrounding each egg measures $2 \frac{1}{2}$ to $3 \mathrm{~mm}$.; the outer envelop, which in the toads forms a sort of tube protecting the eggrs, is here absent; and when, as sometimes happens, the band is deposited in fragments, the eggmasses embracing a stalk may have more the appearance of little balls, resembling, but for the darker colour, those of Hyla arborea.

FIG. 71.

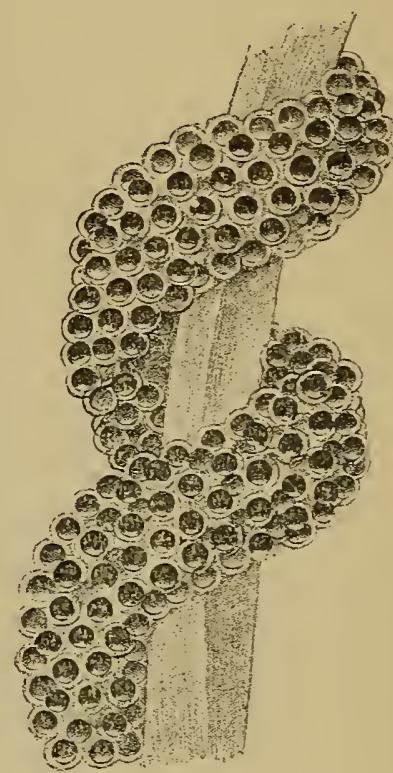

Héron-Royer has ascertained the number of ova in a brood to vary between 1000 and 1600, and the embryo to leave the mucilaginous envelop on the fifth day, at a very low stage of development, tailless, and having not yet developed the gills.

Tadpole (Pl. I, figs. 7 and 8). - Length of body rather more than once and a half its width, and not quite two-thirds the length of the tail. Nostrils halfway between the end of the snout and the eyes, or a little nearer the latter. Eyes on the upper surface of the body, equidistant from the end of the snout and the spiraculum, the distance between them about twice as great as that between the nostrils, and equal to the width of the mouth. Spiraculum on the left side, directed upwards and backwards, nearly equidistant from either extremity of the body, visible from above and from below. Anal opening median, much larger than the opening of the spiraculum. Tail trice and a half to three times as long as deep, ending in an obtuse point; the upper crest very convex, deeper 
than the lower, and rarely extending forwards as far as the level of the spiraculum; the depth of the muscular portion at its base one-third to two-fifths of the greatest total depth.

Beak white, with a black margin. An inverted fold at the side of the lip; this is furnished with a single row of papillæ except on the upper border, which is toothed. Labial teeth in $\frac{4}{4}$ or $\frac{5}{5}$ series, the second and third, both above and below, the longest; the first and second series in both divisions of the lip uninterrupted, or the second upper with very slight median interruption, the others separated in the middle and gradually decreasing in length to the fifth, which if present is short. According to Bedriaga, there may be as many as six series of teeth on the lower lip, the first three of which are uninterrupted.

Lines of crypts usually very apparent, but sometimes very indistinct. On the head they approach each other between the nostrils and completely border the eye posteriorly, the anterior extremities of this naso-orbital hoop approaching each other above the upper lip. Of the two dorsal lines, which diverge posteriorly, the upper, extending to the dorsal edge of the muscular portion of the tail, is interrupted at a short distance behind the eye; its anterior portion may even descend to join the lower line, which thus appears bifurcated in front; the lower line extends, usually uninterrupted, from behind the eye to the middle of the muscular portion of the tail, where it is lost ; both lines, however, may stop short of the tail. A sinuous line, on the flanks, curved above the spiraculum, not bent upwards posteriorly, sometimes extending nearly to the origin of the hind limbs. In addition to these lines a short horizontal branch originates above the upper lip, and bifurcating below the vertical of the anterior border of the eye, forms a hoop which descends to the sides of the throat.

Coloration usually varying from pale grey to olivebrown above, the sides with pale metallic spots; the 
lines of crypts whitish; caudal crests greyish, with blackish spots and white dots, and pale metallic spots. Some specimens, however, have the tail almost spotless; in others, on the contrary, it is very closely spotted, but always less abundantly on the lower crest than on the upper. Lower parts pale grey with silvery spots. Tail and the greater part of the body with fine black decussating lines. I have observed at St. Enogat, in Brittany, a colony of abnormal tadpoles, not exceeding $40 \mathrm{~mm}$. in length when fully developed, which were nearly black on the back, the tail dark brown with the black decussating lines very crowded, the belly of a beautiful steel-blue, and the lines of crypts quite indistinct (see Pl. I, fig. 8).

The largest tadpole obtained by me in Brittany measures $57 \mathrm{~mm}$., body 21 , width of body 15 , tail 36 , depth of tail 14. One from Nice measures $65 \mathrm{~mm}$.

Haвiтat.-Pelodytes punctatus inhabits nearly the whole of France, from the coasts of Brittany, Normandy, and the Pas-de-Calais to the foot of the Pyrenees and the Mediterranean littoral. It has not been found in the North-eastern Departments Nord, Ardennes, and Lorraine, which seem to be outside the eastern limit of its distribution. The only localities east of France whence this species has as yet been recorded are Castino in Southern Piedmont, and Loano in Eastern Liguria. In the Pyrenean peninsula it is on record from the Portuguese provinces Minho, Douro, Alemtejo, and Algarve, and the Spanish provinces New Castille, Valencia, and Andalusia. In no part of its habitat does this species extend to any considerable altitude; in France it avoids the central plateau, and has not been found on the Pyrenees, although inhabiting Spain. The highest recorded altitude is 1450 feet at Castino, Piedmont.

The specimens, male and female, figured on Pl. VIII, are from Nice, received from Dr. J. de Bedriaga. 


\section{Pelobates.}

Wagler, Syst. Amph., p. 206 (1830).

Pupil vertical. Vomerine teeth in short transverse series between the choanæ. Tongue circular, entire or slightly nicked, and free behind. Tympanum absent. Fingers free, toes webbed; outer metatarsals separated by web. Inner metatarsal tubercle shovelshaped. Vertebræ procœlous; diapophyses of sacral vertebra very strongly dilated; urostyle usually fused with sacrum. Omosternum cartilaginous; sternum with a bony style.

Three species of this essentially fossorial genus are known: two from Europe, and one, P. syriacus, Boettger, from Asia Minor and Syria.

The European species are easily distinguished from each other. In P. fuscus the occiput is humped, the orbit is not completely closed by bone behind, and the metatarsal spur or shovel is yellowish or pale brown. In $P$. cultripes the occiput is plane or gently arched, the cranial roof completely surrounds the orbit, and the metatarsal spur is black.

$P$. syriacus agrees with $P$. cultripes in the form of the head and the structure of the skull, with $P$. fuscus in the colour of the spur.

The genus Didocus, Cope (type Rana calcarata, Michahelles), is founded on a young Pelobates cultripes, and is therefore a synonym of Pelobates, as pointed out further on in a foot-note. The adult Pelobates cultripes has also been raised to generic rank by the same author, but quite unnecessarily in my opinion, the only distinctive feature being the greater development of the cranial roof-a mere difference of degree, the importance of which is outweighed by the close resemblance which this species bears in all other respects to its ally P. fuscus. 



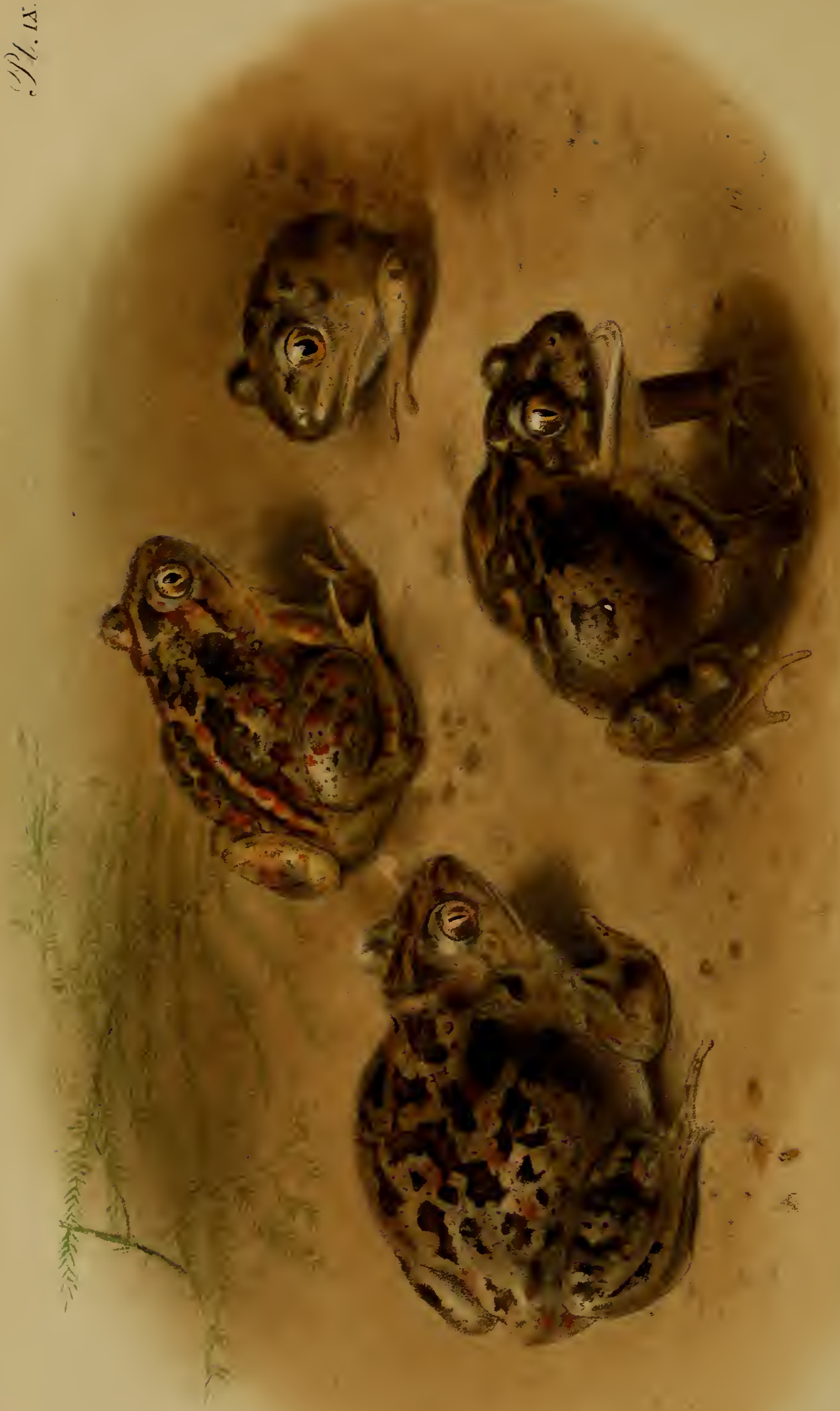




\section{Pelobaties fuscus.}

\section{(Plate IX.)}

Rösel, Hist. Ran., p. 69, pls. xvii-xix (1758).

Bufo fuscus, Laurenti, Syn. Rept., pp. 28 \& 122 (1768); Schneider,

Hist. Amph., i, p. 196 (1799); Daudin, Hist. Rain. Gren. Crap., p. 81, pl. Ixxx, fig. 1 (1803), and Hist. Rept., viii, p. 161

(1803); Duvernoy, Règne Anim., Rept., pl. xxxviii, fig. 1 (1836).

Rana vespertina, Pallas, Reise Rnss. R., i, p. 458 (1771).

Rana fusca, Meyer, Syn. Rept., p. 10 (1795); Sturm, Deutschl.

Faun., iii (1797); Gravenhorst, Delic. Mus. Vratisl., p. 32 (1829).

Bufo vespertinus, Schneider, Hist. Amph., i, p. 225 (1799).

Rana alliacea, Shaw, Gen. Zool., iii, p. 146, pls. xli \& xlii (1802).

Bombina fusca, Koch, in Sturm, Deutschl. Faun., iii (1828)

Bombina marmorata, Koch, 1. c.; Hahn, Faun. Boic., pl. xxi, fig. $b$ (1832).

Bombinator fuscus, Fitzinger, N. Class. Rept., p. 65 (1826).

Pelobates fuscus, Wagler, Syst. Amph., p. 342 (1830); Tschudi,

Class. Batr., p. 83 (1838); Duméril \& Bibron, Erp. Gén., viii, p. 477 (1841); Steenstrup, Isis, 1841, p. 900; Nilsson, Skand. Faun., Amf., p. 96 (1842) ; Günther, Cat. Batr. Sal., p. 40 (1858); Bruch, Würzb. Naturh. Zeitschr., ii, 1861, p. 178, and iii, 1862, p. 181; Collin, Naturh. Tidsskr. (3), vi, 1869, p. 316; Fatio, Vert. Suisse, iii, p. 376 (1872); C. Koch, Ber. Senck. Ges., 1872, p. 151 ; Cornalia, Atti Soc. Ital., xvi, 1873 , p. 96, pls. ii \& iii; De Betta, Faun. Ital., Rett. Anf., p. 71 (1874); Schreiber, Herp. Eur., p. 90, fig. (1875); Leydig, An. Batr., p. 77 (1877); Lessona, Atti Ac. Lincei, Mem. Sc. Fis., i, 1877, p. 1077, pl. iii; Boulenger, Cat. Batr. Ecaud., p. 437 (1882); Fatio, Vert. Suisse, iv, App., p. v (1882); Camerano, Mem. Acc. Torin. (2), xxxv, 1883, p. 217 ; Héron-Royer, Bull. Soc. Et. Sc. Angers, xv, 1886, p. 61 ; Camerano, Boll. Mus. Torin., i, 1886, No. 9; Boulenger, Bull. Soc. Zool. France, 1888, pp. 115 \& 162; Peracca, Boll. Mus. Torin., iii, 1888, No. 46; Wolterstorff, Zool. Anz., 1888, p. 672 ; Héron-Royer \& Van Bambeke, Arch. Biol., ix, 1889 , p. 269 ; Bedriaga, Bull. Soc. Nat. Mosc., 1889, p. 493 ; Boulenger, Proc. Zool. Soc., 1891, p. 614, pl. xlvi, fig. 7 ; Zander, Corr.-Bl. Nat. Ver. Riga, No. 38, 1895, p. 62 ; Werner, Rept. Amph. Oesterr.-Ung., p. 104 (1897); Dürigen, Deutschl. Amph., p. 519, pl. ii, fig. 7, and pl. iii, fig. 1 (1897). Cultripes minor, Müller, Isis, 1832, p. 538, and Zeitschr. f. Physiol., iv, 1832, p. 212.

Pelobates insubricus, Cornalia, Atti Soc. Ven.-Trent., ii, 1873, p. 44.

Pelobates latifrons, Héron-Royer, Bull. Soc. Zool. France, 1888, pp. 85, 108, 117, figs.; Héron-Royer \& Van Bambeke, l. c., p. 272 . 
Vomerine teeth in two strong, transverse, slightly oblique or slightly curved series between the choanæ, the inner borders of which they touch,

FIG. 72.

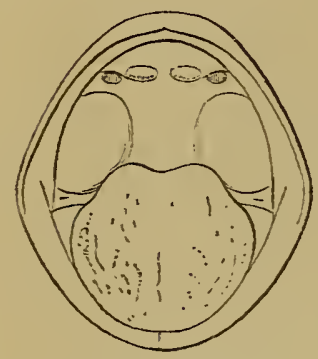

Open mouth. and narrowly separated from each other in the middle. Eustachian tubes very small. Tongue large, thick, circular, sometimes entire, usually feebly nicked behind.

Head very convex, broader than long, the occiput gibbose; the skin adherent to the skull; snout rounded, projecting beyond the mouth, as long as or a little longer than the diameter of the orbit; no canthus rostralis; nostril midway between the eye and the tip of the snout; eye large, prominent; interorbital space convex, much broader than the upper eyelid, and a little greater than the distance between the nostrils; a sort of low knob behind the eye, formed by the squamosal bone.

Fingers moderately elongate, pointed, third much the longest, first and fourth equal and slightly longer than second; subarticular tubercles very indistinct; two rather indistinct carpal tubercles.

Hind limbs robust and short, with swollen calves; the tibio-tarsal articulation reaches the shoulder or the commissure of the mouth, and the tarso-metatarsal the eye, or between the eye and the nostril; tibia shorter than the femur, the heels being widely separated from each other when the legs are folded. Foot much longer than the tibia; toes short, pointed,

FIG. 73.

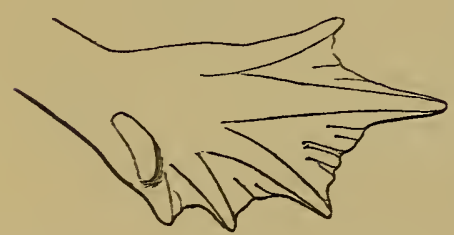

Lower view of foot. broadly webbed, at least twothirds webbed in summer, the web reaching the tips of all the toes in the spring; subarticular tubercles indistinct; a very large, compressed, sharp-edged inner metatarsal tubercle, placed obliquely to the axis of the foot like the inner toe, which it equals or slightly exceeds in length. 
Skin smooth on the head and limbs; sometimes smooth on the back, usually covered with small flat warts of unequal size; lower parts smooth, with a few granules on the pubic region.

Coloration very variable. Ground colour olive-grey, pale brown, yellow, yellowish-white, or brownishwhite, with dark-edged chestnut-brown, olive-brown, or reddish-brown spots, which often simulate larger and smaller islands with numerous indentations, or may be confluent into a pair of longitudinal bands, bordering a pale area of the ground colour along the spine; sometimes the spots are very small and numerous, giving the animal a speckled appearance; the spots often form irregular bands across the hind limbs; a dark streak usually extends on each side of the snout to the eye, involving the nostril, and a dark, continuous or interrupted band sometimes extends from one eyelid to the other across the crown; a light streak of the ground colour is often present on the coccygeal region. In addition to these markings there are often brick-red or vermilion spots or dots, which may be confined to the sides, or so profusely scattered on the whole of the upper surfaces as to almost obscure the ground colour. Lower parts dirty white, uniform, or spotted or speckled with greyishbrown, the soles often greyishbrown; metatarsal spur yellowish, pale horn-colour, or reddish-brown. Iris golden or copper-colour, sometimes fire-colour.

Male distinguished from the female by a large, oval, smooth gland on the upper surface of the brachium. Vocal sacs and copulatory excrescences are absent; during Upper view of fore limb the breeding season, however, small FIG. 74.

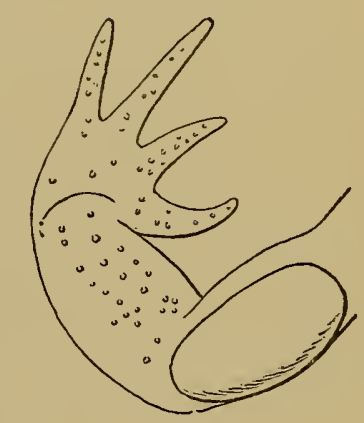
pearl-like, uncoloured excrescences are scattered on the upper surface of the antebrachium and the fingers. 


\section{Measurements (in millimetres).}

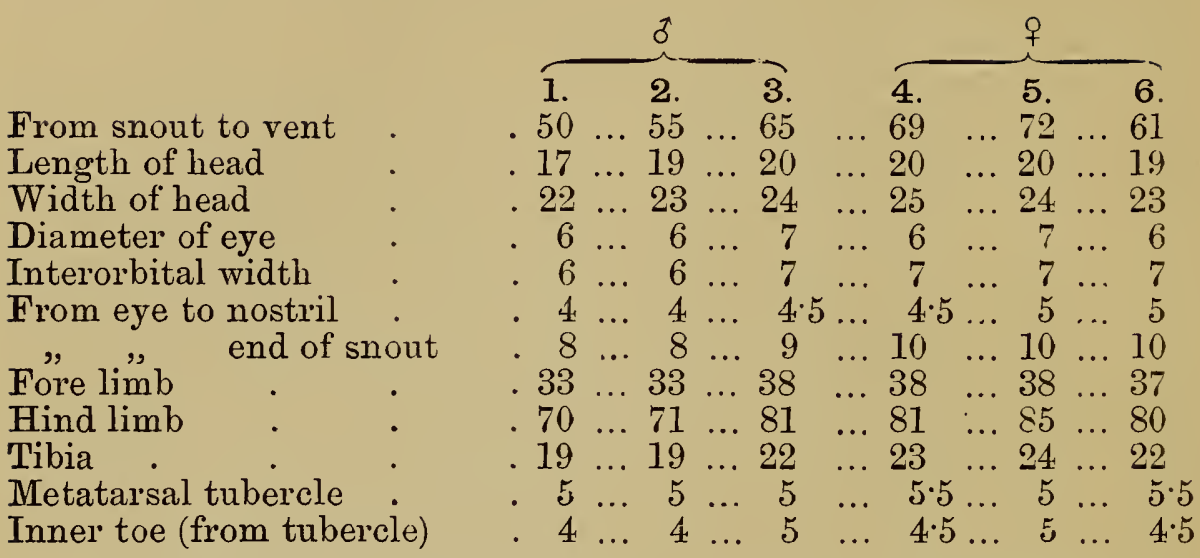

1. Drancy (Seine-et-Oise): Parâtre. 4. Paris : Héron-Royer.

2, 6. Turin: Peracca.

5. Halle/S.: Wolterstorff.

3. Szamos-Ujvar (Transylvania) : Méhely.

Skeleton.-Skull very strongly ossified, the maxillaries, squamosals, nasals, ethmoid, and fronto-parietal rugose, granular, or pitted. Ethmoid entirely ossified, confluent with the likewise ossified nasal capsule, and produced forwards beyond the nasals to between the ascending processes of the præmaxillaries; only a small triangular portion of it is exposed between the nasals and the fronto-parietal. Nasals large, in contact with each other between the nares. Frontoparietal single, widening behind into a more or less developed angular process on each side; this process is more or less widely separated from a corresponding one of the squamosal, with which it is connected by ligament only, the prootic being entirely exposed above. Transverse branch of squamosal expanded, plate-like, suturally united in front with the maxillary.

The degree of roughness of the fronto-parietals and the development of the post-orbital processes vary according to individuals, the bone being generally less developed in this respect in specimens from France than in those from Germany, Austria, and Italy. In quite young specimens the fronto-parietal is nearly 
PELOBA'I'ES.

FIG. 75.

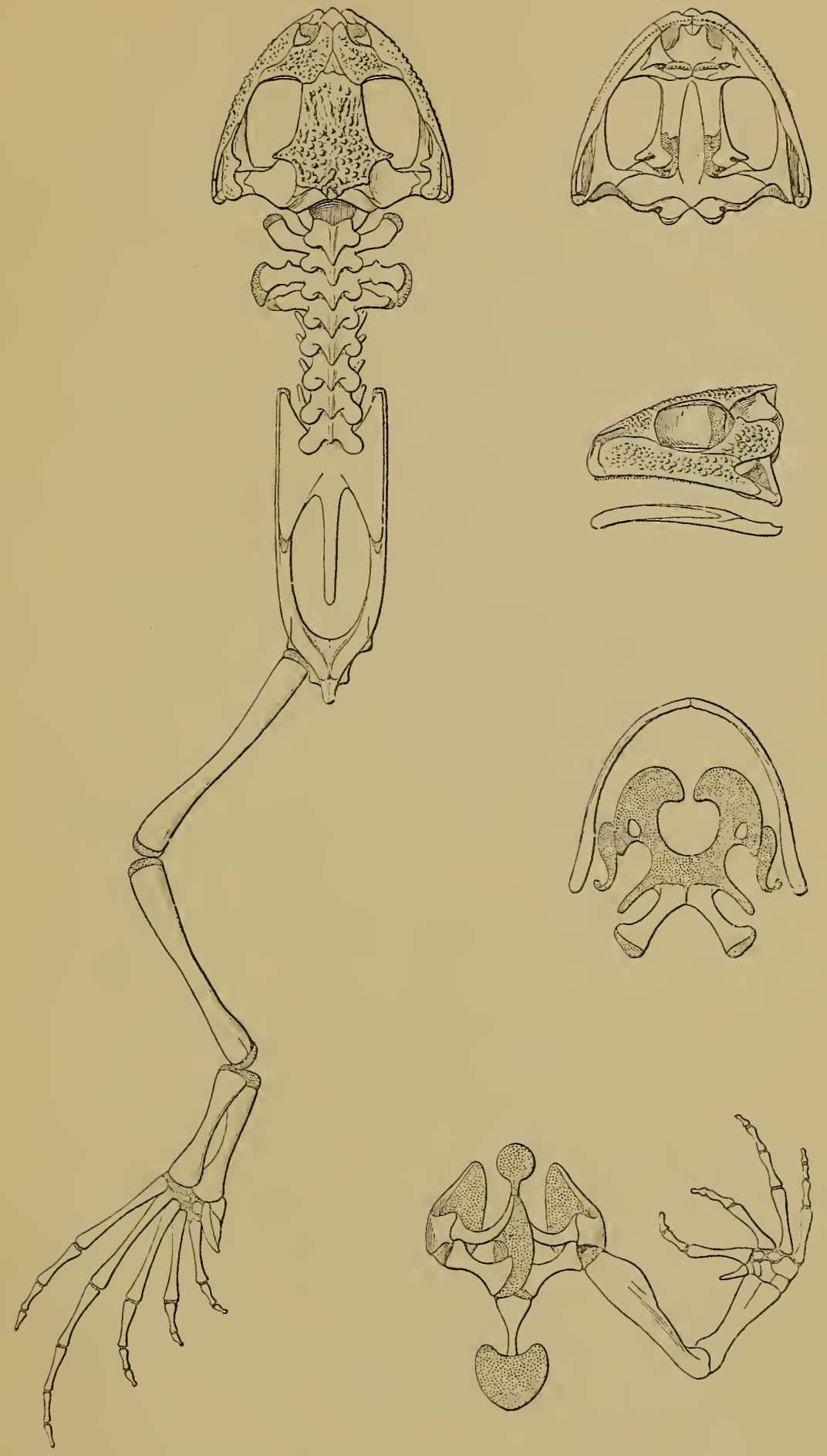

Skeleton of male from Transylvania. 
smooth, and the dermo-ossification, as it develops, produces granular asperities which may become confluent into alveolar ridges, producing a pitted appearance. In very old specimens the sutures between the nasals, the ethmoid, and the fronto-parietal may become obliterated.

Vomers rather large, variable in shape, extending or not to the palatines, which are strongly ossified. On the palatal side the ethmoid extends posteriorly to about the middle of the length of the parasphenoid. Latter large, $\boldsymbol{\perp}$-shaped, its anterior pointed extremity produced to between the palatines. Pterygoids not reaching the palatines, extensively in contact with the parasphenoid. Stapes absent.

Mento-Meckelian or symphysial bones distinct on the inner side only.

Hyoid a large broad cartilaginous plate, with slender postero-lateral processes; anterior processes much expanded and confluent with the lateral wings, enclosing a small fenestra; ceratohyal cornua with short posterior portion detached from the body of the hyoid; thyrohyals large, massive, in contact at the base, diverging and more or less expanded posteriorly.

Vertebral column once and a half to twice as long as the skull. Spine closed above, the neural arch produced posteriorly into a strong median process between the zygapophyses. Three anterior diapophyses strong and long, especially the second, which bears a more or less distinct dorsal knob or process as on the corresponding rib of Discoglossus, - the first directed obliquely forwards, the second and third nearly horizontal; the following short and slender, directed forwards. Sacral vertebra with very strongly dilated diapophyses, the transverse diameter of which is twice and a half to nearly three times in the axial; urostyle short, not longer than the sacral wings, and fused with the sacrum, to the diapophyses of which its anterior portion contributes if these processes be 
not entirely furnished by it, as is sometimes the case.*

Præcoracoids slender, strongly curved, not entering the glenoid cavity; coracoids nearly straight, strongly expanded distally; a cartilaginous omosternum; sternum with a bony style dilated proximally and a large discoid cartilage. Humerus considerably longer than radius-ulna. Eight bones in carpus, three of which are in contact with radius-ulna; a single bone in the pollex.

Pelvis five-sevenths to five-sixths the length of the vertebral column; ilia with an inner upper groove into which the sacral processes slide; pubis absent or reduced to a small bony nodule, not entering the acetabulum. Femur and tibia with cartilaginous epiphyses; tibia shorter than the femur, which is shorter than the pelvis. Calcaneum slightly shorter than astragalus, half as long as tibia; three distal tarsal bones; præhallux with a single very large, compressed, curved phalanx. Terminal phalanges pointed.

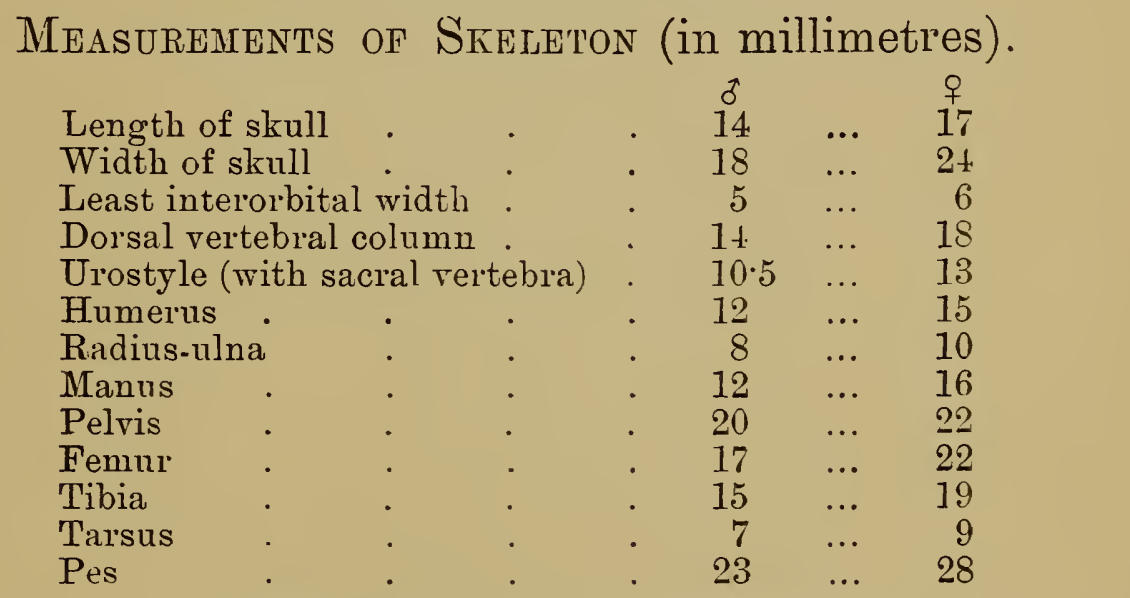

* I have long ago pointed out that the vertebral column figured by Gené in 1839 as of Bombinator belongs to a Pelobates. I should not allude to this again were it not for the fact that Genés error has crept into Bateson's 'Study of Variation,' p. 127, in a paragraph marked with an asterisk as a sign of special importance to the example quoted, and with the addition, by the compiler, of a further error, viz. that the specimen came from Sardinia. The sacrum in the Gené specimen, as well as in other's that have since been described and figured by Adolphi ('Morphol. Jahrb.,' xx, 1895, p. 449, pl. xix), is formed entirely by the processes at the base of the urostyle, and there are thus nine instead of eight præsacral vertebræ. 
Habits.-Pelobates fuscus is a thoroughly burrowing Batrachian, spending the greater part of its existence several feet below the surface of the ground, the capacious lungs filled with a good provision of air ; it buries itself in a nearly erect squatting posture by means of the large sharp-edged horny shovels with which its feet are armed, the digging being effected by alternate lateral movements of the heels, interrupted now and then for a short rest; on sand or a very loose soil less than a minute may suffice for the animal to disappear from sight, the soil falling over and around it so as not to leave a trace of a burrow. The English name "spade-foot," which is applied to its North American representative, Scaphiopus, would be a most appropriate one. Owing to these habits it is only found in localities where the soil is light or sandy; in cultivated districts the extensive growth of asparagus is an almost infallible indication of its presence. In the summer months it emerges an hour or two after sunset, and hopping along frog-like, sets forth in search of its food, consisting of worms, slugs, and all kinds of insects, especially beetles. When suddenly seized it produces a dermal exudation, smelling like garlic, and usually utters a startling shrill cry much like that of a kitten, at the same time opening its mouth in a defiant attitude. Some specimens when repeatedly teased-pinches in the leg and light pokes in the sides being the best method to employ to witness the sight-can be roused to what appears to be a fit of anger lasting several minutes, the animal screaming in a most extraordinary manner, and jumping madly with open mouth as if to snap at its persecutor. The prolonged screams produced on those occasions can only be compared, in a diminutive way, to those of an infant. At the same time the lungs are inflated to their utmost, and the body, swollen like a ball, is raised above ground. A specimen is figured in this attitude on Pl. IX, right hand. These antics are very similar to those performed by Ceratophrys 
ornata, a South American Cystignathoid, of likewise nocturnal and burrowing habits, specimens of which have often been kept in confinement in this country; an important difference being, however, that a large Ceratophrys is able to inflict a very painful bite on the finger of the unwary.

This Batrachian appears in the daytime only during the breeding season, which takes place in March and even as late as May* in Italy, between the end of March and the beginning of May in Central and Northern Europe, stray pairs occurring exceptionally as late as the 21 st of July, according to an observation made by Prof. Van Bambeke at Ghent, Belgium, in 1875. At the time of pairing, at which pools or deep ditches are resorted to, the males, much more numerous than the females, utter under water a monotonous, constantly repeated note-clock-clock, clockclock-cloct:- - produced by alternately shifting the air backwards and forwards from the capacious lungs into the buccal cavity. The female, which answers by a sort of grunt or a deep tock-tock-tock, is seized round the waist, and the egg's are expelled, more or less rapidly, either immediately or within a few days.

The length of the larval life varies considerably; as a rule, the final transformation takes place from the beginning to the end of summer, but several cases of larval hibernation have been observed by Pflüger and Kollmann.

EGGs.-The contents of the two oviducts fuse in the cloaca, and are expelled in a thick band 15 to $20 \mathrm{~mm}$. in diameter when swollen up, in which the ova are irregularly disposed at small interspaces. These bands, which have a strong smell of fish, are twisted round weeds by the female as they are laid. The ova

* According to Spallanzani, who described the oviposition in a pair. brought to him in May, 1780, by a fisherman at Pavia, and who received afterwards other pairs of the same species (Euvres de Spallanzani, III, 'Expériences pour' servir à l'histoire de la Génération,' Pavie, 1787, p. 137). As Crivelli and Camerano have shown, Spallanzani was the first after Rösel to observe this curious Batrachian, which was not rediscovered in Italy until ninety years later. 
are small, 2 to $2 \frac{1}{2} \mathrm{~mm}$. in diameter, grey or brown with white lower pole, and develop rapidly; the embryo, gill-less and tailless, breaks through about the fifth or sixth day, and attaches itself, through its adhesive subcephalic apparatus, to the outer surface of the mucilage.

FIG. 76.

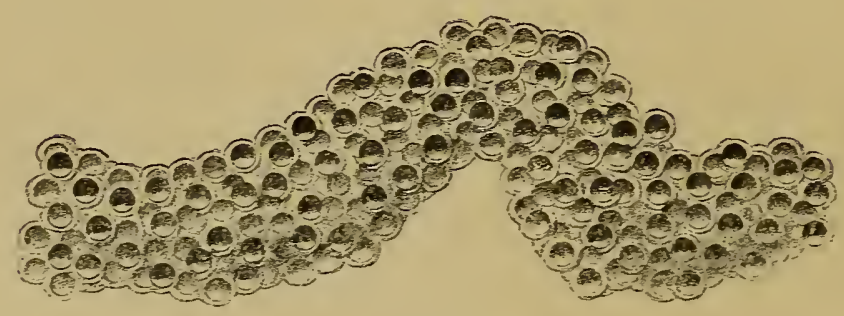

Tadpole (Pl. II, fig. 1).-Length of body once and a half to twice its width, one-half to two-thirds the length of the tail. Nostrils a little nearer the eyes than the end of the snout. Eyes on the upper surface, equidistant from the end of the snout and the spiraculum, the distance between them at least twice, sometimes nearly three times as great as that between the nostrils, and greater than the width of the mouth. Spiraculum on the left side, directed uprards and backwards, equidistant from either extremity of the body or a little nearer the anterior extremity, visible from above and from below. Anal opening median, a little larger than the spiraculum, and close to the body. Tail twice and a half to thrice and one-fifth as long as deep, acutely pointed; upper crest convex, slightly deeper than the lower, not extending far upon the back; the depth of the muscular portion at its base about half the greatest total depth.

Beak black. Lip bordered with papillæ, which form two or more rows on the sides; the papillose border interrupted mesially by a narrow toothed descending lobe, which appears at first sight as continuous with the second upper series of teeth. This anterior series is followed by three or four other series of teeth, which are all widely interrupted in the middle and 
gradually decrease in length,-the fourth, if at all present, being extremely short. On the lower lip we see likewise a short outer series, followed by three or four much longer ones, all of which, with the occasional exception of the first, are interrupted in the middle, and may be more or less broken up on the sides. The series of labial teeth may therefore be formulated as $\frac{4}{4}$ or $\frac{5}{5}$. Small isolated teeth may also be scattered on the papillæ at the angles of the mouth.

I have not been able to distinguish lines of crypts beyond the two series which run from the end of the snout to the upper border of the eyes, passing between the nostrils. I am therefore unable to judge whether the dorsal lines have been correctly figured by Lessona, who rightly regards the figure given by Cornalia as fanciful.

The advanced tadpole is brown or olive-brown above, with or without small darker spots, greyish-white or bluish beneath; sides with roundish whitish or pale golden spots; tail pale brown, with small grey and whitish spots.

The body usually reaches at least the size of a pigeon's egg, but not unfrequently exceeds that size. The largest specimen in the British Museum, from Prague, measures $125 \mathrm{~mm}$., body 38, width of body 25 , tail 87, depth of tail 27. The largest specimen on record is one preserved in the Berlin Museum, obtained in December, 1867, on the Jungfernheide, near Berlin, and which measures $175 \mathrm{~mm}$.

HABITAT. - The range of this species is an extensive but broken one, its occurrence being obviously dependent on the nature of the soil, and restricted to the plain, the highest elevation at which it has yet been recorded being 1400 feet (Val di Susa, Piedmont). $\quad P$. fuscus also appears to avoid competition with its congener P. cultripes; the limit of the range of the two closely meet without anywhere overlapping. It inhabits the north-east and east of France, from Flanders 
to the Jura, westwards to Paris, the Dep. Sarthe, and along the Loire; Belgium (Prov. Limburg, Antwerp, and East Flanders), South Holland, Luxemburg, Switzerland near Basle, Germany (except Würtemberg), Austria-Hungary, Carniola, North Italy (Piedmont, Lombardy, Venetia, Emilia), Denmark, Southern Sweden and Gotland, and Russia, northwards to the Gulf of Riga and eastwards to the Ural River and the Kirghiz Steppes, the Emba River being its easternmost limit.

The species has quite recently been recorded from Lenkoran, south-west coast of the Caspian Sea, by Zander.*

The reported occurrence of Pelobates fuscus in the Cyclacles is probably to be ascribed to a confusion with Bufo viridis, some specimens of which closely resemble this species in their markings.

The specimens represented on Pl. IX are from the environs of Turin, presented by my friend Count Peracca, to whom I am indebted for so much material utilised in the preparation of this work. The lefthand figure is that of a female; the others represent males, one in the act of disappearing under the sand, another in the irritated attitude described above.

* Dr. Zander kindly informs me that the specimens have been presented by him to the Senckenberg MIuseum, Frankfort (M.), and that his determination has been confirmed by Prof. Boettger. 

हो
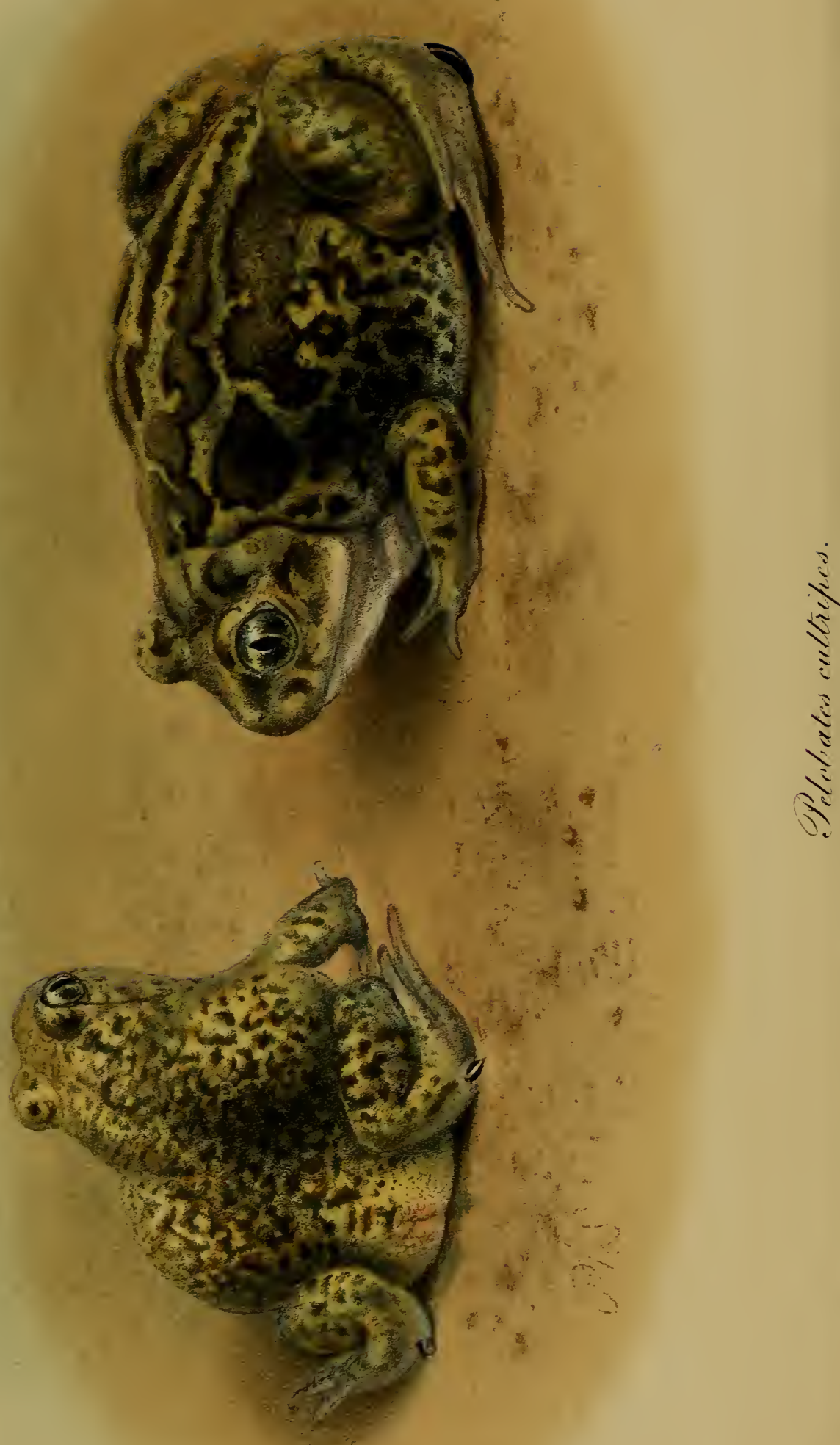


\section{Pelobates cultripes. \\ (Plate X.)}

Rana cultripes, Cuvier, Règne Anim., 2nd ed., ii, p. 105 (1829).

Rana calcarata, Michabelles, Isis, 1830, p. 807 , pl. - .

Cultripes provincialis, Müller, Isis, 1832, p. 538, and Zeitschr. f. Physiol., iv, 1832, p. 212.

Bufo calcaratus, Schinz, Nat. Rept., p. 233, pl. xevi, fig. 2 (1833).

Bombinator fuscus, Dugès, Rech. Ostéol. Batr., p. 7, pl. ii (18:31).

Pelobates cultripes, 'Ischudi, Class. Batr., p. 83 (1838); Duméril \& Bibron, Erp. Gén., viii, p. 483 (1841); Günther, Cat. Batr. Sal., p. 41 (1858); Schreiber, Herp. Eur., p. 92 (1875); Lataste, Herp. Gir., p. 263 (1876); Boulenger, Cat. Batr. Ecaud., p. 438 (1882); Héron-Royer, Bull. Soc. Et. Sc. Anger's, xv, 1886, p. 77; Héron-Ruyel \& Van Bambeke, Arch. Biol., ix, 1889, p. 275; Bedriaga, Bull. Soc. Nat. Mosc., 1889, p. 519, and Amph. Rept. Portug., p. 19 (1889); Boulenger, Proc. Zool. Soc., 1890, p. 664, and 1891, p. 616, pl. xlvi, fig. 8.

Pelobates fiscus, part., Bonaparte, Icon. Faun. Ital., Rett. Anf., (1838).

Didocus* calcaratus, Cope, Journ. Ac. Philad. (2), vi, 1866, p. 81.

In the tongue and vomerine teeth this species entirely agrees with its congener, but it differs in the occasional presence of small, grain-like teeth on the pterygoids and parasphenoid; these teeth are quite rudimentary, and the mucous membrane has to be removed to ascertain their presence. I have found them in three specimens from France (Nantes, Bordeaux, south of France). In one specimen there are about ten teeth on the parasphenoid, at the base of the longitudinal branch of the $\perp$-shaped bone, and two pterygoid teeth close together on the left side; another has the same number on the parasphenoid and a series of four on the pterygoids; and in a third there are eight teeth on the right pterygoid, none being present on the parasphenoid nor on the right pterygoid.

* The genus Didocus was founded upon a young specimen, on the erroneous assumption that in Pelobates cultripes the temporal roof is developed before the tail of the lar'va has disappeared. I have examined the skeleton of a young but fully transformed specimen from Béziers, Hérault, which shows both a large fronto-parietal fontanelle, bordered by smooth fronto-parietals, and an uncovered temple, thus answering in every respect the definition of the genus so rashly established by Cope more than twenty years ago, and still maintained by him in his latest writings. 
Head as in $P$. fuscus, but rather larger in proportion, and not humped on the occiput nor behind the eyes, the skull forming a complete, evenly curved rugose casque entirely surrounding the orbits ; interorbital space nearly flat, usually much broader than the distance between the nostrils.

Shape and proportions of the limbs much as in P. fuscus, but digits more obtuse, and metatarsal shovel sharper and larger, always exceeding the length of the inner toe.

Skin smooth or densely covered above with very small round warts.

Yellowish, whitish, or greenish-yellow above, speckled, spotted or marbled with brown, olive, or greyish-olive, the spots small or large, and but rarely confluent into longitudinal bands. A small male specimen, collected by M. Lataste at Greilhan, Gironde, has four perfectly regular dark dorsal stripes, the median pair extending forwards to the interorbital region, where they meet a dark cross-bar. White beneath, uniform or speckled with greyisholive; metatarsal spur black; toes often tipped with a black horny layer. Iris silvery or greenish-grey, vermiculate with black.

External male sexual characters as in $P$. fuscus.

In describing Pelobates syriacus, Boettger ("Zool. Anz.,' 1889, No. 302) mentions breeding specimens of Pelobates cultripes to be possessed of nuptial asperities on the inner side of the three inner fingers and on the tips of the toes. This extraordinary statement is based on a confusion with the American Scaphiopus hammondii, Baird (dugesii, Brocchi), breeding males of which were erroneously labelled 'Pelobates cultripes, Spain,' in the Senckenberg Museum. The so-called nuptial asperities of the tips of the toes are nothing. but the blackish horny sheaths which cap them, as well as the tarsal spur, at all seasons. I am indebted to the kindness of Prof. Boettger for an opportunity of examining these specimens. 


\section{Measurements (in millimetres).}

From snout to vent.

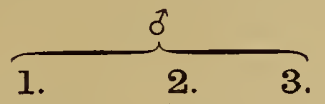

Length of head

$\begin{array}{lllll}66 & \ldots & 77 & \ldots & 57\end{array}$

Width of head

$\begin{array}{lllll}22 & \ldots & 26 & \ldots & 20\end{array}$

$\begin{array}{lllll}.26 & \ldots & 29 & \ldots & 25\end{array}$

Diameter of eye

Interorbital width

From eye to nostril

$\begin{array}{llllll}. & 8 & \ldots & 9 & \ldots & 8\end{array}$

$\begin{array}{lllll}. & 6.5 & \ldots & \ldots & 8\end{array}$

\begin{tabular}{rrrrrr}
\multicolumn{1}{c}{} & $\overbrace{4 .}$ \\
$\ldots$ & 51 & & 5. & & 6 \\
$\ldots$ & 51 & 88 & $\ldots$ & 62 \\
$\ldots$ & 17 & $\ldots$ & 27 & $\ldots$ & 20 \\
$\ldots$ & 21 & $\ldots$ & 36 & $\ldots$ & 25 \\
$\ldots$ & 7 & $\ldots$ & 9 & $\ldots$ & 8 \\
$\ldots$ & 65 & $\ldots$ & 7 & $\ldots$ & 6 \\
$\ldots$ & 5 & $\ldots$ & 8 & $\ldots$ & 5 \\
$\ldots$ & 9 & $\ldots$ & 14 & $\ldots$ & 10 \\
$\ldots$ & 27 & $\ldots$ & 47 & $\ldots$ & 34 \\
$\ldots$ & 67 & $\ldots$ & 118 & $\ldots$ & 79 \\
$\ldots$ & 19 & $\ldots$ & 32 & $\ldots$ & 22 \\
$\ldots$ & 5 & $\ldots$ & 8 & $\ldots$ & 6 \\
$\ldots$ & 3.5 & $\ldots$ & 7 & $\ldots$ & 4
\end{tabular}

For'e limb

end of snout

Hind limb

$\begin{array}{rrrrrr}. & 5 & \ldots & 7 & \ldots & 55 \\ . & & \ldots & \end{array}$

Tibia

Metatar'sal tubercle

Inner toe (from tubercle)

. 10

40

$\begin{array}{llll}\ldots & 13 & \ldots & 10 \\ \ldots & 45 & \ldots & 35\end{array}$

$\begin{array}{llllll}.88 & \ldots & 100 & \ldots & 80\end{array}$

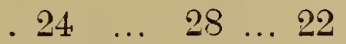

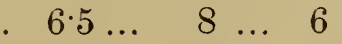

. 5

1. Nantes: Paris Museum.

2. Seville: Calderon.

3, 4. Merida: Boscá.

5. Badajos: Boscá.

6. Abrantes: Gadow.

Skeleror. - The trunk and limbs agree with those of its congener, but the skull is very different, owing to the

\section{FIG. 77.}

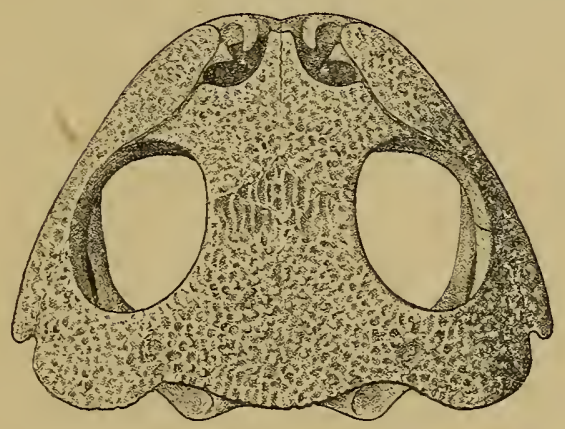

Upper view of skull.

more extensive dermo-ossification of the post-orbital region, which forms a complete roof over the prootic, only the posterior portion of the latter being visible from above. This roof, which completely closes the orbit behind, is formed by the fronto-parietal and the squamosal; the latter bone has a convex posterior border, separated from the likewise curved posterior border of the fronto-parietal plate by a notch, the angle of which corresponds to the suture between the two bones. 
All the bones of the upper surface are closely studded with granular or subconical asperities. A further important difference in the skull of this species compared to $P$. fuscus is the absence of the extraordinary forward prolongation of the ethmoid; this bone does not extend beyond the nasals.

Dugès, basing his observations on this species, has denied the fusion of the sacral vertebra with the coccyx described by Mertens in Pelobates fuscus, with which $P$. cultripes was then confounded; he observes, however, that the articulation, by means of one condyle, is an almost immoveable one.

In a specimen from Bordeaux, from which I prepared the first skeleton, I found matters as stated by Dugès, whilst in two other skeletons, from Bordeaux and Avignon, the two bones are as completely fused as in $P$. fuscus. As the ankylosis of the sacrum and coccyx has often been given as a generic character of Pelobates, it is important to note the inconstancy of the character in this species at least.

Measurements of Skeleton (in millimetres).

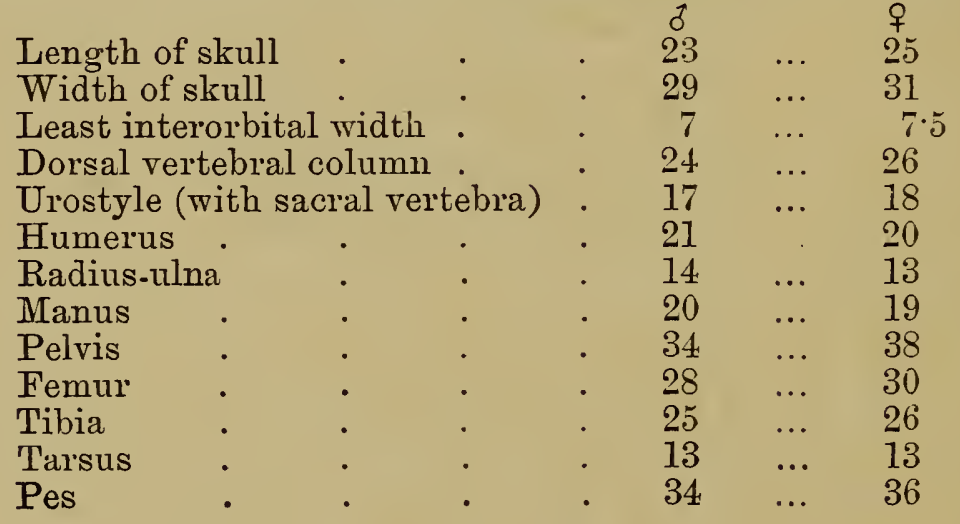

Habi's. - Much the same as those of its congener. $P$. cultripes seems, however, more partial to the coast, being found in abundance, in France, on the sandy dunes of the Atlantic littoral. It breeds in the end of March or April in France, in March in Spain. Its note, which I have only heard in specimens captured 
in summer, may be well rendered by a guttural $c o$, $c o, c o, c o, c o$; its nuptial call is said to be the same.

EGGs.-According to Héron-Royer, they differ but slightly from those of $P$. fuscus; the mucilaginous band is a little narrower and flatter, thus much resembling that of Pelodytes punctatus.

Tadpole (Pl. II, fig. 2).-The differences from $P$. fuscus are but slight, and most of those that have hitherto been relied upon prove not to be absolutely constant. Thus the nostrils, as I now find from Portuguese specimens received from Dr. de Bedriaga since the publication of my ' Synopsis of the Tadpoles,' may be as wide apart as in $P$. fuscus. The series of labial teeth are more broken up, and their arrangement is therefore less easily expressed by a formula. The tail is shorter, not more than once and a half the length of the body. The lines of crypts are usually more distinct, owing to the black colour of the tubules and the lighter colour of the body. Their disposition is well shown in the example figured. The following description is taken from five specimens obtained by M. Lataste near Bordeaux:

Length of body once and two-thirds to once and three-fourths its width, once and one-fourth to once and two-fifths in the length of the tail. Nostrils halfway between the eyes and the end of the snout, or a little nearer the latter. Eyes on the upper surface, a little nearer the spiraculum than the end of the snout, the distance between them nearly twice as great as that between the nostrils, which equals the width of the mouth. Spiraculum equidistant from either extremity of the body. Tail once and two-thirds to once and five-sixths as long as deep, pointed, the muscular portion not half the total depth.

Specimens preserved in spirit, of which I have a good number before me at the present moment, are pale greyish or brownish above and on the sides, the belly dirty white with round white spots. Muscular part of tail pale reddish-brown, with some darker 
brown spots; caudal crests greyish, more or less distinctly spotted or freckled with brown.

The coloration in life is described by Lataste as reddish-yellow above, greyish or bluish-white beneath ; tail with small brown spots. Some twenty years ago I saw a number of large specimens in a small tank in the Botanic Gardens at Bordeaux. My recollection is that they were of a very pale brown, without distinct markings.

Total length $100 \mathrm{~mm}$.; body 39 ; tail 61 ; depth of tail 25.

According to Dugès the size of the body may equal a hen's egg.

Habitat.-France, Spain, and Portugal. In France this species has been found along the west coast to a little north of the mouth of the Loire, and in the southern departments Haute-Garonne, PyrénéesOrientales, Aude, Hérault, Gard, Bouches-du-Rhône, and Vaucluse; in Spain in the provinces Galicia, Estremadura, New Castille, Valencia, Andalusia; and in Portugal in the provinces Douro and Algarve. It probably occurs, as stated by Boscá, all round the coasts of the Pyrenean Peninsula.

The record of the occurrence of Pelobates cultripes in Syria is due to a confusion with an allied species, Pelobates syriacus, to which allusion is made above, p. 192.

The two specimens figured on Pl. X were obtained near Bordeaux by M. F. Lataste. 


SMITHSONIAN INSTITUTION LIBRARIES nhrept OL668.E286X

v. 1 The tailless batrachians of Europ 